Rhode Island College

Digital Commons @ RIC

$12-2009$

\title{
Exploring Some Inattended Affective Factors in Performing Nonroutine Mathematical Tasks
}

John Douglas Butler

Rhode Island College

Follow this and additional works at: https://digitalcommons.ric.edu/etd

Part of the Cognition and Perception Commons, Curriculum and Instruction Commons, Logic and Foundations Commons, Science and Mathematics Education Commons, and the Secondary Education and Teaching Commons

\section{Recommended Citation}

Butler, John Douglas, "Exploring Some Inattended Affective Factors in Performing Nonroutine Mathematical Tasks" (2009). Master's Theses, Dissertations, Graduate Research and Major Papers Overview. 26.

https://digitalcommons.ric.edu/etd/26

This Dissertation is brought to you for free and open access by the Master's Theses, Dissertations, Graduate Research and Major Papers at Digital Commons @ RIC. It has been accepted for inclusion in Master's Theses, Dissertations, Graduate Research and Major Papers Overview by an authorized administrator of Digital Commons @ RIC. For more information, please contact digitalcommons@ric.edu. 
EXPLORING SOME INATTENDED AFFECTIVE FACTORS

IN PERFORMING NONROUTINE MATHEMATICAL TASKS

By

JOHN DOUGLAS BUTLER

A DISSERTATION SUBMITTED IN PARTIAL FULFILLMENT OF THE REQUIREMENTS FOR THE DEGREE OF DOCTOR OF PHILOSOPHY

IN

EDUCATION

UNIVERSITY OF RHODE ISLAND

AND

RHODE ISLAND COLLEGE 


\section{Library Rights Statement}

In presenting this Dissertation in partial fulfillment of the requirements for an advanced degree at the University of Rhode Island, I agree that the Library shall make it freely available for inspection. I further agree that permission for copying, as provided for by the Copyright Law of the United States (Title 17, U.S. Code), of the Dissertation for scholarly purposes may be granted by the Librarian. It is understood that any copying or publication of this Dissertation for financial gains shall not be allowed without my written permission.

I hereby do grant permission to the University of Rhode Island Library to use my Dissertation for scholarly purposes.

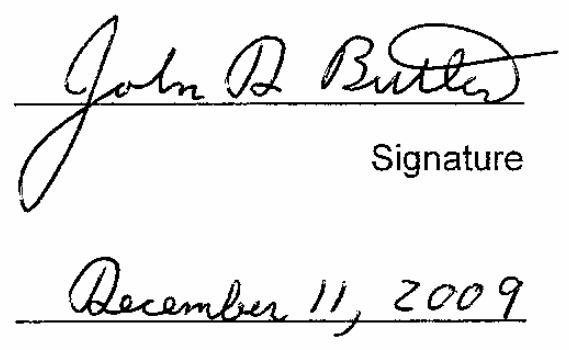

Date 


\section{DOCTOR OF PHILOSOPHY DISSERTATION}

OF

\section{JOHN D. BUTLER}

APPROVED:

Dissertation Committee:

Major Professor

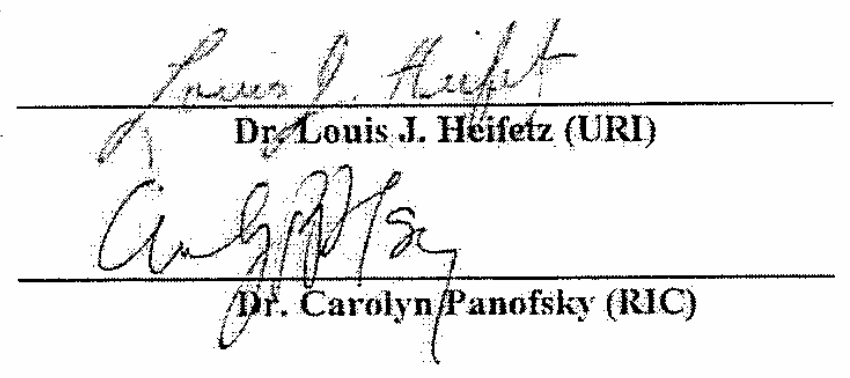

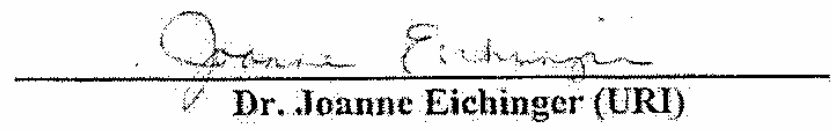

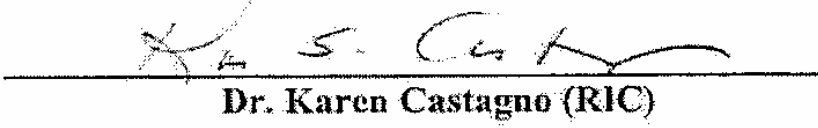

RIC:

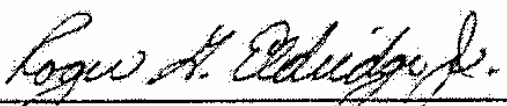

Deá, Feinstein Schoof of Education - RIC

URI:

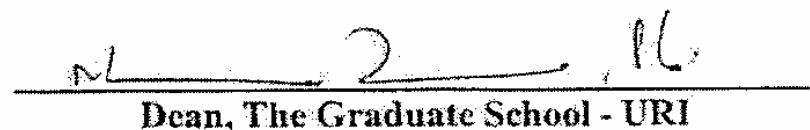




\begin{abstract}
The purpose of this study was to describe students' attempts to solve nonroutine math problems and to explore possible correlates of their performance. The focus of this study was on inattended (i.e., intentionally avoided) dimensions that have been underrepresented in the literature, including attitudes, interests, values, aesthetics, metacognition, and representation. Both objective and subjective datadrawn from 13 separate sources - using quantitative and qualitative procedures, were analyzed. Fine-grained rubrics were developed and used to score student work on six nonroutine math problems. These objective data were complemented with students' written "logs" of their work in real time, followed by semi-structured debriefing interviews after they had finished. Structured scales were used to document students' math-related attitudes, career interests, and work-values, along with essays describing their long-term experience with math, in and out of school. Data was gathered on students' math-aesthetics, including the features of "attractive" problems and their individual preferences for the different modes of instructional explanation. School records provided students' demographic data and their scores on generic measures of aptitude and achievement. Students' age, art discipline, attendance, sending school district, socioeconomic status (SES), and ethnicity were not found to be correlates for either students' aptitude/achievement/experience measures or problem-solving ability. Girls significantly outperformed boys on ability/achievement/experience measures, but not on problem-solving measures. Individualized Education Plan (IEP) status was found to be a strong correlate of both aptitude/achievement/experience and problemsolving measures, with students without IEPs consistently scoring higher on all
\end{abstract}


significant measures than students with IEPs. Overall, most math-related attitude variables had little effect on both aptitude/achievement/experience and problemsolving measures. However, there was strong evidence of students' math-aesthetics in problem solving. Specifically, students appreciating more than one type of solution scored consistently higher in problem-solving measures and frequency of use of higher-order internal representations. A close relationship between metacognition, aesthetics, and representation was found, as well as a strong link between mathematics and language usage. The discovery of students' use of higher-order internal representation during post-task video-taped interviews, undetected by paper-andpencil assessments, supported a conclusion that studies of problem-solving ability cannot be purely quantitative in method but must contain a qualitative component. 


\section{ACKNOWLEDGEMENTS}

Above my desk hangs a framed picture of a mountain range, with each peak progressively increasing in height, left-to-right, beginning with one labeled "EDC 555" (the first course in the Joint URI/RIC Ph.D. in Education Program) and ending with the flag-raised-upon highest peak labeled "MOUNT NEVER-REST DISSERTATION." The title of the picture reads:

\section{CLIMB EVERY MOUNTAIN PHORD EVERY STREAM}

It was traditional for Dr. Louis J. Heifetz to present his graphical representation of the doctoral student's journey - photocopied onto the frosting of a celebratory cake - to third-year cohort members at the end their last class of the threeyear EDP-641 (Field Research Seminar) course. The cake has long since been digested, but the picture remains in pristine condition - a constant reminder of the long journey I have traveled and the many to whom I owe thanks for their guidance and support.

I begin with my Major Professor and mentor, Dr. Louis Heifetz. I learned quite a bit from my research of the literature - but I learned the most from the vast feedback received from Dr. Heifetz. Every comment, correction, and suggestion was always an improvement and kept me on that mountain path. The depth and breadth of his feedback required extensive hours, for which I owe him a tremendous amount of 
gratitude. I am especially thankful that he agreed to continue as my Major Professor beyond his retirement in June, 2008.

Secondly, I would like to thank Dr. Carolyn Panofsky for agreeing to serve on my dissertation committee. Dr. Panofsky (RIC) and Dr. Lou Heifetz (URI) were the Co-directors of the Joint URI/RIC Ph.D. in Education Program when I entered in 2003. In addition to taking courses taught by Dr. Panofsky, I was extremely fortunate to have completed three courses in Discourse Analysis with her. Her expertise and assignments allowed me to develop an appreciation for the advantages of qualitative analyses. By including qualitative elements in my research methodology, I found patterns of data that would not have emerged had my methodology been purely quantitative.

Next, I would like to thank Dr. Joanne Eichinger and Dr. Karen Castagno for serving on my dissertation committee. I am extremely grateful for their valuable feedback on the written and oral Comprehensive Exams, for their refining feedback on my Dissertation Proposal, and for their contributions to the dissertation and overall defense process.

I would also like to thank the faculty and staff of Beacon Charter High School for the Arts (Woonsocket, Rhode Island) for their support, patience, and encouragement during this journey. I would especially like to thank Dr. Robert Pilkington (Principal), James MacDonald (Math and History Teacher), Carrie Appel (English Teacher/Literacy Coach), and Carolyn Taylor (Certified Director of Diverse Learners) at Beacon for help with administering instruments in this study. I would also like to thank Michael Skeldon (Dean of Faculty) and Tina Go (Admissions/Student 
Support) at Beacon for their support during my preparation for my dissertation defense. Above all, I am extremely grateful to the 38 ninth-grade students who willing participated in my study.

Unfortunately, I have found that my pursuit of a Ph.D. has often compromised the time I could spend with family and friends; albeit, by my selfish choice. Therefore, I am dedicating this study to all of my family and friends who have supported me in my quest and have forgiven me for those gatherings that I missed. This study is especially dedicated to my nursing home-bound 99 year-old grandmother, Olga Butler, who for the last five years has asked me every month when I would graduate. Finally, a year ago she became convinced that I was a victim of a conspiracy by the university not to award me a doctorate. I am also dedicating this study to: my parents Benjamin and Theresa Butler; my brothers Stephen, Gary, Jim, and Jeff; my three children, Bryan, Andrew, and Brittany; my wife of 21 years, Corliss; and my very special granddaughter, Emiliana who always provided me a good reason for the only breaks that I've taken this past year since her birth. 


\section{TABLE OF CONTENTS}

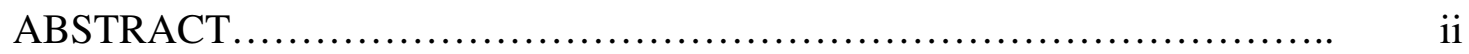

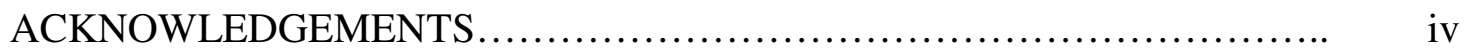

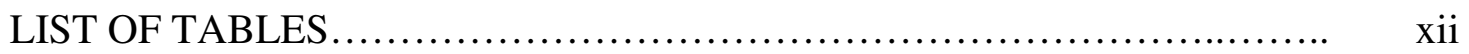

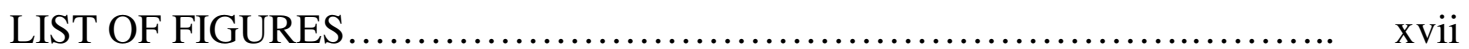

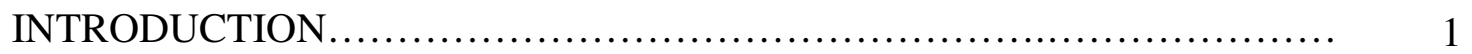

Statement of the Problem............................................ 1

Justification for and Significance of the Study $\ldots \ldots \ldots \ldots \ldots \ldots \ldots \ldots \ldots \ldots \ldots . \ldots \ldots \ldots$

LITERATURE REVIEW ........................................... 5

What is a Problem and what is Problem Solving?................................... 5

Overview....................................................... 8

Aptitude and Achievement...................................... 11

Experiences with and Attitudes toward Mathematics.................. 16

Demographics and Mathematics Achievement....................................... 27

Values and Interests........................................... 37

Mathematical Aesthetics............................................ 39

Real Time Logs and Interviews................................ 46

Literacy and Mathematics Achievement......................... 51

Conclusion..................................................... 54 
METHOD

Overview of Research Design.................................... 58

Research Site.................................................... 60

About the Researcher......................................... 61

Participants/ Sample........................................... 61

Instruments and Measures........................................ 63

Order of Data Collection........................................... 83

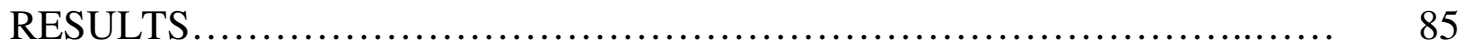

Overview of Data-Analyses....................................... 85

Demographic Variable: Age..................................... 90

Demographic Variable: Art Discipline.......................... 92

Demographic Variable: Attendance................................ 94

Demographic Variable: Ethnicity............................... 96

Demographic Variable: Gender................................ 98

Demographic Variable: IEP....................................... 100

Demographic Variable: Sending School District..................... 102

Demographic Variable: SES................................... 104

Math Related Attitude Variables: Rotter's Internal-External Locus of Control and the Shortened Version of the Fennema-Sherman Mathematics Attitudes Scales. 
Math-Related Attitude Variable: Preferred Mathematical

COPES Values Inventory (COPES)............................. 112

$\begin{array}{ll}\text { Exploring Students' Career Interests using the } & 117\end{array}$

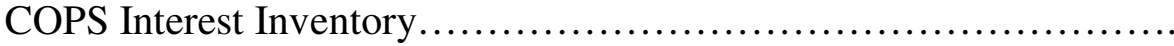

Problem Preference and Problem-Solving Achievement............... 121

Narrative Data on Students' Preferences among Six Nonroutine Problems

Measuring the Relationship between Students' Engagement and Achievement in Their Choice of Problem.........................

Performance Comparisons between Levels of Higher-Order Representation (HOIR).......................................... 132

Relationships of Demographic Variables to Students'

Relationships of Math-Related Attitude Variables to Students'

Relationship of Preferred Mathematical Solutions (PMS) to Levels of Higher-Order Internal Representation (HOIR) ...

Comparisons of the COPES Values Inventory to Students' Levels of Higher-Order Internal Representation (HOIR)

Qualitative Data from Students $(n=7)$ with Two or More Instances of HOIR.

A Detailed Example of HOIR in Problem Solving

Summary of Bivariate Results: Transition to Discussion. 
Foundations for Generalizability..................................... 184

Impact of Consent.............................................. 184

NWEA as an Achievement Metric.................................... 185

Demographic Heterogeneity ...................................... 186

Students' Perception of the Researcher............................... 187

Reporting Effect Sizes.......................................... 188

Summary of Findings and Conclusions................................... 189

Demographic Measures as Possible Correlates of Aptitude,

Achievement, and Experience...................................... 189

Math-Related Attitudes as Possible Correlates of Aptitude,

Achievement, and Experience....................................... 191

Values Variables as Possible Correlates of Aptitude,

Achievement, and Experience...................................... 192

Demographic Measures as Possible Correlates of

Performance Variables on Nonroutine Problems....................... 193

Math-Related Attitudes as Possible Correlates of

Performance Variables on Nonroutine Problems....................... 194

Values Variables as Possible Correlates of

Performance Variables on Nonroutine Problems...................... 195

Correlations between Aptitude/Achievement/Experience

Variables and Performance Variables on Nonroutine Problems.......... 196

What the Qualitative Data Analyses Revealed......................... 197

Limitations..................................................... 198

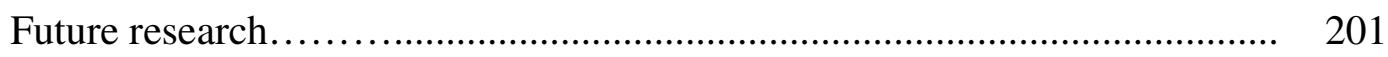


Some Suggested Interventions.................................... 201

NWEA and Problem Solving....................................... 207

NECAP and Problem Solving ....................................... 207

Reflection on Future Research....................................... 211

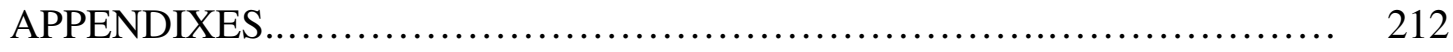

Appendix A: Vita ............................................... 212

Appendix B: IRB Parents' Consent and Students' Assent Forms............. 214

Appendix C: Math Skills Assessment.................................. 219

Appendix D: My Math Experiences Essay............................... 224

Appendix E: Six Nonroutine Problems ............................. 228

Appendix F: Establishing Inter-Rater Agreement for 235

Scoring Nonroutine Math Problems..........................

Appendix G: A Shortened Form of the Fennema-Sherman 272

Mathematics Attitudes Scales (FSMAS-SF)...................

Appendix H: The Rotter Internal-External Locus of Control (I-E).......... 284

Appendix I: Preferred Problem Choice (PPC) Questionnaire................. 293

Appendix J: Individual Graduation Plan - Page 47...................... 294

BIBLIOGRAPHY ..................................................... 295 


\section{LIST OF TABLES}

Number

Page

1. Summary of Literature Review of Six Sources of

Possible Correlates of Problem Solving in Mathematics.............. 55

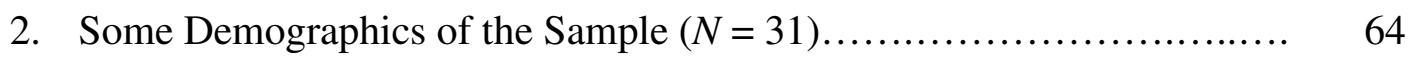

3. Measures of Performance on Nonroutine Problems and

Some Possible Correlates.................................... 65

4. Cursory Assessment of Problem-Solving Ability................... 71

5. Categories of Variables used in Bivariate Analyses................... 88

6. Career Interest Variables.................................... 89

7. Correlations $r$ with Age...................................... 91

8. Comparisons among Art Disciplines........................... 93

9. Correlation $r$ with Attendance..................................... 97

10. Performance Comparisons between Ethnicity...................... 93

11. Students' Mean Scores for Variables by Gender..................... 99

12. Students' Mean Scores for Variables by IEP........................ 101

13. Students' Mean Scores for Variables by School District................. 103

14. Students' Mean Scores for Variables by SES ........................ 105

15. Correlations $r$ between Math-Related Attitudes and Variables........... 107

16. Comparisons between Preferred Mathematical Solutions (PMS) and Variables

17. Mean Scores of the 31 Students on the Eight COPES

Values Scales Relative to National Percentiles 
18. Correlations $r$ between COPES Work-Values and

Aptitude/Achievement/Experience Variables and Performance

Variables on Nonroutine Problems $(N=31)$

19. Students' $(N=31)$ Mean Scores for

Major Occupational Groups.

20. Students' Mean Scores and National Percentiles for

Major Occupational Groups by Gender

21. Preference Ranking of the Six Nonroutine Math Problems $(N=31) \ldots \ldots$

22. Mean Scores on Problem-Solving Rubric by Choice.

23. Correlations $r$ between Students' Problem Preference Ranking and Their Problem-Solving Rubric Score

24. The Six Nonroutine Problems arranged by Students' $(N=31)$

Ranked Choice.

25. Students' Narrative Aesthetic Characteristics

26. Mean Number of Words Written by Students $(N=31)$ for

Their Ranked Chosen Problems

27. Examples of Higher-Order Internal Representation (HOIR)

28. Aptitude/Achievement/Experiences and Problem-Solving Comparisons between Levels of Higher-Order Internal Representation.

29. Demographic Variable Comparisons between Levels of Higher-Order Internal Representation (HOIR).

30. Attitude Variable Comparisons between Levels of Higher-Order Internal Representation (HOIR).

31. PMS Comparisons between Levels of Higher-Order Internal Representation (HOIR)

32. PMS Comparisons between Collapsed Levels of Higher-Order Internal Representation (HOIR) 
33. COPES Work-Values Comparisons between Levels of Higher-Order Internal Representation (HOIR)

34. Correlations $r$ between Performance Variables on Nonroutine

Problems and Aptitude/Achievement/Experience

Variables $(N=31)$

35. Elementary and Middle School Experiences of Students with Two or

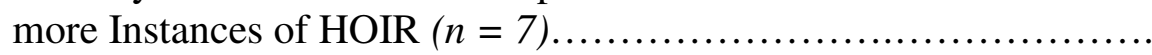

36. General Attitudes toward Math by Students with Two or more

Instances of HOIR $(n=7)$...

37. Interview with Jerry

38. Summary of Demographic Measures as Possible Correlates of Aptitude/Achievement/Experience Variables $(N=31)$

39. Summary of Math-Related Attitude Measures as Possible Correlates of Aptitude/Achievement/Experience Variables $(N=31)$.

40. Summary of Values Measures as Possible Correlates of Aptitude/Achievement/Experience Variables $(N=31)$

41. Summary of Demographic Measures as Possible Correlates of Performance on Nonroutine Mathematics Problems $(N=31)$

42. Summary of Math-Related Attitudes Measures as Possible Correlates of Performance on Nonroutine Mathematics Problems $(N=31)$.

43. Summary of Values Measures as Possible Correlates of Performance on Nonroutine Mathematics Problems $(N=31)$.

44. Summary of Aptitude/Achievement/Experience Measures as Possible Correlates of Performance on Nonroutine Mathematics Problems $(N=31)$

45. Cohen's $d$ Statistic for Significant Findings between

Demographic Variables and Aptitude/Achievement/Experience Variables $(N=31)$

46. Cohen's $d$ Statistic for Significant Findings between Math-Related Attitudes Variables and Aptitude/Achievement/Experience Variables $(N=31)$. 
47. Cohen's $d$ Statistic for Significant Findings between Values

Variables and Aptitude/Achievement/Experience

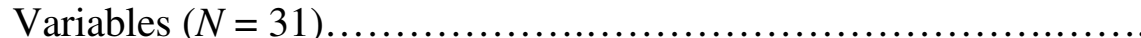

48. Cohen's $d$ Statistic for Significant Findings between Demographic

Variables and Performance Variables on

Nonroutine Problems $(N=31)$

49. Cohen's $d$ Statistic for Significant Findings between Math-Related

Attitude Variables and Performance Variables on

Nonroutine Problems $(N=31)$.

50. Cohen's $d$ Statistic for Significant Findings between Values

Variables and Performance Variables on

Nonroutine Problems $(N=31)$

51. Cohen's $d$ Statistic for Significant Findings between Performance

Variables on Nonroutine Problems and

Aptitude/Achievement/Experience Variables $(N=31)$

52. Summary of Relative Intensity for Sources of Correlates $(N=31)$.

53. Correlations $r$ between NWEA and NECAP Tests $(N=40)$

List of Tables in Appendixes:

B1. Summary of IRB Forms used in my research

C1. Summary of math skills assessment resources.

D1. Summary of my math experiences essay resources

224

E1. Summary of the six nonroutine mathematical problems

228

F1. Framework for Assessing and Approving Inter-Rater Agreement.

239

F2. Student ID's Selected for Stage 1 Scoring.

F3. Summary of the Pilot Study of Inter-Rater Agreement on the

"Count Your Coins" Problem....

F4. Summary of the Pilot Study of Inter-Rater Agreement on the

"Lost in the Auditorium" Problem. 
F5. Summary of the Pilot Study of Inter-Rater Agreement on the "Birthday Money" Problem......................................... 245

F6. Summary of the Pilot Study of Inter-Rater Agreement on the "What's in My Future?" Problem..................................... 246

F7. Summary of the Pilot Study of Inter-Rater Agreement on the "How Many Children Live Next Door?" Problem.................... 247

F8. Summary of the Pilot Study of Inter-Rater Agreement on the "Blind Sided" Problem............................................ 248

F9. Percent Consensus between Raters after Independent Scoring ........... 251

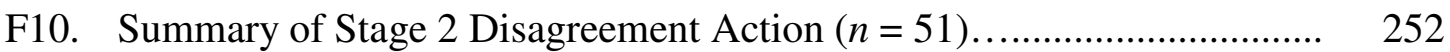

F11. Stage 3 Pearson $r$ Correlations between Rater A and Rater B

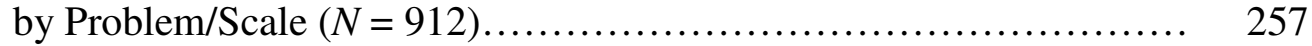

F12. Summary of Scoring Rubrics for the Six Nonroutine Mathematical Problems.......................................... 258

G1. Comparison of the FSMAS and FSMAS-SF Instruments................ 273

H1. Some Selected Reported Norms for the Rotter I-E Scale provided in Lefcourt (1976, Appendix VII, pp.181-182)............... 285 


\section{LIST OF FIGURES}

Number

Page

1. Some sources of possible correlates of performance on nonroutine math problems.................................... 59

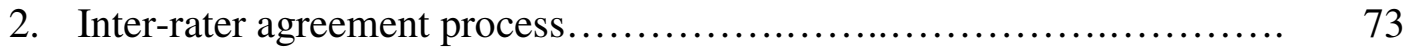

3. Roadmap for bivariate analyses.............................. 87

4. Mean number of words vs. students' problem choice.................. 131

5a. Example of a metacognition intervention for problem solving

- page 1

5b. Example of a metacognition intervention for problem solving

- page 2

6. Proposed nonroutine math problem that promotes writing in mathematics, aesthetics, metacognition, and presentation.

List of Figures in Appendixes:

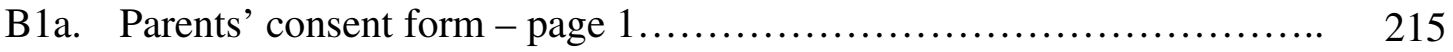

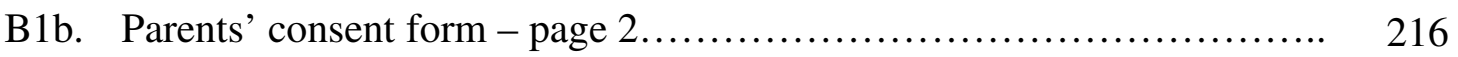

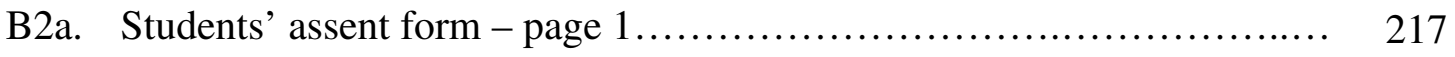

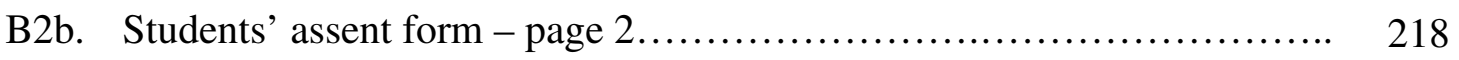

C1. Instructions for math skills assessment - form A.................. 220

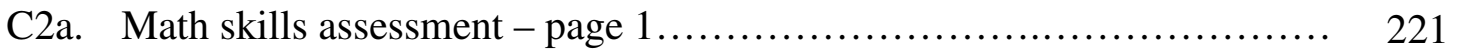

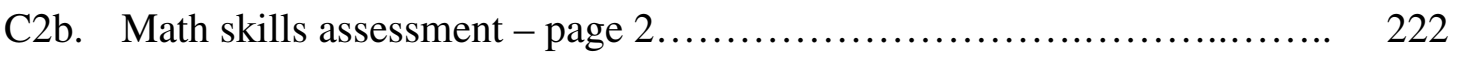

C3. Math skills assessment - form A answer key.................... 223

D1. My mathematics experience writing assignment.................... 225

D2. Math regrets writing prompt................................. 226 
D3. My mathematics experience writing assignment.

E1. "Count your coins" nonroutine problem

E2. "Lost in the auditorium" nonroutine problem

E3. "Birthday money" nonroutine problem

E4. "What's in my future?" nonroutine problem

E5. "How many children live next door?" nonroutine problem

E6. "Blind sided" nonroutine problem.

F1. Inter-rater agreement process.

F2a. Math scoring rubric: count your coins - front side.

F2b. Math scoring rubric: count your coins - back side

F3a. Math scoring rubric: lost in the auditorium - front side

F3b. Math scoring rubric: lost in the auditorium - back side

F4a. Math scoring rubric: birthday money - front side

F4b. Math scoring rubric: birthday money - back side

F5a. Math scoring rubric: what's in my future? - front side.

F5b. Math scoring rubric: what's in my future? - back side

F6a. Math scoring rubric: how many children live next door? - front side.....

F6b. Math scoring rubric: how many children live next door? - back side....

F7a. Math scoring rubric: blind sided - front side

F7b. Math scoring rubric: blind sided - back side

G1. Instructions for the a shortened form of the Fennema - Sherman mathematics attitudes scales (FSMAS-SF). 


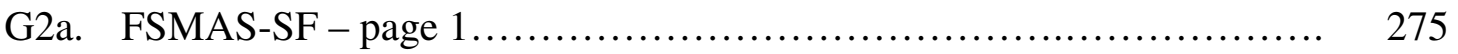

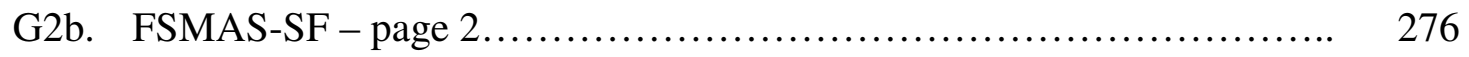

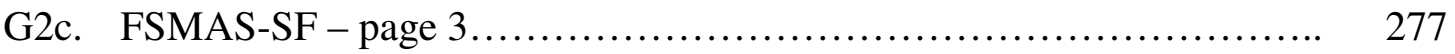

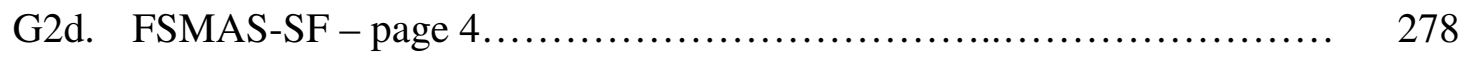

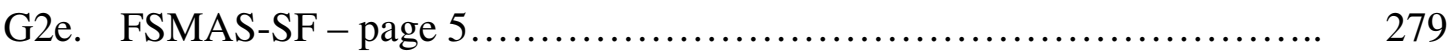

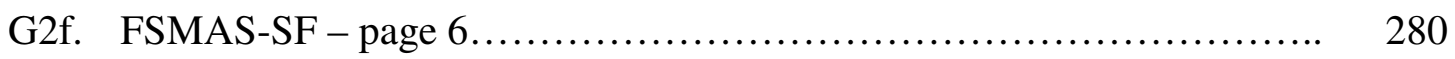

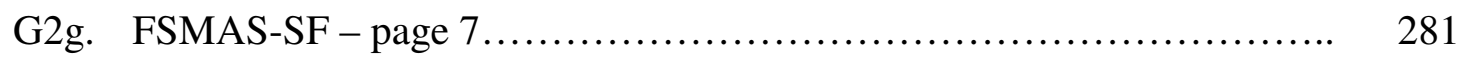

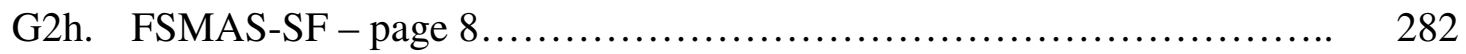

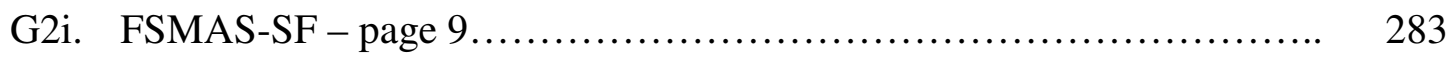

H1. Instructions for the Rotter Internal-External

Locus of Control questionnaire.................................... 286

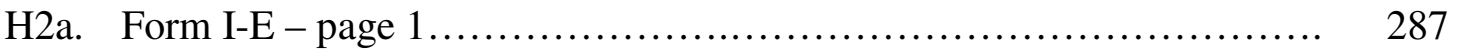

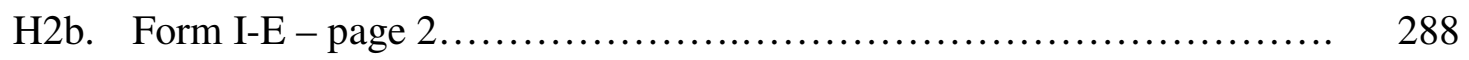

H2c. Form I-E - page 3 ............................................ 289

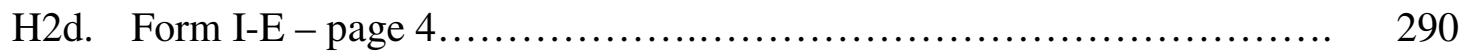

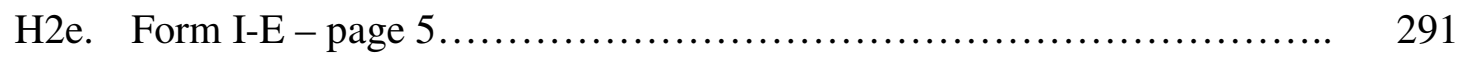

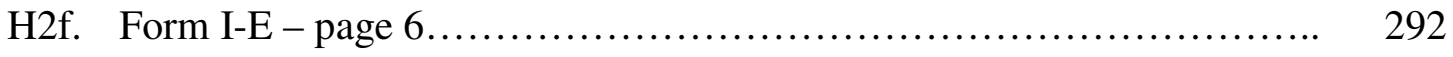


The ability to solve problems is at the heart of mathematics. Mathematics is only "useful" to the extent to which it can be applied to a particular situation and it is the ability to apply mathematics to a variety of situations to which we give the name "problem solving" (Branca, 1985, p. 72).

\section{Statement of the Problem}

The purpose of this study was to describe students' attempts to solve nonroutine math problems and to explore possible correlates of their performance. The focus of this study was on inattended (i.e., intentionally avoided) dimensions that have been underrepresented in the literature including attitudes, interests, values, aesthetics, metacognition, and representation. Several demographic factors were included in the study, as well as intellective variables related to aptitude, achievement, and experience. This study involved both quantitative and qualitative methodologies. 


\section{Justification for and Significance of the Study}

The 2006-2007 state mathematics scores for Rhode Island high school students on the New Standards Reference Examinations (NSRE) revealed that, for the 53 high schools with reported results, only $57 \%$ of students achieved the standard in math skills and only $35 \%$ reached the standard in problem solving. ${ }^{1}$ Furthermore, for each of the 53 high schools, the percent of students reaching the standard for math skills exceeded the percent of students reaching the standard for problem solving (National Center on, 2008a). This latter observation speaks to the fact that, for many students, mathematics instruction continues to be mostly drill-and-practice on routine problems, with minimal, if any, opportunity for productive thinking. Students can learn to master basic skills and follow algorithms and strategies on demand, without grasping an understanding of how to apply these skills to related problem solving (Campione, Brown, \& Connell, 1989; Countryman, 1992).

The weakness in problem solving is not unique to our lower performing schools. From that same data set of 53 high schools, the two highest performing schools in problem solving, both within affluent communities, only had $66 \%$ of their students achieve the standard.

\footnotetext{
1 The 2006-2007 school year was the last year that Rhode Island administered the New Standards Reference Examination (NSRE). The NSRE was replaced by the New England Comprehensive Assessment Program (NECAP). Unlike the NSRE, the NECAP does not consider problem solving as a separate content strand but rather as part of a process strand (partnered with reasoning and proof) that is embedded across the standards. Thus, a separate score for problem solving is no longer reported.
} 
Included in the aforementioned results for the 53 high schools were the results for the Beacon Charter High School for the Arts, located in Woonsocket, Rhode Island, the approved site in which my research was conducted.

The reported value-added ${ }^{1}$ results showed $72 \%$ of the students reaching the standard for math skills and 56\% reaching the standard for problem solving (National Center on, 2008a, 2008c). Although both statistics exceeded the state averages of 57\% and 35\%, respectively, the low proficiency in problem solving served as both an impetus and opportunity for this study.

Another impetus for this study was (and still remains) the No Child Left Behind (NCLB) "high-stakes" requirement of schools to continually improve each year in the areas of mathematics and language arts, by meeting annual targets for the percentage of students achieving at or above the proficient level on state tests. In Rhode Island, failure to meet a 3\% AYP (Adequate Yearly Progress) in any of the three testing areas of mathematics, reading, and writing on the New England Common Assessment Program (NECAP), results initially in a "watch school" status, with no sanctions or interventions. Thereafter, with each continued consecutive year of failure to meet AYP, progressively larger sanctions and interventions are applied (e.g., from offering students the choice to transfer to an extreme of school restructuring).

\footnotetext{
${ }^{1}$ The value-added model compares the performance of each school's students with the performance of similar students statewide, by adjusting for these factors: poverty; nonEnglish speaking background; educational background of the parents; having special learning needs; and having a minority racial-group identity (National Center on, 2008b). A technical bulletin is found in Kajiji (2008).
} 
Since their conception, charter schools in Rhode Island have been a source of controversy. Some state legislators, teacher unions, school districts, school committees, and other community stakeholders have often fought against (and continue to fight) charter school applications. Since the money follows the students, charter school funding is a major contributor to the controversy. There is also a growing movement to break teacher unions, specifically in areas such as: tenure, which has often protected incompetent and/or low motivated teachers in our traditional public schools; the required number of working hours; the pension systems; and health care contributions. Thus, charter schools, like other new alternative schools, are under continuous scrutiny and pressure to show positive results in student achievement, to help quell the voices of naysayers who argue that we should focus on improving our traditional schools rather than offering "schools of choice."

Since it is state testing in the areas of mathematics, reading, and writing that determines the level of school performance and the AYP calculation, this exploratory study might contribute to a long-term commitment to improving student achievement in problem solving.

The following Literature Review contains the pertinent findings that defined the framework for this study. 


\section{Literature Review}

What is a Problem and what is Problem Solving?

Three closely related definitions were found in the literature. Brownell (1942) described a problem as a situation the subject understands but has no immediate means of satisfaction - he is initially perplexed but not confused. To Brownell, problem solving was thus the process of extrication along a continuum stretching from one extreme of perplexity to the other extreme of full understanding.

In his 1962 seminal work, Mathematical Discovery: On Understanding, Learning, and Teaching Problem Solving - Volume I, G. Polya stated: “Thus, to have a problem means: to search consciously for some action appropriate to attain a clearly conceived, but not immediately attainable, aim. To solve a problem means to find such action" (p. 117). Polya also stated that, inherent to every problem, is some degree of difficulty (i.e., if there is no difficulty - there is no problem).

Kilpatrick (1985, p. 2) stated: "In what might be termed the psychological perspective on problems, a problem is defined generally as a situation in which a goal is to be attained and the direct route to the goal is blocked."

Philosopher and mathematician René Descartes (1596 - 1650) proposed a universal method of solving problems, albeit not finished, in Rules for the Direction of Mind (1701). Polya (1962) provided a brief overview of Descartes's three-step process: (a) reduce any type of problem to a mathematical problem; (b) translate any type of mathematical problem into one of algebra; (c) reduce any problem of algebra 
to a single equation. There is little doubt that, despite Descartes's failure to find a universal method for problem solving, his work influenced Polya's modern heuristic (Polya, 1945/2004; Shoenfeld, 1987). In his 1945 epic work, How to Solve It, Polya stated: "The aim of heuristic is to study the methods and rules of discovery and invention" (p. 112). Furthermore, he felt that any serious study of heuristics should consider both the logical and psychological and that experience with problem solving and observing others solving problems must serve as the foundation for building heuristics. Polya proposed a four-step heuristic process (understanding the problem, devising a plan, carrying out the plan, looking back).

Unfortunately, despite this highly cited and distributed work over the last six decades, only one study was found in the literature investigating the relationship between Polya's method and mathematics achievement. Yong and Kiong, 2005 explored the effect of metacognition on problem solving (see Real Time Logs and Interviews: Metacognition, this chapter).

Furthermore, although Polya's four-step process appeared in mathematical textbooks and associated resources, there was relatively little evidence of practice at the classroom level.

Erlwanger (1973) stated that a child getting a correct answer does not always indicate that the child understands what he or she is doing. Campione et al. (1989) and Countryman (1992) agreed that many students can memorize, follow instructions, complete class and homework assignments, and take tests without knowing what their answers mean. By design, too often, the tasks mask the level of students' understanding. Countryman argued that understanding mathematics required 
constructing mathematics through opportunities for students to explore, justify, represent, discuss, use, describe, investigate, and predict (i.e., a heuristic approach) opportunities promoted by the National Council of Teachers of Mathematics (NCTM) in the organizations' Principals and Standards for School Mathematics (National Council of Teachers of Mathematics, 2000).

Of particular interest were open-ended nonroutine (or simply nonroutine) mathematical problems. Open-ended problems had multiple solution strategies and/or had more than one correct answer (Leatham, Lawrence, \& Mewborn, 2005; London, $1989,1993,2007)$. Nonroutine problems required more than solving a single equation or applying a single algorithm (typical of a majority of class work and standardized test questions). Nonroutine problems required higher levels of mathematical understanding. London published a book on nonroutine problems (1989) and a secondary mathematics curriculum of open-ended - nonroutine problems (1993). 


\section{Overview}

The weaknesses in mathematical problem solving, and the quest for underlying causes, have transcended state lines, country borders, and continents (Branca, 1985; Husén, 1967; Robitaille \& Garden, 1989) and as notable in these citations - time.

In her 1960 report, Review of Research on Psychological Problems in Mathematics Education, which reviewed studies between 1948 and 1958, Rosalind L. Feierabend recommended further investigation of the relationship between nonintellective factors (attitudes, anxiety, interests, familial factors, gender) and mathematics achievement.

The thinness of pertinent research literature and examples of "concerns/issues raised" and "directions needed" relative to the teaching and learning of problem solving, spanning the last 50 years, motivated my research and provided the roadmap for it.

Examples from the literature included Edward A. Silver's paper - "Research on Teaching Mathematical Problem Solving: Some Underrepresented Themes and Needed Directions" (Silver, 1985). He proposed ten factors that he believed were fundamental to the teaching and learning of mathematical problem solving: affect, beliefs, classroom ecology, conceptual analyses, group process, individual cognitive differences, metacognition, representation, teachers, and technology. McLeod (1985) stated that research of problem solving has concentrated on cognitive issues rather than affective ones. Kifer and Robitaille (1989) argued that aptitude measures or assessments of prior performance account for some, but not all, of the variation in achievement and that "other noncognitive or affective variables must play a major role 
in determining cognitive outcomes" (p. 178). According to Mandler (1989, p. 3): "Affect is the least investigated aspect of human problem solving, yet it is probably the most often mentioned as deserving further investigation."

Lester (1994) provided an approximate chronology of problem-solving research emphases and methodologies between 1970 and 1994. Between 1970 and 1982, research focused on problem difficulty, characteristics of successful problem solvers, and heuristics training. The two major methodologies used were statistical regression analysis and early teaching experiments. Between 1978 and 1985, the emphasis was on comparing experts and novices in performing problem-solving tasks and strategy training. The two major methodologies used were cases studies and "think aloud" protocol analysis. Between 1982 and 1990, the research focused on metacognition, affect and beliefs, and metacognition training. The two major methodologies used were cases studies and "think aloud" protocol analysis. And, between 1990 and 1994, the emphasis was on social influences and problem solving in context with ethnographic methods dominating the research methodologies used.

Lubienski and Bowen (2000) conducted a survey to assess the relative attention in research between mathematics and the four equity categories: ethnicity, gender, social class, and disability. Using the Educational Resources Information Center (ERIC) database, the study sieved out 3,011 articles pertaining to mathematics education research published between 1982 and 1998 from 48 major educational research journals. Of the 3011 articles, $21 \%$ pertained to "at least one" of the four equity categories. Of these, gender received the most attention with $52 \%$, followed by 
$31 \%$ for disability, $18 \%$ for ethnicity, and $8 \%$ for social class. Elementary education received the most attention. Ethnicity, social class, and disability research peaked at the elementary school level, while gender research peaked at the secondary level. The majority of research focused more on cognition and outcomes than on nonintellective factors.

Since Silver's 1985 paper, although the literature on problem solving has grown considerably, there still remain many inattended and underrepresented areas of inquiry. Furthermore, what little research has been done in these underrepresented areas has yet to affect the way problem solving is taught in the mathematics classroom.

My review of the literature yielded six sources of possible correlates of problem solving in mathematics: aptitude and achievement; attitudes and experiences; demographics (gender, ethnicity, socioeconomic status, school location); values and interests; mathematical aesthetics; and real time logs and interviews (focusing on metacognition and representation). The following sections summarize the research in these six areas. 


\section{Aptitude and Achievement}

Much of the educational research in mathematics has been for the ultimate purpose of improving student achievement. Measurements of student performance, used for comparisons between various populations, have fallen into four general categories: international (e.g., Trends in International Mathematics and Science Study [TIMSS], Program for International Student Assessment [PISA]; national (e.g., National Assessment of Educational Progress [NAEP], Scholastic Aptitude Test [SAT]; state (e.g., California Standards Test [CST], Massachusetts Comprehensive Assessment System [MCAS], New England Common Assessment Program [NECAP], New York State Regents Examination [NYSRE]; and local (e.g., grade point average [GPA], mathematical tasks at the classroom level).

The No Child Left Behind Act of 2001 (NCLB) has forced individual states to set standards to assess students' proficiency in mathematics and reading at various grade levels. In her 2003 Educational Week article “'Proficient' Mark Shifts by State, Grade, Subject," Lynn Olson reported findings of a study by the Northwest Evaluation Association (NWEA), who evaluated where 14 states set their proficiency levels in mathematics and reading. Comparisons were made between student performance on the state tests and the tests produced by NWEA. Despite NCLB's uniform language, rules, and consequences, the results indicated a large disparity between states, grade, and subjects as to what constitutes "proficiency."

Olson (2003) reported that eighth-grade students deemed proficient in mathematics on the Montana state test scored at the 36th percentile on the NWEA test, 
while eighth-grade students deemed proficient in mathematics on the Wyoming state test scored at the 89th percentile on NWEA.

Olson also reported that third-grade students deemed proficient in mathematics on the Arizona state test scored at the 46th percentile on the NWEA test, while eighthgrade students deemed proficient on the Arizona test scored at the 75 th percentile on the NWEA test, reflecting a proficiency bar set at a higher level for eighth-grade than for third-grade.

The NWEA tests were of interest because the intended site for my research uses the NWEA Mathematics, Reading, and Language Usage tests and assesses each student at the beginning and end of each school year. The potential availability of data for students' performance in the content areas of Reading and Language Usage was intriguing, because Fuchs et al. (2008) found that "the link between word identification and problem-solving skill suggests that language may play a role in math problem solving" (p. 43).

My search of the JSTOR electronic data base found no empirical studies using the NWEA tests. However, the Education Resources Information Center (ERIC) database contained an impressive list of research published by NWEA, dealing with reliability and validity of the NWEA tests, the measurement scale, achievement gaps, and the aforementioned inconsistent criteria for proficiency.

In my search of the literature for studies relating such factors as gender, socioeconomic status (SES), and/or ethnicity with students' mathematical achievement, several studies referenced the National Assessment of Educational 
Progress (NAEP). There were two different NAEP assessments referenced: the LongTerm Trend (LTT) NAEP and the Main NAEP. Both assessments measured mathematics and reading but differed in the content assessed, the sample, frequency of assessment administration, and the results reported. These differences meant that results from the LTT NAEP and Main NAEP could not be compared directly (National Center for, 2009a).

Vanneman, Hamilton, Baldwin Anderson, and Rahman (2009) analyzed LTT NAEP data from 1978 to 2004 for Black and White 9- and 13-year-olds and found:

Mathematics scores for both 9- and 13-year-old Black and White students were higher in 2004 than on any previous long-term trend assessment. In addition, the score gaps for Black and White students were narrower in 2004 than in the first assessment in 1978 for both age groups, as scores of Black students showed a greater increase than those of White students. The gaps in 2004 were not significantly different from the gaps in 1999 (p. 6).

Vanneman et al. (2009) analyzed Main NAEP data from 1990 to 2007 for Black and White fourth- and eighth-graders with regards to mathematics scores and achievement gaps and found:

In main NAEP, average fourth-grade mathematics scores for the nation were higher in 2007 than in 1990 for both Black and White public school students. The greater increase for Black fourth-graders resulted in the gap narrowing from 31 points in 1990 to 26 points in 2007. From 2005 to 2007, scores 
increased for both Black and White students, but there was no significant change in the gap.

Average mathematics scores were higher in 2007 than in 1990 for both Black and White eighth-graders. The 31-point gap in 2007 was not significantly different from the 33-point gap in 1990. However, the gap was narrower in 2007, at 31 points, than in 2005, at 33 points. Although scores for both groups were higher in 2007, a greater increase in Black students' scores caused the gap to narrow. The 2-point decrease in the gap from 2005 to 2007 was significant while the 2-point decrease from 1990 to 2007 was not. It is possible that the smaller standard errors in 2005 , due to the increased sample size in that year, allowed the difference in 2005 to be identified as statistically significant (p. 7)

Vanneman et al. (2009) analyzed Main NAEP data from 1990 to 2007 for Black and White fourth- and eighth-graders with regards to mathematics scores and achievement gaps by gender and found:

Average mathematics scores were higher in 2007 than in 1990 for the nation's Black and White fourth-graders, regardless of gender. Among females, the gap was narrower in 2007 as the average score gains of Black females were greater than those of their White peers. Among fourth-grade males, the Black-White gap did not change significantly. 
In addition to the 17-year gain, mathematics scores also increased during the two-year period, 2005 to 2007, for both Black and White fourth-graders, regardless of gender. However, the gaps did not change significantly either for males or for females during this period.

In 2007, average mathematics scores were higher than they had been in 1990 for Black and White eighth-graders. However, the Black-White mathematics gap did not change significantly for either males or females.

At grade 8, mathematics scores increased from 2005 to 2007 for Black and White students, regardless of gender. Female eighth-graders showed a narrowing of the gap during this period as Black females' scores increased more than those of White females, while the gap for males did not change significantly (p. 8).

Vanneman et al. (2009) analyzed Main NAEP data from 2003 to 2007 for Black and White fourth- and eighth-graders with regards to mathematics scores and achievement gaps by family income:

NAEP uses student eligibility for free or reduced-price school lunch as an indicator of family income. At grade 4, mathematics scores were higher in 2007 than in 2003 and 2005 for all Black and White public school students, regardless of school-lunch eligibility. Despite these increases, the only 
significant Black-White gap change was between 2003 and 2007, for students

eligible for reduced-price lunch. At grade 8, mathematics scores were higher in 2007 than in 2003 and 2005 for all Black and White public school students.

The Black-White score gaps for students eligible for free or reduced-price lunch narrowed in 2007 in comparison to both previous assessments, as scores for eligible Black students showed greater gains than those of their White peers (p. 10).

\section{Experiences with and Attitudes toward Mathematics}

General attitudes toward mathematics.

Attitudes are generally defined as "manners of acting, feeling, or thinking that show one's disposition or opinion" (Phillip, 2007, p. 259). Phillip's definition paralleled that of Wagner (1969): “An attitude is composed of affective, cognitive, and behavioral components that correspond, respectively, to one's evaluations of, knowledge of, and predisposition to act toward the object of the attitude" (p. 7). A detailed review of the pertinent literature relative to attitudes and mathematics achievement revealed a wide range of results.

Aiken (1970c) "Attitudes toward Mathematics" provided a comprehensive review of the expanding body of literature in the decade following Feierabend's 1960 report. Aiken found: 
1. The three major methods of measuring attitudes towards mathematics were observational methods; interviews; and self-report methods such as questionnaires, attitude scales, sentence completion, projective techniques, and content analysis of essays.

2. The majority of investigations dealt with attitudes toward mathematics in general rather than attitudes toward specific courses or types of mathematics problems.

3. Definite attitudes toward mathematics may be formed as early as third-grade and tend to be more positive than negative in elementary school, although stability is low in the early grades. Attitudes tend to become increasingly negative as students progress through the grades, with the junior-high school grades being the most influential period for determining attitudes toward mathematics.

4. The relationship between attitudes toward mathematics and achievement in mathematics was not consistent. Overall there was a positive, but small to moderate, correlation between attitudes and achievement.

5. "Several studies suggested that measures of attitudes and anxiety may be better predictors of the achievement of females than of males" (p. 567).

6. "...the results of research have suggested that the teacher, perhaps even more than the parents, is an important determiner of student attitudes" (p. 589). 
Aiken had several criticisms of research on attitudes towards mathematics: crude measures of attitudes; excessive reliance on correlational methods; improper use of covariance analysis; inadequate control of extraneous variables; and failure to use adequate measures of change.

Because of the rapidly growing literature on attitudes toward mathematics, Aiken (1976) updated his 1970 review a mere six years later, with the main themes from 1969 to 1974:

1. "When attitude scores are used as predictors of achievement in mathematics, a low but significant positive correlation is usually found (Neale, 1969)" (p. 295). This occurred at all levels from elementary through post-graduate. This was also found in studies of minority groups and with students of other countries.

2. "The late elementary and early junior-high grades are viewed as being particularly important to the development of attitudes toward mathematics (Callahan, 1971; Taylor, 1970)" (p. 296).

3. "The correlation between attitude and achievement varies not only with grade level but also with the sex of the student and is generally somewhat higher for girls (Behr, 1973)” (p. 296). 
4. "Some of the personality characteristics related to mathematics attitude and achievement are a high sense of personal worth, a greater sense of responsibility, high social standards, high academic achievement motivation, and greater freedom from withdrawing tendencies (Aiken, 1972)” (p. 297).

5. "Furthermore, children with positive attitudes toward mathematics tend to like detailed work, to view themselves as more persevering and self-confident (Aiken, 1972), and to be more "intuitive" than "sensing" in their personality type (May, 1972)" (p. 297).

6. "It has also been reported that children who do well in mathematics are more conforming and obedient in school (Neale, 1969), and their parents are more possessive (Weston, 1969)" (p. 297).

7. “...attitudes and achievement in mathematics are positively related to the attitudes of their parents (Aiken, 1972; Burbank, 1970; Levine, 1973)” (p. 297).

8. "Perhaps the soundest conclusion to be drawn from the results of the studies cited in this review is that changes in attitude toward mathematics involve a complex interaction among student and teacher characteristics, course content, methods of instruction, instructional materials, parental and peer support, and methods of measuring these changes (Leake, 1970). Therefore, the findings of any investigation that does not take into account at least several of these sources of 
variability are severely limited in generalizability to other classroom situations" (p. 302).

9. "Sex and personality variables related to attitude toward and ability in mathematics continues to be a popular topic" (p. 302).

10. "Most important from the standpoint of potential influence on students' attitudes toward mathematics are investigations of the classroom behavior and techniques employed by teachers" (p. 303).

Since Aiken's 1976 update, the literature on attitudes toward mathematics and achievement in mathematics has grown exponentially. Unfortunately, there is little consensus on the relationships between attitudes and achievement. First, there is the dilemma of "which came first, the chicken or the egg" (does attitude affect achievement or does achievement affect attitude)? Second, there is little consensus as to the magnitude of the relationships, whichever causal direction is supported.

Neales (1969) cited three major studies (Anttonen, 1967; Husén, 1967; Ryan, 1968) that reported consistent correlation coefficients in the $.20-.40$ range for attitudes toward mathematics and standardized mathematics achievement test scores and thus supported the view that favorable attitudes lead to learning. However, Neale provided an alternative explanation. That is, the three studies, as well as most nonlongitudinal studies investigating the relationship between attitude toward mathematics and achievement in mathematics, involved a snapshot in time (i.e., the 
survey of attitudes coincides with the time of assessment of achievement). Thus, students who learned the most tended to be rewarded the most and tended to like math; and conversely, the students who learned less, received fewer rewards and thus tended to dislike mathematics. The plausibility of Neales' alternative explanation demanded a higher scrutiny of studies that showed significant positive correlations between general math attitudes and achievement in mathematics.

Ma and Kishnor (1997) explored the relationship between attitudes toward mathematics (ATM) and achievement in mathematics (AIM) by conducting a metaanalysis of 113 primary studies from 1966 to 1993 . The authors reported four results: (a) small effect sizes indicated that there were no meaningful implications for educational practice for relationships between ATM and AIM; (b) grade, ethnicity, sample selection, sample size, and date of publication all had reliable effects on the ATM-AIM relationship; (c) gender did not have a reliable effect on the relationship; and (d) there was no reliable evidence of interaction effects among gender, grade, and ethnicity on the ATM-AIM relationship.

Ma and Kishnor (1997) suggested that junior high school may be the most important period for shaping students' ATM and that the relationship between ATM and AIM may be more practically meaningful at the secondary level than the elementary level. Furthermore, they agreed with Aiken (1970): attitudinal measurements should focus on specific mathematical areas, such as arithmetic or problem solving; mathematics ability should be included as a variable in further ATMAIM research; and there is little understanding of the effects of school-level variables 
such as school size, school mean socioeconomic status, and school policies and practices on the ATM-AIM relationship.

Two international studies of achievement in mathematics, both part of the International Project for the Evaluation of Educational Achievement (IEA), were of interest. The first study, conducted in 1960 - 1964, involved 12 countries and was presented in Husén (1967). The second study, conducted in 1980 - 1982, involved 20 countries and was presented in Robitaille and Garden (1989). Both studies incorporated several attitude scales administered in the form of self-report questionnaires intended to ascertain whether certain attitudes or beliefs were important to mathematics instruction, and second, to test the hypothesis that a positive attitude toward mathematics will cause students to learn mathematics (Neale, 1969).

Husén (1967) found U.S. students who were in grades predominantly comprised of 13-year olds (ages in respective grades vary between states due to differences in state laws that mandate specific birthday cut-off dates for entrance to kindergarten) ranked second out of 12 countries in believing that mathematics allowed for various approaches to solving problems and that math was easy to learn, but ranked tenth in mathematics achievement. Discussing the results of this study, Neale (1969) stated “...attitudes appear to be independent of mathematics achievement” (p. 632). Three scales revealed that the U.S. students did not highly value the place of mathematics in society (ranked 8th out of 12 countries); strongly disliked school and school learning (ranked 12th out of 12 countries); and were very pessimistic about man and his environment (ranked 12th out of 12 countries) (see Husén, 1967, V.2, table 1.16, p. 46). 
In Robitaille and Garden (1989), achievement in mathematics was reported for the specific mathematics subtests of arithmetic, algebra, geometry, measurement, and descriptive statistics. In comparison to the other 19 countries, the U.S. 13-year old population's best subtest performance was the descriptive statistics subtest (9th out of 20 ) and the poorest subtest performance was the measurement subtest (18th out of 20). (Robitaille, 1989, Table 6.5, p. 124). However, the U.S. students scored high (top $25 \%$ ) in the affective measures of home support, which measured to what extent a student perceived encouragement for their mathematics work by their parents, and mathematics and myself, which measured to what extent students viewed themselves as able, motivated, and interested in mathematics. Also, in comparison to other countries, the U.S. students appeared indifferent to the importance of mathematics and to the ease or difficulty of mathematics and had a tended to dislike mathematics.

In contrast, Japan placed first in four out five of the subtests and second in the arithmetic subtest yet the Japanese students reported very little home support and were dead last on the mathematics and myself scale. These results seem to support the body of literature that concludes that correlations between attitudes toward mathematics and achievement in mathematics, although generally positive, are low.

Possible distortion must be addressed relative to the IEA studies discussed. As Berliner and Biddle (1995) pointed out, at the time of the study, Japanese schools were requiring students to take algebra in eighth-grade whereas U.S. students were typically not offered the class until one or two years later. This example, taken in conjunction with the self-report questionnaires on affective factors used in the IEA studies, tempers any use of stated correlation values. The major conclusions/observations 
derived from the review of the studies are that the relationship between attitudes toward mathematics and achievement in mathematics is complex and does not seem to be highly correlated in the affective areas addressed by the IEA studies.

I concluded that general attitudes towards mathematics was not of particular interest for this study. However, attitudes toward specific mathematics tasks (such as problem solving) or types of problems were of interest and thus were a focus of this study.

Locus of control, causal attributions, learned helplessness, and explanatory style.

How students explain their success and failures has been a focus of researchers for decades. "The notions of causal attribution and locus of control are at the center of some of the most interesting current research related to the affective domain and problem solving" (McLeod, 1985, p. 273). Closely related to these are the theories of learned helplessness and explanatory style.

Rotter (1966) used locus of control to describe a dimensional structure of causality within his social learning theory, wherein perceived causes could be located along an internal-external continuum (Weiner, 1986). If individuals strongly believe that they control their destiny, then they have high levels of internal locus of control. Conversely, the individuals who see no connection between personal effort and outcomes - and, instead, attribute outcomes to luck, fate, or the influence of others have high levels of external locus of control. Rotter (1966), Seely (1985), and Weiner (1986) caution that "internal" and "external" should not be mistaken as labels of a 
dichotomy. Locus of control "is a continuum ranging from extreme externality to extreme internality" (Seely, 1985, p. 1).

The theory of learned helplessness was first proposed by Martin E. P. Seligman and colleagues (Overmier \& Seligman, 1967; Seligman, 1975, 1990; Seligman \& Maier, 1967). This theory postulates that an organism that tries to escape an adverse condition by solving a problem, but continuously fails, will eventually give up trying to solve the problem and will learn to live with the adverse condition. Learned helplessness often produces anxiety and/or depression while also reducing one's ability to distinguish solvable problems from insolvable ones. All teachers of mathematics (and many struggling learners) are well acquainted with this phenomenon.

The original theory was found to be inadequate as some subjects, despite adversity, never gave up. Seligman, along with colleagues Lyn Abramson and John Teasdale worked on a reformulation of the learned helplessness theory building upon Bernard Weiner's attribution theory. Subsequently, an introduction to a reformulated helplessness theory was addressed in a special issue of the Journal of Abnormal Psychology in February 1978. The history of learned helplessness is illustrated in Peterson, Maier, \& Seligman (1993).

One of the major outcomes of the reformulation research was the creation of the Attributional Style Questionnaire (ASQ) (Peterson, Semmel, von Baeyer, Abramson, Metalsky, \& Seligman, 1982; Seligman, 1990) and the Children's Attributional Questionnaire (CASQ) (Seligman, 1990). Both instruments were designed to determine whether a subject's explanatory style was one of pessimism or 
one of optimism. Seligman, based on the premise that explanatory styles were modifiable, developed his theory of Learned Optimism (Seligman, 1990).

Of further interest was Seligman's association with social psychologist, Chris Peterson. Peterson developed a method of determining the explanatory style of someone who wouldn't or couldn't take the explanatory-style questionnaires (e.g. someone now deceased). The method was called Content Analysis of Verbatim Explanations (CAVE). Briefly described, the method involved rating causal statements found in written or oral discourse on a scale of 1-7 in each of the three categories of permanent, pervasive, and personal qualities (Peterson 1991a; Peterson 1991b; Seligman, 1990).

\section{Confidence/self-efficacy and self concept toward mathematics.}

"It is reasonable to think of confidence as a belief about one's competence in mathematics" (McLeod, 1992, p. 583). Bandura (1994) defined self-efficacy as: “people's beliefs about their capabilities to produce designated levels of performance that exercise influence over events that affect their lives" (p. 71). I considered these two terms to be synonymous. "Confidence correlates positively with achievement in mathematics, and the relationship is generally quite strong, with correlation coefficients greater than 0.40 appearing in studies at the secondary school level (Reyes, 1984)" (McLeod, 1992, p. 583). An instrument for measuring confidence in mathematics is found in Fennema and Sherman (1976). Reyes (1984) and Meyer and Fennema (1988) conclude, that: "In general, males tend to be more confident than females, even when females may have better reasons, based on their performance, to 
feel confident" (McLeod, 1992, p. 580). Rosenberg (1989) defined the term "selfconcept" as "the totality of the individual's thoughts and feelings with reference to [the] self as an object" (p. 34). The distinction between self-efficacy and self-concept, along with a detailed historical perspective, appeared in Pajares et al. (2001).

\section{Demographics and Mathematics Achievement}

\section{Gender and mathematics achievement.}

A substantial amount of attention has been given in the literature to exploring the relation between gender and the performance of mathematical tasks. Friedman (1989) stated that the topic was highly controversial and arguments for sex-differences "reflect the familiar heredity-environment dichotomy [italics added]" p. 186). Briefly stated, the biological argument has been that females are intrinsically and irreversibly inferior to males in mathematical capabilities. The environmental argument has been there other factors to consider, such as differential coursework (i.e., number of and level of coursework taken), father's occupation, and father's presence (Friedman, 1989).

Friedman (1989) conducted a meta-analysis of 98 studies between 1974 and mid-1987 on sex differences in quantitative mathematical tasks. There were two major findings: First, the small mean effect size was not large enough to claim there were sex differences in the general United States population of school-aged children, although the difference favored a male advantage; second, sex differences decreased 
in higher grades. The latter finding supported a conclusion that sex differences were environmental and not biological.

Several of the studies in Friedman's meta-analysis included measures of affective factors. Sherman and Fennema (1977) compared tenth- and eleventh-grade females and males in mathematics classes on their intent to enroll in additional mathematics courses. Also, included in the study were eight affective variables measured by the Fennema-Sherman Mathematics Attitudes Scales (Fennema \& Sherman, 1976). Significantly more males than females chose to continue their mathematics coursework, especially those from the lower half of the achievement distribution; females did not see mathematics as a male domain; and when controlling for cognitive variables and intent to continue in mathematics coursework, very few sex differences were found with regards to attitudes toward mathematics. This latter finding was replicated by Fennema (1974, 1978), Fennema and Sherman (1977, 1978), and Swafford (1980).

Another study included in Friedman's meta-analysis that considered affective factors was Swafford (1980). Swafford looked at 623 students (329 females, 294 males) enrolled in a traditional first-year algebra course in 17 schools during the 1976 - 1977 academic school year. In addition to measuring sex differences in mathematics achievement, three affective variables were included in the study: usefulness of mathematics; enjoyment of mathematics; and mathematics as a male domain. There were no significant differences between females and males on mathematics achievement or on their attitudes towards the enjoyment and usefulness of 
mathematics. Both females and males tended to disagree with mathematics as a male domain, with females disagreeing significantly more strongly.

A longitudinal study by Tartre and Fennema (1995) of 60 students as they progressed through sixth-, eighth-, tenth- and twelfth-grades, examined the relationship between gender differences on variables of spatial skills (spatial visualization and spatial orientation), verbal skill, mathematics achievement along with four scales (confidence in learning mathematics, perceived usefulness of mathematics, perception of mathematics as a male domain, effect of the teacher on the learning of mathematics) from the Fennema-Sherman Mathematics Attitudes Scales (Fennema \& Sherman, 1976). Major findings: no consistent gender differences were found between means for spatial skills, verbal skill, and mathematics achievement; confidence, spatial skills, and verbal skill were consistently positively correlated with mathematics achievement with no differences between females and males; spatial skills were consistent significant predictors of mathematics achievement in each year of the study for females, but not males; verbal skill was a consistent significant predictor of mathematics achievement for males, but not females; the male domain was the only affective variable that revealed a consistent significant gender difference - males stereotyped mathematics as a male domain more than females did across all grades. According to the authors: "The results from this study suggested that the cognitive variables were more consistently related to mathematics achievement than were the affective factors" (p. 213). 


\section{Disability and mathematics achievement.}

Geary (2004) stated that 5\% to $8 \%$ of school-aged children have some sort of mathematics learning disabilities (MLD). Geary stated "In theory, a learning disability can result from deficits in the ability to represent or process information in one or all of the many mathematical domains (e.g., geometry) or in one or a set of individual competencies within each domain" (p. 4). Swanson and Jerman (2006) broadly defined MLD as "individuals with average intelligence who exhibit poor math skills" (p. 252). Geary (2004) further stated that the determination of MLD is complicated by the task of separating poor achievement due to inadequate instruction from poor achievement due to actual cognitive disability.

Swanson and Jerman (2006) suggested that math disabilities were as common as reading disabilities in school-aged children, but had received far less attention in the literature than reading disabilities. Lewis, Hitch, and Walker (1994) estimated that $40 \%$ of children with reading disabilities also had a mathematics disability (Swanson \& Jerman, 2006).

Unlike reading disabilities, there exists no specific measures for diagnosing MLD. Widely accepted criteria for MLD are scores lower than the 20th or 25th percentile on a standardized mathematics test in combination with a low-average or higher IQ score (Geary, 2004). Swanson and Jerman (2006) classified average intelligence children with standardized math scores below the 25 th percentile as having severe MLD.

They conducted a meta-analysis of 28 articles to compare children with MLD with average achievers and with children with co-morbid disorders (e.g., mathematics 
learning disability plus reading learning disability). None of the studies considered the intersection of math performance with gender, ethnicity, or SES. Therefore, these factors were not included in the meta-analysis. The major findings were:

The magnitude of differences between children with mathematics learning disabilities and average-achieving students did not change with age.

Swanson (1993) compared 32 learning disabled, 14 normal-achieving, and 17 gifted children (fourth- and fifth-graders) on their mental processing during problem solving. No significant differences were found between the ability groups in terms of age or gender. The children were given three problem-solving tasks and a metacognition questionnaire for "think-aloud" sessions. All sessions were taperecorded and transcribed. The major findings included: there were no quantitative differences between the ability groups in terms of their overall mental processing and solution finding. However, there was a significant difference in metacognition for the learning disabled versus the normal and gifted ability groups (i.e., there were no significant differences in metacognition between the normal and gifted groups). Swanson (1993) also suggested that "links between metacognition, mental processing, and solution finding are more likely to emerge in gifted and average achievers than learning disabled children" (p. 885). 


\section{Ethnicity and mathematics achievement.}

In their study: The Third National Assessment: Minorities and Mathematics, Matthews, Carpenter, Lindquist, and Silver (1984) reported on the LTT NAEP mathematics assessment administered in 1982. They found for the third assessment, consistent with the 1978 assessment, black and Hispanic students in all three age groups performed below the national average (i.e., mean percentage of exercises correct) while whites in all three age groups performed above the national average. The mathematics assessment consisted of exercises classified according to four cognitive levels: knowledge, skill, understanding, and application where knowledge and skills were considered the lower two cognitive levels abilities.

For both blacks and Hispanics, the gap between achievement and the national average increased with age - being more pronounced with blacks than Hispanics. One explanation provided by Matthews et al. for the widened performance gap at age seventeen between blacks and whites was the under-representation of black students in more advanced mathematics courses.

An encouraging trend was both blacks and Hispanics gained ground on their white counterparts by achieving at a higher rate in all three age groups between 1978 and 1982. All three ethnic groups had their highest gains, all statistically significant at the $p<.05$ level, at age thirteen. A similar pattern was found when the data on change was arranged by cognitive level of difficulty - black and Hispanic students made substantial gains on whites on exercises assessing the lower cognitive levels of knowledge and skills and all three ethnic groups had the greatest statistically significant gains $(p<.05)$ at age thirteen. 
Matthews et al. (1984) also found that student's achievement class (i.e., lowest quartile, highest quartile) and the racial composition of the school (i.e., 0 - 59\% white, $60-100 \%$ white) were related to the student's achievement in mathematics. Schools with the higher percentage of minorities tended to score below the national average but made significant performance gains between the 1978 and 1982 assessments.

\section{Socioeconomic status (SES) and mathematics achievement.}

It has become common practice in studies of mathematical achievement to include socioeconomic status (SES) as a predictor-variable. A meta-analysis of SES and academic achievement journal articles published between 1990 and 2000 was found in Sirin (2005). The analysis looked at 74 studies involving 101,157 students, 6,871 schools, and 128 school districts.

Sirin (2005, p. 418) provided the following definition: "In general terms, however, SES describes an individual's or a family's ranking on a hierarchy according to access to or control over some combination of valued commodities such as wealth, power, and social status (Mueller \& Parcel, 1981).” Sirin reported a general consensus in the literature that views parental income, parental education, and parental occupation as the three main indicators of SES. The two types of SES measures widely used by educational researchers were (a) an individual student's SES; and (b) an aggregated SES based on the school the student attends. Family incomes at or below the $130 \%$ poverty level qualified students for free meals. Students from families with incomes between $130 \%$ and $185 \%$ of the poverty level qualified for reducedprice meals (Sirin, p. 419). 
Sirin (2005) identified grade level, minority status, and school location as factors that are likely to influence the relationship between SES and academic achievement: longitudinal studies have shown the gap between low-SES and high-SES students was more likely to stay the same as students got older; "Racial and cultural background continues to be a critical factor in academic achievement in the United States" (p. 420); and "even after accounting for family SES, there appear to be a significant number of differences between urban, rural, and suburban schools" ( $\mathrm{p}$. 421).

Major findings by Sirin's meta-analysis included: family SES and SES at the school level were amongst the strongest correlates of academic performance; studies that assessed academic achievement at the subject level reported stronger correlations with math achievement than with verbal and science achievement; SES was a stronger predictor of academic achievement for White students than minority students; and the higher the percentage of minority students in a sample, the lower the correlation between SES and academic achievement. Sirin also suggested information about students' SES should be collected from parents rather than the students.

Lester (2005), in a study of eighth-grade students from 294 middle schools in Virginia, found schools with a higher percentage of students receiving free or reducedpriced lunch than the state average had significantly lower state assessment math scores than those schools with a percentage of students receiving free or reducedpriced lunch below the state average. Further, Lester (2005) found that there were significant differences in the percentage of students receiving free or reduced-priced 
lunch for school location with urban having the highest percentage and suburban having the lowest percentage.

In regards to SES at the student level, a review of Federal guidelines for eligibility for free or reduced-price meals through the National School Lunch Program revealed the following. Families apply for aid through the school their child attends. Per Federal guidelines, the application requires: the names of all household members; the social security number of adult signing the application; the amount of income received by all household members; and the signature of an adult household member certifying the information is correct. An optional section of the application may request children's ethnicity. Categories include: Hispanic/Latino; Not Hispanic/Latino; Asian; White; Black or African American; American Indian or Alaska Native; and Native Hawaiian or Pacific Islander (Free and Reduced, 2009).

A Federal Income Chart is published prior to each school year which provides the household income limitations per number of household members for eligibility for free and reduced-price meals.

\section{School location and mathematics achievement.}

The intended site for my research was an urban charter school in Rhode Island. As a charter school, any student from the more than 40 school districts could apply. The composition and number of sending school districts has changed from year to year. Thus, it was anticipated that the eventual sample could include students from non-urban schools (i.e., rural and suburban). Problematic was the fact that each sending school district controlled its math curriculum so that incoming students have 
varied widely in their math abilities and experience. A cursory review of Rhode Island state mathematics tests scores indicated a pattern of higher scores for more affluent school districts. Therefore, I conducted a search of the literature for studies related to school location (i.e., rural, suburban, and urban) and mathematics achievement. Lester (2005) compared the performance of eighth-grade students from rural, urban, and suburban schools on the Virginia Standards of Learning (SOL) assessment. The study, which involved 294 middle schools, also considered school size and socioeconomic (SES) status. There were no significant differences in mathematics scores between the rural and urban schools, both of which had significantly lower math scores than suburban schools. 


\section{Values and Interests}

Tyler (1973) defined a value as "an object, activity, or idea that is cherished by an individual which derives its educational significance from its role in directing his interests, attitudes, and satisfactions" (p. 7). Examples of values would include patience, compliance, and obedience. I found that values related to mathematics achievement have received very little attention in the literature.

Cattell \& Butcher (1968) found the motivational factors submissiveness (e.g., I want to be polite to adults) and superego (e.g., I want always to show self-control) to have high correlations with achievement, +.50 and +.44 respectively.

Similar findings were noted in Life in Class Rooms, a work of Philip Jackson (1928/1990). Jackson spent two years observing elementary classrooms at the University of Chicago Laboratory School. During that time he made note of what he called the hidden curriculum -

"the crowds, the praise, and the power that combine to give a distinctive flavor to classroom life collectively form a hidden curriculum which each student (and teacher) must master if he is to make his way satisfactorily through the school" (pp. 33-34).

In essence, Jackson (1928/1990) stated that mastery of the hidden curriculum requires that students cultivate the virtues/values of patience, compliance, and obedience. This observation is predicated on the fact that school is not an option; students have to go to school, like it or not. "They have little choice but to adapt, conform, and obey" (Neale, 1969, p. 639). Neale posited that a possible implication of the findings of Cattel and Butcher (1968) and Jackson (1928/1990) was that certain 
fundamental characteristics of the school as an institution overpowered the influences of attitudes toward learning.

As Neale stated, "What makes Sammy learn is not so much that he enjoys discovering the orderliness of mathematical relationships, but rather that he wants to be an obedient person and do his duty" (Neale, 1969, p. 638).

Following Neale's publication, Aiken (1970a) published “Affective factors in mathematics learning: Comments on a paper by Neale and a plan for research." "Neale is certainly correct in his assertions that correlations between scores on attitude scales and mathematics achievement are typically rather low, especially at the elementary level, and that achievement probably has much effect on attitudes as vice versa" (p. 251). However, Aiken questioned the strength of some of Neale's conclusions based on the inadequacies of measures of attitudes (e.g., self-report inventories at the elementary-school level, limited reading abilities, and experiences of students relative to the content of such inventories). Aiken disagreed with Neales contention that the classroom, although frequently highly structured, is still a place where students make choices - when to study, what to study, how to study, etc. Aiken further stated that rather than simply writing off attitudes and interests as not worth further research, what is needed is to investigate the entire domain of affective and cognitive variables relative to mathematics learning. 


\section{Mathematical Aesthetics}

"The branch of knowledge called aesthetics is concerned primarily with the aesthetic feeling and the aesthetic objects which produce it" (Birkhoff, 1956, p.2185). It should be noted that mathematician George David Birkhoff (1884-1944) was referring to aesthetic objects such as those in the fine arts (e.g., paintings, sculptures, musical compositions) as he was writing about the mathematics of aesthetics and not the aesthetics of mathematics. In regards to this latter perspective, Birkhoff's definition, adapted to performing mathematical tasks (e.g., problem solving), is offered: Mathematical Aesthetics may be generally defined as one's feelings towards a problem before, during, or after a problem-solving activity as well as the aesthetic problem (i.e., mathematical entity) that produced the feelings.

Aesthetics in mathematics education has been neglected in the research literature (Burton, 1999; Dreyfus \& Eisenberg, 1986; King, 1992; McLeod, 1992; Reflections on, 2002; Silver \& Metzger, 1989); and in the classroom: "Developing an aesthetic appreciation for mathematics is not a major goal of school curricula. This is a tremendous mistake" (Dreyfus \& Eisenberg, 1986, p. 9). The most recent review of school curricula, now some two decades since Dreyfus and Eisenberg's statement, found little attempt at rectifying the mistake at the classroom level. One exception was found in Sinclair (2001).

Over the last ten years, there has been an increase in the literature related to mathematical aesthetics (e.g., Koichu, Katz, \& Berman, 2007; Sinclair, 2001, 2004; Sinclair \& Crespo, 2006; Wells, 2008). However, the majority of literature may best be described as narrative in nature - strong in the "history of" and "passion for" 
aesthetics but weak or having no empirically based findings (e.g., Sinclair, 2004; Sinclair \& Crespo, 2006; Wells, 2008). The two dominating foci of the studies reviewed were: (a) exploring the differences between experts and novices in problem solving (e.g., Silver \& Metzger, 1989); and (b) exploring attitudes, feelings, and experiences of participants towards solving specific problems and the aesthetic characteristics of those problems and solutions (e.g., Koichu et al., 2007).

Most studies involved undergraduate, graduate, or professional mathematicians as subjects (e.g., Dreyfus \& Eisenberg, 1986; Koichu et al., 2007; Silver \& Metzger, 1989). An exception was Sinclair (2001), who studied eighth-grade students.

Problematic in the empirical studies were the relatively small number of participants. For example, Silver and Metzger (1989) studied five professors and three graduate students; Sinclair (2001) studied 15 eighth-grade students; and Koichu et al. (2007) involved nine undergraduate students.

Some studies involved taped real-time problem-solving activities, wherein think- aloud and/or structured interviews were used (e.g., Silver \& Metzger, 1986). Koichu et al. (2007) studied: (a) the relation between problem characteristics and students' aesthetic judgments; and (b) “elegant" solutions and students' aesthetic judgments. For Part (a), students were asked to complete a questionnaire wherein they rated problem difficulty, challenge, and beauty on a scale "1" to "10." For part (b), students were asked to rate each problem's beauty on a " 1 " to " 10 " scale based on first impression. Then, they were given an expert-provided "elegant" solution and asked if they wanted to revise their initial rating of the beauty of the problem - an assessment technique that I refer to as Preferred Mathematical Solution (PMS). The presentation 
of multiple solutions as a teaching and learning strategy towards advanced thinking in performing mathematical tasks was promoted by Leikin (2007).

In my review of the literature, I did not find a quantitative analysis of the relation between participants' attitudes/feelings/experiences toward the problem and "getting the problem correct." Nor did any of the studies involving students relate mathematical aesthetics to student achievement (e.g., GPA, standardized tests). Furthermore, no study explored the relation between mathematical aesthetics and other factors, such as gender, socioeconomic status, ethnicity, locus of control, and learning disabilities. And, most problematic during the literature review, was the reverberating reminder of Dreyfus and Eisenberg's (1986) aforementioned statement regarding aesthetic appreciation for mathematics as not being a major goal of school curricula. I found no mathematical text books or other teacher resources that included content dedicated to mathematical aesthetics.

Some major findings of the studies were:

Expertise was a function of taste as well as competence. Silver and Metzger (1989) found three roles for aesthetics in expert problem solving. First, "aesthetics principles provide for the basis for either an evaluation of the elegance of results after a solution has been obtained or an appreciation of a problem before its solution" ( $\mathrm{p}$. 65); second, aesthetic principles drive decision making during problem solving; and third, aesthetics provides a basis for linking metacognitive activity (e.g., monitoring and evaluation) and emotional response in problem solving.

It has been proposed that aesthetics is linked to metacognition and intuition. For example, Lester and Garofalo (1982) found that, "Many third- and fifth-graders 
believe that the size and number of numbers in a verbal problem are important indicators of difficulty and that verbal problems are harder than computational problems" - stated in Garofalo and Lester (1985, p. 167). Undoubtedly, preconceptions of this metacognitive nature significantly affect one's mathematical thought process and thereby must be interact with one's aesthetic judgments.

Furthermore, during my review of the literature, I found several narratives on the definition, history, and theories related to aesthetics and mathematics that affected my method. An overview of these is presented in the following:

According to Mathematician George David Birkhoff (1884-1944), “The branch of knowledge called aesthetics is concerned primarily with the aesthetic feeling and the aesthetic objects which produce it" (Birkhoff, 1956, p. 2185). He was referring to aesthetic objects such as those in the fine arts (e.g., paintings, sculptures, musical compositions), insofar as he was writing about the mathematics of aesthetics and not the aesthetics of mathematics. Adapting Birkhoff's definition to performing mathematical tasks (e.g., problem solving), aesthetics in mathematical problem solving may be generally defined as one's feelings towards a problem before, during, or after a problem-solving activity, as well as the characteristics of the aesthetic entity (e.g., mathematical problem) that produced the feelings. However, Sinclair (2004) argued that a student's aesthetic capacity goes beyond labeling an activity as pleasurable or not, or identifying qualities of mathematical entities such as unity, symmetry, and elegance. "Rather, her aesthetic capacity relates to her sensibility in combining information and imagination when making purposeful decisions regarding meaning and pleasure" (p. 262). 
The famous French mathematician and philosopher Jules-Henri Poincaré (1854 - 1912) "asserted that the aesthetic rather than the logical is the dominant element in mathematical creativity" (Davis \& Hersh, 1981, p. 168). "Thus it is this special aesthetic sensibility which plays the role of the delicate sieve of which I spoke, and that sufficiently explains why the one lacking it will never be a real creator" (Poincaré, 1956, p. 2,048). Poincaré believed that the ability to create mathematics was innateeither you were born with it or not - and believed most were not (Papert, 1978). Poincaré believed that fruitful ideas are generated in the conscious state, but that the final choice is done unconsciously by choosing amongst a multitude of combinations that would produce positive feelings with regards to such subjective concepts as balance, beauty, clarity, elegance, harmony, proportion, symmetry, and unity. Only when the combination satisfied one's aesthetic feelings would the idea move into consciousness as an inspiration - a process that Poincaré referred to as intuition or aesthetic sensibility (King, 1992).

Hardy (1967) agreed with Poincaré's aesthetic sensibility, but disagreed that only a few can appreciate the beauty of mathematics. Hardy argued that it has been the treatment of mathematics by much of society as a difficult and stressful subject that has caused most people to be frightened, complacent with mediocre or poor ability, and even to exaggerate their own mathematical stupidity (Hardy, 1967). He cited the widespread popularity of chess, puzzle columns in newspapers, and card games such as bridge - all of them based on rudimentary mathematics and providing "an intellectual kick" not unlike the emotions felt by an expert mathematician working on a proof of a theorem. 
Papert (1978) argued that, "if Poincaré's model turned out to contain elements of a true account of mathematical thinking, it could follow that mathematical education as practiced today is totally misguided and even self-defeating" (p. 106).

King (1992) disagreed: "Perhaps Poincaré was wrong. Maybe the notion extends. Perhaps you can bring students to mathematics early on by emphasizing its aesthetic value rather than its utility or its applicability" (p. 132). "There may exist in the learning and doing of even elementary mathematics, a previously unexplored concept of aesthetic guidance" (p. 134).

Two intriguing theories were found in the literature and are briefly described in the following:

\section{Birkhoff's aesthetic formula.}

In the opening paragraphs of his article, Mathematics of Aesthetics (Birkhoff, 1956, p. 2,185), Birkhoff stated "In fact it is the fundamental problem of aesthetics to determine, within each class of aesthetic objects, those specific attributes upon which the aesthetic value depends." Toward this end, he described the typical aesthetic experience as consisting of three successive phases. First, there must be a preliminary effort toward attention to the object. Secondly, there is a feeling of value that rewards this effort. Third, there is a realization that there is some order to the object (e.g., symmetry, harmony).

Birkhoff argued that the aesthetic feelings toward an object "arise primarily because of an unusual degree of harmonious inter-relation within the object" ( $p$. $2,186)$. He proposed that, for any aesthetic object of a specific class, an aesthetic 
measure variable $M$ could be determined by the basic mathematical formula that relates three measurable variables:

$$
M=\frac{O}{C}
$$

in which the variable $C$ represents the complexity of the object - attributes of the object itself that cause tension in the act of perception; and the variable $O$ represents the order of the object.

Birkhoff noted that his formula is related to the well known desired characteristic of aesthetics that there be unity in variety - a notion developed from the definition of the beautiful formulated by Dutch philosopher François Hemsterhuis (1721-1790) and presented in his 1769 Lettre sur la Sculpture: "that which gives us the greatest number of ideas in the shortest space of time."

\section{Bullough's psychical distance.}

King (1992) provided a significant discussion of Edward Bullough's 1912 article, "Psychical Distance as a Factor in Art and an Aesthetic Principle," which appeared in the British Journal of Psychology. King included the following accolades:

Donald Sherburne, for example, says, "Edward Bullough's theory of the Psychical Distance has become a classic doctrine of aesthetic theory that must be taken into account by all aesthetic thinking. And James L. Jarrett writes of Bullough's ideas, "Perhaps no more influential idea has been introduced into modern aesthetics than that of psychical distance" (p. 196).

"Bullough's concept is that the observer receives from the object an aesthetic experience if and only if this distance remains between certain bounds" (King, 1992, 
p. 199). The distance is not a physical distance, but rather what Bullough calls the psychical distance or what King calls the aesthetic distance. Outside of these certain bounds, two types of failure of aesthetic experience will occur. Bullough referred to these failures as overdistancing and underdistancing. "An observer too close to a work of art will be too practical or subjective toward it to appreciate it properly...If the observer is overdistanced, he will see the object as something cold and withdrawn and he will again fail to appreciate it as art” (King, 1992, p. 200). King stated that most scientists and engineers, who have had to master mathematics through rigorous coursework, are unlikely to have had aesthetic experiences, insofar as they are aesthetically underdistanced. King claimed that this "represents one of the great failures of mathematics education" (p. 205).

Real Time Logs and Interviews

\section{Metacognition.}

Garofalo and Lester (1985), in an introduction to the subject of metacognition and its role in mathematical performance, viewed metacognition as examining one's own cognitive processes (i.e., knowledge and thoughts), actively monitoring them, and regulating and modifying them in relation to some concrete goal or objective. They distinguished between cognition and metacognition: "cognition is involved in doing, whereas metacognition is involved in choosing and planning what to do and monitoring what is being done" (p. 164). According to McLeod (1992): 
Metacognition has received substantial attention in research on mathematical problem solving in recent years (Campione, Brown, \& Connell, 1989; Garofalo \& Lester, 1985; Schoenfeld, 1987b; Silver, 1985) and the links between metacognition and the affective domain have been duly noted as well (Brown, Bransford, Ferrara, \& Campione, 1983; Garner \& Alexander, 1989; Lawson, 1984; McLeod, 1988; Prawat, 1989) (p. 587).

Schoenfeld (1985) argued that many students, when faced with mathematical tasks that are "real" problems to them (i.e., nonroutine) - "problems for which they do not have almost-ready packaged solutions for implementation" (p. 364) - exhibit behaviors, and often failures, in part attributable to lack of productive metacognitions.

Campione et al. (1989) argued that standard educational practices "have not made provision for the incorporation of metacognitive skills, with negative consequences for students" (p. 93). They argued that traditional pedagogy, mostly by direct instruction, emphasizes teaching separate subskills with little opportunity for an interactive classroom - one that promotes students' monitoring and orchestration of their own cognitive skills. Campione et al. pointed out that traditionally in Reading, students are taught decoding before comprehension; in Writing, mechanics before communication; and in Math, algorithms before understanding. There is evidence that by the sixth-grade, although students can master basic skills in reading, writing, and arithmetic, performing the necessary subskills and algorithms on demand, there are indications that many students do not understand the underlying purposes of such skills and strategies well enough to make connections (i.e. transfer) to related problems, a consequence of what the authors refer to as blind instruction. 
Yong and Kiong (2005) used both a quantitative and qualitative methodology to explore students' use of metacognition during problem solving. A random sample of 412 students (approximately 16 years-old) were given a set of four mathematics problems of four levels of difficulty along with a questionnaire that was completed during the problem solving. The questionnaire involved gathering personal information and responses related to their problem-solving experience. Based on performance and responses of the 412 students, 18 students were selected for videotaped interviews. Major findings were:

1. $75.7 \%$ of the students were able to solve level-one (easiest) problems but the number of students dropped to $6.1 \%$ for the level-four (most difficult) problems. Yong and Kiong suggested that this disparity was most likely due to the emphasis by teachers and traditional text books on level-one problems with little opportunity to practice the higher cognitive skills or metacognition demanded by level-four problems.

2. Factor analysis of the questionnaire responses relative to problem-solving confirmed that students, no matter the level of success, employed Polya's four stages of problem solving (understanding the problem, devising a plan, carrying out, looking back)

3. Yong and Kiong (2005) found evidence that supported Schoenfeld's (1985) proposed reasons why students fail to achieve correct answers: (a) they 
commit to one and wrong approach; (b) they fail to question their achievement during their problem solving; and (c) they don't explore alternative solutions. Furthermore, the authors agreed with Shoenfeld (1985) that good problem-solvers continuously question their achievement during the problem-solving process by considering various paths toward solution, making careful decisions such as following productive leads and changing direction if need be.

4. Yong and Kiong (2005) also stated that their research demonstrated the strength of using a mixed methodology that converged findings from different data sources.

\section{Representation.}

Representation, despite its recognition as an important activity in most current problem-solving models (Noddings, 1985) was one of Edward A. Silver's (1985) "Some Underrepresented Themes and Needed Directions" in the teaching of mathematical problem solving. Silver argued that distinctions between mental representations and physical representations (e.g., diagrams, tables, charts, or equations) need to be explored. The first stage of Polya's (1945/2004) heuristic problem-solving model, understanding the problem, recommends: "Draw a figure. Introduce suitable notation" (p. xvi).

Kaput (1985) provided a broad definition of representation as "something that stands for something else" (p. 383) and further provided five uses of the term in 
problem-solving research: (a) mental representation; (b) computer representation; (c) explanatory representation; (d) mathematical representation; and (e) symbolic representation - as with external mathematical notation. An essential question posited by Kaput "has to do with how students choose and then work with a mental representation when confronted with a problem to solve" (p. 381).

For purposes of my research, there are two types of representation, external and internal. External representation includes symbols, words, and structured systems. Internal representation or mental representation “include students' personal symbolization of constructs and assignments of meaning to mathematical notations, as well as their natural language, their visual imagery and spatial representation, their problem-solving strategies and heuristics, and (very important) their affect in relation to mathematics" (Goldin \& Shteingold, 2001, p. 2).

All of mathematics are, arguably, external representations. These include mathematical symbols; the ancient Greeks undefined terms of point, line, and plane; structured systems such as Euclidean, Elliptical, and Hyperbolic geometries; Cartesian and polar coordinate systems, etc. It is the interpretation (i.e., mental representation) of these external representations that is key to problem solving. "The interaction between internal and external representation is fundamental to effective teaching and learning" Goldin and Shteingold (2001, p. 2).

A collection of relevant research regarding representation was found in Cuoco and Curcio (2001): “The Roles of Representation in School Mathematics: 2001 Yearbook" 


\section{Literacy and Mathematics}

Educators have argued for many years that promoting the development of communication skills in mathematical learning (e.g., writing tasks) leads to deeper understanding of mathematical concepts (Shield \& Galbraith, 1998). A highly cited text on the subject was found in Writing to Learn Mathematics (Countryman, 1992). The National Council of Teachers of Mathematics (NCTM), in the organizations' Principals and Standards for School Mathematics, stated that communication is an essential component of mathematics and mathematics education. NCTM further stated that instructional programs, from prekindergarten through twelfth-grade should enable all students to organize and consolidate their mathematical thinking through communication; communicate their mathematical thinking coherently and clearly to peers, teachers, and others; analyze and evaluate the mathematical thinking and strategies of others; and use the language of mathematics to express mathematical ideas precisely (National Council of Teachers of Mathematics, 2000).

Shield and Galbraith (1998) stated, "The use of writing as a learning activity in mathematics has been the subject of many publications. However, little evidence has been presented to support the claims that writing enhances learning in mathematics" (p. 29). This sentiment was supported by Pugalee (2004) who stated that the relationship between writing and mathematics has been largely neglected in educational research with much of the literature being narrative in nature - describing writing in mathematics in general terms - lacking analytic support.

Furthermore, a certain level of proficiency in literacy is prerequisite to problem solving. In each of his four phases of problem solving (understanding the problem, 
devising a plan, carrying out the plan, looking back) Polya (1945/2004) presented a group of questions and suggestions that were designed to promote and assist metacognition (Polya did not use the term metacognition) throughout the entire problem-solving process (e.g., What is unknown? Can you write them down? Could you restate the problem?). "Research also shows that writing supports metacognition" (Pugalee, 2004).

A position paper by the United Nations Educational, Scientific and Cultural Organization (UNESCO) (2004), contained the following draft of a definition for "literacy":

Literacy is the ability to identify, understand, interpret, create, communicate and compute, using printed and written materials. Literacy involves a continuum of learning in enabling individuals to achieve their goals, to develop their knowledge and potential, and to participate fully in their community and wider society" (p. 13).

The words identify, understand, and interpret in the above definition are imbedded in Polya's heuristic. Thus, I identified literacy (i.e., reading and writing) as an important consideration for any study regarding mathematical problem solving. A review of traditional introductory algebra books found that key vocabulary words fell within two general categories. In the first, were words that would be considered uncommon to students' normal discourse outside of the mathematics classroom (e.g., coefficient, exponent, monomial, parabola, transversal, vertex). A second category were vocabulary words with multiple meanings that might be familiar 
outside of the math classroom, but had specific meanings and often quite different meanings when used in the mathematics world (e.g., cube, degree, domain, product, radical, rational).

Further review of the algebra books revealed that a majority began with instruction and practice involving the translation of words into numbers and symbols and vice versa - more appropriately described as the writing of mathematical (e.g., algebraic) expressions for verbal expressions and the reverse, writing verbal expressions for mathematical expressions (e.g., Holliday, Cuevas, Luchin, Carter, Marks, Day, et al. [2008]). The mastering of this skill is prerequisite to solving many math problems.

Silver (1979) examined mathematical word problem similarity dimensions perceived by eighth-grade students; and the relationship of the students' perception of problem similarity and performance on tests of verbal and mathematical problemsolving ability. Problem similarity was constrained to two categories (mathematical structure, contextual details). Silver (1979) found a significantly positive correlation between the tendency to sort problems on the basis of mathematical structure and all of the general verbal and mathematical ability measures. Furthermore, his results confirmed that lower performing students tended to perceive problem relatedness as determined by contextual details rather than by the underlying mathematical structure.

Shield and Galbraith (1998) explored the writing products of eighth-grade math students and developed a method for coding parts of written mathematical presentations. They found little evidence to support the claim that writing tasks in mathematics leads to deeper understanding of the concepts. They stated that the 
students' writing products appeared to be limited to the types of presentation they were familiar with from textbooks.

Pugalee (2004) analyzed ninth-grade algebra students' written and verbal descriptions of their mathematical problem solving processes. His major findings included: students who wrote descriptions of their thinking were significantly more successful in the problem solving tasks $(p<.05)$ than students who verbalized their thinking; students who constructed global plans were more successful problem solvers; a majority of students do not verify their final answers; and he found writing can be an effective tool in supporting metacognitive behaviors.

\section{Conclusion}

We are nearly fifty years post Feierabend's (1960) call for further research on the affective and cognitive domains - during which the body of literature has expanded exponentially - yet research has fallen unacceptably short in accounting for the majority of variation in achievement in mathematics, especially in problem solving. Empirical studies of problem solving at the middle and secondary school levels and in urban schools was disturbingly sparse. From the summary provided in Table 1, I concluded that areas such as mathematical aesthetics, metacognition, representation, values and interests, etc. were worthy of my research toward explaining at least some of the variation. 


\section{Table 1}

Summary of Literature Review of Six Sources of Possible Correlates of Problem Solving in Mathematics

\begin{tabular}{|c|c|c|c|}
\hline Source of possible cor & relates & $\begin{array}{l}\text { Major findings that influenced my } \\
\text { Method }\end{array}$ & $\begin{array}{l}\text { Research } \\
\text { methodologies used }\end{array}$ \\
\hline \multirow[t]{2}{*}{$\begin{array}{l}\text { Aptitude and } \\
\text { Achievement }\end{array}$} & & $\begin{array}{l}\text { NCLB levels of proficiency vary by } \\
\text { state, grade, and subject; NWEA is } \\
\text { age and grade independent. }\end{array}$ & $\begin{array}{l}\text { state and local } \\
\text { assessments; IQ; } \\
\text { SAT scores. }\end{array}$ \\
\hline & General attitudes. & $\begin{array}{l}\text { There is a low but significantly } \\
\text { positive correlation between } \\
\text { general attitudes and achievement } \\
\text { in mathematics. }\end{array}$ & $\begin{array}{l}\text { observational; } \\
\text { questionnaires and } \\
\text { scales; content } \\
\text { analysis of } \\
\text { essays. }\end{array}$ \\
\hline \multirow[t]{2}{*}{$\begin{array}{l}\text { Attitudes/Experiences } \\
\text { Toward Mathematics }\end{array}$} & $\begin{array}{l}\text { Locus of control, causal } \\
\text { attributions, learned } \\
\text { helplessness, and } \\
\text { explanatory style. }\end{array}$ & $\begin{array}{l}\text { No empirical studies were found } \\
\text { specific to mathematics achievement } \\
\text { or problem solving. }\end{array}$ & $\begin{array}{l}\text { questionnaires and } \\
\text { scales. }\end{array}$ \\
\hline & $\begin{array}{l}\text { Confidence, self- } \\
\text { efficacy, and self } \\
\text { concept toward } \\
\text { mathematics. }\end{array}$ & $\begin{array}{l}\text { Confidence has a moderate but } \\
\text { significantly positive correlation } \\
\text { with mathematics achievement; } \\
\text { males tend to be more confident } \\
\text { than females. }\end{array}$ & $\begin{array}{l}\text { questionnaires and } \\
\text { scales. }\end{array}$ \\
\hline
\end{tabular}




\begin{tabular}{|c|c|c|c|}
\hline Source of possible & correlates & $\begin{array}{l}\text { Major findings that influenced my } \\
\text { Method }\end{array}$ & $\begin{array}{l}\text { Research } \\
\text { methodologies used }\end{array}$ \\
\hline \multirow{5}{*}{$\begin{array}{l}\text { Demographics and } \\
\text { Mathematics } \\
\text { Achievement }\end{array}$} & Gender. & $\begin{array}{l}\text { Sex differences were not significant } \\
\text { but favored males; sex differences are } \\
\text { environmental not biological; sex } \\
\text { differences decreased in higher years; } \\
\text { males stereotyped mathematics as a } \\
\text { male domain more than females; verbal } \\
\text { skills were a consistent significant } \\
\text { predictor of math achievement for } \\
\text { males but not females. }\end{array}$ & $\begin{array}{l}\text { questionnaires and } \\
\text { scales; state and } \\
\text { local assessments. }\end{array}$ \\
\hline & Disability. & $\begin{array}{l}\text { Students with learning disabilities } \\
\text { may have different metacognitive } \\
\text { processes than normal achievers. }\end{array}$ & $\begin{array}{l}\text { questionnaires and } \\
\text { scales; state and } \\
\text { local assessments. }\end{array}$ \\
\hline & Ethnicity. & $\begin{array}{l}\text { Blacks and Hispanics continued to } \\
\text { trail whites however the achievement } \\
\text { gap is narrowing. }\end{array}$ & $\begin{array}{l}\text { NAEP data; State } \\
\text { and local } \\
\text { assessments. }\end{array}$ \\
\hline & Socioeconomic status. & $\begin{array}{l}\text { Family SES is strongly correlated } \\
\text { with math achievement. }\end{array}$ & $\begin{array}{l}\text { eligibility for } \\
\text { free and reduced- } \\
\text { priced meals. }\end{array}$ \\
\hline & School location. & $\begin{array}{l}\text { Few empirical studies; suburban } \\
\text { schools have significantly higher } \\
\text { math scores than rural or urban } \\
\text { schools which have no significant } \\
\text { differences between them. }\end{array}$ & $\begin{array}{l}\text { NAEP data; State } \\
\text { and local } \\
\text { assessments. }\end{array}$ \\
\hline
\end{tabular}

table continued 


\begin{tabular}{|c|c|c|}
\hline Source of possible correlates & $\begin{array}{l}\text { Major findings that influenced my } \\
\text { Method }\end{array}$ & $\begin{array}{l}\text { Research } \\
\text { methodologies used }\end{array}$ \\
\hline Values and Interests & $\begin{array}{l}\text { Few empirical studies; submissiveness } \\
\text { and superego have high correlations } \\
\text { with achievement. No empirical } \\
\text { studies specific to problem solving. }\end{array}$ & $\begin{array}{l}\text { questionnaires and } \\
\text { scales. }\end{array}$ \\
\hline $\begin{array}{l}\text { Mathematical } \\
\text { Aesthetics }\end{array}$ & $\begin{array}{l}\text { Few empirical studies; small sample } \\
\text { sizes; no intersections with } \\
\text { demographics; not a priority in school } \\
\text { curricula; no evidence of integration } \\
\text { at the classroom level; may be closely } \\
\text { related to metacognition and } \\
\text { representation. }\end{array}$ & $\begin{array}{l}\text { taped interviews; } \\
\text { think-aloud; } \\
\text { examination of } \\
\text { student work. }\end{array}$ \\
\hline \multirow{2}{*}{$\begin{array}{l}\text { Real Time Logs and } \\
\text { Interviews }\end{array}$} & $\begin{array}{l}\text { Few empirical studies; failure/low } \\
\text { achieving may be due to lack of } \\
\text { productive metacognition; } \\
\text { opportunities not apparent at the } \\
\text { classroom level; may be closely } \\
\text { related to mathematical aesthetics } \\
\text { and representation. }\end{array}$ & $\begin{array}{l}\text { taped interviews; } \\
\text { think-aloud; } \\
\text { examination of } \\
\text { student work. }\end{array}$ \\
\hline & $\begin{array}{l}\text { Expanding body of literature; } \\
\text { interaction between internal and } \\
\text { external representation is fundamental } \\
\text { to effective teaching and learning; } \\
\text { may be closely related to } \\
\text { metacognition and mathematical } \\
\text { aesthetics. }\end{array}$ & $\begin{array}{l}\text { taped interviews; } \\
\text { think-aloud; } \\
\text { examination of } \\
\text { student work. }\end{array}$ \\
\hline $\begin{array}{l}\text { Literacy and } \\
\text { Mathematics } \\
\text { Achievement }\end{array}$ & $\begin{array}{l}\text { Few empirical studies; writing can be } \\
\text { an effective tool for metacognitive } \\
\text { behaviors; students' who write more } \\
\text { about their problem-solving experience } \\
\text { are better problem solvers. }\end{array}$ & $\begin{array}{l}\text { taped interviews; } \\
\text { think-aloud; } \\
\text { examination of } \\
\text { student work. }\end{array}$ \\
\hline
\end{tabular}




\section{Method}

\section{Overview of Research Design}

The purpose of this study was to describe students' attempts to solve nonroutine math problems and to explore possible correlates of their performance. I analyzed both objective and subjective data—drawn from 13 separate sources - using quantitative and qualitative procedures.

I developed fine-grained rubrics to score their work on six nonroutine math problems. I complemented these objective data with students' written "logs" of their work in real time, followed by semi-structured debriefing interviews after they had finished. I used structured scales to document students' math-related attitudes, career interests, and work-values, along with essays describing their long-term experiences with math, in and out of school. I gathered data on students' math-aesthetics, including the features of "attractive" problems and their individual preferences for the different modes of instructional explanation. School records provided students' demographic data and their scores on generic measures of aptitude and achievement.

Figure 1 summarizes the lines of analysis used to document the students' performance on nonroutine math problems and to identify some correlates of their performance. 


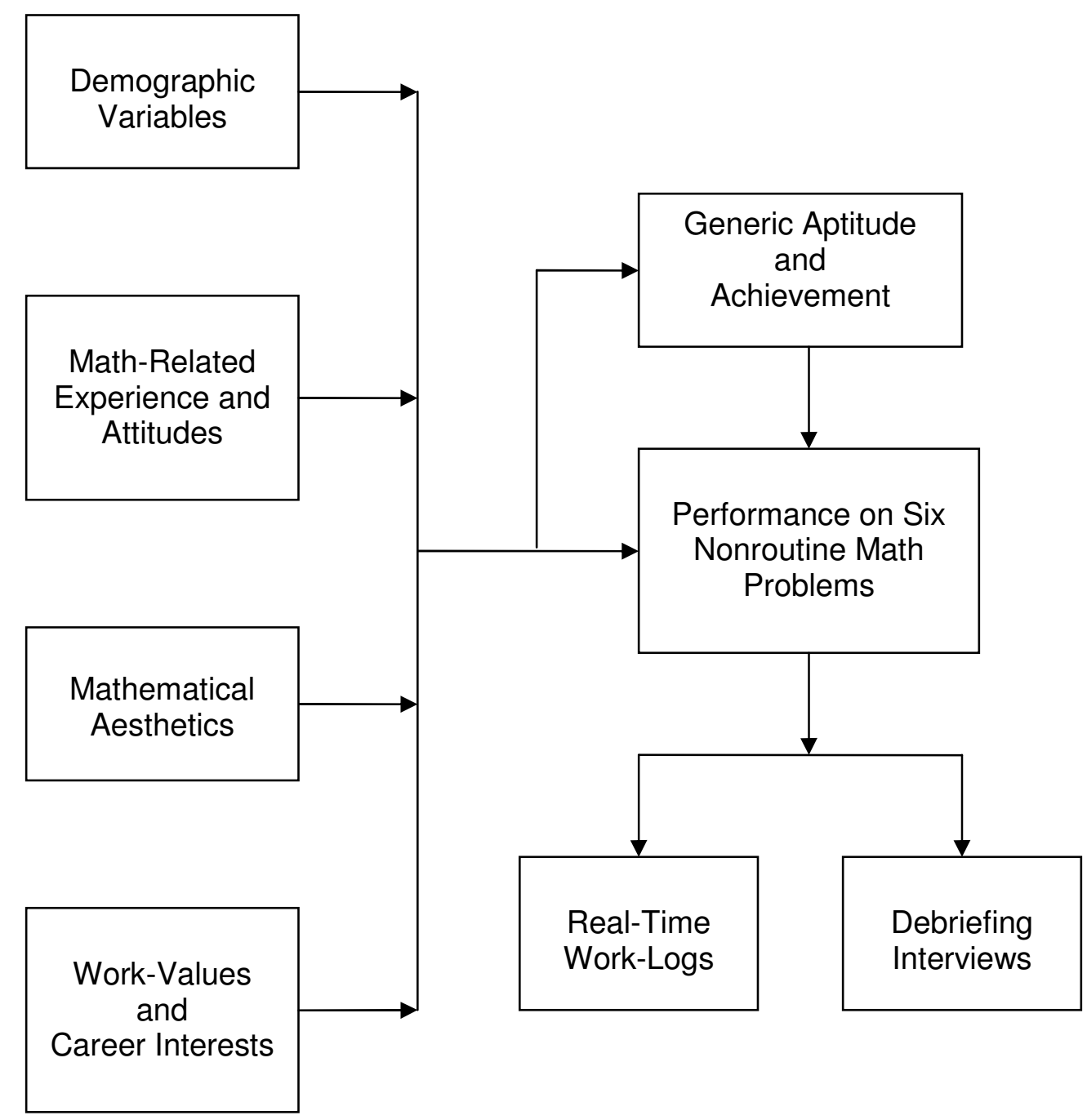

Figure 1. Some sources of possible correlates of performance on nonroutine math problems. 


\section{Research Site}

All research involving students' participation (e.g., administration of tests, questionnaires, math problems, videotaped interviews) as well as the retrieval of student record data (e.g., date of birth, sending school district, free and reduced lunch status, Individualized Education Plan [IEP] status) took place at the Beacon Charter High School for the Arts, in Woonsocket, RI.

Beacon Charter High School for the Arts (BCHS), which opened in 2003, is a charter school (grades $9-12$ ) whose program of study combines a college preparatory program with a business and arts program that focuses on three disciplines: culinary arts, theater arts, and visual arts.

Charter schools are public schools authorized by the State of Rhode Island to operate independently from many of the rules and regulations of the state and local district. In exchange for greater autonomy, charter schools are more accountable for meeting student achievement goals; their charters can be revoked for inadequate performance. Charter schools provide greater choice to parents and students seeking alternatives to what traditional public education provides. Because of their autonomy, charter schools are encouraged to be innovative and creative in their educational philosophies. They are also expected to be laboratories and vanguards in improving and expanding opportunities within public education (Office of the, 2006).

BCHS serves students from several surrounding school districts, including: Woonsocket, Cumberland, Burrillville, North Smithfield, Pawtucket, Lincoln, North Providence, Providence, Johnston, and West Warwick. Students come to Beacon with 
diverse experiences and abilities. The majority of current students come from the closest districts, in part because of transportation issues.

\section{About the Researcher}

Since the 2005/2006 school year, I have been employed by the Beacon Charter High School for the Arts (the approved site for this research) as a full-time mathematics teacher for grades 9-12. I am certified as a "Professional Teacher of Secondary Mathematics" by the Rhode Island Department of Education. My vita is in Appendix A.

\section{Participants/ Sample}

This study involved ninth-grade students who were taking math for the first time at Beacon Charter High School. Students at Beacon take math in either the fall semester or the spring semester, because mathematics is a half-year course (meeting every day). All mathematics classes are homogeneous by grade and heterogeneous by ability (i.e., no tracking).

URI's Institutional Review Board (IRB) had approved January 25th, 2008 as the starting date for this study. At that time, there were 62 ninth-graders at Beacon, 44 of whom had not taken math in the Fall term of 2007 and would be taking math in the Spring of 2008. I recruited these 44 students, using the Informed Consent Form for Parents/Guardians and the Students' Assent Form that the IRB had approved (see Appendix B). All 44 (100\%) volunteered to participate in the study. 
Six students had high rates of absenteeism and left the district before the end of the study. Another seven students missed one or more of the six days (three in the fall, three in the spring) of district-mandated testing on the Measures of Academic Progress of the Northwest Evaluation Association (NWEA). The final sample of participants included the 31 ninth-graders with complete data on these achievement measures, which were central to this study.

The 31 students came from three classes of Algebra 1. Two classes were taught by me, and the third class by the other math teacher at Beacon (Rhode Island certified in Secondary Mathematics). Prior to the start of the research, the other math teacher had agreed to participate in the research by helping to administer all assessments. We collected the data at similar times from all three classes.

To protect the students' anonymity, each received an identification number known only by me. Table 2 provides some general characteristics of the sample $(N=$ $31)$, retrieved from school records. Worthy of note of the sample were: $64.5 \%(20 / 31)$ of the students were White compared to the Rhode Island public school average of $68.9 \% ; 67.7 \%(21 / 31)$ of the students qualified for free or reduced lunch compared with the Rhode Island public school average of $38.0 \%$; and $25.8 \%(8 / 31)$ of the students had Individualized Education Plans (IEPs) and were receiving general education with supports compared with the Rhode Island public school average of $12.3 \%$ (the total state average for special needs students, which included selfcontained and homebound/hospitalized, was 18\%) (Information Works! \&, 2009). 
Instruments and Measures

This section describes the tools that I used to gather information on the 31 students' performance on six nonroutine math problems and on the seven categories of possible correlates (see Figure 1). Table 3 lists the sources of data for each category of variables from Figure 1. 
Table 2

Some Demographics of the Sample $(N=31)$

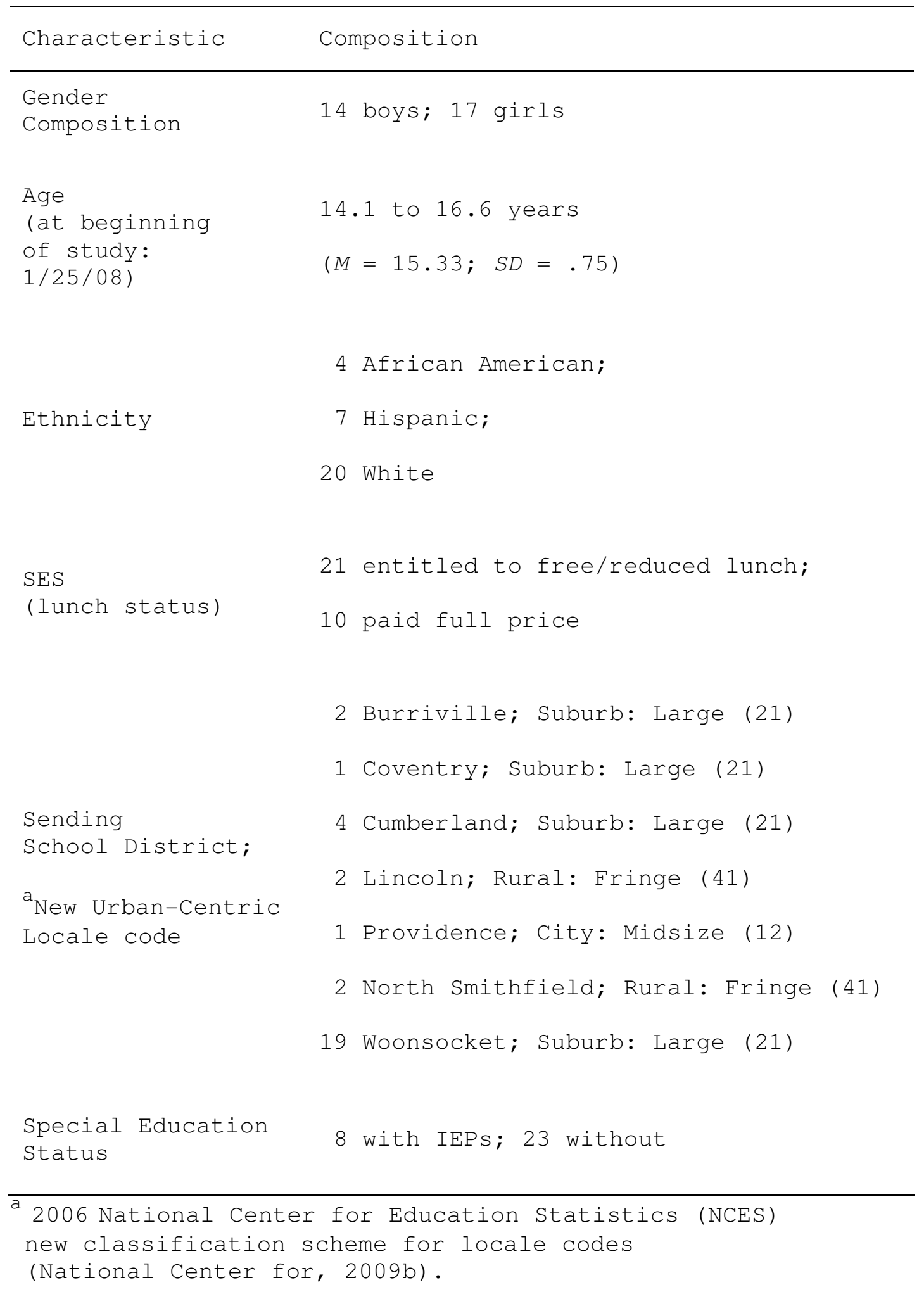


Table 3

Measures of Performance on Nonroutine Problems and Some Possible Correlates

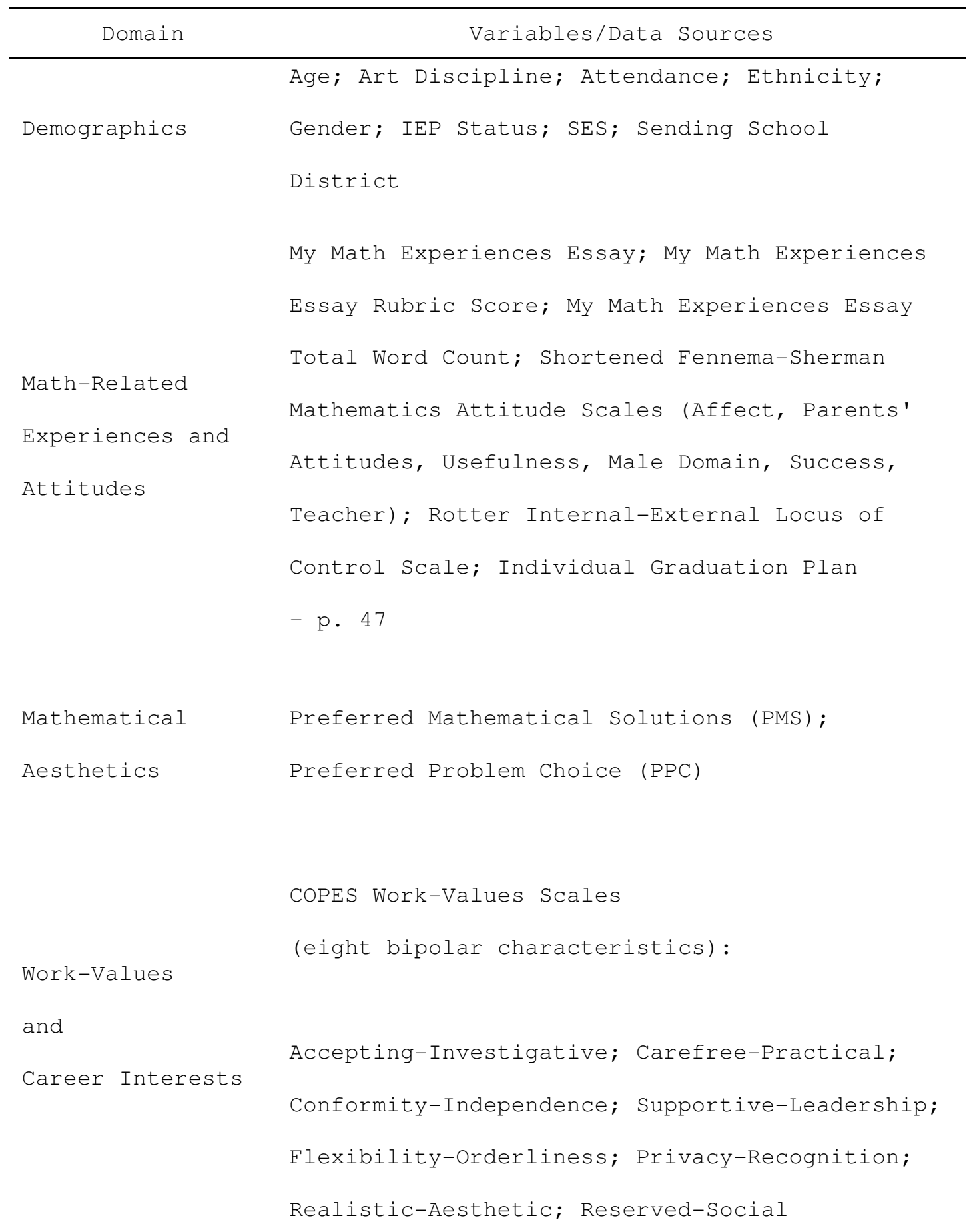




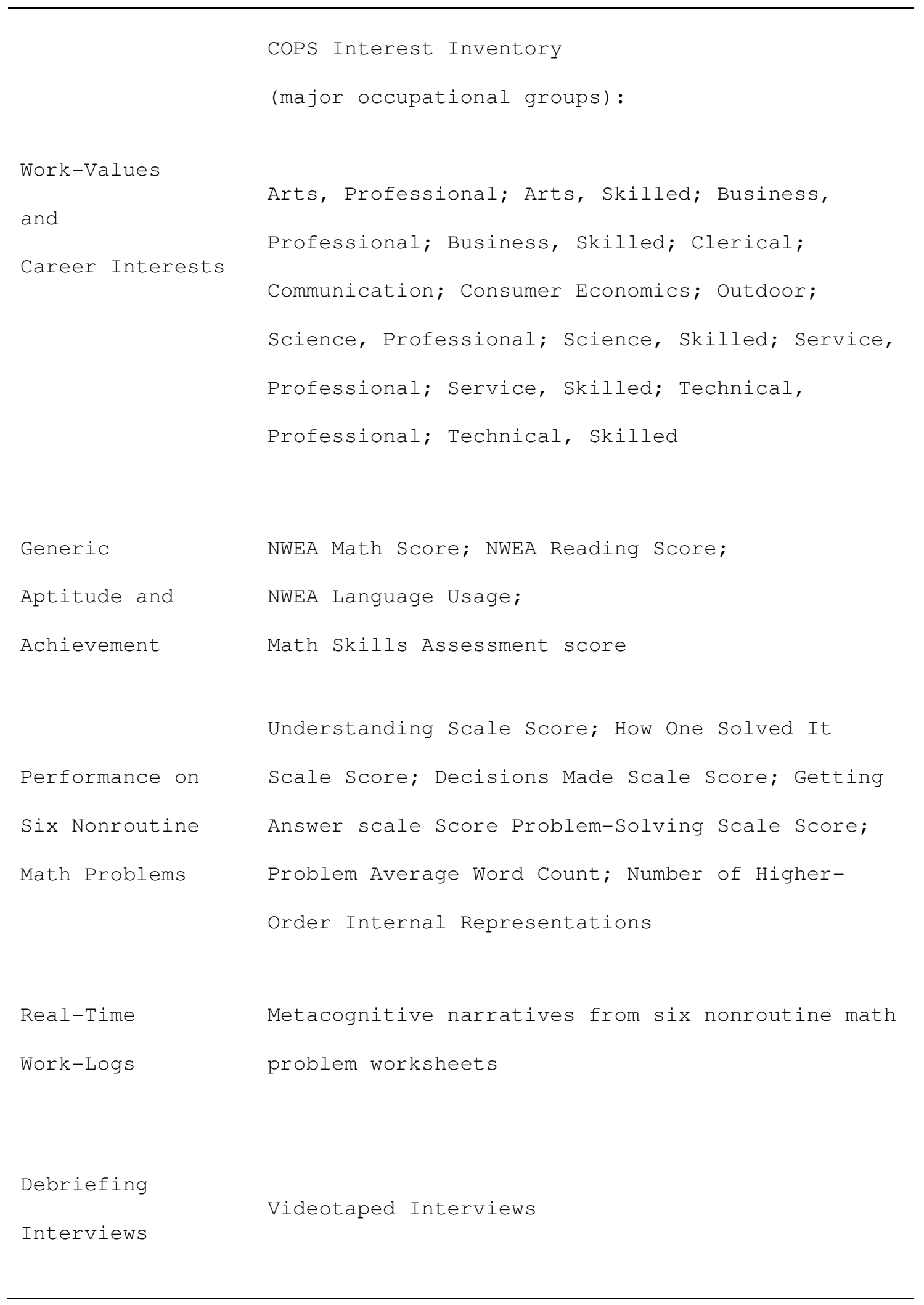


Northwest Evaluation Association's (NWEA) Measures of Academic Progress $(M A P)$ in mathematics, reading, and language usage.

Students take the Northwest Evaluation Association's (NWEA) Mathematics, Reading, and Language Usage computerized adaptive tests on separate days (the NWEA independently scores the tests). Each of the three tests begins with items at a student's current grade-level, then proceeds to harder or easier items, depending on a student's success/failure on the most recent items. This iterative process quickly establishes a student's true level of achievement, at which point the test ends minimizing failure, frustration, and fatigue.

Each test yields a Rasch-unit score in one content area (Mathematics, Reading, Language Usage). Scores reflect students' achievement levels, independent of age and grade (e.g., a score of 205 shows the same level of learning in an 11-year-old sixthgrader and a 15-year-old ninth-grader). Each continuum of scores is a true intervalscale (e.g., any increase of 20 points represents the same amount of improved achievement), making it especially useful for measuring growth over time. The NWEA has established respectable levels of reliability and validity for the MAP (NWEA, 2004). NWEA uses data from the 2008 NWEA RIT Scale Norms Study which included more than 2.8 million students, from 6,905 schools in 1,123 districts located in 42 states (Normative Data, 2008) for comparison of a student's grade-level performance to the performance of students in the same grade taking the test relative to the beginning of the year, middle of the year and end of the year, testing windows across the nation. 
Students at Beacon take NWEA Mathematics, Reading, and Language Usage tests in the fall and spring terms of each year. In this research, I used the average of a student's two scores (from Fall of 2007 and Spring of 2008).

\section{Math skills assessment.}

The Math Skills Assessment Form A (see Appendix C) is a 15-item overview of basic math skills. The first five items require the ordering of positive and negative integers, fractions, and decimals. The remaining ten questions involve arithmetic operations on positive and negative numbers. Form A is used to assess students' readiness for Algebra 1 and is typically given to every incoming student within the first week of ninth-grade math.

The Math Skills Assessment was originally developed at Coventry High School (Coventry, Rhode Island) by me and Stephen P. Walker, another math teacher, as part of a study of the accuracy of placement of incoming ninth-graders into one of five possible tracks, based solely on middle school teacher recommendations (Walker \& Butler, 2005). The assessment includes three stand-alone tests (Form A, B, and C), which are progressively more difficult.

To assess the students' skills at the beginning of the Beacon math experience, I administered Form A to all 31 students on January 28, 2008, the first day of the new semester, and scored them myself. Forms B and C were not administered, as they were designed to determine students' readiness for higher ability tracks in ninth-grade 
mathematics (e.g., advanced Algebra 1, Algebra 2), opportunities that Beacon does not offer at the ninth-grade level.

“My math experiences” essay.

The Rhode Island Department of Education (RIDE) standards for grades 9 - 12 require reading and writing across all content areas. As one means of addressing this requirement at Beacon Charter High School, every teacher in every content area must assign at least one paper during each semester, using the style of the Modern Language Association (MLA). The Beacon faculty developed a schoolwide rubric for scoring the MLA-style papers.

The mathematics department at Beacon requires from every incoming ninthgrader a five paragraph, MLA-style essay reflecting upon their pre-Beacon math experiences. This assignment normally occurs within the first week of math class as to capture incoming ninth-grade students' attitudes and experiences towards math prior to Beacon teacher influence.

In this study, students drew guidance from an illustrative essay entitled "Math Regrets" (describing a teacher's math experiences when she was a student). The students received a graphic organizer to aid in structuring their five paragraphs. There was no time limit on generating the essay - two class periods were sufficient for most to complete the assignment. I collected essays from all 31 students.

Included for part of the analyses, was a quantitative measure, readily available in the form of a rubric score. A certified "highly qualified" Beacon English teacher scored each essay for its MLA style, using a 100 point rubric (variable: My Math 
Experiences Essay Rubric Score - see Table 3). In addition, I conducted content analyses in order to identify common themes in students' accounts of their experiences.

Appendix D contains the My Mathematics Experiences Writing Assignment, Math Regrets prompt, and My Mathematics Experiences Graphic Organizer.

\section{Six nonroutine math problems.}

Students' performance on nonroutine mathematical problems was the major focus of my research, along with the search for correlates of their performance. I gave the 31 students six nonroutine math problems to solve (see Appendix E). The first four problems (Count Your Coins, Lost in the Auditorium, Birthday Money, and What's in My Future?) were administered on separate days in my perceived increasing order of difficulty.

Each 11" by 17" problem worksheet had three sections: the problem statement; a workspace for showing calculations; and a blank space for students to explain their thinking. However, the latter space was not filled in until after the problem had been scored and photocopied. My scoring did not appear on the work, but on a corresponding rubric sheet (i.e., the students did not know whether they had solved the problem at that stage). After my scoring, I returned the work to the students, who filled in the space adjacent to their calculations to explain what they had been thinking as they worked toward a solution (i.e., metacognition). 
Based on their four problem scores and my assessment of their post-task writing strengths, I selected six students who met the criteria shown in Table 4:

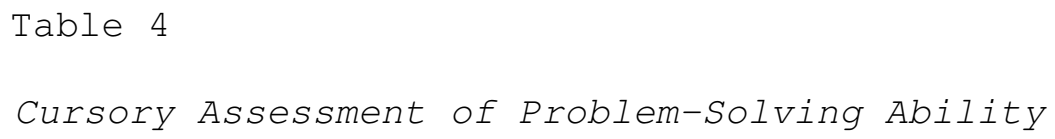

\begin{tabular}{ccc}
\hline Problem-Solving Ability & \multicolumn{2}{c}{ Writing } \\
(based on four problems) & Good & Weak \\
\hline High & 1 & 1 \\
Medium & 1 & 1 \\
Low & 1 & 1 \\
\hline
\end{tabular}

I then had all 31 students solve the two remaining problems (How Many Children Live Next Door? and Blind Sided), following the same procedures used with the first four problems.

I interviewed each of the six students from Table 4 individually immediately after they had completed the last two problems. The setting for all of the interviews was the math classroom. Two chairs, one for me and one for the student, were set up in front of a music stand, holding the problem worksheet. Each student's written explanations served as a prompt for questioning during the recorded interviews. I used both a camcorder and a separate tape recorder as a precaution in case of equipment failure. Following the interview sessions, I transcribed the recordings. 
I and the other Beacon math teacher scored the six nonroutine math problems for all 31 students. He was compensated for his work (which also included refinement of the rubrics). In order to establish inter-rater agreement, we followed a three-stage process, as shown in Figure 2. This process yielded inter-rater reliability of $r=.96$ (p $<.0001)$. Appendix F includes the scoring rubrics and details on the process for assessing inter-rater agreement. 


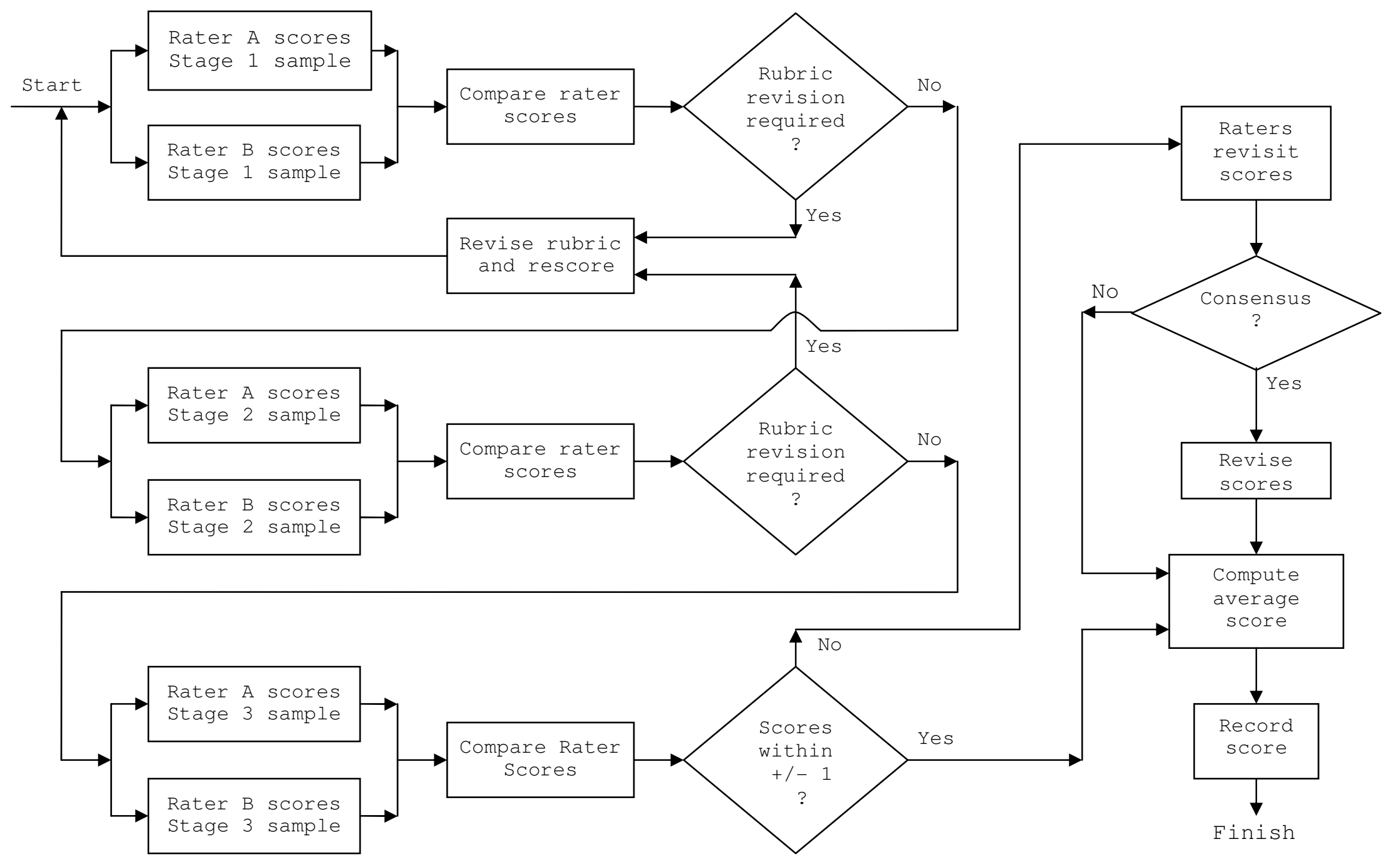

Figure 2. Inter-rater agreement process 


\section{School records.}

I used school records to retrieve student data on attendance, art discipline, date of birth, ethnicity, gender, sending school district, free and reduced lunch status, Individualized Education Plan (IEP) status, Individual Graduation Plan (Individual, 2007), and NWEA scores.

A shortened form of the Fennema - Sherman mathematics attitudes scales (FSMAS-SF).

The FSMAS-SF scale is a 51-item (six scales) 5-point Likert-type response format developed by Mulhern and Rae (1998) based on an analysis of the original 108-item (nine scales) 5-point Likert-type response format (FSMAS) presented in Fennema \& Sherman (1976).

The original Fennema \& Sherman (1976) instrument took about 45 minutes to complete and participants often lost interest as time went on (Mulhern \& Rae, 1998). Descriptions of each of the six scales of the FSMAS-SF are:

1. Mathematics-Related Affect (MRA) scale:

Higher scores indicate greater confidence of students in performing mathematical tasks.

2. Parent's Attitudes (PA) scale:

Higher scores indicate stronger perceptions that parents are interested in the student's mathematical ability, encourage it, and have confidence in it. 
3. Usefulness (U) scale:

Higher scores indicate that students see greater usefulness of mathematics now and in relationship to their future education, vocation, or other activities.

4. Male Domain (MD) scale:

Higher scores indicate that students see mathematics as more of a male domain.

5. Success (S) scale:

Higher scores indicate that students more strongly anticipate positive consequences as a result of their success in mathematics.

6. Teacher (T) scale:

Higher scores indicate that students perceive that their teachers have more positive attitudes toward them as learners of mathematics.

Reliability and validity of the FSMAS-SF were adequately addressed in Mulhern and Rae (1998).

I administered the FSMAS-SF to all 31 students. Appendix G contains the instrument and scoring method. 


\section{Rotter's internal-external locus of control questionnaire.}

As part of this research, I administered the Rotter's Internal-External Locus of Control (IE) Questionnaire (Rotter, 1966) to all 31 students. Reliability and validity were adequately addressed in Rotter (1966).

The Rotter internal-external locus of control scale is a 23 -item, forced choice questionnaire with six filler items adapted from the 60-item James Scale (Lefcourt, 1976, Appendix IV, pp.166-169). The Rotter (IE) is scored in the external direction, that is, the higher the score the more external the individual. Internal individuals attribute their fate to their own abilities and effort whereas external individuals attribute their fate to events outside of their control such as good or bad luck.

Appendix $\mathrm{H}$ contains the instrument; its instructions, and the scoring method.

\section{Preferred mathematical solution (PMS) questionnaire.}

It is proposed by this author that a major flaw in the pedagogy of mathematical problem solving can be attributed to the fact that mathematics textbooks and teachers present one and only one method of solution to a problem. The method of solution may or may not be the most efficient solution nor one that the learner may appreciate and/or easily grasp.

Part of the research involved mathematical aesthetics (students' feelings about different types of problems and different approaches to explicating them). I developed an instrument to explore students' aesthetic preferences for various types of solutions (e.g., algebraic, tabular, pictorial/ graphical). I based this instrument on three of the six nonroutine math problems: Lost in the Auditorium; What's in my Future?; and How 
many Children Live Next Door? I chose these three problems because there were at least three different ways to solve them that could be easily presented side by side.

The instrument was designed such that each of the three problems was presented on a separate 11 " by 17 " sheet with a landscape orientation. There was a place for the student's name and the date at the top left of the sheet. Just below the name, appeared the problem title (e.g., Lost in the Auditorium). Below the problem title was the exact problem statement as it appeared on the worksheet originally administered to the students. Below the problem statement, the worksheet was divided into three or four large columns leaving about a two inch margin along the bottom of the sheet. In each column appeared a different approach to solution for the particular problem. The Lost in the Auditorium problem had four solutions (one algebraic, two tabular and one pictorial/graphical). The other two problems had three solutions: one algebraic solution, one tabular solution, and one pictorial/graphical solution.

At the bottom left of the sheet, in the margin just below the columns, a space was provided with the following question presented:

"Which solution do you like best and why? Please explain below:"

Students qualified for one of four groups based on their pattern of Preferred Mathematical Solutions (PMS). Students who preferred the algebraic solution (in at least two of the three problems) belonged to the Algebraic group. Those who preferred the pictorial solution (in at least two of the three problems) belonged to the Pictorial group. Those who preferred the tabular solution (in at least two of the three problems) 
belonged to the Tabular group. Finally, students who had three different preferences (one for each problem) belonged to the Hybrid group.

Preferred problem choice (PPC) questionnaire.

In addition to Preferred Mathematical Solutions (PMS), a second aesthetic measure Preferred Problem Choice (PPC) questionnaire was used to explore students' attitudes towards types of nonroutine math problems and their extent of engagement and achievement in problem solving, I developed a questionnaire that asked students to rank the six nonroutine problems from " 1 " (liked the most) to "6" (liked the least) and to provide reasons for their rankings.

After students completed all six nonroutine problems, and prior to any disclosure of methods for solving the problems or solutions to the problems, I administered this questionnaire to all 31 students. The questionnaire appears in Appendix I. 
COPS interest inventory.

(Publisher: EditS; P.O. Box 7234/San Diego, CA 92167)

(for reliability and validity see: Brief summary of the, (2007); for the use of, see Knapp-Lee, 1995).

The Career Occupational Preference System (COPS) Interest Inventory consists of 168 items defining 14 types of occupations: Science, Professional; Science, Skilled; Technology, Professional; Technology, Skilled; Consumer Economics; Outdoor; Business, Professional; Business, Skilled; Clerical; Communication; Arts, Professional; Arts, Skilled; Service, Professional; and Service, Skilled.

Note. “...professional [italics added] occupations, usually those requiring college training and often advanced degrees... skilled [italics added] occupations requiring vocational or on-the-job training in which a college degree may not be required for acceptance" (COPSystem:, 2004, p. 1).

There are 12 items defining each of the 14 occupations with a maximum score of 3 points per item or 36 points per occupation. Each item has a four-choice response: Like very much. (3 points); like moderately (2 points); dislike moderately (1 point); and dislike very much (0 point). 
COPES values inventory.

(Publisher: EditS; P.O. Box 7234/San Diego, CA 92167)

(for reliability and validity see: Brief summary of the, (2007); for use of, see Knapp-Lee, 1995).

The Career Orientation Placement and Evaluation Survey (COPES) consists of 128 items defining eight work-value scales. On each of the scales, scores may range from 0 (full amount of the trait on the left; none of the trait on the right) to 8 (equal amounts of both traits) to 16 (full amount of the trait on the right; none of the trait on the left). The following descriptions of the scales are excerpted from COPSystem: (2004, p. 5).

1. Accepting-Investigative Scale. Accepting individuals value clear-cut activities in which they see the concrete results of their work and do not need to solve many complex problems. Investigative individuals value intellectual curiosity and the challenge of solving complex tasks.

2. Carefree-Practical Scale: Carefree individuals value activities where they can be carefree and use their imaginations. Practical individuals value proper appreciation of one's belongings and practical, efficient ways of doing things.

3. Conformity-Independence Scale: Conforming individuals value working under careful supervision, where clear directions and regulations can be followed. 
Independent individuals value the freedom to work on their own, independent of regulations and social conventions.

4. Supportive-Leadership Scale: Supportive individuals value activities in which they can be good followers and do not need to direct or instruct others. Leadership individuals value opportunities to make decisions, to direct others, and to speak for the group.

5. Flexibility-Orderliness Scale: Flexible individuals value activities where they can take things as they come, without being constrained by rigid plans. Orderly individuals value organization, keeping things neat and in their proper place.

6. Privacy-Recognition Scale: Private individuals value keeping their activities quiet and shun fame. Recognition individuals seek fame and contact with important people.

7. Realistic-Aesthetic Scale: Realistic individuals value activities that focus on objective reality. Aesthetic individuals prefer to focus on subjective involvement with, and appreciation of, artistic aspects of the world.

8. Reserved-Social Scale: Reserved individuals value spending time on their own projects and tending to their own affairs. Social individuals value working with and helping others. 
Individual graduation plan - p. 47.

Every student at Beacon Charter High School is required to maintain an Individual Graduation Plan (IGP) during their years at Beacon. The IGP serves as a historical record of student achievement and accomplishments as well as a guide for future planning. The particular IGP that the ninth-graders were using at the time of research contained a page (p. 47) that dealt with students' feelings toward reading and mathematics (see Appendix J; Individual, 2007). Students were asked to answer four questions related to reading and four questions related to mathematics. The four selfreflective short-response (1-2 sentences) questions relative to mathematics were:

1. What and how is mathematics important in my life?

2. What do my grades and test scores show about my mathematics ability?

3. How will mathematics help me with my educational and career goals?

4. What type of help do I need to succeed in mathematics?

I conducted content analyses of students' responses.

Other measures performed for analyses.

1. Simple word counts were made on 31 students' My Math Experiences Essays (variable: Essay Total Word Count) and on each of their six nonroutine math problems (variable: Problem Average Word Count). The premises behind this measure were two-fold. First, the measure was used as 
an indicator of student engagement with the task, secondly to explore the relationship between writing and mathematical problem solving: Does the more one writes about the experiences during and after problem solving (i.e., metacognition) correlate with higher problem-solving achievement?

2. I reviewed the 31 students' six nonroutine math problems for instances of Higher-Order Internal Representation (HOIR). Types of instances are problem-specific and are detailed in the Results chapter. I used the HOIR measure to test students' ability to efficiently organize, to recognize patterns, to translate into an analogous scenarios (e.g., verbal to algebraic; diagramming) - indicators that would correlate with better problem solving.

\section{Order of Data Collection}

The order of retrieval of data was primarily based on time-sensitivity and secondarily on length of task.

Part of the goals of this research was to assess incoming ninth-graders to Beacon Charter High School on their attitudes toward math and their math ability, it was essential to first collect any data that might have been influenced by Beacon math teachers (e.g., attitudes toward math, attitudes toward teacher, math skills, problemsolving strategies). Therefore, the Math Skills Assessment and the My Math Experiences essays were administered within the first week of the research (began January 28, 2008). 
Multi-item questionnaires were administered by descending number of item numbers (i.e., greatest number of item numbers to least) to minimize student fatigue/disinterest as the research progressed.

The NWEA tests are given every fall and spring to all Beacon students. The schedule of the tests are determined by the school and thus there was no flexibility for me to adjust the scheduling of this particular source of data nor was there any need to.

Those sources of data that were not as time sensitive, such as the COPS Interest and COPES Values inventories and school records, were handled last. 
Results

\section{Overview of Data-Analyses}

The first part of this chapter covers statistical analyses, which were mostly bivariate, and the second part covers the qualitative analyses (e.g., content analysis of student narratives and videotaped interviews).

Bivariate analyses were performed between variables from five categories (see Table 5): eight demographic variables; eight math-related attitude variables; six aptitude/achievement/experience variables; eight work-values; and seven nonroutine math problem performance variables. Figure 3 provides a sequential outline of these bivariate analyses, as they will appear in this chapter.

Virtually all analyses involved the 31 students who had complete NWEA data from Fall semester of 2007 and Spring semester of 2008 (because of missing data, a few analyses involved 29 of the 31 students). The statistical significance was always $p$ $<.05$. Whenever directional tests were an option (i.e., with $t$-tests, Pearson $r$, and 2by-2 chi-square tables), I used the two-tailed (non-directional) versions, because this was an exploratory study, with no explicit, directional hypotheses.

In terms of describing the strength of Pearson $r$ correlations in this chapter, I used the approximate guidelines (i.e., $\pm 1.00=$ perfect correlation; $\pm .80=$ strong correlation; $\pm .50=$ moderate correlation; $\pm .20=$ weak correlation; $\pm .00=$ no correlation) provided in Hatcher and Stepanski (1994). 
A set of 14 other variables dealing with career interests (see Table 6) were not involved in the analyses in Table 5. These variables profiled the career interests of the sample of 31 students as a whole, to discern their preferences for occupations with higher/lower need for mathematical skill. Other analyses compared girls and boys within the sample, then related their interest levels to national, gender-specific profiles. 

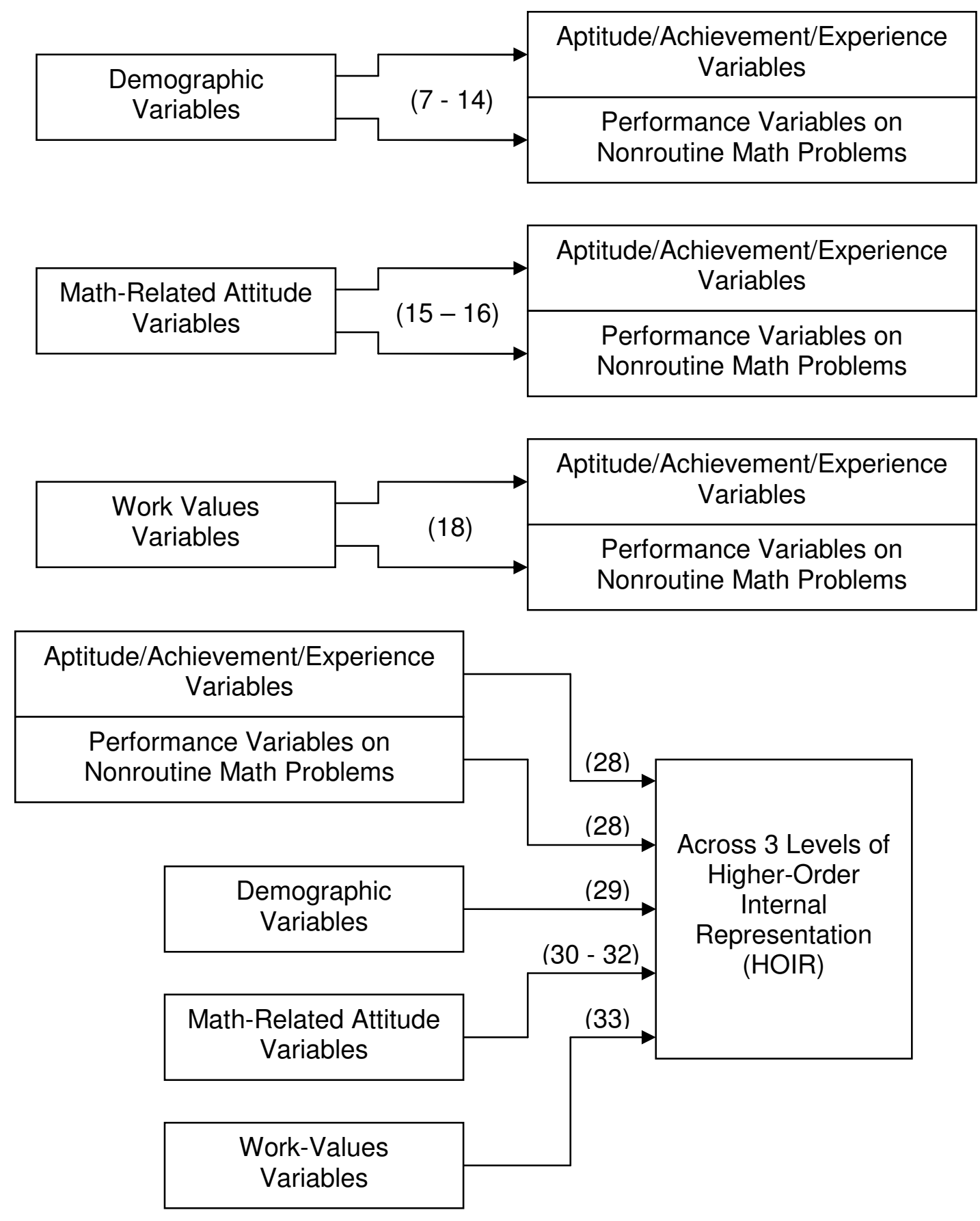

Aptitude/Achievement/Experience
Variables

$\stackrel{\begin{array}{c}\text { Performance Variables on } \\ \text { Nonroutine Math Problems }\end{array}}{\stackrel{(34)}{\longrightarrow}}$

Figure 3. Roadmap for bivariate analyses.

(Numbers in parentheses reflect tables reporting results) 
Table 5

Categories of Variables Used in Bivariate Analyses

Demographics :

Age; Art Discipline; Attendance; Ethnicity; Gender; IEP Status; SES; Sending School District Math-Related Attitudes:

Fennema-Sherman Mathematics Attitude Scales (Affect, Parents'Attitudes, Usefulness, Male Domain,

Success, Teacher); Rotter Internal-External Locus of Control Scale; Preferred Mathematical Solutions (pictorial, tabular, algebraic, hybrid)

Aptitude, Achievement, Experience:

Northwest Evaluation Association's Achievement Tests (Mathematics, Reading, Language Usage);

Math Skills Assessment; My Math Experiences Essay (Rubric Score, Total Word Count)

COPES Work-Values Scales (eight bipolar characteristics):

Accepting-Investigative; Carefree-Practical; Conformity-Independence; Supportive-Leadership;

Flexibility-Orderliness; Privacy-Recognition; Realistic-Aesthetic; Reserved-Social

Performance on Six Nonroutine Math Problems:

Rubric Scales (Understanding, How One Solved It, Decisions Made, Getting Answer, and Total Scores); Average Word Count; Number of Higher-Order Internal Representations 
Table 6

Career Interest Variables

\begin{tabular}{cl}
\hline & Occupational Group Values \\
\hline 2 & Arts, Professional \\
3 & Business, Professional \\
4 & Business, Skilled \\
5 & Clerical \\
6 & Communication \\
7 & Consumer Economics \\
8 & Outdoor \\
9 & Science, Professional \\
13 & Technical, Professional \\
11 & Service, Professional \\
&
\end{tabular}


Demographic Variable: Age

The mean age of the Beacon Charter High ninth-grade students $(N=31)$, at the beginning of this study (1/25/08) with complete sets of NWEA fall and spring data was $15.33(S D=0.75)$ years, ranging from 14.1 years to 16.6 years. A major contributing factor to these older students may be the fact that Charter schools often attract students who have been retained in earlier grades in traditional schools due to poor performance and who are seeking an alternative path to high school graduation. Such students contributed to the variability in the ages of the 31 students.

How did students' age relate to the 13 aptitude/achievement variables?

Table 7 shows the Pearson $r$ correlations between age and the six Aptitude/Achievement/Experience variables and the seven Performance Variables on Nonroutine Math Problems. Within each set, the correlations are listed from highest to lowest.

All 13 correlations were not significant; however, two interesting patterns were apparent. All six Aptitude/Achievement/Experience variables had a negative correlation with age suggesting that the older the student, the lower the Aptitude/Achievement/Experience scores.

In contrast, the second pattern revealed that, all seven measures of performance on the Nonroutine Math Problems had a positive correlation with age suggesting that the older the student, the higher the problem-solving scores. 
Table 7

Correlations $r$ with Age

\begin{tabular}{|c|c|c|c|}
\hline \multirow{2}{*}{\multicolumn{2}{|c|}{ Variable }} & \multicolumn{2}{|c|}{$N=31$} \\
\hline & & r & $p$ \\
\hline 1 & NWEA Language Usage Average RIT & -.26 & .1503 \\
\hline 2 & My Math Experiences Essay Rubric Score & -.24 & .1699 \\
\hline 3 & NWEA Mathematics Average RIT & -.22 & .2355 \\
\hline 4 & My Math Experiences Essay Total Word Count & -.20 & .2770 \\
\hline 5 & NWEA Reading Average RIT & -.19 & .3185 \\
\hline 6 & Math Skills Assessment & -.04 & .8302 \\
\hline 1 & Getting Answer Scale Score & .19 & .3091 \\
\hline 2 & Problem-Solving Total Rubric Score & .13 & .4752 \\
\hline 3 & Understanding scale Score & .12 & .5325 \\
\hline 4 & How One Solved It scale score & .11 & .5526 \\
\hline 5 & Decisions Made Scale Score & .10 & .6066 \\
\hline 6 & Number of Higher-Order Representations & .09 & .6158 \\
\hline 7 & Problem Average Word Count & .07 & .7129 \\
\hline
\end{tabular}


Demographic Variable: Art Discipline

As described in the Introduction, Beacon Charter High School for the Arts offers students three art disciplines: Culinary Arts, Theater Arts, and Visual Arts. The sample $(N=31)$ included seven culinary arts students, 13 theater arts students, and 11 visual arts students.

Table 8 shows one-way ANOVAs comparing students in the three art disciplines on the six Aptitude/Achievement/Experience variables and the seven Performance Variables on Nonroutine Math Problems. Within each set of variables, the ANOVAs are listed from highest to lowest $F$-statistic.

None of the 13 ANOVAs even approached significance $(p<.05)$. The smallest $p$-value was .2282, and 12 of the $13 p$-values exceeded .3899 . These nonsignificant differences favored the theater arts students on all six of the Aptitude/Achievement/Experience variables. On the most important problem-solving variable (Problem-Solving Total Rubric Score), the three groups of students were nearly identical ( $p=.9889)$. 
Table 8

Comparisons among Art Disciplines

\begin{tabular}{|c|c|c|c|c|c|c|c|c|c|}
\hline & \multirow[b]{2}{*}{ Variable } & \multicolumn{2}{|c|}{$\begin{array}{c}\text { Culinary Arts } \\
n=7\end{array}$} & \multicolumn{2}{|c|}{$\begin{array}{c}\text { Theater Arts } \\
n=13\end{array}$} & \multicolumn{2}{|c|}{$\begin{array}{c}\text { Visual Arts } \\
n=11\end{array}$} & \multicolumn{2}{|c|}{$N=31$} \\
\hline & & $M$ & $S D$ & $M$ & $S D$ & $M$ & $S D$ & $F$ & $p$ \\
\hline 1 & Math Skills Assessment & 57.13 & 21.74 & 72.31 & 19.02 & 67.88 & 15.15 & 1.56 & .2282 \\
\hline 2 & NWEA Mathematics Average RIT & 217.07 & 14.31 & 223.85 & 12.90 & 216.73 & 14.41 & .97 & .3899 \\
\hline 3 & $\begin{array}{l}\text { My Math Experience Essay Rubric } \\
\text { Score }\end{array}$ & 82.00 & 6.08 & 84.46 & 10.86 & 79.73 & 8.90 & .77 & .4716 \\
\hline 4 & $\begin{array}{l}\text { My Math Experience Essay Total } \\
\text { Word Count }\end{array}$ & 353.71 & 121.87 & 456.85 & 173.68 & 413.91 & 230.95 & .69 & .5085 \\
\hline 5 & NWEA Reading Average RIT & 219.79 & 10.30 & 219.81 & 14.73 & 215.05 & 12.51 & .47 & .6313 \\
\hline 6 & NWEA Language Usage Average RIT & 211.21 & 9.27 & 214.89 & 14.86 & 212.95 & 11.71 & .20 & .8213 \\
\hline 1 & Problem Average Word Count & 22.57 & 9.87 & 23.97 & 13.56 & 17.58 & 9.45 & .98 & .3895 \\
\hline 2 & $\begin{array}{l}\text { Number of Higher-Order } \\
\text { Representations }\end{array}$ & .71 & .95 & .77 & .93 & 1.09 & 1.22 & .38 & .6853 \\
\hline 3 & Decisions Made Scale Score & 10.79 & 4.14 & 11.31 & 4.63 & 10.27 & 3.86 & .18 & .8397 \\
\hline 4 & Understanding Scale Score & 12.21 & 3.71 & 11.35 & 4.05 & 11.77 & 4.12 & .11 & .8960 \\
\hline 5 & How One Solved It Scale Score & 10.36 & 3.98 & 10.19 & 4.43 & 10.82 & 5.11 & .06 & .9446 \\
\hline 6 & Getting Answer Scale Score & 11.21 & 5.25 & 10.69 & 3.47 & 10.59 & 4.87 & .05 & .9547 \\
\hline 7 & $\begin{array}{l}\text { Problem-Solving Total Rubric } \\
\text { Score }\end{array}$ & 44.57 & 16.83 & 43.54 & 16.01 & 43.46 & 17.49 & .01 & .9889 \\
\hline
\end{tabular}




\section{Demographic Variable: Attendance}

School attendance records indicated the number of days that the 31 students were absent during the Fall 2007 semester $(M=14.44, S D=12.70)$ - the semester prior to the research. The number of days absent included both excused and unexcused absences. The fall semester was the first semester for these students at Beacon Charter High School and was used to establish a baseline rate of attendance.

Table 9 presents the Pearson $r$ correlations between the number of days absent and the six Aptitude/Achievement/Experience variables, as well as the seven Performance Variables on Nonroutine Math Problems. Within each set of variables, the $r$-values appear in descending order.

Only one of the $13 r$-values was significant at $p<.05$ (this is the number of significant results that would be expected by chance: .05 x $13=.65)$. The 12 nonsignificant results were about evenly split between positive and negative correlations (what one would expect merely from sampling error if the Null Hypothesis were true: population correlation $=0$ ). Overall, attendance did not seem to be related to the 13 measures of aptitude/achievement/experience or problem-solving performance. 
Table 9

Correlations $r$ with Attendance

\begin{tabular}{|c|c|c|c|}
\hline & \multirow[b]{2}{*}{ Variable } & \multicolumn{2}{|c|}{$N=31$} \\
\hline & & $r$ & $p$ \\
\hline 1 & My Math Experiences Essay Rubric Score & -.38 & .0359 \\
\hline 2 & My Math Experiences Essay Total Word Count & -.23 & .2224 \\
\hline 3 & Math Skills Assessment & -.20 & .2754 \\
\hline 4 & NWEA Language Usage Average RIT & -.20 & .2865 \\
\hline 5 & NWEA Reading Average RIT & -.16 & .3805 \\
\hline 6 & NWEA Mathematics Average RIT & .00 & .9806 \\
\hline 1 & Number of Higher-Order Representations & .25 & .1777 \\
\hline 2 & Problem Average Word Count & -.25 & .1792 \\
\hline 3 & Getting Answer Scale Score & .18 & .3226 \\
\hline 4 & How One Solved It scale score & .15 & .4099 \\
\hline 5 & Problem-Solving Total Rubric Score & .14 & .4380 \\
\hline 6 & Understanding Scale Score & .14 & .4660 \\
\hline 7 & Decisions Made Scale Score & .08 & .6609 \\
\hline
\end{tabular}


Demographic Variable: Ethnicity

The sample $(N=31)$ included four African-American students, seven Hispanic students, and 20 White students. Table 10 shows one-way ANOVAs comparing the three ethnic groups on the six Aptitude/Achievement/Experience variables and the seven Performance Variables on Nonroutine Math Problems. Within each set, the comparisons are listed from highest to lowest $F$-statistic.

While none of the ANOVAs was significant $(p<.05)$, eight of the 13 were trend-level significant $(.05 \leq p<.10)$. The Hispanic students scored lowest on all eight of the trend-level ANOVAs, with African-American students scoring highest on three of them, and White students scoring highest on the other five. 
Table 10

Performance Comparisons between Ethnicity

\begin{tabular}{|c|c|c|c|c|c|c|c|c|c|}
\hline & \multirow[b]{3}{*}{ Variable } & \multirow{2}{*}{\multicolumn{2}{|c|}{$\begin{array}{c}\text { African-American } \\
n=4\end{array}$}} & \multicolumn{2}{|c|}{ Hispanic } & \multicolumn{2}{|c|}{ White } & \multirow{2}{*}{\multicolumn{2}{|c|}{$N=31$}} \\
\hline & & & & $n$ & 7 & & 20 & & \\
\hline & & $M$ & $S D$ & $M$ & $S D$ & $M$ & $S D$ & $F$ & $p$ \\
\hline 1 & $\begin{array}{l}\text { NWEA Mathematics Average } \\
\text { RIT }\end{array}$ & 228.25 & 11.67 & 210.50 & 17.35 & 221.35 & 11.51 & 2.78 & .0792 \\
\hline 2 & $\begin{array}{l}\text { NWEA Language Usage } \\
\text { Average RIT }\end{array}$ & 220.13 & 9.76 & 204.93 & 12.77 & 214.98 & 11.71 & 2.65 & .0881 \\
\hline 3 & Math Skills Assessment & 73.33 & 5.43 & 55.21 & 20.27 & 70.34 & 18.66 & 2.06 & .1457 \\
\hline 4 & $\begin{array}{l}\text { My Math Experiences Essay } \\
\text { Rubric Score }\end{array}$ & 90.50 & 8.70 & 80.86 & 10.07 & 81.05 & 8.62 & 1.96 & .1599 \\
\hline 5 & NWEA Reading Average RIT & 220.63 & 10.93 & 211.29 & 16.42 & 220.00 & 11.62 & 1.30 & .2877 \\
\hline 6 & $\begin{array}{l}\text { My Math Experiences Essay } \\
\text { Total Word Count }\end{array}$ & 523.00 & 192.83 & 351.57 & 77.88 & 420.75 & 206.48 & 1.10 & .3475 \\
\hline 1 & $\begin{array}{l}\text { Problem-Solving Total } \\
\text { Rubric Score }\end{array}$ & 44.25 & 12.91 & 31.79 & 10.6 & 47.83 & 16.83 & 2.87 & .0733 \\
\hline 2 & $\begin{array}{l}\text { Problem Average Word } \\
\text { Count }\end{array}$ & 32.17 & 16.48 & 16.17 & 8.10 & 21.06 & 10.45 & 2.81 & .0775 \\
\hline 3 & $\begin{array}{l}\text { Decisions Made Scale } \\
\text { Score }\end{array}$ & 11.13 & 3.07 & 7.79 & 2.53 & 11.83 & 4.38 & 2.76 & .0803 \\
\hline 4 & Understanding scale Score & 12.25 & 3.30 & 8.86 & 3.20 & 12.58 & 3.87 & 2.70 & .0848 \\
\hline 5 & $\begin{array}{l}\text { Getting Answer scale } \\
\text { Score }\end{array}$ & 10.50 & 3.94 & 7.79 & 2.97 & 11.88 & 4.36 & 2.64 & .0889 \\
\hline 6 & $\begin{array}{l}\text { How One solved It scale } \\
\text { Score }\end{array}$ & 10.38 & 3.09 & 7.36 & 2.51 & 11.55 & 4.79 & 2.54 & .0971 \\
\hline 7 & $\begin{array}{l}\text { Number of Higher-Order } \\
\text { Representations }\end{array}$ & 1.00 & .82 & .43 & .53 & 1.00 & 1.17 & .83 & .4449 \\
\hline
\end{tabular}


Demographic Variable: Gender

The sample $(N=31)$ included 17 girls and 14 boys. Table 11 shows $t$-tests comparing girls and boys on the six Aptitude/Achievement/Experience variables and the Performance on Nonroutine Math Problems. Within each set, the comparisons are listed from highest to lowest $t$-statistic.

In all 13 comparisons, girls outperformed boys. Four significant findings favored the girls over the boys: NWEA Language Usage Average RIT score, My Math Experiences Essay Rubric score, NWEA Mathematics Average RIT score, and My Math Experiences Essay Total Word Count.

It is worth noting that the two highest $t$-statistics were language usage related and of approximately equal magnitude (i.e., NWEA Language Usage Average RIT score and Math Experiences Essay Total Word Count). 
Table 11

Students' Mean Scores for Variables by Gender

\begin{tabular}{|c|c|c|c|c|c|c|c|}
\hline & & Girls & $=17)$ & Boys ( $r$ & $=14)$ & $(N$ & $31)$ \\
\hline & Variable & $M$ & $S D$ & $M$ & $S D$ & t & $p$ \\
\hline 1 & $\begin{array}{l}\text { NWEA Language } \\
\text { Usage Average } \\
\text { RIT }\end{array}$ & 220.06 & 8.43 & 205.25 & 11.70 & 4.09 & .0003 \\
\hline 2 & $\begin{array}{l}\text { My Math } \\
\text { Experiences } \\
\text { Essay Total Word } \\
\text { Count }\end{array}$ & 512.12 & 199.37 & 304.43 & 71.27 & 4.00 & .0007 \\
\hline 3 & $\begin{array}{l}\text { My Math } \\
\text { Experiences } \\
\text { Essay Rubric } \\
\text { Score }\end{array}$ & 85.88 & 9.49 & 77.79 & 6.90 & 2.66 & .0125 \\
\hline 4 & $\begin{array}{l}\text { NWEA Mathematics } \\
\text { Average RIT }\end{array}$ & 224.79 & 12.09 & 213.71 & 13.55 & 2.40 & .0228 \\
\hline 5 & $\begin{array}{l}\text { NWEA Reading } \\
\text { Average RIT }\end{array}$ & 220.68 & 13.84 & 215.00 & 11.28 & 1.23 & .2274 \\
\hline 6 & $\begin{array}{l}\text { Math Skills } \\
\text { Assessment }\end{array}$ & 69.02 & 19.57 & 65.24 & 18.16 & .55 & .5845 \\
\hline 1 & $\begin{array}{l}\text { Number of } \\
\text { Higher-Order } \\
\text { Representations }\end{array}$ & 1.12 & 1.22 & .57 & .65 & 1.60 & .1231 \\
\hline 2 & $\begin{array}{l}\text { Problem Average } \\
\text { Word Count }\end{array}$ & 23.97 & 12.61 & 18.25 & 9.39 & 1.41 & .1705 \\
\hline 3 & $\begin{array}{l}\text { How One Solved } \\
\text { It Scale Score }\end{array}$ & 11.09 & 5.22 & 9.69 & 3.31 & .87 & .3892 \\
\hline 4 & $\begin{array}{l}\text { Problem-Solving } \\
\text { Total Rubric } \\
\text { Score }\end{array}$ & 45.50 & 18.36 & 41.61 & 13.89 & .66 & .5139 \\
\hline 5 & $\begin{array}{l}\text { Understanding } \\
\text { Scale Score }\end{array}$ & 12.09 & 4.36 & 11.21 & 3.30 & .62 & .5419 \\
\hline 6 & $\begin{array}{l}\text { Getting Answer } \\
\text { Scale Score }\end{array}$ & 11.18 & 4.88 & 10.29 & 3.53 & .57 & .5726 \\
\hline 7 & $\begin{array}{l}\text { Decisions Made } \\
\text { Scale Score }\end{array}$ & 11.15 & 4.50 & 10.43 & 3.98 & .47 & .6391 \\
\hline
\end{tabular}


Demographic Variable: IEP

The sample $(N=31)$ included eight students with an Individualized Education Plan (IEP). All eight IEPs were reviewed prior to administering assessments and followed with regards to accommodations (e.g., extended time) written into the IEP.

Table 12 shows $t$-tests comparing the eight IEP students and the 23 other students on the six Aptitude/Achievement/Experience variables and the seven Performance Variables on Nonroutine Math Problems. Within each set, the comparisons are listed from highest to lowest $t$-statistic.

In all 13 comparisons, non-IEP students outperformed students with IEPs with eight differences being significant: NWEA Mathematics Average RIT Score, NWEA Reading Average RIT Score, NWEA Language Usage Average RIT Score, Understanding Scale Score, Problem-Solving Total Rubric Score, Decisions Made Scale Score, Getting Answer Scale Score, and How One Solved It Scale Score.

Despite their consistent differences on measures of aptitude/achievement/experience and measures of performance on nonroutine math problems, the groups had virtually identical scores on the Math Experiences Essay Rubric Score. 
Table 12

Students' Mean Scores for Variables by IEP

\begin{tabular}{|c|c|c|c|c|c|c|c|}
\hline & \multirow[b]{2}{*}{ Variable } & \multicolumn{2}{|c|}{$\begin{array}{l}\text { Non-IEP } \\
(n=23)\end{array}$} & \multicolumn{2}{|c|}{$\begin{array}{c}\text { IEP } \\
(n=8)\end{array}$} & \multicolumn{2}{|c|}{$(N=31)$} \\
\hline & & $M$ & $S D$ & $M$ & $S D$ & $t$ & $p$ \\
\hline 1 & $\begin{array}{l}\text { NWEA Mathematics } \\
\text { Average RIT }\end{array}$ & 224.17 & 11.63 & 207.19 & 11.85 & 3.54 & .0014 \\
\hline 2 & $\begin{array}{l}\text { NWEA Reading } \\
\text { Average RIT }\end{array}$ & 221.85 & 11.33 & 207.38 & 11.32 & 3.11 & .0041 \\
\hline 3 & $\begin{array}{l}\text { NWEA Language } \\
\text { Usage Average } \\
\text { RIT }\end{array}$ & 216.07 & 11.77 & 205.63 & 11.38 & 2.18 & .0376 \\
\hline 4 & $\begin{array}{l}\text { Math Skills } \\
\text { Assessment }\end{array}$ & 70.44 & 17.27 & 58.31 & 21.00 & 1.62 & .1162 \\
\hline 5 & $\begin{array}{l}\text { My Math } \\
\text { Experiences } \\
\text { Essay Total Word } \\
\text { Count }\end{array}$ & 426.35 & 196.97 & 395.25 & 157.62 & .40 & .6903 \\
\hline 6 & $\begin{array}{l}\text { My Math } \\
\text { Experiences } \\
\text { Essay Rubric } \\
\text { Score }\end{array}$ & 82.44 & 8.85 & 81.63 & 10.93 & .21 & .8351 \\
\hline 1 & $\begin{array}{l}\text { Understanding } \\
\text { Scale Score }\end{array}$ & 12.80 & 3.72 & 8.50 & 2.35 & 3.05 & .0048 \\
\hline 2 & $\begin{array}{l}\text { Problem-Solving } \\
\text { Total Rubric } \\
\text { Score }\end{array}$ & 48.33 & 15.68 & 30.56 & 8.94 & 3.02 & .0053 \\
\hline 3 & $\begin{array}{l}\text { Decisions Made } \\
\text { Scale Score }\end{array}$ & 11.98 & 4.08 & 7.50 & 2.07 & 2.95 & .0062 \\
\hline 4 & $\begin{array}{l}\text { Getting Answer } \\
\text { Scale Score }\end{array}$ & 11.96 & 4.12 & 7.38 & 2.68 & 2.92 & .0067 \\
\hline 5 & $\begin{array}{l}\text { How One Solved } \\
\text { It Scale Score }\end{array}$ & 11.59 & 4.47 & 7.19 & 2.37 & 2.64 & .0133 \\
\hline 6 & $\begin{array}{l}\text { Number of } \\
\text { Higher-Order } \\
\text { Representations }\end{array}$ & 1.00 & 1.13 & .50 & .53 & 1.66 & .1096 \\
\hline 7 & $\begin{array}{l}\text { Problem Average } \\
\text { Word Count }\end{array}$ & 23.25 & 11.92 & 16.02 & 8.49 & 1.58 & .1261 \\
\hline
\end{tabular}


Demographic Variable: Sending School District

The sample $(N=31)$ included 19 students from the Woonsocket school district (Beacon Charter High School is considered a stand-alone school district within the Woonsocket school district boundaries) and 12 students from other districts.

Table 13 shows t-tests comparing the two groups of students on the six Aptitude/Achievement/Experience variables and the seven Performance Variables on Nonroutine Math Problems. Within each set, the comparisons are listed from highest to lowest $t$-statistic.

Although there were no significant differences, out-of district students outperformed students within the district on 12 of the 13 measures (albeit very slightly in most cases). 
Table 13

Students' Mean Scores by Sending School District

\begin{tabular}{|c|c|c|c|c|c|c|c|}
\hline & \multirow[b]{2}{*}{ Variable } & \multicolumn{2}{|c|}{$\begin{array}{l}\text { Out of } \\
\text { District } \\
(n=12)\end{array}$} & \multicolumn{2}{|c|}{$\begin{array}{l}\text { Within } \\
\text { District } \\
(n=19)\end{array}$} & \multicolumn{2}{|c|}{$(N=31)$} \\
\hline & & $M$ & $S D$ & $M$ & $S D$ & $t$ & $p$ \\
\hline 1 & $\begin{array}{l}\text { My Math } \\
\text { Experiences } \\
\text { Essay Total Word } \\
\text { Count }\end{array}$ & 476.92 & 174.21 & 381.32 & 187.39 & 1.42 & .1661 \\
\hline 2 & $\begin{array}{l}\text { NWEA Language } \\
\text { Usage Average } \\
\text { RIT }\end{array}$ & 217.00 & 11.26 & 211.08 & 12.8 & 1.31 & .1997 \\
\hline 3 & $\begin{array}{l}\text { My Math } \\
\text { Experiences } \\
\text { Essay Rubric } \\
\text { Score }\end{array}$ & 83.33 & 11.22 & 81.53 & 8.01 & .52 & .6045 \\
\hline 4 & $\begin{array}{l}\text { Math Skills } \\
\text { Assessment }\end{array}$ & 68.88 & 18.05 & 66.32 & 19.57 & .36 & .7182 \\
\hline 5 & $\begin{array}{l}\text { NWEA Mathematics } \\
\text { Average RIT }\end{array}$ & 220.50 & 14.16 & 219.34 & 13.85 & .22 & .8237 \\
\hline 6 & $\begin{array}{l}\text { NWEA Reading } \\
\text { Average RIT }\end{array}$ & 217.83 & 13.93 & 218.29 & 12.54 & .09 & .9253 \\
\hline 1 & $\begin{array}{l}\text { Number of } \\
\text { Higher-Order } \\
\text { Representations }\end{array}$ & 1.17 & 1.19 & .68 & .89 & 1.29 & .2068 \\
\hline 2 & $\begin{array}{l}\text { Problem Average } \\
\text { Word Count }\end{array}$ & 23.36 & 14.83 & 20.14 & 8.96 & .76 & .4553 \\
\hline 3 & $\begin{array}{l}\text { Decisions Made } \\
\text { Scale Score }\end{array}$ & 10.42 & 4.75 & 11.08 & 3.83 & .43 & .6724 \\
\hline 4 & $\begin{array}{l}\text { Getting Answer } \\
\text { Scale Score }\end{array}$ & 11.25 & 5.70 & 10.47 & 3.22 & .43 & .6728 \\
\hline 5 & $\begin{array}{l}\text { How One Solved } \\
\text { It Scale Score }\end{array}$ & 10.88 & 5.95 & 10.18 & 3.35 & .37 & .7184 \\
\hline 6 & $\begin{array}{l}\text { Problem-Solving } \\
\text { Total Rubric } \\
\text { Score }\end{array}$ & 44.38 & 20.81 & 43.34 & 13.05 & .17 & .8658 \\
\hline 7 & $\begin{array}{l}\text { Understanding } \\
\text { Scale Score }\end{array}$ & 11.83 & 4.72 & 11.61 & 3.39 & .16 & .8766 \\
\hline
\end{tabular}


Demographic Variable: SES

The sample $(N=31)$ included 21 students who qualified for free or reduced lunch. These students were classified as Low-SES (Socioeconomic Status) while the other 10 were classified as High-SES.

Table 14 shows $t$-tests comparing the two SES groups on the six Aptitude/Achievement/Experience variables and the seven Performance Variables on Nonroutine Math Problems. Within each set, the comparisons are listed from highest to lowest $t$-statistic.

Although the high SES students outperformed the low SES students on 12 of the 13 variables, there were no significant differences and many of them were very small. The absence of SES-differences was unexpected, but grounds for optimism (addressed in the Discussion chapter). 
Table 14

Students' Mean Scores for Variables by SES

\begin{tabular}{|c|c|c|c|c|c|c|c|}
\hline & \multirow[b]{2}{*}{ Variable } & \multicolumn{2}{|c|}{$\begin{array}{l}\text { High-SES } \\
(n=10)\end{array}$} & \multicolumn{2}{|c|}{$\begin{array}{l}\text { LOW-SES } \\
(n=21)\end{array}$} & \multicolumn{2}{|c|}{$(N=31)$} \\
\hline & & $M$ & $S D$ & $M$ & $S D$ & t & $p$ \\
\hline 1 & $\begin{array}{l}\text { NWEA Language } \\
\text { Usage Average } \\
\text { RIT }\end{array}$ & 218.10 & 10.52 & 211.12 & 12.80 & 1.50 & .1451 \\
\hline 2 & $\begin{array}{l}\text { My Math } \\
\text { Experiences } \\
\text { Essay Rubric } \\
\text { Score }\end{array}$ & 84.50 & 10.92 & 81.14 & 8.41 & .94 & .3532 \\
\hline 3 & $\begin{array}{l}\text { My Math } \\
\text { Experiences } \\
\text { Essay Total Word } \\
\text { Count }\end{array}$ & 461.10 & 208.02 & 397.95 & 175.60 & .88 & .3848 \\
\hline 4 & $\begin{array}{l}\text { NWEA Reading } \\
\text { Average RIT }\end{array}$ & 220.65 & 14.22 & 216.90 & 12.35 & .75 & .4580 \\
\hline 5 & $\begin{array}{l}\text { NWEA Mathematics } \\
\text { Average RIT }\end{array}$ & 222.15 & 14.18 & 218.67 & 13.74 & .65 & .5188 \\
\hline 6 & $\begin{array}{l}\text { Math Skills } \\
\text { Assessment }\end{array}$ & 69.32 & 21.81 & 66.35 & 17.58 & .41 & .6873 \\
\hline 1 & $\begin{array}{l}\text { Getting Answer } \\
\text { Scale Score }\end{array}$ & 11.90 & 4.94 & 10.24 & 3.94 & 1.01 & .3199 \\
\hline 2 & $\begin{array}{l}\text { Problem Average } \\
\text { Word Count }\end{array}$ & 23.50 & 14.44 & 20.38 & 9.99 & .70 & .4881 \\
\hline 3 & $\begin{array}{l}\text { Problem-Solving } \\
\text { Total Rubric } \\
\text { Score }\end{array}$ & 46.45 & 18.29 & 42.45 & 15.36 & .64 & .5290 \\
\hline 4 & $\begin{array}{l}\text { Decisions Made } \\
\text { Scale Score }\end{array}$ & 11.45 & 4.07 & 10.52 & 4.25 & .57 & .5698 \\
\hline 5 & $\begin{array}{l}\text { Understanding } \\
\text { Scale Score }\end{array}$ & 12.15 & 4.61 & 11.48 & 3.59 & .45 & .6592 \\
\hline 6 & $\begin{array}{l}\text { How One Solved } \\
\text { It Scale Score }\end{array}$ & 10.95 & 5.23 & 10.21 & 4.15 & .42 & .6744 \\
\hline 7 & $\begin{array}{l}\text { Number of } \\
\text { Higher-Order } \\
\text { Representations }\end{array}$ & .80 & .92 & .90 & 1.09 & .26 & .7952 \\
\hline
\end{tabular}


Math Related Attitude Variables: Rotter's Internal-External Locus of Control and the Shortened Version of the Fennema-Sherman Mathematics Attitudes Scales

As described in the Method chapter, the 31 students completed the six Fennema-Sherman Mathematics Attitudes Scales in their shortened form (Mulhearn \& Rae, 1998), as well as the Internal-External Locus of Control Scale (Rotter, 1966).

The matrix in Table 15 shows the correlations between these seven attitude variables and the six Aptitude/Achievement/Experience variables and the Performance Variables on Nonroutine Math Problems. Of the 91 analyses performed (7 attitude scales $\mathrm{x} 13$ variables) only six were found to be significant $(p<.05)$, which is slightly more than what would be expected merely by chance $(.05 \times 91=4.55 \approx 5)$.

Three of the five significant correlations involved the Male Domain Scale (with the NWEA Language Usage, NWEA Reading, and My Math Experiences Essay Rubric scores.). There were only two significant correlations (between Math Affect and Getting the Answer Scale Score; and between Math Affect and the ProblemSolving Total Rubric Score) that dealt with the students' actual performance in solving the six problems.

The most noteworthy aspect of Table 15, other than Math Affect, was the apparent irrelevance of six of the seven scales of students' attitudes as correlates of their generic mathematical ability and their performance in solving non-traditional problems. 
Table 15

Correlations r between Math-Related Attitudes and Variables

\begin{tabular}{|c|c|c|c|c|c|c|c|c|}
\hline & \multirow[b]{2}{*}{ Variable } & \multicolumn{7}{|c|}{ Attitude Variables ${ }^{a}$} \\
\hline & & $M R A^{b}$ & $\mathrm{PA}^{\mathrm{C}}$ & $\mathrm{U}^{\mathrm{d}}$ & $M D^{e}$ & $S^{f}$ & $\mathrm{~T}^{\mathrm{g}}$ & $I E^{h}$ \\
\hline 1 & NWEA Mathematics Average RIT & $\begin{array}{c}.20 \\
(.2853)\end{array}$ & $\begin{array}{c}.03 \\
(.8897)\end{array}$ & $\begin{array}{c}.17 \\
(.3515)\end{array}$ & $\begin{array}{c}-.31 \\
(.0939)\end{array}$ & $\begin{array}{c}.04 \\
(.8449)\end{array}$ & $\begin{array}{c}-.02 \\
(.9271)\end{array}$ & $\begin{array}{c}-.14 \\
(.4404)\end{array}$ \\
\hline 2 & NWEA Reading Average RIT & $\begin{array}{c}.09 \\
(.6420)\end{array}$ & $\begin{array}{c}.01 \\
(.9713)\end{array}$ & $\begin{array}{c}.19 \\
(.3082)\end{array}$ & $\begin{array}{c}-.44 \\
.0129\end{array}$ & $\begin{array}{c}-.06 \\
(.7677)\end{array}$ & $\begin{array}{c}.07 \\
(.7105)\end{array}$ & $\begin{array}{c}-.09 \\
(.6250)\end{array}$ \\
\hline 3 & NWEA Language Usage Average RIT & $\begin{array}{c}-.21 \\
(.2613)\end{array}$ & $\begin{array}{c}-.05 \\
(.7866)\end{array}$ & $\begin{array}{c}-.10 \\
(.6059)\end{array}$ & $\begin{array}{c}-.45 \\
.0107\end{array}$ & $\begin{array}{c}.04 \\
(.8358)\end{array}$ & $\begin{array}{c}-.29 \\
(.1105)\end{array}$ & $\begin{array}{c}.00 \\
(.9967)\end{array}$ \\
\hline 4 & Math Skills Assessment & $(.04)$ & $\begin{array}{c}-.07 \\
(.7270)\end{array}$ & $\begin{array}{c}-.09 \\
(.6285)\end{array}$ & $\begin{array}{c}-.16 \\
(.4021)\end{array}$ & $\begin{array}{c}.14 \\
(.4502)\end{array}$ & $\begin{array}{c}-.15 \\
(.4089)\end{array}$ & $\begin{array}{c}.01 \\
(.9778)\end{array}$ \\
\hline 5 & My Math Experiences Essay Rubric Score & $\begin{array}{c}-.01 \\
(.9556)\end{array}$ & $\begin{array}{c}.15 \\
(.4130)\end{array}$ & $\begin{array}{c}.10 \\
(.6106)\end{array}$ & $\begin{array}{c}-.40 \\
. .0279\end{array}$ & $\begin{array}{c}-.02 \\
(.9156)\end{array}$ & $\begin{array}{c}-.15 \\
(.4316)\end{array}$ & $\begin{array}{c}-.00 \\
(.9834)\end{array}$ \\
\hline 6 & $\begin{array}{l}\text { My Math Experiences Essay Total Word } \\
\text { Count }\end{array}$ & $\begin{array}{l}-.12 \\
(.5147)\end{array}$ & $\begin{array}{c}.16 \\
(.3996)\end{array}$ & $\begin{array}{l}-.17 \\
(.3747)\end{array}$ & $\begin{array}{l}-.22 \\
(.2368)\end{array}$ & $\begin{array}{c}.15 \\
(.4216)\end{array}$ & $\begin{array}{l}-.37 \\
-.0378\end{array}$ & $(.9071)$ \\
\hline 1 & Understanding Scale Score & $(.08706)$ & $\begin{array}{c}.28 \\
(.1252)\end{array}$ & $(.2469)$ & $\begin{array}{c}-.16 \\
(.4039)\end{array}$ & $(.08706)$ & $\begin{array}{c}.21 \\
(.2594)\end{array}$ & $\begin{array}{l}-.10 \\
(.5933)\end{array}$ \\
\hline 2 & How One Solved It scale score & $\begin{array}{l}.07 \\
(.7131)\end{array}$ & $\begin{array}{c}.17 \\
(.3529)\end{array}$ & $\begin{array}{c}.11 \\
(.5682)\end{array}$ & $\begin{array}{l}-.28 \\
(.1308)\end{array}$ & $\begin{array}{l}.07 \\
(.7131)\end{array}$ & $\begin{array}{c}.18 \\
(.3293)\end{array}$ & $\begin{array}{c}-.16 \\
(.3780)\end{array}$ \\
\hline 3 & Decisions Made Scale Score & $\begin{array}{l}.10 \\
(.5748)\end{array}$ & $\begin{array}{l}.28 \\
(.1286)\end{array}$ & $\begin{array}{l}.25 \\
(.1665)\end{array}$ & $\begin{array}{l}-.15 \\
(.4263)\end{array}$ & $\begin{array}{l}.10 \\
(.5748)\end{array}$ & $\begin{array}{c}.33 \\
(.0716)\end{array}$ & $\begin{array}{l}-.10 \\
(.6030)\end{array}$ \\
\hline 4 & Getting Answer Scale Score &. .0086 & $\begin{array}{c}.26 \\
(.1570)\end{array}$ & $\begin{array}{c}.19 \\
(.2938)\end{array}$ & $\begin{array}{c}-.19 \\
(.3134)\end{array}$ & $(.8230)$ & $(.2244)$ & $\begin{array}{c}-.21 \\
(.2665)\end{array}$ \\
\hline 5 & Problem-Solving Total Rubric Score &. .43 & $\begin{array}{c}.26 \\
(.1653)\end{array}$ & $(.2864)$ & $\begin{array}{c}-.20 \\
(.2777)\end{array}$ & $\begin{array}{c}.08 \\
(.6845)\end{array}$ & $\begin{array}{c}.24 \\
(.1866)\end{array}$ & $\begin{array}{c}-.15 \\
(.4253)\end{array}$ \\
\hline 6 & Problem Average Word Count & $\begin{array}{c}.17 \\
(.3477)\end{array}$ & $\begin{array}{c}.25 \\
(.1777)\end{array}$ & $\begin{array}{c}.02 \\
(.9360)\end{array}$ & $\begin{array}{c}-.13 \\
(.4900)\end{array}$ & $\begin{array}{c}.11 \\
(.5505)\end{array}$ & $\begin{array}{c}.30 \\
(.0955)\end{array}$ & $\begin{array}{c}.07 \\
(.6978)\end{array}$ \\
\hline 7 & Number of Higher-Order Representations & $\begin{array}{c}.31 \\
(.0944)\end{array}$ & $\begin{array}{c}.00 \\
(.9979)\end{array}$ & $\begin{array}{c}.09 \\
(.6334)\end{array}$ & $\begin{array}{c}-.22 \\
(.2441)\end{array}$ & $\begin{array}{c}.03 \\
(.8561)\end{array}$ & $\begin{array}{c}.08 \\
(.6532)\end{array}$ & $\begin{array}{c}-.04 \\
(.8218)\end{array}$ \\
\hline
\end{tabular}


${ }^{a}$-values are shown followed by p-values in parenthesis. p indicates significance at the .05 level.

${ }^{b}$ Mathematics-Related Affect (MRA); higher scores indicate greater confidence of students in performing mathematical tasks.

${ }^{C}$ Parent's Attitudes (PA); higher scores indicate stronger perceptions that one's parents are interested in the student's mathematical ability, encourage it, and have confidence in it.

${ }^{d}$ Usefulness (U); higher scores indicate that students see greater usefulness of mathematics now and in relationship to their future education, vocation, or other activities.

eMale Domain (MD); higher scores indicate that students see mathematics as more of a male domain.

${ }^{\mathrm{f}}$ Success (S); higher scores indicate that students more strongly anticipate positive consequences as a result of their success in mathematics.

${ }^{9}$ Teacher $(\mathrm{T})$; higher scores indicate that students perceive that their teachers have more positive attitudes toward them as learners of mathematics.

${ }^{h}$ Rotter's Locus of Control Internal-External Scale (IE); higher scores indicate a more external locus of control (belief that important events in one's life are influenced more by others or by chance than by one's own efforts). 
Math-Related Attitude Variable: Preferred Mathematical Solutions (PMS)

As described in the Method chapter, the 31 students completed six non-routine math problems: (1) Count Your Coins; (2) Lost in the Auditorium; (3) Birthday Money; (4) What's in My Future? (5) How Many Children Live Next Door? and (6) Blind Sided.

Of the six problems, problems numbered (2), (3), and (4) were selected for the development of an instrument; wherein, three different types of solutions were presented side-by-side on a single page for each of the three problems. One solution was algebraic in nature, another used pictures, and the third used a table. The 31 students were asked to select which solution they preferred. This administration was done after the students had completed all six problems earlier in the study. Thus, this post-test response by the students may or may not have corresponded to how they actually approached the problem (perhaps a recommended analysis for the future).

Students qualified for one of four groups based on their pattern of Preferred Mathematical Solutions (PMS). Students who preferred the algebraic solution (in at least two of the three problems) belonged to the Algebraic group. Those who preferred the pictorial solution (in at least two of the three problems) belonged to the Pictorial group. Those who preferred the tabular solution (in at least two of the three problems) belonged to the Tabular group. Finally, students who had three different preferences (one for each problem) belonged to the Hybrid group. Two of the 31 students in the sample were missing data for the PMS instrument described above. Of the remaining 29 students, their PMS data placed 14 in the Pictorial group, nine in the Tabular group, four in the Algebraic group, and two in the Hybrid group. 
Table 16 shows one-way ANOVAs comparing the four PMS groups on the six Aptitude/Achievement/Experience variables and the seven Performance Variables on Nonroutine Math Problems. Within each set, the comparisons are listed from highest to lowest $F$-statistic.

For five of the 13 ANOVAs, the $F$-statistic was significant $(p<.05)$ : NWEA Language Usage Average RIT; Number of Higher-Order Representations; Decisions Made Scale Score; Problem-Solving Total Rubric Score; and Understanding Scale Score. Post hoc paired comparisons, using the Student-Newman-Keuls procedure, at the .05 level, were performed on the five significant variables. In four of the five posthoc analyses, the mean scores of the Hybrid group were significantly higher than the means of the Algebraic, Pictorial, and Tabular groups (which did not differ significantly from each other). On NWEA Language Usage, there was no significant pair wise differences (although the Hybrid group once again had the highest mean).

The small sample sizes $(n=2)$ for Hybrids and $(n=4)$ for Algebraics was seen as potentially problematic with regards to sampling error and generalizations to other populations of students. 
Table 16

Comparisons between Preferred Mathematical Solutions (PMS) and Variables

\begin{tabular}{|c|c|c|c|c|c|c|c|c|c|c|c|}
\hline & \multirow[b]{2}{*}{ Variable } & \multicolumn{2}{|c|}{$\begin{array}{c}\text { Algebraic } \\
n=4\end{array}$} & \multicolumn{2}{|c|}{$\begin{array}{l}\text { Pictorial } \\
n=14\end{array}$} & \multicolumn{2}{|c|}{$\begin{array}{c}\text { Tabular } \\
n=9\end{array}$} & \multicolumn{2}{|c|}{ Hybrid } & \multicolumn{2}{|c|}{$N=29$} \\
\hline & & $M$ & $S D$ & $M$ & $S D$ & $M$ & $S D$ & $M$ & $S D$ & $F$ & $p$ \\
\hline 1 & $\begin{array}{l}\text { NWEA Language Usage } \\
\text { Average RIT }\end{array}$ & 213.13 & 9.00 & $\underline{206.61}$ & 12.77 & $\underline{220.00}$ & 10.31 & $\underline{223.50}$ & 4.24 & 3.18 & $.0414^{a}$ \\
\hline 2 & $\begin{array}{l}\text { NWEA Mathematics } \\
\text { Average RIT }\end{array}$ & 227.75 & 7.71 & 213.54 & 12.68 & 222.00 & 16.58 & 228.00 & 1.41 & 1.80 & .1724 \\
\hline 3 & Math Skills Assessment & 76.68 & 12.79 & 60.00 & 19.05 & 73.32 & 21.33 & 70.00 & 4.67 & 1.35 & .2806 \\
\hline 4 & $\begin{array}{l}\text { My Math Experiences } \\
\text { Essay Rubric Score }\end{array}$ & 77.00 & 12.52 & 80.71 & 6.70 & 86.44 & 11.48 & 86.00 & 2.83 & 1.30 & .2970 \\
\hline 5 & $\begin{array}{l}\text { NWEA Reading Average } \\
\text { RIT }\end{array}$ & 220.38 & 16.15 & 213.29 & 8.71 & 220.39 & 17.39 & 228.25 & 1.06 & 1.17 & .3412 \\
\hline 6 & $\begin{array}{l}\text { My Math Experiences } \\
\text { Essay Total Word Count }\end{array}$ & 352.75 & 90.87 & 414.50 & 227.00 & 439.44 & 196.54 & 478.00 & 1.41 & .24 & .8697 \\
\hline 1 & $\begin{array}{l}\text { Number of Higher-Order } \\
\text { Representations }\end{array}$ & 1.00 & .82 & .64 & .74 & .56 & .73 & 2.50 & .71 & 4.08 & $.0173^{a}$ \\
\hline 2 & $\begin{array}{l}\text { Decisions Made Scale } \\
\text { Score }\end{array}$ & 10.50 & 3.32 & 10.50 & 3.89 & 9.39 & 3.35 & 18.75 & 1.06 & 3.79 & $.0228^{a}$ \\
\hline 3 & $\begin{array}{l}\text { Problem-Solving } \\
\text { Total Rubric Score }\end{array}$ & 42.50 & 14.20 & 43.11 & 14.63 & 36.28 & 13.11 & 71.00 & 2.12 & 3.45 & $.0316^{\mathrm{a}}$ \\
\hline 4 & $\begin{array}{l}\text { Understanding Scale } \\
\text { Score }\end{array}$ & 11.38 & 3.40 & 11.54 & 3.43 & 9.83 & 3.53 & 18.00 & 0.00 & 3.17 & $.0417^{\mathrm{a}}$ \\
\hline 5 & $\begin{array}{l}\text { Getting Answer scale } \\
\text { Score }\end{array}$ & 10.50 & 4.04 & 10.86 & 3.73 & 8.56 & 3.45 & 17.00 & 3.54 & 2.97 & .0513 \\
\hline 6 & $\begin{array}{l}\text { How One Solved It } \\
\text { scale score }\end{array}$ & 10.13 & 3.86 & 10.21 & 4.29 & 8.50 & 3.36 & 17.25 & 0.35 & 2.79 & .0612 \\
\hline 7 & $\begin{array}{l}\text { Problem Average Word } \\
\text { Count }\end{array}$ & 15.08 & 4.51 & 20.54 & 9.82 & 22.63 & 14.99 & 33.75 & 6.95 & 1.29 & .3004 \\
\hline
\end{tabular}

an overall significant F-statistic justified post hoc paired comparisons using the student-Newman-Keuls procedure. Means with underlines were not significantly different at a $p<.05$ level of significance. 


\section{COPES Values Inventory (COPES)}

As described in the Method chapter, the 31 students completed the COPES Values Unit, consisting of 128 items defining eight work value scales. Each scale is a continuum from 0 points on the left to a maximum score of 16 points on the right; end-points of each scale are labeled with bipolar adjectives that define the trait on which the students rated themselves.

Table 17 includes the mean scores of the 31 students on the eight COPES scales, along with each mean's percentile on the national distribution of scores. The national mean, by definition, falls at the fiftieth percentile $\left(P_{50}\right)$. Sample means falling above $P_{55}$ or below $\mathrm{P}_{45}$ indicated scales on which the sample students differed, on average, from the national distribution.

The sample of 31 students resembled the national distribution on the dimensions of Flexibility-Orderliness $\left(P_{50}\right)$, Privacy-Recognition $\left(P_{52}\right)$, and Supportive-Leadership $\left(P_{46}\right)$. They showed progressively larger departures from the national means by favoring Independence over Conformity $\left(P_{57}\right)$, Reserved over Social $\left(P_{40}\right)$, Carefree over Practical $\left(P_{37}\right)$, Accepting over Investigative $\left(P_{36}\right)$, and Aesthetic over Realistic $\left(P_{82}\right)$.

The matrix in Table 18 shows correlations between the COPES work-values and the six Aptitude/Achievement/Experience variables and the seven Performance Variables on Nonroutine Math Problems. Of the 104 correlations (8 work-values scales x 13 variables), 11 were significant $(p<.05)$, which is about twice the number to be expected merely by chance $(.05 \times 104=5.2)$. The significant correlations had very distinct patterns: 10 of the 11 involved measures of general 
aptitude/achievement/experience (top section of Table 18); only one of them involved specific performance on the non-routine math problems (bottom section of Table 18). None of the significant correlations involved the COPES scales of Investigative-Accepting, Practical-Carefree, Leadership-Supportive, OrderlinessFlexibility, or Social-Reserved. Scores on the Aesthetic-Realistic scale and the Independence-Conformity scale positively correlated with the NWEA Language, Reading, and Mathematics scores, as well as the Math Skills Assessment scores; the closer students were to the Aesthetic side or the Independence side of their respective scales, the higher they tended to score on these four measures of aptitude/achievement/experience. Finally, scores on the Recognition-Privacy scale positively correlated with the NWEA Language and Mathematics scores, as well as the Number of Higher-Order Internal Representations used with the non-routine math problems; the closer students were to the Recognition side of the scale, the higher they tended to score on these measures. 
Table 17

Mean Scores of the 31 Students on the Eight COPES Values Scales Relative to National Percentiles ${ }^{b}$

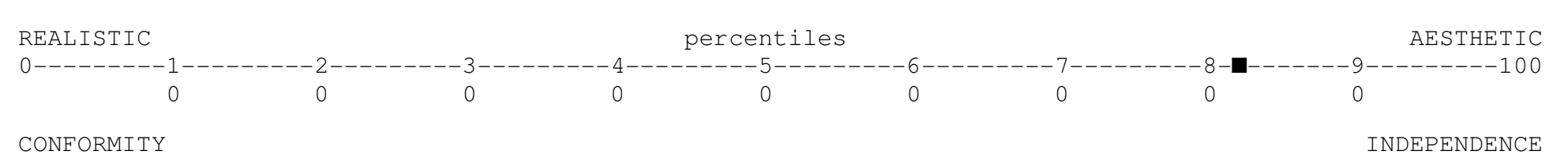

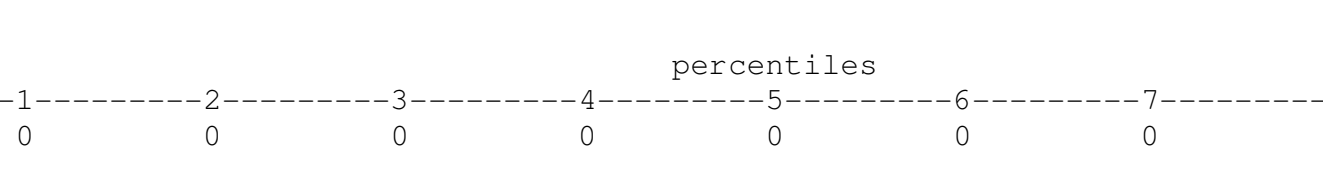
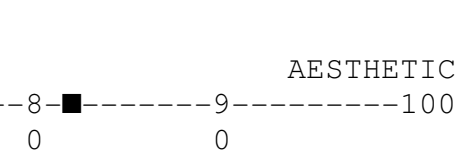

$M^{\mathrm{a}} \quad S D$

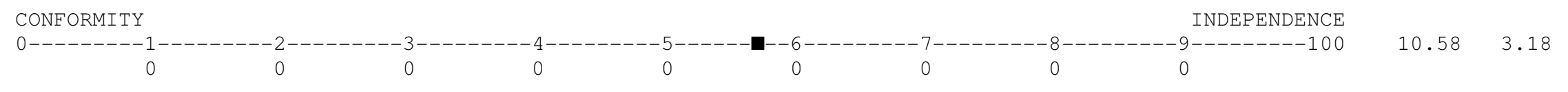

PRIVACY RECOGNITION

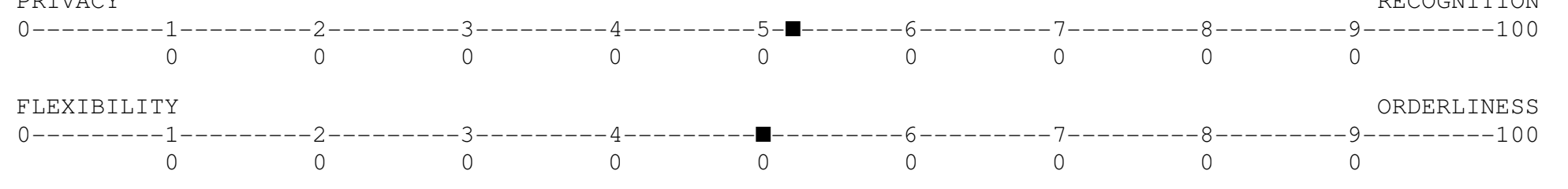

SUPPORTIVE
$0-------1--------2---------3---------4------$
0

LEADERSHIP

\section{RESERVED}

$\begin{array}{ccc}\text { RESERVED } & & \\ 0---------1---------2---------3------- & 0 \\ 0 & 0 & 0\end{array}$

-

$\begin{array}{ccc}6---------7--------8---------9---------100 \\ 0 & 0 & 0\end{array}$

3.45

CAREFREE

$0------1$

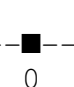

$6---------7-$

(2)

SOCIAL

0

0

0
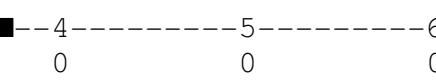

$-6-$
0

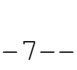

ACCEPTING

$0---------1---------2---------3---$

$-\mathbf{- 1 - -}$

$-5---------6$

INVESTIGATIVE
$6---------7---------8---------9--------100$

a Scores may range from 0 (full amount of the trait on the left; none of the trait on the right) to 8 (equal amounts of both traits) to 16 (full amount of the trait on the right; none of the trait on the left).

bstimated national percentiles were extrapolated from copsystem (2004). Because scores on the eight scales have different distributions, similar scores on different scales may have very different percentiles. 
Table 18

Correlations r between COPES Work-Values and Aptitude/Achievement/Experience Variables and Performance Variables on Nonroutine Problems $(N=31)$

\begin{tabular}{|c|c|c|c|c|c|c|c|c|c|}
\hline \multirow{2}{*}{\multicolumn{2}{|c|}{ Variable }} & \multicolumn{8}{|c|}{ COPES Work-Values Scales ${ }^{a}$} \\
\hline & & $\mathrm{A} I^{\mathrm{b}}$ & $\mathrm{BJ}^{\mathrm{C}}$ & $C K^{d}$ & $\mathrm{DL}^{\mathrm{e}}$ & $E M^{f}$ & $\mathrm{FN}^{\mathrm{g}}$ & $\mathrm{GO}^{\mathrm{h}}$ & $\mathrm{HP}^{\mathrm{i}}$ \\
\hline 1 & NWEA Mathematics Average RIT & $\begin{array}{c}.08 \\
(.6594)\end{array}$ & $\begin{array}{c}-.05 \\
(.8045)\end{array}$ & $\begin{array}{r}.49 \\
.0054\end{array}$ & $\begin{array}{c}.10 \\
(.5798)\end{array}$ & $\begin{array}{c}-.17 \\
(.3537)\end{array}$ & $\begin{array}{r}.38 \\
. .0368\end{array}$ & $\begin{array}{r}.52 \\
\bullet .0027\end{array}$ & $\begin{array}{c}.28 \\
(.1216)\end{array}$ \\
\hline 2 & NWEA Reading Average RIT & $\begin{array}{l}.03 \\
(.8771)\end{array}$ & $\begin{array}{c}-.24 \\
(.1857)\end{array}$ & $\begin{array}{l}.50 \\
.0040\end{array}$ & $(.03)$ & $\begin{array}{c}-.25 \\
(.1772)\end{array}$ & $\begin{array}{c}.26 \\
(.1561)\end{array}$ & $\begin{array}{l}.56 \\
.0011\end{array}$ & $\begin{array}{c}.27 \\
(.1456)\end{array}$ \\
\hline 3 & NWEA Language Usage Average RIT & $\begin{array}{c}-.02 \\
(.9084)\end{array}$ & $\begin{array}{c}-.22 \\
(.2355)\end{array}$ & $\begin{array}{l}.51 \\
. .0037\end{array}$ & $\begin{array}{c}.06 \\
(.7478)\end{array}$ & $\begin{array}{c}-.15 \\
(.4278)\end{array}$ & $\begin{array}{r}.38 \\
. .0333\end{array}$ & $\begin{array}{l}.58 \\
.0006\end{array}$ & $\begin{array}{c}.21 \\
(.2481)\end{array}$ \\
\hline 4 & Math Skills Assessment & $\begin{array}{c}-.14 \\
(.4576)\end{array}$ & $\begin{array}{c}-.03 \\
(.8802)\end{array}$ & $\begin{array}{l}.39 \\
.0307\end{array}$ & $\begin{array}{c}.27 \\
(.1360)\end{array}$ & $\begin{array}{c}-.24 \\
(.1946)\end{array}$ & $(.0542)$ & $\begin{array}{l}.40 \\
. .0251\end{array}$ & $\begin{array}{c}.21 \\
(.2681)\end{array}$ \\
\hline 5 & $\begin{array}{l}\text { My Math Experiences Essay Rubric } \\
\text { Score }\end{array}$ & $\begin{array}{l}.06 \\
(.7601)\end{array}$ & $\begin{array}{l}.07 \\
(.7211)\end{array}$ & $\begin{array}{l}.20 \\
(.2765)\end{array}$ & $\begin{array}{c}-.11 \\
(.5610)\end{array}$ & $\begin{array}{c}.15 \\
(.4240)\end{array}$ & $\begin{array}{l}.24 \\
(.1884)\end{array}$ & $\begin{array}{l}.29 \\
(.1170)\end{array}$ & $\begin{array}{c}.12 \\
(.5273)\end{array}$ \\
\hline 6 & $\begin{array}{l}\text { My Math Experiences Essay Total } \\
\text { Word Count }\end{array}$ & $\begin{array}{l}.00 \\
(.9821) \\
\end{array}$ & $\begin{array}{c}.10 \\
(.6103) \\
\end{array}$ & $\begin{array}{c}.21 \\
(.2658) \\
\end{array}$ & $\begin{array}{c}.15 \\
(.4221) \\
\end{array}$ & $\begin{array}{c}.12 \\
(.5362) \\
\end{array}$ & $\begin{array}{l}.33 \\
(.0736) \\
\end{array}$ & $\begin{array}{l}.31 \\
(.0871) \\
\end{array}$ & $\begin{array}{l}-.00 \\
(.9978) \\
\end{array}$ \\
\hline 1 & Understanding Scale Score & $\begin{array}{c}.06 \\
(.7509)\end{array}$ & $\begin{array}{c}-.23 \\
(.2117)\end{array}$ & $\begin{array}{c}.07 \\
(.6914)\end{array}$ & $\begin{array}{c}-.13 \\
(.4922)\end{array}$ & $\begin{array}{c}-.11 \\
(.5419)\end{array}$ & $\begin{array}{c}.26 \\
(.1544)\end{array}$ & $\begin{array}{c}.18 \\
(.3454)\end{array}$ & $\begin{array}{c}.12 \\
(.5344)\end{array}$ \\
\hline 2 & How One Solved It scale score & $\begin{array}{c}-.04 \\
(.8487)\end{array}$ & $\begin{array}{c}-.15 \\
(.4159)\end{array}$ & $\begin{array}{c}.10 \\
(.5933)\end{array}$ & $\begin{array}{c}-.11 \\
(.5663)\end{array}$ & $\begin{array}{c}-.10 \\
(.5994)\end{array}$ & $\begin{array}{c}.22 \\
(.2247)\end{array}$ & $\begin{array}{c}.18 \\
(.3327)\end{array}$ & $\begin{array}{c}.01 \\
(.9543)\end{array}$ \\
\hline 3 & Decisions Made Scale Score & $\begin{array}{c}.14 \\
(.4623)\end{array}$ & $\begin{array}{c}-.13 \\
(.4970)\end{array}$ & $\begin{array}{c}.04 \\
(.8165)\end{array}$ & $\begin{array}{c}-.02 \\
(.9238)\end{array}$ & $\begin{array}{c}-.04 \\
(.8102)\end{array}$ & $\begin{array}{c}.24 \\
(.1973)\end{array}$ & $\begin{array}{c}.07 \\
(.6972)\end{array}$ & $\begin{array}{c}.16 \\
(.4044)\end{array}$ \\
\hline 4 & Getting Answer scale Score & $\begin{array}{c}.09 \\
(.6168)\end{array}$ & $\begin{array}{c}-.24 \\
(.1943)\end{array}$ & $\begin{array}{c}.18 \\
(.3251)\end{array}$ & $\begin{array}{c}-.00 \\
(.9946)\end{array}$ & $\begin{array}{c}-.16 \\
(.0708)\end{array}$ & $\begin{array}{c}.33 \\
(.0708)\end{array}$ & $\begin{array}{c}.20 \\
(.2740)\end{array}$ & $\begin{array}{c}.15 \\
(.4101)\end{array}$ \\
\hline 5 & $\begin{array}{l}\text { Problem-Solving Total Rubric } \\
\text { Score }\end{array}$ & $\begin{array}{l}.06 \\
(.7310)\end{array}$ & $\begin{array}{c}-.19 \\
(.2982)\end{array}$ & $\begin{array}{l}.10 \\
(.5748)\end{array}$ & $\begin{array}{c}-.07 \\
(.7275)\end{array}$ & $\begin{array}{c}-.11 \\
(.5645)\end{array}$ & $\begin{array}{l}.27 \\
(.1376)\end{array}$ & $\begin{array}{c}.16 \\
(.3781)\end{array}$ & $\begin{array}{c}.11 \\
(.5515)\end{array}$ \\
\hline 6 & Problem Average Word Count & $\begin{array}{c}.21 \\
(.2474)\end{array}$ & $(.07210)$ & $\begin{array}{l}-.24 \\
(.1843)\end{array}$ & $\begin{array}{l}-.33 \\
(.0699)\end{array}$ & $(.177$ & $\begin{array}{c}-.11 \\
(.5518)\end{array}$ & $\begin{array}{c}-.16 \\
(.3778)\end{array}$ & $\begin{array}{c}.13 \\
(.4739)\end{array}$ \\
\hline 7 & $\begin{array}{l}\text { Number of Higher-Order } \\
\text { Representations }\end{array}$ & $\begin{array}{c}-.12 \\
(.5114)\end{array}$ & $\begin{array}{c}-.22 \\
(.2449)\end{array}$ & $(.0789)$ & $\begin{array}{c}.09 \\
(.6256)\end{array}$ & $\begin{array}{c}-.25 \\
(.1688)\end{array}$ & $\begin{array}{r}.38 \\
. .0328\end{array}$ & $\begin{array}{c}.30 \\
(.0993)\end{array}$ & $\begin{array}{c}-.03 \\
(.8533)\end{array}$ \\
\hline
\end{tabular}


ar-values are shown followed by p-values in parenthesis. $p$ indicates significance at the .05 level.

${ }^{\mathrm{b}} \mathrm{AI}=$ Accepting-Investigative Scale. Accepting individuals value clear-cut activities in which they see the concrete results of their work and do not need to solve many complex problems. Investigative individuals value intellectual curiosity and the challenge of solving complex tasks.

${ }^{C_{B J}}=$ Carefree-Practical Scale. Carefree individuals value activities where they can be carefree and use their imaginations. Practical individuals value proper appreciation of one's belongings and practical, efficient ways of doing things

${ }^{d} \mathrm{CK}=$ Conformity-Independence Scale. Conforming individuals value working under careful supervision, where clear directions and regulations can be followed. Independent individuals value the freedom to work on their own, independent of regulations and social conventions.

${ }^{e} \mathrm{DL}=$ Supportive-Leadership Scale. Supportive individuals value activities in which they can be good followers and do not need to direct or instruct others. Leadership individuals value opportunities to make decisions, to direct others, and to speak for the group.

$\mathrm{f}_{\mathrm{EM}}=$ Flexibility-Orderliness Scale. Flexible individuals value activities where they can take things as they come, without being constrained by rigid plans. Orderly individuals value organization, keeping things neat and in their proper place.

${ }^{g}$ FN $=$ Privacy-Recognition Scale. Private individuals value keeping their activities quiet and shun fame. Recognition individuals seek fame and contact with important people.

$\mathrm{h}_{\mathrm{GO}}=$ Realistic-Aesthetic Scale. Realistic individuals value activities that focus on objective reality. Aesthetic individuals prefer to focus on subjective involvement with, and appreciation of, artistic aspects of the world

${ }^{i} \mathrm{HP}=$ Reserved-Social Scale. Reserved individuals value spending time on their own projects and tending to their own affairs. Social individuals value working with and helping others. 
Exploring Students' Career Interests using the COPS Interest Inventory

As described in the Method chapter, The COPS Interest Inventory

(COPSystem, 2004) was selected to explore two questions about students' career interests:

1. What were the career interests of the sample as a whole $(N=31)$ ?

2. Were career interests of the 17 girls and the 14 boys similar or different, especially in areas considered more math intensive, such as scientific and technical fields?

The COPS Interest Inventory consists of 168 features of 14 occupational groups (12 features for each group). Students rated each feature on a 0-to-3 point scale, with the mean score on the 12 features of an occupational group (from 0 to 36 points) indicating how much a student liked/disliked that group (the higher the score, the more favorable the student's opinion).

Table 19 lists the 14 major occupational groups in descending order of the 31 students' mean scores. The Professional and Skilled Arts groups had the two highest levels of interest. This is not surprising at Beacon Charter High School for the Arts. 
Table 19

Students' $(N=31)$ Mean Scores for Major

Occupational Groups

\begin{tabular}{|c|c|c|c|}
\hline & Occupational Group & $M$ & $S D$ \\
\hline 1 & Arts, Professional ${ }^{1}$ & 16.323 & 8.264 \\
\hline 2 & Arts, Skilled ${ }^{2}$ & 15.129 & 9.182 \\
\hline 3 & Service, Professional ${ }^{1}$ & 13.567 & 9.194 \\
\hline 4 & Consumer Economics & 12.516 & 7.070 \\
\hline 5 & Service, Skilled ${ }^{2}$ & 10.800 & 8.422 \\
\hline 6 & Technical, Professional ${ }^{1}$ & 10.452 & 8.778 \\
\hline 7 & Business, Skilled ${ }^{2}$ & 10.419 & 7.741 \\
\hline 8 & Outdoor & 9.935 & 9.128 \\
\hline 9 & Technical, Skilled ${ }^{2}$ & 9.871 & 9.465 \\
\hline 10 & Communication & 9.258 & 8.250 \\
\hline 11 & Science, Professional ${ }^{1}$ & 9.065 & 7.945 \\
\hline 12 & Business, Professional ${ }^{1}$ & 8.194 & 7.195 \\
\hline 13 & Clerical & 8.065 & 8.286 \\
\hline 14 & Science, Skilled ${ }^{2}$ & 6.677 & 6.901 \\
\hline
\end{tabular}

1 "...professional [italics added] occupations, usually those requiring college training and often advanced degrees..." (COPSystem, 2004, p. 1).

2 "...skilled [italics added] occupations requiring vocational or on-the-job training in which a college degree may not be required for acceptance" (COPSystem, 2004, p. 1). 


\section{Occupational group interest by gender.}

Table 20 shows $t$-tests comparing interest levels of the 17 girls and the 14 boys in the sample: 10 occupational groups where boys showed more interest than girls, followed by the four occupational groups where girls showed more interest than boys. Within each set, the comparisons are listed from highest to lowest $t$-statistic.

Girls were not significantly higher on any of the comparisons. Boys showed significantly higher interest in the Technical-Skilled, Science-Professional, TechnicalProfessional, Science-Skilled, and Business-Professional occupations. For the girls' 14 means and the boys' 14 means, Table 20 includes the gender-specific national percentile scores. On average, boys were at the 48th percentile and girls were at the 32nd. Boys had higher national percentiles on 13 of the 14 occupational groups (girls were slightly higher on Service-Skilled occupations). 
Table 20

Students' Mean Scores and National Percentiles for Major occupational Groups by Gender

\begin{tabular}{|c|c|c|c|c|c|c|c|c|c|}
\hline & $\begin{array}{l}\text { Occupational } \\
\text { Group }\end{array}$ & $\begin{array}{l}\text { Gir } \\
M\end{array}$ & $\begin{array}{c}\text { 1s } \quad(n= \\
S D\end{array}$ & $\begin{array}{l}\text { 17) } \\
P^{a}\end{array}$ & $\begin{array}{l}\text { Boy } \\
M\end{array}$ & $\begin{array}{c}S \quad(n= \\
S D\end{array}$ & $P^{a}$ & $\begin{array}{l}(N= \\
t\end{array}$ & $\begin{array}{r}31) \\
p\end{array}$ \\
\hline 1 & $\begin{array}{l}\text { Technical, } \\
\text { Skilled }\end{array}$ & 4.53 & 13.78 & 35 & 16.36 & 10.32 & 56 & 4.07 & .0009 \\
\hline 2 & $\begin{array}{l}\text { Science, } \\
\text { Professional }\end{array}$ & 4.82 & 4.07 & 13 & 14.21 & 8.56 & 48 & 3.77 & .0014 \\
\hline 3 & $\begin{array}{l}\text { Technical, } \\
\text { Professional }\end{array}$ & 6.35 & 5.44 & 23 & 15.43 & 9.63 & 35 & 3.14 & .0053 \\
\hline 4 & $\begin{array}{l}\text { Science, } \\
\text { Skilled }\end{array}$ & 4.06 & 5.01 & 19 & 9.86 & 7.70 & 46 & 2.53 & .0171 \\
\hline 5 & $\begin{array}{l}\text { Business, } \\
\text { Professional }\end{array}$ & 5.59 & 5.05 & 11 & 11.36 & 8.27 & 27 & 2.39 & .0236 \\
\hline 6 & Clerical & 5.47 & 6.77 & 14 & 11.21 & 9.09 & 47 & 2.02 & .0531 \\
\hline 7 & Outdoor & 7.71 & 7.46 & 39 & 12.64 & 10.46 & 60 & 1.53 & .1364 \\
\hline 8 & $\begin{array}{l}\text { Consumer } \\
\text { Economics }\end{array}$ & 11.53 & 6.63 & 48 & 13.71 & 7.64 & 70 & .85 & .4010 \\
\hline 9 & $\begin{array}{l}\text { Business, } \\
\text { Skilled }\end{array}$ & 9.41 & 7.48 & 45 & 11.64 & 8.16 & 48 & .79 & .4338 \\
\hline 10 & $\begin{array}{l}\text { Commun- } \\
\text { ication }\end{array}$ & 9.12 & 8.75 & 30 & 9.43 & 7.93 & 42 & .10 & .9189 \\
\hline 1 & $\begin{array}{l}\text { Service, } \\
\text { Professional }\end{array}$ & 15.88 & 9.80 & 37 & 10.54 & 7.66 & 42 & 1.62 & .1162 \\
\hline 2 & $\begin{array}{l}\text { Arts, } \\
\text { Skilled }\end{array}$ & 16.65 & 9.92 & 53 & 13.29 & 8.18 & 62 & 1.01 & .3186 \\
\hline 3 & $\begin{array}{l}\text { Arts, } \\
\text { Professional }\end{array}$ & 16.71 & 8.21 & 43 & 15.86 & 8.62 & 45 & .28 & .7813 \\
\hline 4 & $\begin{array}{l}\text { Service, } \\
\text { Skilled }\end{array}$ & 11.12 & 6.87 & 46 & 10.39 & 10.40 & 45 & .23 & .8179 \\
\hline $\mathrm{C}$ & nn Mea & 9.21 & 6.80 & 32 & 12.57 & 8.76 & 48 & & \\
\hline
\end{tabular}

${ }^{a}$ National percentiles extrapolated from Copsystem (2004) 
Problem Preference and Problem-Solving Achievement

Three questions were the focus of the following analyses:

1. Given the six nonroutine math problems in this study, how do students rank these problems from "like the most" to "like the least" and why?

2. How does liking or disliking a problem relate to students' achievement in solving the problem?

3. How does liking or disliking a problem relate to students' engagement in solving the problem?

As described in the Method chapter, the 31 students completed six nonroutine math problems: (a) Count Your Coins; (b) Lost in the Auditorium; (c) Birthday Money; (d) What's in My Future? (e) How Many Children Live Next Door? and (f) Blind

Sided.

After administering all six problems, and prior to any disclosure of methods for solving the problems or solutions to the problems, students were asked to rank the six problems from "1" (liked the most) to "6" (liked the least) and to provide reasons for their decisions. Furthermore, a word count was determined for each problem as a means of quantifying student engagement with the problem. 
Table 21 shows a distribution of students' rankings of the six nonroutine math problems in descending order of preference. "Lost in the Auditorium" and "Count Your Coins" were ranked first or second by a majority of the students.

\begin{tabular}{|c|c|c|c|c|c|c|c|}
\hline Preference & Ranking & of the & Six & Nonroutine & Math & Problems & $(N=31)$ \\
\hline & $\begin{array}{c}\text { Liked } \\
\text { the } \\
\text { Most }\end{array}$ & & $\leftarrow$ & Choice $\longrightarrow$ & & $\begin{array}{c}\text { Liked } \\
\text { the } \\
\text { Least }\end{array}$ & $\begin{array}{r}\text { Mean } \\
\text { Choice }\end{array}$ \\
\hline & 1 & 2 & 3 & 4 & 5 & 6 & \\
\hline $\begin{array}{l}\text { Lost in the } \\
\text { Auditorium }\end{array}$ & 5 & 13 & 7 & 3 & 1 & 2 & 2.61 \\
\hline $\begin{array}{l}\text { Count Your } \\
\text { Coins }\end{array}$ & 14 & 3 & 4 & 4 & 2 & 4 & 2.65 \\
\hline $\begin{array}{l}\text { Birthday } \\
\text { Money }\end{array}$ & 7 & 6 & 7 & 4 & 4 & 3 & 3.03 \\
\hline $\begin{array}{l}\text { What's in } \\
\text { My Future }\end{array}$ & 2 & 4 & 4 & 12 & 4 & 5 & 3.87 \\
\hline Blind Sided & 1 & 4 & 5 & 6 & 8 & 7 & 4.19 \\
\hline $\begin{array}{l}\text { How Many } \\
\text { Children }\end{array}$ & 2 & 1 & 4 & 2 & 12 & 10 & 4.65 \\
\hline
\end{tabular}

Students' performance on the 186 problems (6 problems x 31 students) was compared to their ranked preferences of the problems.

In order to assess linearity and/or evidence of curvilinearity, scatterplots of the two variables with regression lines were generated using $\mathrm{SAS}^{\circledR}$ statistical software.

Both of the scatterplots (plotted as $\mathrm{A} * \mathrm{~B}$ and $\mathrm{B} * \mathrm{~A}$ ) showed no compelling evidence of curvilinearity. Accordingly, the Pearson $r$ correlation was an appropriate 
measure of the relationship between preference and performance. There was a significant, nearly moderate, positive linear relationship between students' preference and their problem-solving performance, $r(184)=-.377, p<.0001$. (The negative $r$ value occurs because a lower rank means higher preference).

Table 22 shows the mean problem-solving rubric score for the students' first through sixth preferences of problems.

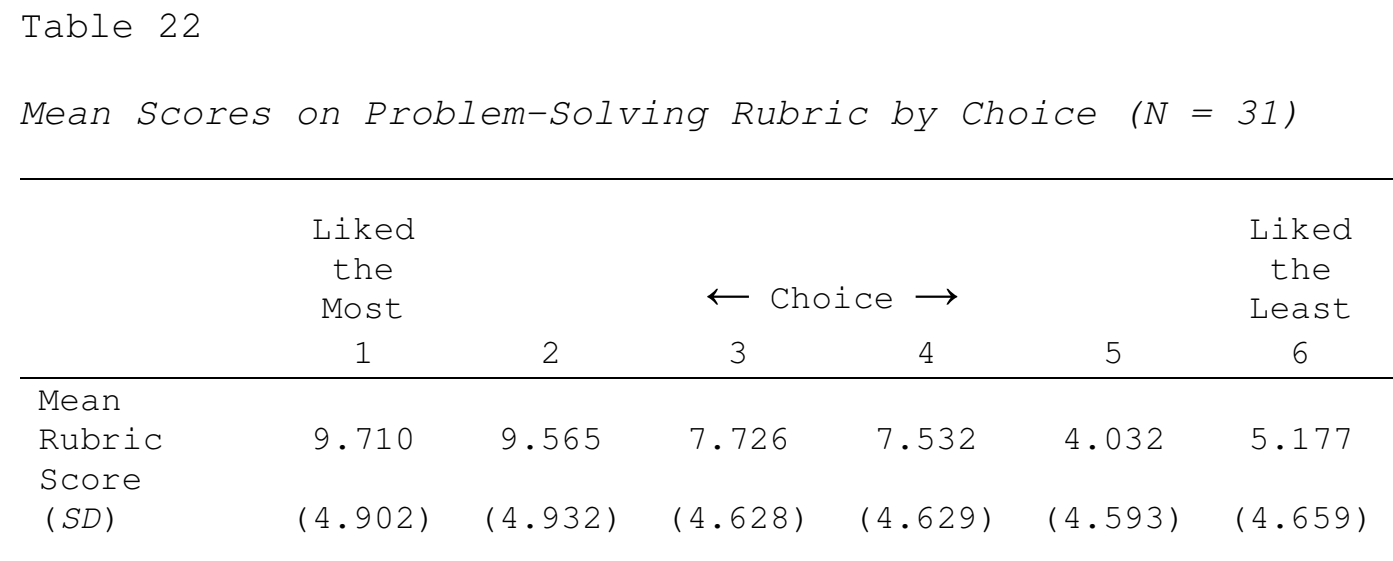

Except for the mean rubric score on Choice 6, the pattern suggests that the more students liked a problem, the higher was their problem-solving performance.

For each of the six nonroutine math problems, a separate Pearson $r$ correlation was calculated between a given student's ranking of the problem (1 to 6) and their rubric score on that problem. Table 23 shows the $r$-values in descending order.

The "Lost in the Auditorium" problem was trend-level significant $(p=.0793)$ $(.05 \leq p<.10)$; however, the five other nonroutine problems had no significant findings. 


\begin{tabular}{|c|c|c|}
\hline \multirow[b]{2}{*}{ Problem } & \multicolumn{2}{|c|}{$N=31$} \\
\hline & $r$ & $p$ \\
\hline Lost in the Auditorium & -.32 & .0793 \\
\hline Birthday Money & -.22 & .2290 \\
\hline How Many Children & -.18 & .3220 \\
\hline Blind Sided & -.10 & .5834 \\
\hline Count Your Coins & -.06 & .7343 \\
\hline What's in My Future & -.03 & .8716 \\
\hline
\end{tabular}

Table 24 shows the mean preference score and mean problem-solving score on each of the six nonroutine math problems. Except for the mean values reported as Choice 1 and Choice 2, this pattern once again suggests that, the more students liked a problem, the higher was their problem-solving performance. 


\begin{tabular}{|c|c|c|}
\hline \multicolumn{3}{|c|}{$\begin{array}{l}\text { The six nonroutine problems arranged by students' } \\
(N=31) \text { ranked choice }(1=\text { first choice,..., } 6=\text { si } \\
\text { choice) }\end{array}$} \\
\hline Problem & $\begin{array}{l}\text { Mean } \\
\text { Ranked } \\
\text { Choice }\end{array}$ & $\begin{array}{l}\text { Mean Rubric } \\
\text { Score for the } \\
\text { Given Problem, } \\
(S D)\end{array}$ \\
\hline $\begin{array}{l}\text { Lost in the } \\
\text { Auditorium }\end{array}$ & 2.61 & $\begin{array}{l}10.258 \\
(4.835)\end{array}$ \\
\hline Count Your Coins & 2.65 & $\begin{array}{l}10.823 \\
(2.676)\end{array}$ \\
\hline Birthday Money & 3.03 & $\begin{array}{l}9.274 \\
(4.129)\end{array}$ \\
\hline $\begin{array}{l}\text { What's in My } \\
\text { Future }\end{array}$ & 3.87 & $\begin{array}{l}5.581 \\
(4.751)\end{array}$ \\
\hline Blind Sided & 4.19 & $\begin{array}{l}5.355 \\
(4.233)\end{array}$ \\
\hline How Many Children & 4.65 & $\begin{array}{c}2.452 \\
(4.003)\end{array}$ \\
\hline
\end{tabular}


Narrative Data on Students' Preferences among Six Nonroutine Problems

To investigate the aesthetic nature of students' preferences among the six nonroutine problems, I performed a Content Analysis on the 31 students' questionnaires.

The method of analysis involved combining the narrative responses for students' Choice 1 and Choice 2 problems and sieving for positive reported characteristics/reasons, then combining the narrative responses for students' Choice 5 and Choice 6 problems and sieving for negative reported characteristics/reasons.

By focusing on each student's top two and bottom two problems (and ignoring the middle two), I tried to highlight the distinguishing features of "liked" and "disliked" problems. Table 25 summarizes the qualitative data on positive and negative features of liked and disliked problems, respectively. 
Table 25

Students' Narrative Aesthetic Characteristics

(data from the Aesthetic Ranking Questionnaire)

\begin{tabular}{|c|c|c|c|c|}
\hline Themes & $\begin{array}{l}\text { Aest } \\
\quad \text { (Choices } \\
\text { Positive } \\
\text { words/ } \\
\text { phrases } \\
\text { (frequency) } \\
\end{array}$ & $\begin{array}{l}\text { etic Charact } \\
1 \text { and } 2)^{a} \\
\text { Number of } \\
\text { students } \\
\text { (percentage) } \\
\end{array}$ & $\begin{array}{l}\text { ristics } \\
\quad \text { (Choices } \\
\text { Negative } \\
\text { words/ } \\
\text { phrase } \\
\text { frequency) }\end{array}$ & $\begin{array}{l}\text { and } 6)^{\mathrm{b}} \\
\text { Number of } \\
\text { students } \\
\text { (percentage) }\end{array}$ \\
\hline $\begin{array}{l}\text { Overall } \\
\text { level of } \\
\text { difficulty }\end{array}$ & $\begin{array}{l}\text { easy }(21) ; \\
\operatorname{basic}(1)\end{array}$ & $\begin{array}{c}22 / 31 \\
(71.0 \%)\end{array}$ & $\begin{array}{l}\text { hard (3); } \\
\text { difficult (2); } \\
\text { impossible } \\
(1) ;\end{array}$ & $\begin{array}{c}6 / 31 \\
(19.4 \%)\end{array}$ \\
\hline $\begin{array}{l}\text { Source of } \\
\text { Difficulty }\end{array}$ & $\begin{array}{l}\text { somewhat } \\
\text { challenging } \\
\text { (3); } \\
\text { understand- } \\
\text { able (3); } \\
\text { made me } \\
\text { think (1); } \\
\text { made sense } \\
\text { (1) }\end{array}$ & $\begin{array}{c}8 / 31 \\
(25.8 \%)\end{array}$ & $\begin{array}{l}\text { confusing (7); } \\
\text { no numbers (5) } \\
\text {; } \\
\text { made no sense } \\
\text { (2); not } \\
\text { understandable } \\
(1) ; \\
\text { too many } \\
\text { numbers (1); } \\
\text { too many steps } \\
(1) ; \\
\text { too many words } \\
(1)\end{array}$ & $\begin{array}{l}18 / 31 \\
(58.1 \%)\end{array}$ \\
\hline $\begin{array}{l}\text { Overall } \\
\text { Feelings }\end{array}$ & $\begin{array}{l}\text { like }(6) ; \\
\text { enjoy }(2) ; \\
\text { love }(1)\end{array}$ & $\begin{array}{c}9 / 31 \\
(29.0 \%)\end{array}$ & $\begin{array}{l}\text { hate (5); } \\
\text { dislike (1); }\end{array}$ & $\begin{array}{l}6 / 31 \\
(19.4 \%)\end{array}$ \\
\hline $\begin{array}{l}\text { Sources of } \\
\text { Feelings }\end{array}$ & $\begin{array}{l}\text { fun (5); } \\
\text { interesting } \\
\text { (1); } \\
\text { Okay (1) }\end{array}$ & $\begin{array}{c}7 / 31 \\
(22.6 \%)\end{array}$ & $\begin{array}{l}\text { annoying (2); } \\
\text { boring (2); } \\
\text { blah (1); } \\
\text { dumb (1); } \\
\text { frustrating } \\
\text { (1); } \\
\text { not fun (1); } \\
\text { sucked (1); } \\
\text { uninteresting } \\
(1)\end{array}$ & $\begin{array}{c}10 / 31 \\
(32.3 \%)\end{array}$ \\
\hline
\end{tabular}

${ }^{a}$ Choices 1 or 2: Lost in the Auditorium (18); Count You Coins (17); Birthday Money (13); What's in My Future? (6); Blind Sided (5); How Many Children? (3).

${ }^{\mathrm{b}}$ Choices 5 or 6: How Many Children? (22); Blind Sided (15); What's in My Future? (9); Birthday Money (7); Count You Coins (6); Lost in the Auditorium (3); 
From Table 25, "easy" was the most frequently used positive term used by students to describe their first or second choice problems. A more thorough study of all 186 responses (31 students x 6 responses) for the six nonroutine problems revealed that $20.4 \%(38 / 186)$ of the responses contained the term "easy." A check of the 38 "easy" responses, across the six problems, revealed that only $23.7 \%(9 / 38)$ of the students who thought the particular problem was easy actually got the correct answer.

The content analysis of the students' narratives revealed other patterns. On the last preferred problem (“How Many Children Live Next Door?”), 19\% (6/31) of students noted that the problem was hard, made no sense, and/or was confusing because there were no numbers in the wording of the problem statement.

In regards to the "Count Your Coins" problem, one student reported that it would have been easier to solve the problem if "I had something physical." In regards to the "Blind Sided" problem (which dealt with a picture of a cube presented as three different views) one student stated "I hate not having the actual block." Another student on the same problem stated "I made a model..." 
Measuring the Relationship between Students' Engagement and Achievement in Their Choice of Problem

An analysis was done to determine if there was a relationship between students' relative preference for a problem and their engagement with that problem. The measure of engagement was based on a word count of the specific problem based on the premise that students' propensity to write about solving a problem, in a voluntary situation with no time or length restrictions, is an indicator of their engagement with the problem.

In order to assess linearity and/or evidence of curvilinearity, the two variables students' problem preference rankings and their Problem-Solving Rubric Score were plotted with regression lines using $\mathrm{SAS}^{\circledR}$ statistical software.

Both of the scatterplots (plotted as $\mathrm{A} * \mathrm{~B}$ and $\mathrm{B} * \mathrm{~A}$ ) showed no compelling evidence of curvilinearity. Accordingly, the Pearson $r$ correlation was calculated. The results revealed a weak, but nearly significant positive linear relationship between students' ranking of a problem and the number of words written by the students for that problem, $r(184)=-.143, p=0.0513$ (the negative $r$ value occurs because a lower rank means higher preference).

Table 26 shows the mean number of words that students wrote for each of the six problems across the six levels of choice. 


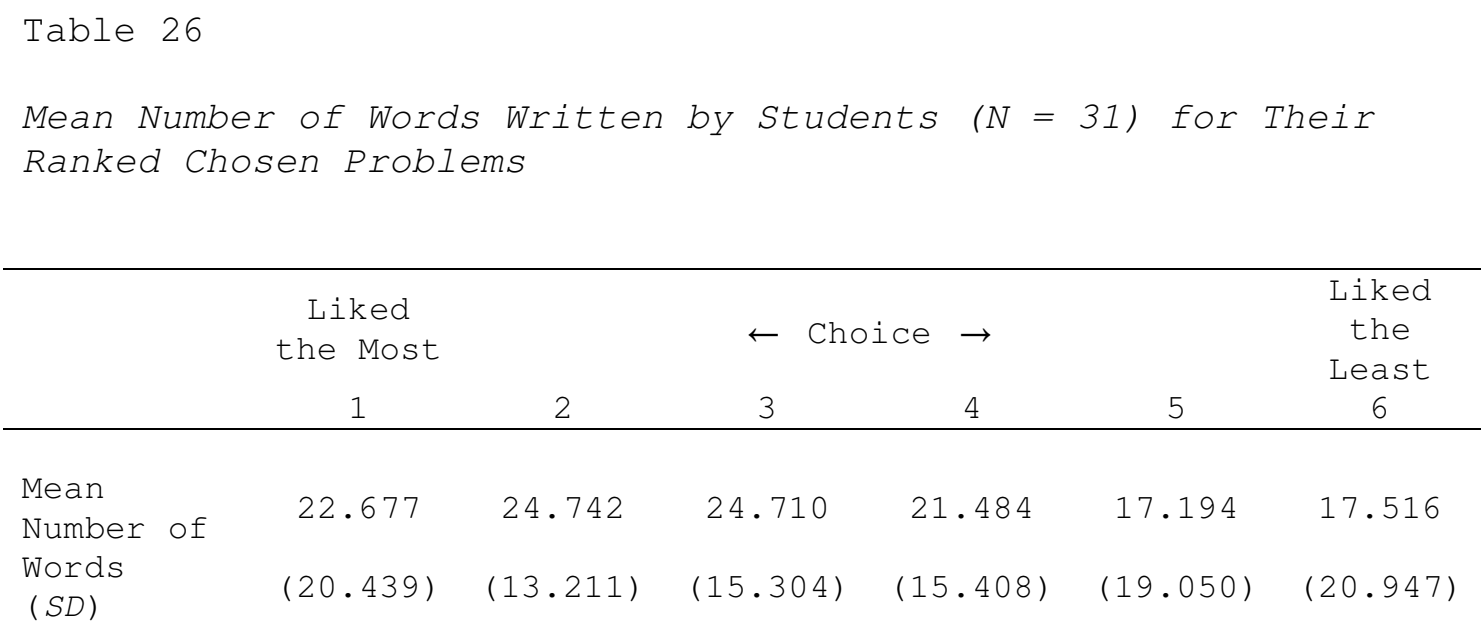

Although the means do not consistently decline across the six levels of preference, the top three choices all have higher means than the bottom three choices. This pattern, shown graphically in Figure 4, is consistent with the weak Pearson $r$ correlation determined from the scatterplot, between students' ranking of a problem and the number of words written by the students for that problem, previously discussed. 


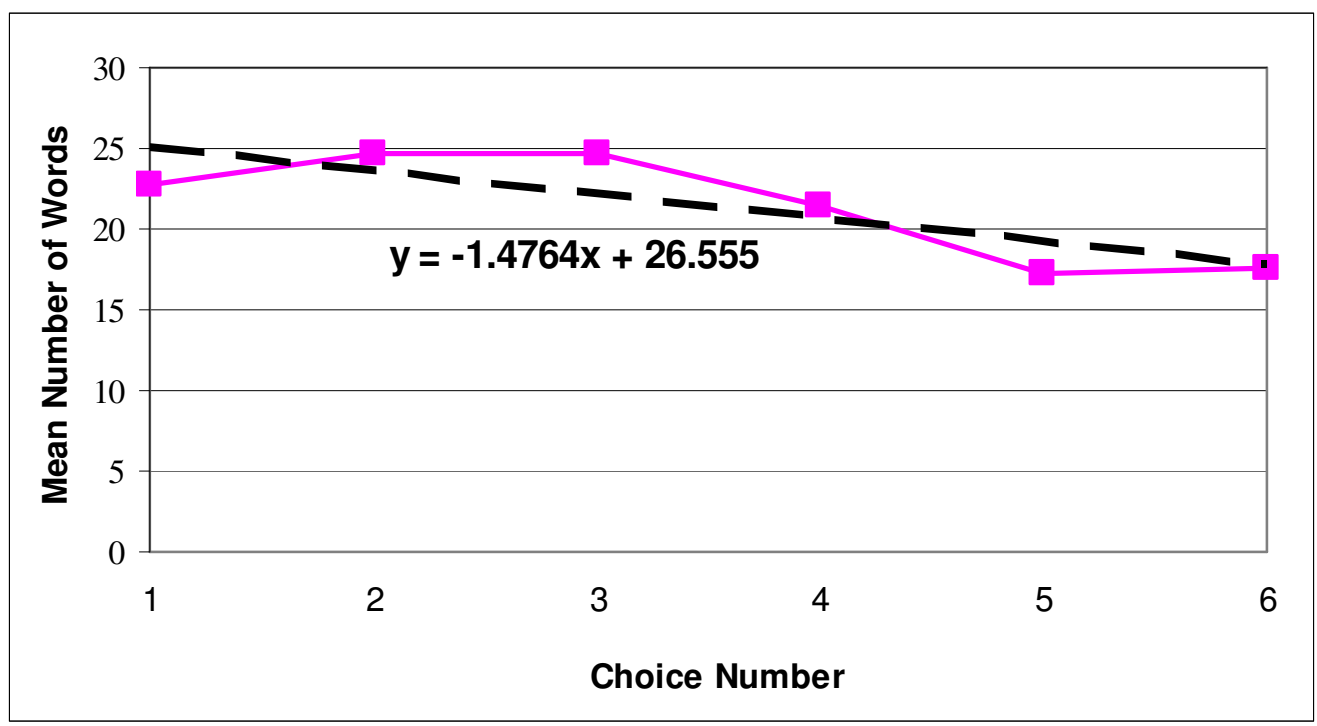

Figure 4. Mean number of words vs. students' problem choice. The dashed line represents the "Line-of-best-fit" for the plotted data. The equation of the line appears below the line. 
Performance Comparisons between Levels of Higher-Order

Representation (HOIR)

As described in the Method chapter, one focus of this study pertained to the types and frequency of representation students employed in solving the six nonroutine math problems. Of primary interest were instances of higher-order internal representation (HOIR). An example of HOIR in the Count Your Coins problem was a systematic listing of combinations in ascending or descending order by coin value exhausting all combinations of each value before continuing to the next coin value, (i.e., in order by quarters, dimes, nickels, then pennies; or, the reverse order of pennies, nickels, dimes, and quarters). Table 27 shows examples of HOIR for all six nonroutine problems.

During the analyses, three levels of higher-order internal representation (HOIR) emerged. Of the 31 students in the study, seven had two or more instances of HOIR, 10 had exactly one instance of HOIR, and 14 had no instances of HOIR. Table 28 shows one-way ANOVAs comparing students in the three HOIRlevels on the six Aptitude/Achievement/Experience variables and six of the seven Performance on Nonroutine Math Problems. The seventh variable, Number of HigherOrder Internal Representations, is inherently significant due to the manner of partitioning students into three discrete groups (i.e., levels of HOIR). Within each set of analyses, Table 28 lists them from highest to lowest $F$-statistic. 
Table 27

Examples of Higher-Order Internal Representations (HOIR)

Problem Example of a HOIR

Lost in Drew a model of eight doors and associated each

the door with 7 possible paths, without drawing or

Auditorium stating all paths, writing the algebraic equation: $8 \times 7=56$ ways

Count your (ascending or descending coin value) by exhausting Coins all possibilities of a specific coin value then moving to the next sequential value.

Stated that the sister is correct because there Birthday are two sequences possible; and specifically Money listed members of both sequences (or described the
formation of the sequences), that satisfy the conditions of the problem statement.

What's in

Specifically stated that the total number of My Future? squares in each step can be modeled by the generalized algebraic expression $x(x+1)$ where $x$ is the number of rows and $(x+1)$ is the number of columns; or the distributed equivalent: $x^{2}+x$.

Blind Drew or constructed a correctly labeled 3-D model Sided or diagram simulating 3-D imaging.

How Many Children Live Next Door?
Drew a correctly labeled model showing four boys and three girls; and as a check: restated the two conditions satisfied; or stated four boys and three girls; and as a check: restated the two conditions. 
Table 28

Aptitude/Achievement/Experience and Problem-Solving Comparisons between Levels of Higher-Order Internal Representation

\begin{tabular}{|c|c|c|c|c|c|c|c|c|c|}
\hline & \multirow{3}{*}{$\begin{array}{l}\text { Aptitude/Achievement and } \\
\text { Problem-Solving Variables }\end{array}$} & \multirow{2}{*}{\multicolumn{2}{|c|}{$\begin{array}{c}\text { HOIR } \geq 2 \\
n=7\end{array}$}} & \multirow{2}{*}{\multicolumn{2}{|c|}{$\begin{array}{c}\text { HOIR }=1 \\
n=10\end{array}$}} & \multirow{2}{*}{\multicolumn{2}{|c|}{$\begin{array}{l}\text { OIR }=0 \\
n=14\end{array}$}} & \multirow{2}{*}{\multicolumn{2}{|c|}{$N=31$}} \\
\hline & & & & & & & & & \\
\hline & & $M$ & $S D$ & $M$ & $S D$ & $M$ & $S D$ & $F$ & $p$ \\
\hline 1 & NWEA Language Usage Average RIT & 223.79 & 4.97 & $\underline{205.75}$ & 12.61 & 213.61 & 11.37 & 5.76 & $.0080^{a}$ \\
\hline 2 & $\begin{array}{l}\text { My Math Experiences Essay Total } \\
\text { Word Count }\end{array}$ & 595.00 & 231.15 & 394.30 & 145.10 & 347.14 & 132.41 & 5.60 & $.0090^{a}$ \\
\hline 3 & NWEA Mathematics Average RIT & 231.07 & 6.23 & 217.30 & 12.35 & $\underline{215.93}$ & 14.94 & 3.61 & $.0403^{a}$ \\
\hline 4 & NWEA Reading Average RIT & 224.57 & 8.52 & 213.05 & 9.93 & 218.50 & 15.42 & 1.75 & .1930 \\
\hline 5 & Math Skills Assessment & 77.16 & 8.48 & 62.66 & 14.45 & 65.71 & 23.66 & 1.36 & .2734 \\
\hline 6 & $\begin{array}{l}\text { My Math Experiences Essay Rubric } \\
\text { Score }\end{array}$ & 85.43 & 8.52 & 84.20 & 10.18 & 79.21 & 8.58 & 1.43 & .2560 \\
\hline 1 & How One Solved It scale score & 16.43 & 3.37 & 10.60 & 2.51 & 7.36 & 2.55 & 25.64 & $<.0001^{\mathrm{a}}$ \\
\hline 2 & $\begin{array}{l}\text { Problem-Solving Total Rubric } \\
\text { Score }\end{array}$ & 65.29 & 10.47 & 43.65 & 11.45 & 33.04 & 9.40 & 22.76 & $<.0001^{a}$ \\
\hline 3 & Getting Answer scale score & 16.50 & 2.80 & $\underline{10.30}$ & 3.16 & $\underline{8.25}$ & 2.64 & 19.75 & $<.0001^{\mathrm{a}}$ \\
\hline 4 & Decisions Made Scale Score & 15.71 & 3.03 & 11.35 & 3.50 & 8.00 & 2.30 & 16.86 & $<.0001^{a}$ \\
\hline 5 & Understanding Scale Score & 16.64 & 2.32 & $\underline{11.40}$ & 3.02 & $\underline{9.43}$ & 2.69 & 16.42 & $<.0001^{a}$ \\
\hline 6 & Problem Average Word Count & 29.17 & 14.18 & 21.20 & 11.35 & 17.63 & 8.56 & 2.62 & .0904 \\
\hline
\end{tabular}

${ }^{a}$ An overall significant F-statistic justified post hoc paired comparisons using the StudentNewman-Keuls procedure. Means with underlines were not significantly different at p < 05 . 
In eight of the 12 ANOVAs, the $F$-statistic was significant $(p<.05)$ : NWEA Language Usage Average RIT, NWEA Mathematics Average RIT, How One Solved It Scale score, Problem-Solving Total Rubric score, Getting Answer Scale score, Decisions Made Scale score, Understanding Scale score and My Math Experiences Essay Total Word Count. Following the eight significant ANOVAs, the three HOIR levels were subjected to pair-wised multiple comparisons, using the Student-NewmanKeuls procedure at the .05 level of significance.

In all eight analyses, the "HOIR $\geq 2$ " group was significantly higher than the "HOIR = 1" and "HOIR = 0" groups. In five of these analyses, the "HOIR = 1" and "HOIR $=0 "$ groups were not significantly different. In the other three analyses, the "HOIR $=1$ " was significantly higher than the "HOIR $=0 . "$

For all 12 ANOVAs, the seven students with two or more instances of HOIR had the highest mean scores, while in nine out of the 12 comparisons, students with no HOIR had the lowest mean scores.

It is worth noting that the NWEA Language Usage Average RIT and the My Math Experiences Essay Total Word Count had the most significant $F$-statistics amongst the group of six Aptitude/Achievement/Experience variables, which suggests a strong link between literacy and mathematics. 
Relationships of Demographic Variables to Students' Levels of Higher-Order Internal Representation (HOIR)

Depending on the number of problems - out of six - in which students had used higher-order internal representations (HOIR), students fell into three groups: $\operatorname{HOIR} \geq 2(n=7) ; \operatorname{HOIR}=1(n=10) ;$ and HOIR $=0(n=14))$. Chi-square $\left(\chi^{2}\right)$ analyses explored the relationship between student's HOIR-levels and six demographic variables: Gender, Ethnicity, IEP status, Art Discipline, Sending District, and SES. Table 29 shows the results of the six $\chi^{2}$ analyses, listed from highest to lowest $\chi^{2}$ value.

Unlike other statistical tests, the calculated value of $\chi^{2}$ is directly proportional to sample size. So, for contingency tables of a given size (e.g., 3-by-2), if the same pattern appeared with a sample of 60 and a sample of 30 , the calculated value of $\chi^{2}$ would be twice as large with the sample of 60 , even though the degrees of freedom (which determine the critical values) would be the same (2). This unique feature of $\chi^{2}$, in conjunction with the modest sample size of 31 , justifies some brief comments on patterns that are suggestive, but not statistically significant. None of the analyses in Table 29 was significant at the .05 -level.

The seven students at the highest HOIR-level (HOIR $\geq 2$ ) were more likely to be: girls; white or African-American (not Hispanic); without an IEP; culinary or visual (not theater) artists; out-of-district; and high SES. Among the 17 students with any use of HOIR (HOIR $\geq 1)$, however, there were much smaller differences on gender, IEP status, and SES. 
Table 29

Demographic Variable Comparisons between Levels of Higher-Order Internal Representation (HoIR)

\begin{tabular}{|c|c|c|c|c|c|c|c|c|c|c|c|c|}
\hline & \multicolumn{2}{|c|}{ Demographics } & \multicolumn{2}{|c|}{ HOIR $\geq 2$} & \multicolumn{2}{|c|}{$\mathrm{HOIR}=1$} & \multicolumn{2}{|c|}{$\mathrm{HOIR}=0$} & \multicolumn{2}{|c|}{ Total } & \multicolumn{2}{|c|}{$N=31$} \\
\hline & Variable & Subgroup & Freq. & Prop. & Freq. & Prop. & Freq. & Prop. & Freq. & Prop. & $x^{2}$ & $p$ \\
\hline \multirow{3}{*}{1} & \multirow{3}{*}{ Gender } & Girls & 6 & .35 & 4 & .24 & 7 & .41 & 17 & 1.00 & \multirow{3}{*}{3.72} & \multirow{3}{*}{.1560} \\
\hline & & & & & & & & & & & & \\
\hline & & Boys & 1 & .07 & 6 & .43 & 7 & .50 & 14 & 1.00 & & \\
\hline \multirow{3}{*}{2} & \multirow{3}{*}{ Ethnicity } & $\begin{array}{l}\text { African } \\
\text { American }\end{array}$ & 1 & .25 & 2 & .50 & 1 & .25 & 4 & 1.00 & \multirow{3}{*}{3.62} & \multirow{3}{*}{.4596} \\
\hline & & Hispanic & 0 & .00 & 3 & .43 & 4 & .57 & 7 & 1.00 & & \\
\hline & & White & 6 & .30 & 5 & .25 & 9 & .45 & 20 & 1.00 & & \\
\hline \multirow[b]{2}{*}{3} & \multirow[b]{2}{*}{ IEP } & Non-IEP & 7 & .30 & 6 & .26 & 10 & .43 & 23 & 1.00 & \multirow[b]{2}{*}{3.54} & \multirow[b]{2}{*}{.1701} \\
\hline & & IEP & 0 & .00 & 4 & .50 & 4 & .50 & 8 & & & \\
\hline \multirow{3}{*}{4} & \multirow{3}{*}{$\begin{array}{c}\text { Art } \\
\text { Discipline }\end{array}$} & Culinary & 2 & .29 & 1 & .14 & 4 & .57 & 7 & 1.00 & \multirow{3}{*}{1.84} & \multirow{3}{*}{.7644} \\
\hline & & Theater & 2 & .15 & 5 & .38 & 6 & .46 & 13 & 1.00 & & \\
\hline & & Visual & 3 & .27 & 4 & .36 & 4 & .36 & 11 & 1.00 & & \\
\hline \multirow{2}{*}{5} & \multirow{2}{*}{$\begin{array}{c}\text { Sending } \\
\text { District }\end{array}$} & Outside & 4 & .33 & 4 & .33 & 4 & .33 & 12 & 1.00 & \multirow{2}{*}{1.62} & \multirow{2}{*}{.4457} \\
\hline & & Inside & 3 & .16 & 6 & .32 & 10 & .53 & 19 & 1.00 & & \\
\hline \multirow{3}{*}{6} & \multirow{3}{*}{ SES } & High & 3 & .30 & 2 & .20 & 5 & .50 & 10 & 1.00 & \multirow{3}{*}{1.12} & \multirow{3}{*}{.5704} \\
\hline & & & & & & & & & & & & \\
\hline & & Low & 4 & .19 & 8 & .38 & 9 & .43 & 21 & 1.00 & & \\
\hline
\end{tabular}


Relationships of Math-Related Attitude Variables to Students' Levels of Higher-Order Internal Representation (HOIR)

Table 30 shows one-way ANOVAs comparing students in the three HOIRlevels on seven attitude variables: the six scales in the Shortened Form of the Fennema - Sherman Mathematics Attitudes Scales (FSMAS-SF), consisting of six scales and Rotter's Internal-External Locus of Control Scale (IE). The results are listed from highest to lowest $F$-statistic, none of which was significant $(\mathrm{p}<.05)$. 
Table 30

Attitude Variable Comparisons between Levels of Higher-Order Internal Representation (HOIR)

\begin{tabular}{|c|c|c|c|c|c|c|c|c|c|}
\hline & \multirow[b]{2}{*}{ Attitude Variable } & \multicolumn{2}{|c|}{$\begin{array}{c}\text { HOIR } \geq 2 \\
n=7\end{array}$} & \multicolumn{2}{|c|}{$\begin{array}{c}\text { HOIR }=1 \\
n=10\end{array}$} & \multicolumn{2}{|c|}{$\begin{array}{c}\mathrm{HOIR}=0 \\
n=14\end{array}$} & \multicolumn{2}{|c|}{$N=31$} \\
\hline & & $M$ & $S D$ & M & $S D$ & $M$ & $S D$ & $F$ & $p$ \\
\hline 1 & Usefulness scale Score ${ }^{a}$ & 30.71 & 5.99 & 34.60 & 3.92 & 29.86 & 5.02 & 2.83 & .0757 \\
\hline 2 & Math Affect Scale Score & 31.71 & 11.27 & 34.00 & 8.31 & 26.50 & 6.95 & 2.45 & .1047 \\
\hline 3 & Male Domain scale Score & 19.14 & 3.02 & 22.50 & 4.38 & 22.57 & 5.58 & 1.39 & .2668 \\
\hline 4 & Teacher Scale Score ${ }^{d}$ & 21.86 & 4.34 & 23.10 & 2.73 & 21.14 & 3.30 & .98 & .3895 \\
\hline 5 & Success scale score $e^{e}$ & 33.00 & 3.37 & 34.40 & 3.69 & 32.50 & 4.00 & .76 & .4784 \\
\hline 6 & Rotter's Locus of Control (IE) ${ }^{g}$ & 11.71 & 2.43 & 11.10 & 3.11 & 11.86 & 2.98 & .21 & .8149 \\
\hline 7 & Parents' Attitude Scale Score ${ }^{f}$ & 31.43 & 8.50 & 30.60 & 5.40 & 30.57 & 6.49 & .04 & .9574 \\
\hline
\end{tabular}

'measures students' beliefs about the usefulness of mathematics currently, and in relationship to their future education, vocation, or other activities.

b measures confidence in one's ability to learn and to perform well on mathematical tasks. The dimension ranges from distinct lack of confidence to definite confidence.

cmeasures the degree to which students see mathematics as a male, neutral, or female domain.

'measures students' perceptions of their teacher's attitudes toward them as learners of mathematics.

emeasures the degree to which students anticipate positive or negative consequences as a result of success in mathematics.

'measures students' perception of their mother's/father's interest, encouragement, and confidence in the student's ability. Adapted from Fennema et al. (1976).

gmeasures locus of control scored in the external direction, that is, the higher the score the more external the individual. 
Relationship of Preferred Mathematical Solutions (PMS) to Levels of Higher-Order Internal Representation (HOIR)

As previously explained in the subsection Math-Related Attitude Variable: Preferred Mathematical Solutions (PMS) in this chapter, students were assigned to one of four groups (Algebraic, Pictorial, Tabular, Hybrid) depending on their PMS data to non-routine problems. As previously noted, two of the 31 students were missing data on their preferences. Therefore, the following analysis is based on 29 students.

Table 31 compares students in their four PMS groups on their preference (Algebraic, Pictorial, Tabular, Hybrid) and the three levels of Higher-Order Internal Representation (HOIR): HOIR $\geq 2 ; \mathrm{HOIR}=1$; and HOIR $=0$.

Although Table 31 did not yield a significant $\chi^{2}$ value $(p=.1557)$, there tended to be greater use of HOIR among Hybrid and Algebraic students--83\% (5/6) used at least one HOIR--than among Pictorial and Tabular students--only 48\% (11/23) used at least one HOIR. Collapsing the 3-by-4 Table 31 into the 2-by-2 Table 32, came closer to, but did not achieve a significant $\chi^{2}$ value $(p=.1194)$. 
Table 31

PMS Comparisons between Levels of Higher-order Internal Representation (HOIR)

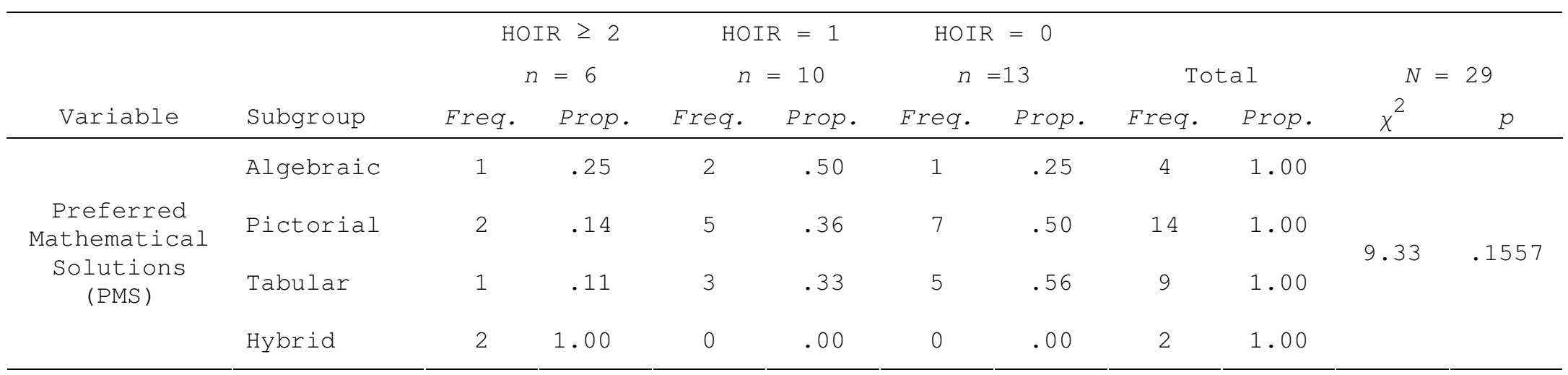

Table 32

PMS Comparisons between Collapsed Levels of Higher-Order Internal Representation (HoIR)

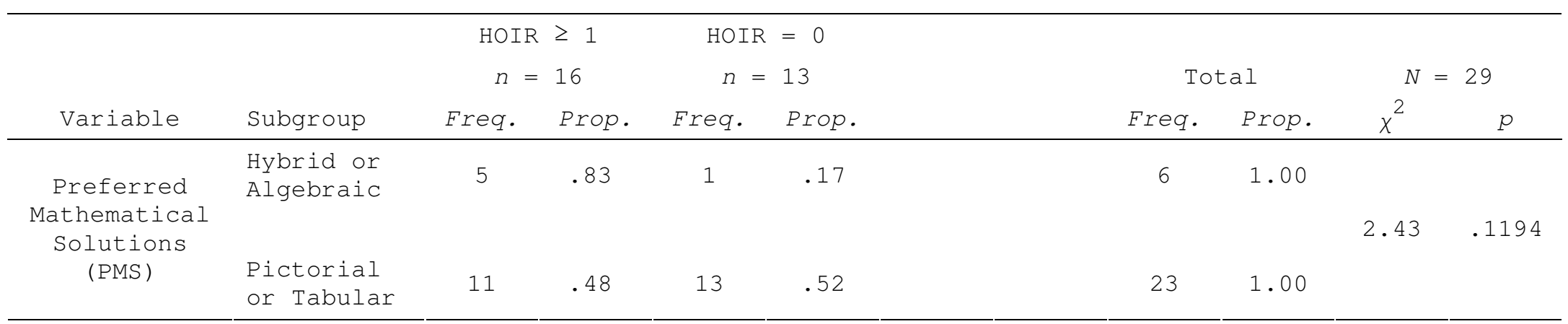


Comparisons of the COPES Values Inventory to Students'

Levels of Higher-Order Internal Representation (HOIR)

Depending on the number of problems--out of six--in which students $(N=31)$ had used higher-order internal representations (HOIR), students were divided into three groups: HOIR $\geq 2(n=7) ; \mathrm{HOIR}=1(n=10)$; and HOIR $=0(n=14)$.

As discussed in the Method chapter, students $(N=31)$ were administered the COPES Values Inventory consisting of 128 items defining eight work value scales. Each scale is a continuum from 0 points on the left to a maximum score of 16 points on the right. The extremes of the values coincide with the left and right poles of the continuum.

Table 33 shows one-way ANOVAs comparing students in the three HOIRlevels on the eight scales of the COPES Values Inventory. The results are listed from highest to lowest $F$-statistic, none of which was significant $(p<.05)$.

However, the trend-level significant $p$-values $.05 \leq p<.10$ obtained for the Aesthetic vs. Reality scale, Practical vs. Carefree scale, and Recognition vs. Privacy scale, suggested some patterns:

Compared to students with HOIR $=0$ or HOIR $=1$, the seven students who demonstrated two or more instances of Higher-Order Internal Recognition (HOIR $\geq$ 2) tended to be: more Aesthetic (i.e., having a higher regard for the arts); more Carefree (i.e., being more carefree and value using their imagination); and higher on the Recognition scale (i.e., value being famous and/or knowing important people). 
Table 33

COPES Work-Values Comparisons between Levels of Higher-Order Internal Representation (HoIR)

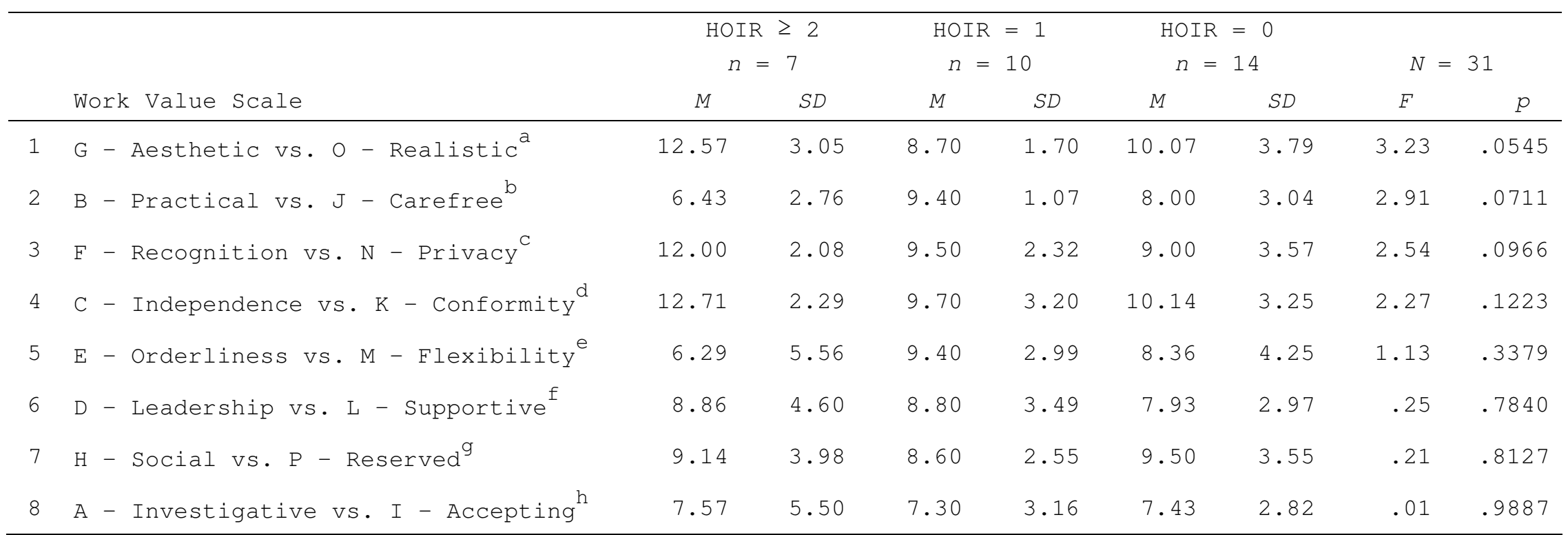

${ }^{a}$ No appreciation for the arts $($ Low $=0$ ) to appreciation for the arts $($ High $=16)$.

${ }^{\mathrm{b}}$ Carefree, use of imagination (Low $=0$ ) to appreciation of one's belongs and efficient ways of doing things $(\mathrm{High}=16)$.

${ }^{C}$ Values privacy (Low $=0$ ) to values being famous or knowing important people (High = 16).

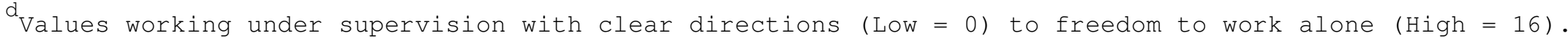

Values no need to keep things orderly (Low =0) to keeping things neat and organized (High = 16).

${ }^{f}$ Values being a good follower (Low = 0) to making decisions, and speaking for the group (High = 16).

${ }^{9}$ Values tending to own affairs or projects (Low $=0$ ) to helping others, being a team player (High = 16 ).

ho need to solve complex problems (low $=0)$ to intellectual curiosity and challenging tasks (High = 16$)$. 
The matrix in Table 34 shows correlations between the seven Performance Variables on Nonroutine Math Problems and the six Aptitude/Achievement/Experience variables. Of the 42 correlations, six were significant $(p<.05)$.

NWEA Mathematics was significantly correlated with four of the seven Performance Variables on Nonroutine Problems (How One Solved It, Getting Answer, Total Rubric Score, Number of HOIR) and trend-level significant $(.05 \leq p<.10)$ with Understanding.

Essay Rubric Score was weak-to-moderate positively correlated with Average Problem Word Count.

Essay Word Count was weak-to-moderate positively correlated with the Number of HOIR. 
Table 34

Correlations $r$ between Performance Variables on Nonroutine Problems and Aptitude/Achievement/Experience Variables $(N=31)$

\begin{tabular}{|c|c|c|c|c|c|c|c|}
\hline & & Performa & ce Varia & les on $\mathrm{N}$ & nroutine & Problems & \\
\hline $\begin{array}{l}\text { Aptitude, } \\
\text { Achievement, } \\
\text { Experience } \\
\text { Variables }\end{array}$ & $\begin{array}{l}\text { Under- } \\
\text { stand- } \\
\quad \text { ing }\end{array}$ & $\begin{array}{l}\text { How one } \\
\text { Solved } \\
\text { It }\end{array}$ & $\begin{array}{l}\text { Deci- } \\
\text { sions } \\
\text { Made }\end{array}$ & $\begin{array}{l}\text { Getting } \\
\text { Answer }\end{array}$ & $\begin{array}{l}\text { Total } \\
\text { Rubric } \\
\text { Score }\end{array}$ & $\begin{array}{l}\text { Number } \\
\text { of HOIR }\end{array}$ & $\begin{array}{l}\text { Average } \\
\text { Problem } \\
\text { Word } \\
\text { Count }\end{array}$ \\
\hline $\begin{array}{l}\text { NWEA } \\
\text { Language } \\
\text { Usage }\end{array}$ & $\begin{array}{l}.15720 \\
(.3984)\end{array}$ & $\begin{array}{l}.19857 \\
(.2842)\end{array}$ & $\begin{array}{l}.09724 \\
(.6028)\end{array}$ & $\begin{array}{l}.22293 \\
(.2280)\end{array}$ & $\begin{array}{l}.17634 \\
(.3427)\end{array}$ & $\begin{array}{l}.26534 \\
(.1491)\end{array}$ & $\begin{array}{l}.12137 \\
(.5155)\end{array}$ \\
\hline $\begin{array}{l}\text { NWEA } \\
\text { Mathematics }\end{array}$ & $\begin{array}{l}.35129 \\
(.0526)\end{array}$ & $\begin{array}{l}.38044^{\mathrm{a}} \\
.0347\end{array}$ & $\begin{array}{l}.35301 \\
(.0514)\end{array}$ & $\begin{array}{r}.39264 \\
.0289\end{array}$ & $\begin{array}{r}.38352 \\
\bullet .0332\end{array}$ & $\begin{array}{l}.40161 \\
\bullet .0251\end{array}$ & $\begin{array}{l}.10490 \\
(.5744)\end{array}$ \\
\hline NWEA Reading & $\begin{array}{l}.22527 \\
(.2231)\end{array}$ & $\begin{array}{l}.18525 \\
(.3184)\end{array}$ & $\begin{array}{l}.20037 \\
(.2798)\end{array}$ & $\begin{array}{l}.23957 \\
(.1943)\end{array}$ & $\begin{array}{l}.21987 \\
(.2346)\end{array}$ & $\begin{array}{l}.15417 \\
(.4076)\end{array}$ & $\begin{array}{l}.10242 \\
(.5835)\end{array}$ \\
\hline Math Skills & $\begin{array}{l}.05697 \\
(.7608)\end{array}$ & $\begin{array}{l}.12236 \\
(.5120)\end{array}$ & $\begin{array}{l}.13952 \\
(.4541)\end{array}$ & $\begin{array}{l}.18843 \\
(.3100)\end{array}$ & $\begin{array}{l}.13300 \\
(.4757)\end{array}$ & $\begin{array}{l}.20177 \\
(.2764)\end{array}$ & $\begin{array}{r}-.08398 \\
(.6533)\end{array}$ \\
\hline $\begin{array}{l}\text { Essay Rubric } \\
\text { Score }\end{array}$ & $\begin{array}{l}.18447 \\
(.3205)\end{array}$ & $\begin{array}{l}.22999 \\
(.2133)\end{array}$ & $\begin{array}{l}.20893 \\
(.2593)\end{array}$ & $\begin{array}{l}.13965 \\
(.4537)\end{array}$ & $\begin{array}{l}.19816 \\
(.2853)\end{array}$ & $\begin{array}{l}.18270 \\
(.3252)\end{array}$ & $\begin{array}{r}.35796 \\
\bullet .0480\end{array}$ \\
\hline $\begin{array}{l}\text { Essay Word } \\
\text { Count }\end{array}$ & $\begin{array}{l}.19514 \\
(.2928)\end{array}$ & $\begin{array}{l}.29615 \\
(.1057)\end{array}$ & $\begin{array}{l}.19668 \\
(.2889)\end{array}$ & $\begin{array}{l}.28064 \\
(.1262)\end{array}$ & $\begin{array}{l}.25308 \\
(.1695)\end{array}$ & $\begin{array}{r}.39543 \\
\bullet .0277\end{array}$ & $\begin{array}{l}.25772 \\
(.1616)\end{array}$ \\
\hline
\end{tabular}


Qualitative Data from Students $(n=7)$ with Two or More Instances of HOIR

I performed content analyses on two documents from each of the seven students with HOIR $\geq 2$ : "My Math Experiences" essay along with a page (p. 47) from the Individual Graduation Plan (IGP) which had brief responses to four selfreflective questions about mathematics:

1. Why and how is mathematics important in my life?

2. What do my grades and test scores show about my mathematics ability?

3. How will mathematics help me with my educational and career goals?

4. What type of help do I need to succeed in mathematics?

My content analyses considered two categories: elementary school experiences (grades 1 - 5) and middle school experiences (grades 6 -8). Three general themes emerged: experiences with teachers; general attitudes toward mathematics; and family support. Table 35 summarizes the seven students' themes from elementary and middle school. Table 36 summarizes the seven students' responses to the four questions posed on the Individual Graduation Plan (Individual, 2007, p. 47). 
Table 35

Elementary and Middle School Experiences of Students with Two or More Instances of HOIR $(n=7)$

ID Elementary School (grades 1 - 5) Middle School (grades 6 - 8)

Liked math.

08 Hated her 4th grade teacher; 5th grade teacher was her favorite

09 Scored high; Didn't need help.

Didn't go to preschool;

Learned to count by playing drums at an early age; Was in special ed. until 3rd grade; Attributes failures/low selfesteem to being placed in a room with kids who couldn't talk or had turrets [Tourette syndrome].

Bad experiences; Bad behavior;

13 Poor grades; Instances of learned helplessness.
Hated math.

7 th grade teacher had poor teaching methods; $8^{\text {th }}$ grade teacher had poor classroom management.

Math was easy; Did minimum to pass and got poor grades; Slept, and fooled around because of boredom.

6 th grade math was cool - was very nice and helped a lot. 7 th and 8th grade teachers were horrible.

Bad experiences; Bad behavior; Handed work late; Cheated off the smart kids.

Had the meanest teacher. 
ID Elementary School (grades 1 - 5) Middle School (grades 6 - 8)

1st' 2nd, and 3rd grade teachers were interesting and fun; Enjoyed going to school; Math was favorite subject; Always had fun in school; Felt I had control of my grades;

Early years were my favorite; With 4th, 5th and on to middle school my opinion toward math changed; Started failing in 4th grade because of long division and in 5th grade because of decimals: Afraid to ask for help in both grades.

Math was fun.

Only remember learning math in 5 th grade.

Remember long division was boring.

1st grade was boring because I already knew the math.

24 In 2nd grade I was tested and put in an enriched class once a week for the rest of elementary school.
6 th grade teacher was repetitious (but helped with understanding); 6 th grade things got better;

7 th grade math was confusing also the teacher had poor classroom management - it was an absolutely horrible year; 8th grade - bad teacher with no patience;

Math was worse subject for grades 6 - 8 - math was not fun anymore.

Loathed math in 6 th grade. didn't like the type of math - boring time and tiring; Math wasn't favorite subject but wasn't the worse. 8th grade teacher made math fun.

Middle school was easy but teachers were mean and didn't do anything fun - I was bored and math was not fun; 6 th and 7 th grade slept a lot but passed; 8th grade teacher had poor classroom management. In 8th grade - didn't care, slept in almost every class, didn't do my work, was absent for a long time and was retained; Failed math in the repeated 8th grade year. 
Additional comments from the essays.

1. Student ID number 08: states that she is almost age 17 in the ninth-grade at Beacon having repeated the ninth-grade twice before at another high school.

2. Student ID number 13: Repeating ninth-grade (this is first year at Beacon). She doesn't see the purpose of learning math after sixth-grade since you won't use the math unless you are a rocket scientist, architect or math teacher. She states that she was recently diagnosed with ADHD and now feels she is doing better since she is on medication. 
Table 36

General Attitudes towards Math by Students with Two or More Instances of HOIR $(n=7)$

\begin{tabular}{ccccc}
\hline & My & & How will & \\
& feelings & What do my & math help & What type \\
ID My feelings & toward the & math & me with my of help do \\
toward Math & importance & grades & education I need with \\
& of math in & show? & and career & math? \\
& my life & goals? &
\end{tabular}

Math is my

08 favorite subject

It is important in my life.

It is

Math is boring but easy

important

in my

life.

Math is confusing,

10 boring, and it sucks; never liked it; hate it.
It's not

that important in my life.

It is important in my life.
I understand math.
It will

help me when I am a hairdresser.
I don't need help.
Almost I don't everything need help has to do except for with math. motivation.

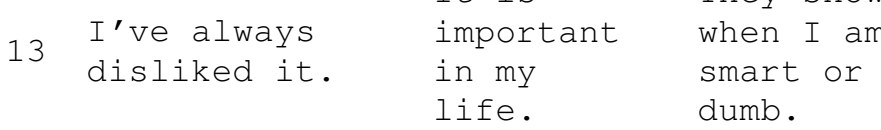

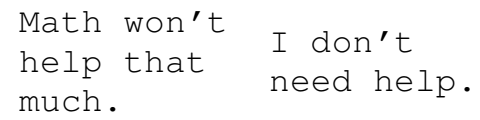




\begin{tabular}{cccc} 
& My & & How will \\
& feelings & What do my math help & What type \\
ID My feelings & toward the & math & me with my of help do \\
toward Math & of math in & show? & and career \\
& my life & & goals? \\
\hline
\end{tabular}

Math is my

favorite

subject until

14

4th grade -

after that my

opinion

changed.

Math was fun

in Elementary

school; I

loathed it in

216 th grade. Not my favorite or least favorite subject in middle school
It is

important I'm okay I don't I don't

in my

life.
Math is

not my

best

subject

but I'm at

a 9th-10th

grade

level.
With money and taxes.
I need help with

decimals.
I used to be good at it but I don't care about math as much now. If I wanted to, I could be good at math again.
It's not

that

important

in my

life.
It won't

help

unless it I don't

has to do need help. with

prices. am good

but I

don't try. 


\section{Comments on family support.}

Four of the seven (ID numbers $08,09,14$, and 21) made no reference to any family members in any context. One student (ID number 13) mentioned that her mother helped quiz her in early elementary school years. Another student (ID number 24) stated that her mother helped with math and her parents bought her workbooks in kindergarten - which she loved. The remaining student (ID number 10) stated that there was no family support for education at home. This student claimed that the parents were drug addicts and abusive; by the student's age of 14, her family had moved 14 times (mentions several cities); attended three middle schools; her father was arrested and the student moved to Woonsocket to live with her grandparents. In reference to her family, she states that she does not think suicide is good, but if they did it, it would bring her great joy.

Worthy of note in all seven cases is the lack of any mention of family support beyond early elementary school. Only one, student (ID number 21), mentioned siblings: In regards to the importance of mathematics in her life, she wrote: "Mathematics is important when I count money, so I can see if my siblings stole." 


\section{A Detailed Example of HOIR in Problem Solving}

As part of this study, I recruited six students for videotaped voluntary interviews after they had finished their work on the nonroutine math problems. I chose two high-performing students (who got the correct answer), two medium-performing students (who had some reasonable approach, but didn't get the answer), and two lowperforming students (no correct answer and little or no work shown). During one of the videotaped interviews, a student who had only written a color on his worksheet, the color green - the wrong answer, and no work, mentioned that he had made a 3-D model (refer to Turn 2 in Table 37). Upon further questioning, Jerry (not his real name) began an elaborate demonstration of representation toward solving the problem. This revelation would have gone undetected had there not been these "qualitative" interviews designed within this study as the student made no mention on the "Blind Sided" problem worksheet or his narrative as to making a 3-D model. Although Jerry did not get the correct answer, the method was an example of high order internal representation that, in most cases, would have resulted in a correct answer. It is very possible that Jerry made a careless mistake in the final labeling of the 3-D cube he fabricated. 
Interview with Jerry: representation by origami.

The opening video shot is a close-up of Jerry's worksheet of the "Blind Sided" problem on a music stand. On the left side of the worksheet, under the statement "Please show all your work in the space below," Jerry has printed the word Green in large letters and then crossed it out. Just below it, he has written Green again but has not crossed it out. This is the only work shown.

On the right side of the worksheet, reserved for Jerry's narrative on how he solved the problem, he has simply written:

"I chose green because the cube just flips around and I flipped view 3." Table 37 provides an excerpt from my interview with Jerry. 
Table 37

Interview with Jerry

\begin{tabular}{|c|c|c|}
\hline $\begin{array}{l}\text { Turn }^{1} \\
\text { Number }\end{array}$ & Speaker & Discourse \\
\hline 1 & Interviewer: & $\begin{array}{l}\text { This was the last problem I gave you. This } \\
\text { was the cube problem, where there were } \\
\text { different colors on different faces of the } \\
\text { cube. You gave me an answer of "green" and } \\
\text { could you just explain a little about how did } \\
\text { you approach this problem? }\end{array}$ \\
\hline 2 & Jerry: & $\begin{array}{l}\text { Alright...the first thing I tried was looking } \\
\text { at the visual squares view one, two, and } \\
\text { three... trying, thinking of, you know, that } \\
\text { flipping around... trying to think of which } \\
\text { colors were where. } \\
\text { I eventually made a 3-D model of...of a box - } \\
\text { marked down the colors, and winded up finding } \\
\text { out that it showed most of the colors but, } \\
\text {...as it says ...up there, it says there are only } \\
\text { five different colors. } \\
\text { There was green, red, blue, white, and } \\
\text { yellow... and there is six sides to the cube, } \\
\text { so I winded up figuring out that... there is an } \\
\text { extra one of the colors and,... I winded up } \\
\text { coming to the conclusion that it was green. }\end{array}$ \\
\hline 3 & Interviewer: & $\begin{array}{l}\text { Okay, you said you ended up making a model. } \\
\text { Can you describe how you made that model? }\end{array}$ \\
\hline
\end{tabular}

${ }^{1}$ Turn refers to a switch in the person speaking. The Turn Number is sequentially assigned for purposes of referencing in the text 


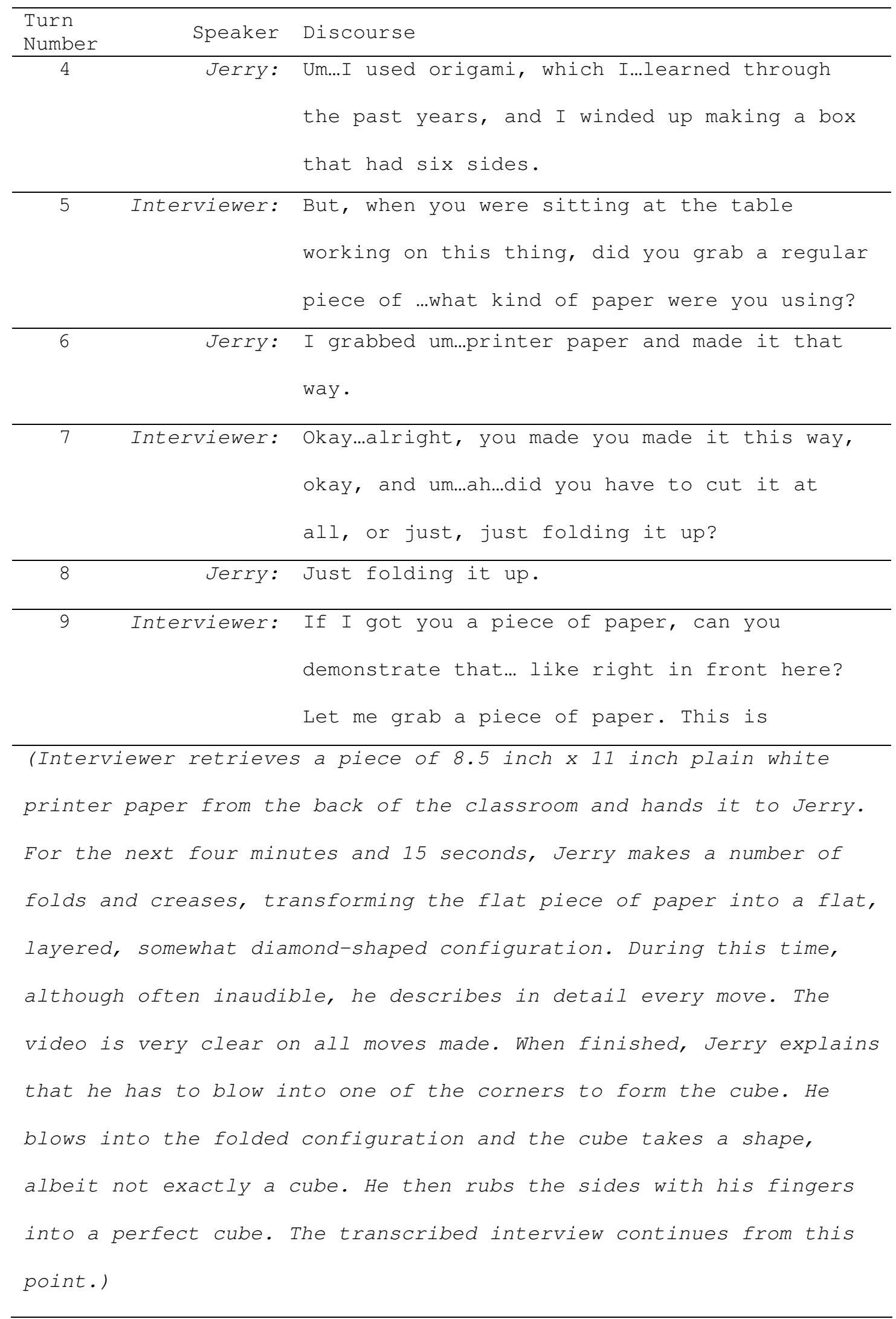




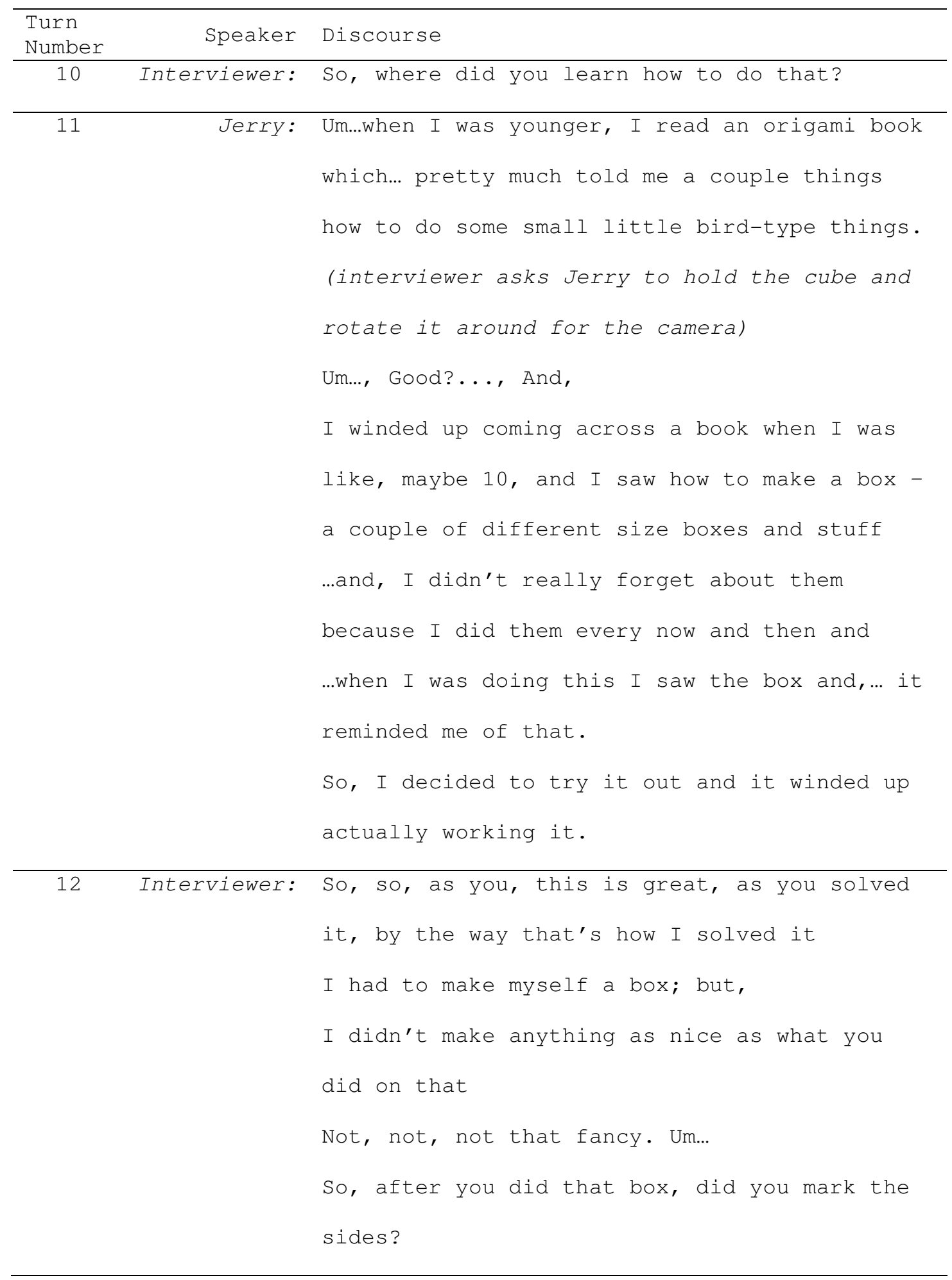




\begin{tabular}{|c|c|c|}
\hline $\begin{array}{l}\text { Turn } \\
\text { Number }\end{array}$ & Speaker & Discourse \\
\hline 13 & Jerry: & $\begin{array}{l}\text { Yeah, I wrote down the different colors: } \\
\text { green, blue, red, white. }\end{array}$ \\
\hline & Interviewer: & $\begin{array}{l}\text { Did you write down the actual words out or } \\
\text { did you just write letters, the first } \\
\text { letters? }\end{array}$ \\
\hline 14 & Jerry: & I wrote the words \\
\hline 15 & Interviewer: & All the words out, okay \\
\hline 16 & Jerry: & $\begin{array}{l}\text { And then, I went around it... } \\
\text { I did exactly what the views show...how to flip } \\
\text { it and stuff. } \\
\text { And, it was kind of hard at first but then... I } \\
\text { winded up choosing that it was green. }\end{array}$ \\
\hline 17 & Interviewer: & $\begin{array}{l}\text { Okay... well, compared to these two problems, } \\
\text { "The Brothers and Sisters" and this one right } \\
\text { here, which one did you like better? }\end{array}$ \\
\hline 18 & Jerry: & $\begin{array}{l}\text { Honestly, I like them both kind of the same } \\
\text { because... } \\
\text { "The Brothers and Sisters" one was } \\
\text { challenging and this one I got to do my } \\
\text { favorite thing, which is...origami. }\end{array}$ \\
\hline 19 & Interviewer: & Okay. \\
\hline 20 & Jerry: & And, it was kind of challenging. \\
\hline 21 & Interviewer: & So that's great, fantastic... \\
\hline
\end{tabular}

[End of this excerpt of the interview] 


\section{Summary of Bivariate Results: Transition to Discussion}

This section summarizes the extensive bivariate analyses that I performed and reported in this chapter for the students $(N=31)$. For purposes of consistency in organization, tables were constructed based on the Roadmap for Bivariate Analyses shown in Figure 3.

Tables 38,39 , and 40 provided a narrative summary of all findings arranged by the three categories of possible sources of correlates: Demographics, Math-Related Attitudes, and Values measured against the six measures of the criterion-variable category of Aptitude/Achievement/Experience.

Tables 41,42 , and 43 provided a narrative summary of all findings arranged by the three categories of possible sources of correlates: Demographics, Math-Related Attitudes, and Values measured against the seven measures of the criterion-variable category of Performance Variables on Nonroutine Problems.

Table 44 provided a narrative summary of all findings of the bivariate analyses performed between the six measures of Aptitude/Achievement/Experience; and the seven measures of Performance Variables on Nonroutine Problems.

Tables 45, 46, and 47 paralleled Tables 38,39 , and 40 respectively and provided a summary of effect sizes (Cohen's $d$ statistic) for only the significant and trend-level significant $(.05 \leq p<.10)$ findings arranged by the three categories of possible sources of correlates: Demographics, Math-Related Attitudes, and Values measured against the six measures of the criterion-variable category of Aptitude/Achievement/Experience. 
Tables 48, 49, and 50 paralleled Tables 41, 42, and 43 respectively and provided a summary of effect sizes (Cohen's $d$ statistic) for only the significant and trend-level significant $(.05 \leq p<.10)$ findings arranged by the three categories of possible sources of correlates: Demographics, Math-Related Attitudes, and Values measured against the seven measures of the criterion-variable category of Performance Variables on Nonroutine Problems.

Table 51 paralleled Table 34 and provided a summary of effect sizes (Cohen's $d$ statistic) for only the significant and trend-level significant $(.05 \leq p<.10)$ findings for the bivariate analyses performed between the six measures of Aptitude/Achievement/Experience; and the seven measures of Performance Variables on Nonroutine Problems. 
Table 38

Summary of Demographic Measures as Possible Correlates of Aptitude/Achievement/Experience Variables $(N=31)$

Age

There were no significant correlations with any of the six measures of Aptitude, Achievement, and Experience.

Art Discipline

Students in the culinary $(n=7)$, theater $(n=13)$, and visual $(n=11)$ arts had no significant differences on any of the six measures of Aptitude, Achievement, and Experience.

Attendance

There was only one significant correlation (Essay Rubric Score) with the six measures of Aptitude, Achievement, and Experience. The negative correlation was weak to moderate. The more days absent, the lower the essay rubric score.

Ethnicity

There were trend-level significant (.05 $\leq p<.10)$ differences on two measures (NWEA Language Usage and NWEA Mathematics) of the six measures of Aptitude, Achievement, and Experience. African-American students $(n=4)$ scored higher than both Hispanic $(n=7)$ and White $(n=20)$ students. Hispanic students scored the lowest on both measures.

Gender

There were four significant differences (NWEA Language Usage, NWEA Mathematics, Essay Rubric Score, Essay Word Count) on the six measures of Aptitude, Achievement, and Experience. Girls $(n=17)$ scored higher than boys ( $n=$ 14) on all four measures. 
IEP status

There were three significant differences (NWEA Language Usage, NWEA Mathematics, NWEA Reading) on the six measures of Aptitude, Achievement, and Experience. Students without IEPs $(n=23)$ scored higher than students with IEPs $(n=8)$ on all three measures.

Sending School District

There were no significant differences on any of the six measures of Aptitude, Achievement, and Experience. Students from out of district $(n=12)$ scored slightly higher than students within district $(n=19)$ on five of six measures (scoring slightly lower on NWEA Reading).

Socioeconomic Status (SES)

There were no significant differences on any of the six measures of Aptitude, Achievement, and Experience. High-SES students $(n=10)$ scored slightly higher than LOW-SES students $(n=21)$ on all six measures. 
Table 39

Summary of Math-Related Attitude Measures as Possible

Correlates of Aptitude/Achievement/Experience $(N=31)$

Mathematics-Related Affect

There were no significant correlations with any of the six measures of Aptitude, Achievement, and Experience.

\section{Parents' Attitudes}

There were no significant correlations with any of the six measures of Aptitude, Achievement, and Experience.

Usefulness

There were no significant correlations with any of the six measures of Aptitude, Achievement, and Experience.

Male Domain

There were three significant correlations (NWEA Language Usage, NWEA Reading, Essay Rubric Score) and a trendlevel significant $(.05 \leq p<.10)$ (NWEA Math) correlation with the six measures of Aptitude, Achievement, and Experience. All significant and trendlevel correlations were negative in direction, meaning that the less students perceived mathematics as a male domain the higher they performed.

\section{Success}

There were no significant correlations with any of the six measures of Aptitude, Achievement, and Experience.

Teacher

There was only one significant correlation (Essay Word Count) with the six measures of Aptitude, Achievement and Experience. The correlation was weak to moderate in the negative direction, meaning that students who perceived their teachers as having more positive attitudes toward them as learners of mathematics tended to write less on their essay. 
Rotter's Internal-External Locus of Control Scale

There were no significant correlations with any of the six measures of Aptitude, Achievement, and Experience.

Preferred Mathematical Solutions

There was only one significant difference (NWEA Language Usage) with the six measures of Aptitude, Achievement and Experience. Post hoc paired comparisons resulted in no pair wise group differences (although the Hybrid group had the highest mean). 
Table 40

Summary of Values Measures as Possible Correlates of

Aptitude/Achievement/Experience ( $N=31)$

Accepting-Investigative Scale (AI)

There were no significant correlations with any of the six measures of Aptitude, Achievement, and Experience.

Carefree-Practical Scale (BJ)

There were no significant correlations with any of the six measures of Aptitude, Achievement, and Experience.

Conformity-Independence Scale (CK)

There were four significant correlations (NWEA Language Usage, NWEA Mathematics, NWEA Reading, Math Skills) with the six measures of Aptitude, Achievement, and Experience. All four correlations were positive in direction, meaning that the more the student valued working on their own, the higher their achievement.

Supportive-Leadership Scale (DL)

There were no significant correlations with any of the six measures of Aptitude, Achievement, and Experience.

Flexibility-Orderliness Scale (EM)

There were no significant correlations with any of the six measures of Aptitude, Achievement, and Experience.

Privacy-Recognition Scale (FN)

There were two significant positive correlations (NWEA Language Usage, NWEA Mathematics) and two trend-level significant $(.05 \leq p<.10)$ positive correlations (Math Skills, Essay Word Count) with the six measures of Aptitude, Achievement, and Experience. Students who valued fame and contact with important people tended to achieve more. 
Realistic-Aesthetic Scale (GO)

There were four significant positive correlations (NWEA Language Usage, NWEA Mathematics, NWEA Reading, Math Skills) and one trend-level significant $(.05 \leq p<.10)$ positive correlation (Essay Word Count) with the six measures of Aptitude, Achievement, and Experience. The more students valued the artistic aspects of the world, the higher they achieved.

Reserved-Social Scale (HP)

There were no significant correlations with any of the six measures of Aptitude, Achievement, and Experience. 
Table 41

Summary of Demographic Measures as Possible Correlates of Performance on Nonroutine Mathematics Problems ( $N=31$ )

Age

There were no significant correlations with any of the seven measures of problem-solving performance.

Art Discipline

Students in the culinary $(n=7)$, theatre $(n=13)$, and visual $(n=11)$ arts had no significant differences on the seven measures of problem-solving performance.

Attendance

There were no significant correlations with any of the seven measures of problem-solving performance.

Ethnicity

There were trend-level significant $(.05 \leq p<.10)$ differences on six measures [all except Number of Higher-Order Internal Representations (HOIR)] of problem-solving performance. Hispanic students $(n=7)$ scored lowest on all six. White students $(n=20)$ and African-American students $(n=4)$ had similar scores, with White students slightly higher on five of six measures.

Gender

There were no significant differences. Girls $(n=17)$ scored higher than boys $(n=14)$ on all seven measures of problem-solving performance.

IEP Status

Students without IEPs $(n=23)$ scored higher than students with IEPs $(n=8)$ on all seven measures of problem-solving performance, with five significant differences (all except Problem Average Word Count and Number of Higher-Order Representations). 
Sending School District

There were no significant differences on the seven measures of problem-solving performance. Students from out of district $(n=12)$ scored slightly higher than students within district $(n=19)$ on six of seven measures (all except Decisions Made Scale Score).

Socioeconomic Status (SES)

There were no significant differences on the seven measures of problem-solving performance. High-SES students $(n=10)$ scored slightly higher than Low-SES students $(n=21)$ on six measures (all except Number of HOIR) . 
Table 42

Summary of Math-Related Attitude Measures as Possible Correlates of Performance on Nonroutine Mathematics Problems $(N=31)$

Mathematics-Related Affect

There were two significant positive correlations (Getting Answer, Total Rubric Score) and one trend-level significant $(.05 \leq p<.10)$ positive correlation [Number of Higher-Order Internal Representations (HOIR)] with the seven measures of problem-solving performance. The more confidence students have in performing mathematical tasks, the higher their problem-solving performance.

Parents' Attitudes

There were no significant correlations with any of the seven measures of problem-solving performance.

Usefulness

There were no significant correlations with any of the seven measures of problem-solving performance.

Male Domain

There were no significant correlations with any of the seven measures of problem-solving performance.

Success

There were no significant correlations with any of the seven measures of problem-solving performance.

Teacher

There were no significant correlations with any of the seven measures of problem-solving performance.

Rotter's Internal-External Locus of Control Scale

There were no significant correlations with any of the seven measures of problem-solving performance. 
Preferred Mathematical Solutions

There were significant group-differences on four of the seven problem-solving variables (Understanding, Decisions Made, Total Rubric Scores, Number of HigherOrder Representations). In each case, the means of the Hybrid group $(n=2)$ were significantly higher than the means of the Algebraic $(n=4)$, Pictorial $(n=14)$, and Tabular $(n=9)$ groups, which did not differ significantly from each other. 
Table 43

Summary of Values Measures as Possible Correlates of

Performance on Nonroutine Mathematics Problems $(N=31)$

Accepting-Investigative Scale (AI)

There were no significant correlations with any of the seven measures of problem-solving performance.

Carefree-Practical Scale (BJ)

There were no significant correlations with any of the seven measures of problem-solving performance.

Conformity-Independence Scale (CK)

There were no significant correlations with any of the seven measures of problem-solving performance.

Supportive-Leadership Scale (DL)

There were no significant correlations with any of the seven measures of problem-solving performance.

Flexibility-Orderliness Scale (EM)

There were no significant correlations with any of the seven measures of problem-solving performance.

Privacy-Recognition Scale (FN)

There was a significant, positive correlation with the Number of Higher-Order Internal Representations (HOIR). I.e., the more that students sought recognition for their accomplishments, the more HOIRs they tended to use in their problem solving.

Realistic-Aesthetic Scale (GO)

There were no significant correlations with any of the seven measures of problem-solving performance.

Reserved-Social Scale (HP)

There were no significant correlations with any of the seven measures of problem-solving performance. 
Table 44

Summary of Aptitude, Achievement and Experience Measures as Possible Correlates of Performance on Nonroutine Mathematics Problems $(N=31)$

NWEA Language Usage

There were no significant correlations with any of the seven measures of problem-solving performance.

NWEA Mathematics

There were four significant positive correlations [How One Solved It, Getting Answer, Total Rubric Score, Number of Higher-Order Internal Representations (HOIR)]. There were positive trend-level significant $(.05 \leq p<$ .10) correlations on two measures (Understanding, Decisions Made).

NWEA Reading

There were no significant correlations with any of the seven measures of problem-solving performance.

Math Skills

There were no significant correlations with any of the seven measures of problem-solving performance.

Essay Rubric Score

There was one significant positive correlation (Problem Average Word Count). The higher the students" "My Math Experiences" essay rubric score, the more words students wrote, on average, across the six nonroutine math problems.

Essay Word Count

There was one significant positive correlation (Number of HOIR). The more students wrote on their "My Math Experiences" essay, the more instances of HOIR they exhibited. 
Table 45

Cohen's d Statistic for Significant Findings between Demographic Variables and Aptitude/Achievement/Experience Variables $(N=31)$

Aptitude/Achievement/Experience Variables

\begin{tabular}{|c|c|c|c|c|c|c|}
\hline $\begin{array}{l}\text { Demographic } \\
\text { Variables }\end{array}$ & $\begin{array}{l}\text { NWEA } \\
\text { Lang . }\end{array}$ & $\begin{array}{l}\text { NWEA } \\
\text { Math }\end{array}$ & $\begin{array}{l}\text { NWEA } \\
\text { Read. }\end{array}$ & $\begin{array}{l}\text { Math } \\
\text { Skills }\end{array}$ & $\begin{array}{c}\text { Essay } \\
\text { Rubric } \\
\text { Score }\end{array}$ & $\begin{array}{l}\text { Essay } \\
\text { Word } \\
\text { Count }\end{array}$ \\
\hline
\end{tabular}

Age

Art

Discipline

Attendance

$0.81^{\mathrm{a}}$

Ethnicity

$\mathrm{T}^{\mathrm{b}}$

$\mathrm{T}$

Gender

1.53

0.90

0.99

1.49

IEP

$\begin{array}{lll}0.93 & 1.50 & 1.32\end{array}$

Sending

District

Socio-

economic

Status

${ }^{a}$ small effect size: $0.2 \leq d<0.5$;

medium effect size: $0.5 \leq d<0.8$;

large effect size: $\quad d \geq 0.8$

$\mathrm{b}_{\mathrm{T}}$ indicates trend-level significanct $(.05 \leq p<.10)$ 
Table 46

Cohen's d Statistic for Significant Findings between MathRelated Attitude Variables and Aptitude/Achievement/Experience Variables $(N=31)$

Aptitude/Achievement/Experience Variables

\begin{tabular}{|c|c|c|c|c|c|c|}
\hline $\begin{array}{l}\text { Math-Related } \\
\text { Attitude } \\
\text { Variables }\end{array}$ & $\begin{array}{l}\text { NWEA } \\
\text { Lang • }\end{array}$ & $\begin{array}{l}\text { NWEA } \\
\text { Math }\end{array}$ & $\begin{array}{l}\text { NWEA } \\
\text { Read. }\end{array}$ & $\begin{array}{c}\text { Math } \\
\text { Skills }\end{array}$ & $\begin{array}{c}\text { Essay } \\
\text { Rubric } \\
\text { Score }\end{array}$ & $\begin{array}{l}\text { Essay } \\
\text { Word } \\
\text { Count }\end{array}$ \\
\hline \multicolumn{7}{|l|}{$\begin{array}{l}\text { Math-Related } \\
\text { Affect }\end{array}$} \\
\hline \multicolumn{7}{|l|}{$\begin{array}{l}\text { Parent's } \\
\text { Attitude }\end{array}$} \\
\hline \multicolumn{7}{|l|}{ Usefulness } \\
\hline Male Domain & $1.00^{\mathrm{a}}$ & $\mathrm{T}^{\mathrm{b}}$ & 1.00 & & 0.87 & \\
\hline \multicolumn{7}{|l|}{ Success } \\
\hline Teacher & & & & & & 0.81 \\
\hline \multicolumn{7}{|l|}{$\begin{array}{l}\text { Locus of } \\
\text { Control }\end{array}$} \\
\hline $\begin{array}{l}\text { Preferred } \\
\text { Math } \\
\text { Solution }\end{array}$ & 1.25 & & & & & \\
\hline
\end{tabular}

${ }^{a}$ small effect size: $0.2 \leq d<0.5$; medium effect size: $0.5 \leq d<0.8$; large effect size: $\quad d \geq 0.8$

$\mathrm{b}_{\mathrm{T}}$ indicates trend-level significanct $(.05 \leq p<.10)$ 
Table 47

Cohen's d Statistic for Significant Findings between Values Variables and Aptitude/Achievement/Experience Variables $(N=31)$

Aptitude/Achievement/Experience Variables

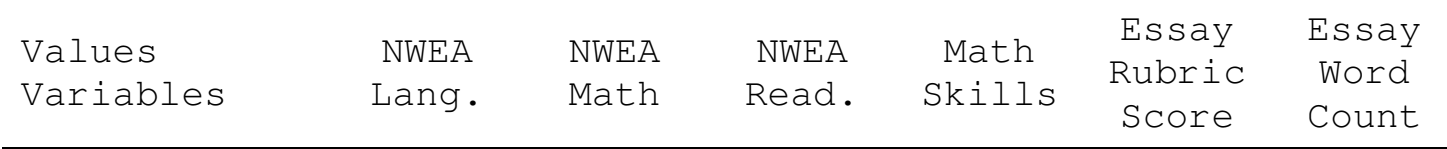

Accepting-

Investiga-

tive

AI)

Carefree-

Practical

(BJ)

Conformity-

Independence $\quad 1.19 \quad 1.12 \quad 1.15 \quad 0.84$

(CK)

Supportive-

Leadership

(DL)

Flexibility-

Orderliness

(EM)

Privacy-

Recognition

0.84

$0.81^{a}$

$\mathrm{T}^{\mathrm{b}}$

$\mathrm{T}$

( $\mathrm{EN})$

Realistic-

Aesthetic

(GO)

$\begin{array}{llll}1.24 & 1.22 & 1.34 & 0.87\end{array}$

$\mathrm{T}$

Reserved-

Social

(HP)

$\begin{array}{lc}{ }^{\mathrm{a}} \text { small effect size: } & 0.2 \leq d<0.5 ; \\ \text { medium effect size: } & 0.5 \leq d<0.8 ; \\ \text { large effect size: } & d \geq 0.8 \\ \mathrm{~b}_{\mathrm{T}} \text { indicates trend-level significant }(.05 \leq p<.10)\end{array}$ 
Table 48

Cohen's d Statistic for Significant Findings between Demographic Variables and Performance Variables on Nonroutine Problems $(N=31)$

\begin{tabular}{|c|c|c|c|c|c|c|c|}
\hline $\begin{array}{l}\text { Demographic } \\
\text { Variables }\end{array}$ & $\begin{array}{l}\text { Under- } \\
\text { stand- } \\
\text { ing }\end{array}$ & $\begin{array}{l}\text { Performar } \\
\text { How one } \\
\text { Solved } \\
\text { It }\end{array}$ & $\begin{array}{l}\text { e Vari } \\
\text { Deci- } \\
\text { sions } \\
\text { Made }\end{array}$ & $\begin{array}{l}\text { oles on } \mathrm{N} \\
\text { Getting } \\
\text { Answer }\end{array}$ & $\begin{array}{c}\text { nroutine } \\
\text { Total } \\
\text { Rubric } \\
\text { Score }\end{array}$ & $\begin{array}{l}\text { Problems } \\
\text { Number } \\
\text { of HOIR }\end{array}$ & $\begin{array}{l}\text { Average } \\
\text { Word } \\
\text { Count }\end{array}$ \\
\hline \multicolumn{8}{|l|}{ Age } \\
\hline \multicolumn{8}{|l|}{$\begin{array}{l}\text { Art } \\
\text { Discipline }\end{array}$} \\
\hline \multicolumn{8}{|l|}{ Attendance } \\
\hline Ethnicity & $T^{a}$ & $\mathrm{~T}$ & $\mathrm{~T}$ & $\mathrm{~T}$ & $\mathrm{~T}$ & & $\mathrm{~T}$ \\
\hline \multicolumn{8}{|l|}{ Gender } \\
\hline IEP & $1.29^{\mathrm{b}}$ & 1.12 & 1.25 & 1.24 & 1.28 & & \\
\hline \multicolumn{8}{|l|}{$\begin{array}{l}\text { Sending } \\
\text { District }\end{array}$} \\
\hline $\begin{array}{l}\text { Socio- } \\
\text { economic }\end{array}$ & & & & & & & \\
\hline
\end{tabular}

${ }^{\mathrm{a}} \mathrm{T}$ indicates trend-level significant $(.05 \leq p<.10)$

${ }^{b}$ small effect size: $0.2 \leq d<0.5$; medium effect size: $0.5 \leq d<0.8$; large effect size: $\quad d \geq 0.8$ 
Table 49

Cohen's d Statistic for Significant Findings between MathRelated Attitude Variables and Performance Variables on Nonroutine Problems $(N=31)$

\begin{tabular}{|c|c|c|c|c|c|c|c|}
\hline \multirow[b]{2}{*}{$\begin{array}{l}\text { Math-Related } \\
\text { Attitude } \\
\text { Variables }\end{array}$} & \multirow[b]{2}{*}{$\begin{array}{l}\text { Under- } \\
\text { stand- } \\
\text { ing }\end{array}$} & \multicolumn{4}{|c|}{ Performance Variables on Nonroutine } & \multicolumn{2}{|l|}{ Problems } \\
\hline & & $\begin{array}{l}\text { How one } \\
\text { Solved } \\
\text { It }\end{array}$ & $\begin{array}{l}\text { Deci- } \\
\text { sions } \\
\text { Made }\end{array}$ & $\begin{array}{l}\text { Getting } \\
\text { Answer }\end{array}$ & $\begin{array}{l}\text { Total } \\
\text { Rubric } \\
\text { Score }\end{array}$ & $\begin{array}{l}\text { Number } \\
\text { of HOIR }\end{array}$ & $\begin{array}{l}\text { Average } \\
\text { Word } \\
\text { Count }\end{array}$ \\
\hline $\begin{array}{l}\text { Math-Related } \\
\text { Affect }\end{array}$ & & & & 1.03 & $0.94^{\mathrm{a}}$ & $\mathrm{T}^{\mathrm{b}}$ & \\
\hline \multicolumn{8}{|l|}{$\begin{array}{l}\text { Parent's } \\
\text { Attitude }\end{array}$} \\
\hline \multicolumn{8}{|l|}{ Usefulness } \\
\hline Male Domain & & & & & & & \\
\hline \multicolumn{8}{|l|}{ Success } \\
\hline Teacher & & & $\mathrm{T}$ & & & & $\mathrm{T}$ \\
\hline \multicolumn{8}{|l|}{$\begin{array}{l}\text { Locus of } \\
\text { Control }\end{array}$} \\
\hline $\begin{array}{l}\text { Preferred } \\
\text { Math } \\
\text { Solution }\end{array}$ & 1.25 & $\mathrm{~T}$ & 1.34 & $\mathrm{~T}$ & 1.28 & 1.40 & \\
\hline
\end{tabular}

${ }^{a}$ small effect size: $0.2 \leq d<0.5$; medium effect size: $0.5 \leq d<0.8$; large effect size: $\quad d \geq 0.8$

$\mathrm{b}_{\mathrm{T}}$ indicates trend-level significant $(.05 \leq p<.10)$ 
Table 50

Cohen's d Statistic for Significant Findings between Values Variables and Performance Variables on Nonroutine Problems $(N=31)$

\begin{tabular}{|c|c|c|c|c|c|c|c|}
\hline \multirow[b]{2}{*}{$\begin{array}{l}\text { Values } \\
\text { Variables }\end{array}$} & \multirow[b]{2}{*}{$\begin{array}{l}\text { Under- } \\
\text { stand- } \\
\text { ing }\end{array}$} & \multicolumn{4}{|c|}{ Performance Variables on Nonroutine } & \multirow{2}{*}{$\begin{array}{l}\text { Problems } \\
\text { Number } \\
\text { of HOIR }\end{array}$} & \multirow[b]{2}{*}{$\begin{array}{c}\text { Average } \\
\text { Word } \\
\text { Count }\end{array}$} \\
\hline & & $\begin{array}{l}\text { How one } \\
\text { Solved } \\
\text { It }\end{array}$ & $\begin{array}{l}\text { Deci- } \\
\text { sions } \\
\text { Made }\end{array}$ & $\begin{array}{l}\text { Getting } \\
\text { Answer }\end{array}$ & $\begin{array}{l}\text { Total } \\
\text { Rubric } \\
\text { Score }\end{array}$ & & \\
\hline \multicolumn{8}{|l|}{$\begin{array}{l}\text { Accepting- } \\
\text { Investiga- } \\
\text { tive } \\
\text { AI) }\end{array}$} \\
\hline \multicolumn{8}{|l|}{$\begin{array}{l}\text { Carefree- } \\
\text { Practical } \\
(\mathrm{BJ})\end{array}$} \\
\hline $\begin{array}{l}\text { Conformity- } \\
\text { Independence } \\
(\mathrm{CK})\end{array}$ & & & & & & $\mathrm{T}$ & \\
\hline \multicolumn{8}{|l|}{$\begin{array}{l}\text { Supportive- } \\
\text { Leadership } \\
\text { (DL) }\end{array}$} \\
\hline \multicolumn{8}{|l|}{$\begin{array}{l}\text { Flexibility- } \\
\text { Orderliness } \\
(\mathrm{EM})\end{array}$} \\
\hline $\begin{array}{l}\text { Privacy- } \\
\text { Recognition } \\
(\mathrm{FN})\end{array}$ & & & & $\mathrm{T}$ & & $0.84^{a}$ & \\
\hline $\begin{array}{l}\text { Realistic- } \\
\text { Aesthetic } \\
(\mathrm{GO})\end{array}$ & & & & & & $T^{b}$ & \\
\hline $\begin{array}{l}\text { Reserved- } \\
\text { Social } \\
\text { (HP) }\end{array}$ & & & & & & & \\
\hline
\end{tabular}

${ }^{a}$ small effect size: $0.2 \leq d<0.5$; medium effect size: $0.5 \leq d<0.8$; large effect size: $\quad d \geq 0.8$

$\mathrm{b}_{\mathrm{T}}$ indicates trend-level significant $(.05 \leq p<.10)$ 
Table 51

Cohen's d Statistic for Significant Findings between Aptitude/Achievement/Experience Variables and Performance Variables on Nonroutine Problems ( $N=31)$

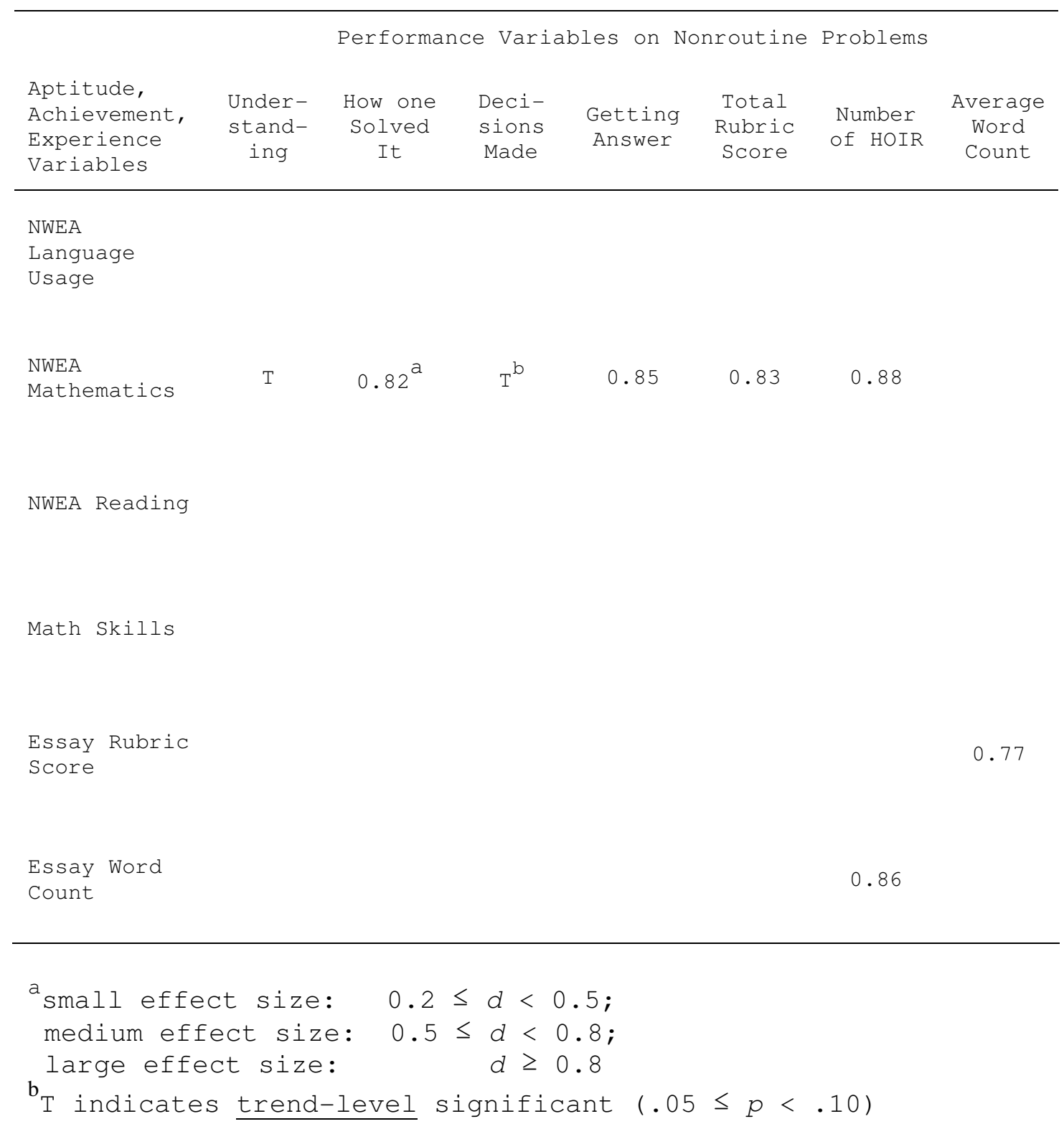




\section{Introduction to the Intensity Product Statistic}

As stated in the APA Publication Manual (2002), $p$-values do not directly reflect "the magnitude of an effect or the strength of a relationship" and "it is almost always necessary to include some index of effect size or strength of relationship in your Results section" (p. 25). This was the impetus behind the inclusion of Cohen's $d$ statistic in the previous tables as an index of effect size.

As a further method of distinguishing the strength of effect between the three categories of sources of possible correlates in Figure 3: Demographics, Math-Related Attitudes, and Values, I developed the concept of the Significant p-Value Density (SPD) and the Intensity Product Statistic (IPS).

For a correlation matrix with only significant $p$-values considered:

The Significant p-Value Density (SPD) is defined as:

$$
\begin{aligned}
& \mathrm{SPD}=\frac{\text { total number of significant } p \text {-values }}{\text { total number of bivariate analyses }} \\
& \text { SPD can range from } 0 \text { (no significant relationships) to } 1 \text { (all relationships }
\end{aligned}
$$
significant).

$\mathrm{AES}=$ Average Effect Size which is the arithmetic mean of all effect sizes in the matrix calculated for significant $p$-values.

$$
\mathrm{AES}=\frac{\sum d(\text { whenever } p \text { is sig. })}{\text { number of sig. } p \text {-values }}
$$


I define the Intensity Product Statistic (IPS) as:

$\mathrm{IPS}=\mathrm{SPD} \times \mathrm{AES}$

Therefore,

IPS $=\frac{\sum d(\text { whenever } p \text { is sig. })}{\text { total number of analyses }}$

Note. I found no similar metrics in the literature comparable to either my concept of SPD or IPS.

Table 52 provides the significant $p$-value density (SPD), the average effect size (AES), based on Cohen's $d$ statistic, and the Intensity Product Statistic (IPS) for the three categories of possible correlates (Demographics, Math-Related Attitudes, Values) of the two categories of criterion-variables (Aptitude/Achievement/Experience Variables; Performance Variables on Nonroutine Math Problems).

As shown in Table 52, the 24 measures of possible correlates had a greater intensity (IPS $=0.17$ ) with the category of Aptitude/Achievement/Experience Variables than the category of Performance Variables on Nonroutine Math Problems $($ IPS $=0.08)$. 


\begin{tabular}{|c|c|c|c|c|c|c|}
\hline \multirow{3}{*}{$\begin{array}{l}\text { Summary of Relative } \\
(N=31) \\
\text { Categories of } \\
\text { possible correlates }\end{array}$} & \multicolumn{6}{|c|}{ Intensity for Sources of Correlates } \\
\hline & \multicolumn{3}{|c|}{$\begin{array}{c}\text { Aptitude/Achievement/ } \\
\text { Experience } \\
\text { Variables } \\
\text { (six measures) }\end{array}$} & \multicolumn{3}{|c|}{$\begin{array}{c}\text { Performance } \\
\text { Variables on } \\
\text { Nonroutine Math } \\
\text { Problems } \\
\text { (seven measures) }\end{array}$} \\
\hline & SPD & $\mathrm{AES}$ & IPS & SPD & AES & IPS \\
\hline $\begin{array}{c}\text { Demographics } \\
\text { (eight measures) }\end{array}$ & .167 & 1.18 & 0.20 & .089 & 1.24 & 0.11 \\
\hline $\begin{array}{c}\text { Math-Related } \\
\text { Attitude } \\
\text { Variables } \\
\text { (eight measures) }\end{array}$ & .104 & 0.99 & 0.10 & .107 & 1.21 & 0.13 \\
\hline $\begin{array}{l}\text { Values } \\
\text { (eight measures) }\end{array}$ & .208 & 1.06 & 0.22 & .017 & 0.84 & 0.01 \\
\hline Column Means & .160 & 1.08 & 0.17 & .071 & 1.10 & 0.08 \\
\hline
\end{tabular}

Some key observations included:

1. The eight measures of Demographics had a higher density of significant findings (SPD = .167) for measures of aptitude/achievement/experience than for measures of problem solving (SPD = .089). However, average effect size was very slightly stronger with measures of problem solving $(\mathrm{AES}=1.24)$ than with measures of aptitude/achievement/experience $(\mathrm{AES}=1.18)$. 
2. The eight measures of Math-Related Attitudes had similar densities of significant findings $(\mathrm{SPD}=.104)$ for measures of aptitude/achievement/experience and for measures of problem solving $(\mathrm{SPD}=.107)$. However, average effect size was stronger with measures of problem solving $(\mathrm{AES}=1.21)$ than with measures of aptitude/achievement/experience $(\mathrm{AES}=0.99)$.

3. The greatest disparities appeared with the category of eight Values measures. For measures of aptitude/achievement/experience, SPD = .208 compared to SPD $=.017$ for measures related to problem-solving performance. Likewise, the average effect size was greater for measures of aptitude/achievement/experience $(\mathrm{AES}=1.06)$ compared with the average effect size for measures related to problem solving $(\mathrm{AES}=0.84)$. Consequently the intensity product statistic was greater for measures of aptitude/achievement/experience (IPS $=0.22$ ) than for measures of problem solving $($ IPS $=0.01)$. 


\section{Discussion}

\section{Foundations for Generalizability}

A major feature that separated my research from previous studies was the extent of the generalizability that I could claim, based on five key elements: impact of consent; NWEA as an achievement metric; demographic heterogeneity; students' perception of the researcher; and reporting of effect sizes.

\section{Impact of Consent}

For purposes of ensuring ethical treatment, research in school settings such as mine, has required written permission by parents for their children to participate. In a study by Blom-Hoffman et al. (2009), published school-based prevention and intervention literature was examined to assess the state of the field in terms of consent procedures and participation rates. They found that a major flaw with the published literature was the lack of information pertaining to recruitment procedures, response rate, and consent status (consent-granted, no-reply, or consent-denied). "Of nearly 500 studies reviewed, only $11.5 \%$ reported both consent procedures and participation rates. Studies using active consent procedures had a mean participation rate of $65.5 \%$ (range: $11-100 \%)$ " (Blom-Hoffman et al., 2009, p. 3). Of concern was the potential for sample bias. Students of parents granting consent may not be representative of the eligible population. In one of the few empirical studies specifically evaluating sample bias resulting from a requirement for written parental consent, Kearney, Hopkins, Mauss, and Weisheit (1983) contacted 1,618 parents of students across grades four 
through 12 for written permission for the students to complete questionnaires related to alcohol and drugs. Of the eligible population, $51 \%$ granted permission, $34 \%$ did not respond, and 15\% denied consent. A major finding by Kearney et al. (1983) was that there was a difference in response patterns from parents of students across racial/ethnic groups -“white children are substantially overrepresented among the participants and that black and, particularly, Asian students are underrepresented" (p. 99). Other findings included no evidence of sample bias with respect to student gender, and mixed results with regards to academically related measures (i.e., reading and vocabulary test scores).

In my study, all 44 eligible students agreed to participate. Subsequently, all parents consented to allow their child to participate. Eventually, the number of actual participants declined to 38 , solely because of students leaving the school district. Further, of the 38 actual participants, despite their ability to end their participation in the research at any point, none chose to do so. These rates of initial consent and complete participation effectively eliminated concerns over sample bias in my study.

\section{NWEA as an Achievement Metric}

An advantage of my study was the ability to access achievement data for students' performance on the Northwest Evaluation Association's (NWEA) Mathematics, Reading, and Language Usage tests (which all Beacon students are required to take twice a year). The NWEA tests, available across the nation, are the only highly reliable, valid, and externally scored assessments with a scale that reflect students' achievement levels, independent of age and grade. Many previous studies 
have used state tests and home-grown assessments as criterion-variables. This might limit their generalizability, insofar as, the proficiency levels vary from state to state (Olson, 2003) as well as at the school district and classroom levels.

\section{Demographic Heterogeneity}

My exploratory study involved students drawn from seven different school districts, ranging from the National Center for Education Research's (NCES) urbancentric locale codes of Rural: Fringe to City: Midsize (Table 2). Thus, my research involved students entering Beacon with various mathematics experiences and abilities from a variety of community types and across a range of socioeconomic status (SES). The sample was fairly evenly split between girls and boys. However, the percentage of the number of students with Individualized Education Plans (IEPs) with regards to full inclusion (i.e., general education with support) was approximately twice the state average (only the Rhode Island School for the Deaf had a higher percentage of special needs students). Furthermore, all Beacon math classes were grouped homogeneously by grade but heterogeneously by ability (i.e., there was no tracking). Unlike previous studies that have focused on the math performance of specific groups, such as students of a particular ethnicity (e.g., Gutiérrez, 2000), gifted children (e.g., Glennon, 1957), children with learning disabilities (e.g., Cawley, Fitzmaurice, Shaw, Kahn, \& Bates III, 1979), female math students (e.g., Leder, 1980), and private schools (e.g., Sander, 1997), I have greater generalizability due to the demographic diversity of my sample. 


\section{Students' Perception of the Researcher}

McCall and Simmons (1969) stated:

...it is extremely useful for the observer to acquire some advanced knowledge of the role structure among the subjects and to determine where he is most likely to fit within that structure. The role which he claims - or to which he is assigned by the subjects—is perhaps the single most important determinant of what he will be able to learn (p. 29).

In many studies in school settings, the researchers are strangers. Often they are not part of the learning community, but, have been granted permission to observe classes or administer instruments. Most problematic to the researcher is that the subjects do not know how to be studied: "they do not know what he expects of them or offers to them. Does he know all? What does he want to know? What does he deserve to know? “(McCall \& Simmons, 1969, p. 28). In such circumstances, it is hard to determine the extent of behavioral changes by subjects in the study. If the researcher chooses to be invisible, any behavior changes are independent of researcher affect. However, the researcher most likely has distanced himself from his subjects to the point of compromising the capture of at least some data. On the other hand, the researcher being in close proximity most likely affects the subjects' social environment and thereby influences behavior changes (i.e., induces distortion). The question becomes whether or not the behavioral changes significantly affect the data. 
In my study, the ninth-grade students whom I had previously taught in the Fall of 2007 were excluded from eligibility in the research. Further, the timing of the research on ninth-graders taking math with me in the Spring of 2008, and the small size of Beacon Charter High School, allowed the ninth-grade students at the beginning of the 2007/2008 school-year to become familiar with me as a teacher on the Beacon faculty - rather than a stranger in the building. They saw me at school events and were familiar with my role as advisor to several school clubs. And, students talk to each other. Most likely they had already heard of my teaching ability/style from former students of mine. This relationship was important in the consent acquisition stage (Blom-Hoffman et al., 2009) and most likely contributed to students' $100 \%$ consent rate and participation rate and for their extraordinary cooperation during the data acquisition component of my research.

\section{Reporting Effect Sizes}

The American Psychological Association's (APA) 2002 Publication Manual (5th Ed.) lists the failure of reporting effect sizes as a common defect found by editors of submitted papers. It was surprising to find that the majority of studies relevant to my research failed to report effect sizes. As previously discussed, $p$-values do not directly reflect the magnitude of an effect or the strength of a relationship. Therefore, when I found significant $p$-values, I used Cohen's $d$ statistic as my index of effect size. 


\section{Summary of Findings and Conclusions}

Demographic Measures as Possible Correlates of Aptitude, Achievement, and Experience

There were no significant findings $(p<.05)$ for relationships between five out of the eight demographic variables: age; art discipline (i.e., culinary, theater, or visual arts); ethnicity; sending district (i.e., inside district or outside district); SES (i.e., free/reduced lunch or fully paid) with aptitude/achievement/experience variables (Table 45). Of these, the lack of significant findings with SES is promising, in that the meta-analyses of Sirin (2005), who analyzed studies between 1990 and 2000, reported higher achievement for students of higher SES. In my study, although high SES students consistently outperformed low SES students on all six measures of aptitude/achievement/experience variables, differences were neither trend-level significant $(.05 \leq p<.10)$, or significant $(p<.05)$.

Also promising were trend-level relationships between ethnicity and two measures of Aptitude, Achievement, and Experience (NWEA Mathematics, NWEA Language Usage). Large effect sizes were found in both cases (Table 45). AfricanAmerican students scored higher than both Hispanic and White students. Several past studies have shown that minorities have made significant gains in closing the achievement gap (e.g., Mathews et al., 1984).

Gender and Individualized Education Plan (IEP) status correlated with several measures of Aptitude, Achievement, and Experience. Girls outperformed boys on four of the six measures (NWEA Language Usage, NWEA Mathematics, Essay Rubric 
Score, Essay Word Count) with large effect sizes for all four measures (Table 45). This was a promising outcome, insofar as recent attention has focused on attracting more girls into math and science areas. Although past studies have consistently shown an advantage by males in mathematics achievement, the differences have been insignificant (Fennema \& Sherman, 1976; Friedman, 1989; Swafford, 1980).

Students without IEPs scored significantly higher than students with IEPs on the NWEA Language Usage, Mathematics, and Reading tests, with large effect sizes in all three cases (Table 45). The lower performance on both the mathematics and reading tests by students with IEPs paralleled findings by Lewis et al. (1994).

There was only one significant correlation found between students' attendance and Aptitude/Achievement/Experience variables (Essay Rubric Score). The correlation was negative, suggesting that the more days a student was absent, the higher the rubric score on My Math Experiences Essay. This outcome was the opposite of what I would have predicted (refer to my discussion of attendance in the Limitations section of this chapter). 
Math-Related Attitudes as Possible Correlates of Aptitude, Achievement, and Experience

An abundance of research in the literature had long established that, at best, there was a weak-to-moderate positive correlation between general attitudes toward mathematics and achievement (Aiken, 1970a, 1976; Anttonen, 1967; Husén, 1967; Neale, 1969; Ryan, 1968) with correlations in the consistent range of approximately .20 to .40 . My results revealed an apparent overall general lack of effect of students' attitudes with regards to Aptitude/Achievement/Experience variables with only $10 \%$ of the bivariate analyses producing significant correlations. Of particular note, there were no significant correlations between the eight measures of Math-Related Variables and the two math specific achievement variables: NWEA Math and Math Skills. This finding supports the suggestion by Neale (1969) that attitudes toward mathematics had little effect on mathematics achievement (see my comments in "Reflection on Future Research" - this chapter). However, three of the Math-Related Attitude variables (Male Domain Scale, Teacher Scale, Preferred Mathematical Solution [PMS]) produced significant findings and large effect sizes with one or more of the other six Aptitude/Achievement/Experience variables (Table 46):

Three significant findings (NWEA Language Usage, NWEA Reading, Essay Word Count) along with large effect sizes were found for the Male Domain Scale of the Shortened Form of the Fennema - Sherman Mathematics Attitudes Scales (FSMAS-SF). The results were promising from the standpoint that the less the students (girls and boys) perceived mathematics as a male domain, the higher they achieved. 
A large effect size was found between the Teacher Scale on the Shortened Form of the Fennema - Sherman Mathematics Attitudes Scales (FSMAS-SF) and the Essay Word Count. The correlation was negative and leads to an unexpected interpretation - the more that students perceived their teacher as having positive attitudes toward them as learners of mathematics, the less they tended to write on their essay.

Values Variables as Possible Correlates of Aptitude, Achievement, and Experience

Three Values Scales (Conformity-Independence; Privacy-Recognition; Realistic-Aesthetic) produced significant findings with one or more of the six Aptitude/Achievement/Experience variables:

With regards to the Conformity-Independence Scale, the more students valued working on their own, the higher they achieved on the NWEA Language Usage, NWEA Mathematics, NWEA Reading tests, and the Math Skills assessment, with large effect sizes in all four cases (Table 47).

With regards to the Privacy-Recognition Scale, students who valued fame and contact with important people tended to achieve more on the NWEA Language Usage and NWEA Mathematics tests, with large effect sizes in both cases (Table 47).

With regards to the Realistic-Aesthetic Scale, the more students valued the artistic world, the higher they achieved on the NWEA Language Usage, NWEA 
Mathematics, NWEA Reading tests, and the Math Skills assessment, with large effect sizes in all four cases (Table 47).

It is interesting to note that the three scales that produced significant positive correlations and large effect sizes with the NWEA tests were directly related to the art world - artists generally work alone, seek fame, and certainly appreciate art.

Furthermore, these findings coincide with the results reported in Table 17, wherein Beacon students were at the 82 nd percentile nationally on the Realistic-Aesthetic (meaning they strongly appreciated the art world more than peers across the nation) and the results reported in Table 19, wherein Beacon students' two highest mean scores on the fourteen possible major occupational groups were Arts Professional and Arts Skilled. The consistency in the results and the underlying art theme nicely coincides with the focus of the Beacon Charter High School for the Arts.

Demographic Measures as Possible Correlates of Performance Variables on Nonroutine Problems

Students' age at the beginning of the research; chosen art discipline (i.e., culinary, theater, or visual arts); attendance rate in the semester prior to the research; sending school district (i.e., inside district or outside district); and socioeconomic status (free/reduced lunch or fully paid), were not found to be correlates for either students' aptitude/achievement/experience measures or problem-solving ability. 
Ethnicity was trend-level significant $(.05 \leq p<.10)$ on six of the seven problem-solving measures (not on Number of Higher Order Internal Representations [HOIR]).

The major significant findings were with IEP status. Students without IEPs scored higher on all seven measures of performance on nonroutine problems with five of the seven being significant (not on [HOIR] or Average Word Count), with large effect sizes in the five significant cases (Table 48). An interesting finding was that there was no significant difference between students with IEPs and students without IEPs in their ability to demonstrate higher-order internal representations (HOIR) in problem solving or in the average number of words they wrote during their problem solving experience - two promising outcomes.

\section{Math-Related Attitudes as Possible Correlates of Performance Variables on Nonroutine Problems}

A similar pattern to the relationship between Math-Related Attitudes and aptitude/achievement/experience measures was also found with problem-solving measures: There was an apparent overall general lack of effect of students' attitudes with regards to performance variables on nonroutine problems with only $11 \%$ of the bivariate analyses producing significant correlations (Table 49). However, there were two Math-Related Attitude variables (Math-Related Affect (i.e., confidence), Preferred Mathematical Solution [PMS]) that produced significant findings with one or more of the seven problem-solving measures. 
Of particular note, were the large effect sizes between Preferred Mathematical Solution (PMS) and four of the seven problem solving measures (Understanding, Decisions Made, Total Rubric Score, Number of HOIR) providing strong evidence of students' math-aesthetics in problem solving. Specifically, students who had high Preferred Mathematical Solution (PMS) scores were better problem solvers. Students who were able to appreciate more than one type of solution (Hybrids) scored consistently higher in problem-solving measures and frequency of use of higher-order internal representations (HOIR) than the Algebraic, Pictorial, and Tabular groups, which did not differ significantly from each other. In contrast, PMS was not a correlate of aptitude/achievement/experience measures. Further evidence for the significance of math-aesthetics was presented in Table 28 in which the students' ranking of the nonroutine problems compared to their success in solving the problem revealed the pattern: The more students liked a problem, the higher was their problemsolving performance. This suggests that aesthetics may play a key role in student engagement in problem solving.

Values Variables as Possible Correlates of Performance Variables on Nonroutine Problems

Only one significant finding resulted between the eight Values scales and the seven problem-solving measures (Privacy-Recognition Scale and the Number of HOIR) (Table 50). Students who favored seeking fame and wanted to associate with famous people demonstated more instances of higher-order internal representation. 
Correlations between Aptitude/Achievement/Experience Variables and Performance Variables on Nonroutine Problems

As shown in Table 51, there were only five significant relationships (all with large effect sizes) between the six aptitude/achievement/experience measures and the seven problem-solving measures. NWEA Mathematics was significantly positively correlated, with large effect sizes, on three of the seven problem-solving measures (How One Solved It, Getting Answer, Total Rubric Score) and thus a strong predictor of a student's performance in problem solving but not in their use of higher-order internal representation. Essay Rubric score was significantly positively correlated with Average Word Count (the higher students achieved in writing skills the more words they wrote on their six nonroutine problems). There was also a significantly positive correlation between My Math Experiences Essay Word Count and the Number of HOIR. These latter two findings suggests a linkage between language usage and mathematics.

From Table 52, in terms of my Intensity Product Statistic (IPS), the 24 measures of possible correlates had a greater overall effect (more than two-to-one) on the six measures of aptitude/achievement/experience than on the seven measures of problem solving. 


\section{What the Qualitative Data Analyses Revealed}

From the students' narrative responses on the Aesthetic Ranking Questionnaire, "easy" was the most frequently used word (Table 32). Unfortunately, only $24 \%$ who thought a problem was easy, got the correct answer. This result coincides with Husén's (1967) findings in a study of the International Project for the Evaluation of Educational Achievement (IEA) conducted between 1960 - 1964, involving 12 countries. Husén (1967) found that U.S. thirteen year-old students ranked second out of 12 countries in believing that mathematics allowed for various approaches to solving problems and that math was easy to learn, but ranked tenth in mathematics achievement. Discussing the results of this study, Neale (1969) stated “...attitudes appear to be independent of mathematics achievement" (p. 632). This latter quote also matches my findings with regards to math-related attitudes and achievement previously discussed in this chapter.

In my content analyses of the essays from the seven students who demonstrated two or more instances of higher-order internal representations, there was no mention of family support beyond elementary school. Furthermore, four of the seven students made no mention of family members at all.

The content analyses of students' narratives provided insight to students' math-aesthetics. For example, as previously discussed, with the least preferred problem (How Many Children Live Next Door?), 19\% of students noted that the problem was hard, made no sense, and/or was confusing because there were no numbers in the problem statement. 
During Jerry's interview, he explained his use of origami to solve the Blind Sided problem, a compelling example of higher-order internal representation. Without my interviews with student participants, such insights into their strategies would have gone undetected.

Both the quantitative and qualitative components of my study confirmed that students do employ Polya's (1945/2004) four stages of problem solving (understanding the problem, devising a plan, carrying out the plan, looking back). This finding was supported by Yong and Kiong (2005).

Furthermore, both methodologies confirmed a close relationship between metacognition, aesthetics, and representation in problem solving.

These findings argue that a qualitative component should be considered in any research on mathematical problem solving.

\section{Limitations}

One limitation to my analyses pertained to attendance. I used the students' attendance data from the Fall of 2007 (the semester prior to my research) as a means of establishing a benchmark. All 31 students in my research did not take math during the fall semester. Therefore, the effect of missing math classes on math achievement or on problem-solving measures could not be assessed and was never intended to be part of my research. The purpose of including the attendance data was to explore how attendance might be related to the many variables considered in this study, particularly 
math-related attitudes. Perhaps, eighth-grade middle school attendance and eighthgrade math grades would have been useful data.

Even though the ethnic composition of the 31 students (four AfricanAmericans, seven Hispanics, 20 Whites) reflected the overall school population, a larger sample of ethnic subgroups would have yielded more powerful statistical analyses.

In this study, students with an IEPs were treated as having learning disabilities in general - I did not refine to the specific content area of disability (e.g., reading, language usage, mathematics). Not all students have a mathematics learning disability. In addition, some of the 31 students without an IEP might have qualified using the widely accepted criteria for defining math learning disabilities based on standardized test math scores and IQ scores (Swanson \& Jerman, 2006).

Given the small numbers of students entering Beacon Charter High School for the Arts (Woonsocket, Rhode Island) from several of the districts, in the analyses involving sending school districts, I compressed the seven districts (Table 2) into two groups: Inside District and Outside District. Those students that had attended Woonsocket Middle School were considered Inside District. Students who had attended middle schools in surrounding communities were considered Outside District. A larger sample size would have allowed a comparison of students' mathematics aptitude/achievement/experience and problem-solving ability by district. Any significant findings between districts could have led to further investigation of possible correlates (e.g., curriculum, teacher experience, pedagogy, resources). 
Further, I found the definitions and use of the classifications of urban, suburban, and rural in the research literature to be problematic for comparison purposes as the terms were not clearly defined. As noted in Table 2, I used the National Center for Education Research's (NCES) urban-centric locale codes (National Center for, 2009b) to describe/distinguish the seven relevant sending school districts.

My research was limited to incoming ninth-grade students. In other words, students who had completed eighth-grade but had not taken a ninth-grade math prior to being a participant. The six nonroutine problems selected were done so as to match the expected math level of the sample. However, incoming students from seven different school districts would most likely have not had the same mathematics experiences. Research in other grade levels might require a different set of problems.

The My Math Regrets Writing Prompt (Figure D2) gave students some direction in writing their My Math Experience Essay. That prompt might have constrained students' thinking of their own experiences to those similar to the prompt's author. 


\section{Future Research}

A worrisome outcome of my study was the consistently low performance of students with IEPs on both aptitude/achievement/experience measures and problemsolving measures. Students with IEPs in Rhode Island are required to take the same state test (NECAP) as non-IEP students, and Beacon Charter High School has a much higher proportion of special needs students than the Rhode Island public high school average. Therefore, students with IEPs at Beacon would be a primary target for problem-solving interventions and their rigorous evaluation.

In an interview with the Beacon Charter High School's Certified Director of Diverse Learners, I confirmed that it is rare for students with IEPs to have a learning disability solely in the area of mathematics (i.e., Math Learning Disability [MLD] ). The majority of students are diagnosed with deficiencies in reading and language usage. Unlike reading disabilities, there exists no specific measures for diagnosing MLDs (Swanson \& Jerman, 2006). Future research is recommended toward developing an instrument for diagnosing MLDs. This would permit the comparative evaluation of problem-solving interventions for students with different patterns of disability.

\section{Some Suggested Interventions}

My study indicated strong links among language usage, mathematics achievement, problem solving, metacognition, aesthetics, and representation. Therefore, improving problem-solving ability might be best served by interventions 
that provide opportunities for students to write as they solve problems (i.e., metacognition), to solve problems of interest (i.e., math-aesthetics), that are nonroutine (i.e., opportunities for representation). As a framework for further research, I would recommend two interventions:

\section{My action/ my metacognition intervention.}

In Figure 5a and 5b, I propose a template based on the format that I developed for the six nonroutine problems in my study. On the left side of Page 1 (Figure 5a) I have provided the prompts Given, Find, and Solution based on Polya's (1945/2004) four stages of problem solving. On the left side of the page, I have provided room for real-time metacognition. This framework can be used for either routine or nonroutine problems. In this particular example, I have modeled my thought process for the students.

The intervention spans two days. On the first day, students complete Page 1. The problem is collected and graded. On the second day, the corrected problem is returned to students to complete (Page 2, Figure 5b). On Page 2 students are asked to reflect upon their problem-solving experience in Part 1. Also, in Part 2, they are asked to investigate alternative solutions from peer students. This latter exercise promotes seeking other methods of representation. 
NAME:

DATE:

Word Problem:

"Share Power"

When Andy, Felicia and Tom started a company, they invested these amounts of money:

Andy - \$1,000

Felicia - \$5,000

Tom - \$7,500

What fraction of the total amount invested was Andy's investment?

\begin{tabular}{|c|c|}
\hline My Action & $\begin{array}{c}\text { My Metacognition } \\
\text { (Explain what you are thinking as you } \\
\text { solve the problem) }\end{array}$ \\
\hline $\begin{array}{l}\text { Given: } \\
\text { three investments: } 1,000,5000 \text {, and } 7,500 \text { dollars }\end{array}$ & $\begin{array}{l}\text { First I need to find the total amount of money } \\
\text { invested to start this company. } \\
\text { This means that I must add the three amounts } \\
\text { that were invested. }\end{array}$ \\
\hline $\begin{array}{l}\text { Find: } \\
\text { the fraction of the total amount invested that } \\
\text { represents Andy's investment }\end{array}$ & $\begin{array}{l}\text { I get } \$ 13,500 \text { as the total amount invested. } \\
\text { This figure represents the Whole. } \\
\text { Each investor contributes a portion or } \\
\text { fraction to the whole. Since there were three }\end{array}$ \\
\hline $\begin{array}{l}\text { Solution: } \\
\text { Total amount invested by all three: }\end{array}$ & $\begin{array}{l}\text { investors, there must be three fractions } \\
\text { involved. And all three fractions must add up } \\
\text { to } 1 \text { (the whole). }\end{array}$ \\
\hline $\begin{array}{l}1,000+\$ 5,000+\$ 7,500=\$ 13,500 \\
\text { Andy’s fraction (portion): } \\
\qquad \frac{\$ 1,000}{\$ 13,500}=\left(\frac{10}{135}\right)\end{array}$ & $\begin{array}{l}\text { Since the question only asks for Andy's } \\
\text { fraction, I divided his investment by the total } \\
\text { amount invested and got } \frac{10}{135} \text {. }\end{array}$ \\
\hline Check: & \\
\hline $\begin{array}{l}\text { Felicia's fraction (portion): } \\
\qquad \frac{\$ 5,000}{\$ 13,500}=\frac{50}{135}\end{array}$ & $\begin{array}{l}\text { Finally, even though I wasn't asked to } \\
\text { calculate Felicia's and Tom's fractions, I } \\
\text { chose to do so as a means of checking my } \\
\text { answer for Andy's fraction. }\end{array}$ \\
\hline $\begin{array}{l}\text { Tom's fraction (portion): } \\
\qquad \frac{\$ 7,500}{\$ 13,500}=\frac{75}{135}\end{array}$ & $\begin{array}{l}\text { I calculated the fractions for Felicia and Tom } \\
\text { and then added them to Andy's. I knew that } \\
\text { all three fractions must add up to a value of } 1 \text {, } \\
\text { which represents the whole. }\end{array}$ \\
\hline $\begin{array}{l}\text { Sum of the parts must }=\text { the Whole: } \\
\frac{10}{135}+\frac{50}{135}+\frac{75}{135}=\frac{10+50+75}{135}=\frac{135}{135}=1 \sqrt{ }\end{array}$ & $\begin{array}{l}\text { It checked out, so my circled answer is } \\
\text { probably correct. }\end{array}$ \\
\hline
\end{tabular}

Figure 5a. Example of a metacognition intervention for problem solving - page 1 


\section{Reflection Activity}

1. Did you get the correct answer?

Yes

No

If no, try to explain what you did wrong:

If yes, compare your method for the correct solution to the one provided.

2. Find a classmate who got the correct answer but used a different method than you (or the solution provided), and explain the different method below:

$\mathrm{M}(\mathrm{N} \& \mathrm{O})-10-4$ Accurately solves problems that involve but are not limited to proportional relationships, percents, ratios, and rates. (The problems might be drawn from contexts outside of and within mathematics including those that cut across content strands or disciplines.) (State).

Problem source: New England Common Assessment Program: Student Practice Test Booklet 2007; Grade 11; p. 4, Problem \#6a.

Figure $5 b$. Example of a metacognition intervention for problem solving - page 2 


\section{Improved nonroutine problem construction.}

Figure 6 shows an example of a nonroutine problem, designed to provide opportunities for employing writing, aesthetics, metacognition, and higher orders of representations throughout the problem-solving process. The problem statement, by providing a scenario that students can relate to, provides a "hook" to encourage the student to read on. Task requirements inherently require the student to write about their feelings toward the problem, explain their thought process, and form internal and external representations (e.g., select geometric shapes, create a mathematical equation, create a table).

Future research could involve comparing the problem-solving achievement of cohorts of students with and without these interventions.

An intriguing result of my exploratory research was the evidence that aesthetics does play a significant part in students' problem-solving activity, as shown in their Preferred Mathematical Solution (PMS), Preferred Problem Choice (PPC), and Number of Higher-Order Internal Representations. Further research might look at what specific characteristics of a mathematical problem might attract student engagement (e.g., relevance, interesting diagram, perceived short time to complete task) or repulse a student (e.g., too many words, no numbers, confusing vocabulary, perceived long time to complete of task). Classification of problem types and multiple solution types with respect to students' math-aesthetic preferences might lead to increased student engagement and, ultimately, better problem solvers. 


\section{How much does that Soda really cost?}

\section{Problem Statement:}

I recently stopped at a fast-food restaurant to purchase a large soda for the long drive home. After I drove off and got on the highway, I began drinking my soda. After just a few sips, it was gone - seems that the cup was filled nearly to the top with ice. I had paid $\$ 1.59$ for the soda plus an $8 \%$ tax. So, given the few sips of soda, what did that soda really cost me?

With a little research, I found the following facts:

The restaurant offers two standard sizes of soda, a 21 ounce (medium) and a 32 ounce cup (large). The 21 ounce soda sells for $\$ 1.39$ and the 32 ounce sells for $\$ 1.59$. The 21 ounce cups cost 3.50 cents each, while the 32 ounce cups cost 8.00 cents. Lids for either size cost 2.00 cents each, straws cost 1.50 cents, and the actual soda costs 1.32 cents per ounce. Assume the ice does not cost anything.

\section{Research questions:}

Given samples of each of the two different size cups, complete the following:

1. Using complete sentences, write a reflective paragraph addressing the following two questions: Has this ever happened to you? How much ice do you normally like in your cup of soda (e.g., no ice, half filled with ice, filled to the brim with ice)?

2. What standard geometric shapes with known equations could be used to represent the shape of the cups? Provide a sketch.

3. From (2) above, create a general mathematical model for each cup shape. Next, calculate the volume of each cup size in cubic inches and then convert to ounces (use the conversion: 1 cubic inch $=0.576$ U.S. fluid ounce). Explain any discrepancies, if any, between the advertised size and your calculations.

4. By experiment, determine if each size cup really holds the advertised volume. Does this volume coincide with filling the cup right to the brim? If not, how high?

5. Cups are rarely filled to the brim to avoid spillage. Determine a reasonable estimate of the actual volume filled? Explain your reasoning.

6. How does the amount of ice a customer uses affect the profit? Create a table showing the profit for each soda size for three cases: no ice, half filled with ice, and filled to the brim with ice. Include the per unit price of the soda paid for each of the three cases in your table.

Note: Make sure you record any part numbers or descriptions from the sample cups that will completely identify the particular cup you are analyzing. Show all work, make neat diagrams and tables, and explain your reasoning along the way!

Figure 6. Proposed nonroutine math problem that promotes writing in mathematics, aesthetics, metacognition, and representation. 
NWEA and Problem Solving

Another recommendation for further research involves assessing the predictability of students' problem-solving ability from the regression equation determined in my study:

Based on the significant results of the bivariate analysis of NWEA Mathematics RIT score as a predictor of problem-solving ability, $r(29)=.384, p=$ .0332 and the large effect size (Cohen's $d=0.83$ ), the following regression equation could be used to predict students' problem-solving ability and to provide insight as to which students would be in need of interventions (replication and reconciliation with another sample of Beacon students would be required).:

Total Problem-Solving Rubric Score $=$

0.451 x (NWEA Mathematics RIT score) - 55.389

Perhaps, with this information, the classroom teacher could select peer tutors from higher achieving students, select lower achieving students for remediation, or use the data to strategically assign group membership.

NECAP and Problem Solving

In my introduction chapter, I stated that improving performance on the Rhode Island state test (the New England Common Assessment Program [NECAP]), was a 
major impetus for my study. I opened my Introduction with a quotation from Branca $(1985, \mathrm{p}, 72)$ that began: "The ability to solve problems is at the heart of mathematics. Mathematics is only "useful" to the extent to which it can be applied to a particular situation...”

I stated that the 2006-2007 state mathematics scores for Rhode Island high school students on the New Standards Reference Examinations (NSRE) revealed that, for each of the 53 high schools, the percent of students reaching the standard for math skills exceeded the percent of students reaching the standard for problem solving.

I further stated that the newly implemented NECAP state math assessment does not consider problem solving as a separate content strand, but rather as part of a process strand (partnered with reasoning and proof) that is embedded across the standards. Thus, a separate score for problem solving is not reported. Given Branca's emphasis on the ability to problem solve as the end-game of mathematical knowledge, I found it curious as to why the architects of the NECAP math assessment chose not to report a separate score for problem-solving ability. Thus, pertinent to my dissertation, the question arises: How well do students' NECAP math scores correlate with their Total Problem-Solving Rubric Score? Foundational information for future research towards addressing this question is offered in the following:

Two studies have shown that NWEA tests are positively correlated with the NECAP tests. In the first study, Cronin (2007) provided an estimated point on the NWEA RIT scales that would be equivalent to the minimum score for proficiency on the NECAP Reading and Mathematics tests for third- through eighth-grade. 
Unfortunately the study ended at eighth grade, providing no information at the high school grade level.

In a similar study in September, 2009, I used data for 40 Beacon eleventhgrade students who had taken both assessments in the Fall of 2008 and had complete sets of scores for both the NWEA and NECAP tests. I first established that all three NECAP tests (Mathematics, Reading, Writing) were significantly positively correlated with the NWEA tests. The Pearson $r$ correlations, followed by the associated $p$-values in parenthesis, are shown in Table 53.

\begin{tabular}{|c|c|c|c|}
\hline Correlations & $r$ between NWEA & and NECAP Tests & $(N=40)$ \\
\hline & $\begin{array}{c}\text { NECAP } \\
\text { Mathematics }\end{array}$ & $\begin{array}{c}\text { NECAP } \\
\text { Reading }\end{array}$ & $\begin{array}{c}\text { NECAP } \\
\text { Writing } \\
\end{array}$ \\
\hline $\begin{array}{c}\text { NWEA } \\
\text { Mathematics }\end{array}$ & $\begin{array}{c}.74^{\mathrm{a}} \\
(<.0001) \\
2.20\end{array}$ & $\begin{array}{c}.46 \\
(.0029) \\
1.04\end{array}$ & $\begin{array}{c}.53 \\
(.0004) \\
1.25\end{array}$ \\
\hline $\begin{array}{c}\text { NWEA } \\
\text { Reading }\end{array}$ & $\begin{array}{c}.46 \\
(.0025) \\
1.04\end{array}$ & $\begin{array}{c}.64 \\
(.0001) \\
1.67\end{array}$ & $\begin{array}{c}.54 \\
(.0003) \\
1.28\end{array}$ \\
\hline $\begin{array}{c}\text { NWEA } \\
\text { Language } \\
\text { Usage }\end{array}$ & $\begin{array}{c}.49 \\
(.0015) \\
1.12\end{array}$ & $\begin{array}{c}.35 \\
(.0267) \\
0.75\end{array}$ & $\begin{array}{c}.45 \\
(.0040) \\
1.01\end{array}$ \\
\hline
\end{tabular}


Since my research has shown that Total Problem-Solving Rubric Score is significantly positively correlated with NWEA Mathematics and from Table 53, NWEA Mathematics is significantly positively correlated with NECAP Mathematics, it seems reasonable to suggest that Total Problem-Solving Rubric Score should be correlated with NECAP Mathematics (i.e., if $A$ is positively correlated with $B$, and $B$ is positively correlated with $C$, then $A$ is positively correlated with $C$ ).

This scenario was exactly addressed by Langford, Schwertman, and Owens (2001) in an article entitled Is the Property of Being Positively Correlated Transitive? The authors concluded "no" and provided a mathematical proof.

Thus, further research would be needed to assess the correlation between eleventh-grade students' NECAP math scores and their performance on solving nonroutine problems. This would involve administering nonroutine problems to eleventh-grade students around the time they are taking the NECAP exam. Failure to attain a positive significant correlation might suggest that the NECAP is not an adequate predictor of students' problem-solving ability. 


\section{Reflection on Future Research}

Up to this point, I have proffered recommendations based on the results of my tangible data derived from the method proposed, approved, and completed. However, I would be remiss if I did not comment on the need for further research based upon what I intentionally neglected to pursue in my analyses due to limitations in instrumentation. For example, several students in my study wrote 'I don't know' on one or more of the six nonroutine problems they were asked to solve. To what extent does learned helplessness (Seligman, 1975) play a part? I found that confidence (Math-Related Affect) was significantly positively correlated with problem solving. To what extent does learned optimism (Seligman, 1990) play a part?

It has been some 40 years since Neale (1969) suggested that attitudes toward mathematics had little effect on mathematics achievement and that the virtues of patience, compliance, and obedience probably had more effect on achievement than attitude, interest, or curiosity (Aiken, 1970a). Other than Cattel and Butcher (1968), I found no studies that have explored the relationship of patience, compliance, and obedience to mathematics achievement. Has this been an oversight, or inattended? When we ask math students to show all their steps, follow algorithms, explain their reasoning, and check their work; certainly patience, compliance, and obedience seem inherently necessary. Perhaps, it's time to assess the relationship of these virtues with problem-solving ability. 


\section{Appendix A}

\section{Vita}

John D. Butler, son of Benjamin L. Butler and Theresa Butler, was born October 5, 1955, in Warwick, RI. He earned the rank of Eagle Scout in 1970 and graduated from Warwick Veterans Memorial High School in 1973. In high school, he was a member of the marching band, concert band, jazz band, served as band president, won second chair clarinet in the Rhode Island State Orchestra All-State Competition and was the recipient of the John Phillip Sousa Band Award.

Although interested in music, John decided to pursue an engineering degree. He attended the Community College of Rhode Island for two years earning an Associates of Science in Engineering degree in 1977. He then entered Western New England College (WNEC) in Springfield, MA and graduated in 1979 with a Bachelor of Science in Mechanical Engineering degree. While at WNEC, he served as president of the American Society of Mechanical Engineers (ASME) Student Section, placed first in the 1979 ASME Regional Conference (University of Massachusetts), placed second in the 1979 National Design Engineering Contest (St. Louis, MO), was a presenter at the 1979 ASME Winter Annual Meeting (New York), and was the recipient of the 1979 WNEC Engineering Book Award.

Upon graduation, John was hired by Artos Engineering (New Berlin, WI). After one year he was promoted to project engineer and designed and supervised installations of automated wire processing machines throughout Europe.

On November 27, 1982, John married Corliss E. Manning, daughter of Corliss and Robert Manning of Warwick, RI. They raised three children: Bryan, Andrew, and Brittany). In 1983, he was hired by General Electric Medical Systems in Milwaukee as an 
X-Ray Systems Design Engineer and was instrumental in the design of several x-ray vascular systems and did extensive research in the area of x-ray image quality. During this time, he co-founded the Mechtrix Corporation located in Menomonee Falls, WI and served as Chief Engineer for ten years during which he earned a registered Professional Engineer (PE) status. In 1995, John, Corliss, and their three children moved back to Rhode Island to be near family as their oldest son, Bryan, was battling Leukemia. John worked as a senior project engineer for the Stanley Bostitch Corporation (East Greenwich, RI), followed by several years as Director of Engineering for the Applitek Corporation (Providence, RI). During his twenty-two years in engineering, John was the inventor of fifteen U.S. and several foreign patents and published several technical articles in Wiring Harness News, based in Richmond, Illinois.

Making a career change in 2001 from engineering to high school math teacher, he taught mathematics for two years at the Providence Place Academy, a public high school focusing on retailing and marketing. In 2003, John earned a Master's in Teaching Mathematics from Providence College and in 2003, was accepted into the Joint URI/RIC Ph.D. in Education Program. In 2004, he was hired by Coventry High School and taught mathematics for two years followed by four years at Beacon Charter High School for the Arts (BCHS) located in Woonsocket, RI. He became tenured in 2008. In his fifth year at BCHS as a mathematics teacher/math coach, Johns also serves as the School Improvement Team Chair, Advisor for the after-school math club, school's house band, and Co-advisor of the robotics club and venturing crew. John has also been a member of the Rhode Island College Upward Bound Faculty since 2006. John hopes to defend his dissertation in late Fall of 2009. 


\section{Appendix B}

\section{IRB Parents' Consent and Students’ Assent Forms}

Table B1

Summary of IRB Forms used in My Research

\begin{tabular}{cc}
\hline IRb form title & Figure \\
\hline Informed Consent Form For Parents/Guardians & Bla \\
To Altow Students To Participate In A Research Project & and \\
At The Beacon Charter High School For The Arts & Blb \\
Students'Assent Form For Joining A Research Project & B2a \\
To Improve The Teaching And Learning Of Mathematics & and \\
At The Beacon Charter High School For The Arts & B2b \\
\hline
\end{tabular}




\section{INFORMED CONSENT FORM FOR PARENTS/GuARDians TO ALLOW Students To Participate In a Research Project To Improve The Teaching AND LeARNing Of Mathematics At The Beacon Charter high School For The ARts}

\section{Why Is This Research Project Important?}

Today's students will need stronger math skills than any previous generation. More jobs than ever before will require workers who are competent and comfortable with math. Math skills will make it easier to manage their family finances. Knowledge of math will help them when they need to vote on school budgets and other public funding projects.

Helping students develop these important math skills is one of the biggest challenges for our public schools--not only in Rhode Island, but across the U.S.A. On state and national tests, many students' math scores lag behind their scores in other subjects.

Even students with good calculating skills often have a hard time using their skills to solve larger problems. While they know how to use the separate tools in their math tool-box, they are not sure how to combine their tools to build a solution.

We must help all students to get bigger math tool-boxes, to use their tools more effectively, and to enjoy using them.

What Are The Goals of This Research Project?

Some students enjoy math, do well in math courses, and look forward to learning more math and adding to their math tool-boxes. Many other students hate and fear math, struggle in math courses, and can't wait to be done with math forever.

The purpose of this project is to learn--with the valuable help of all of these math students--how they work with their own math toolboxes:

(1) what tools these diverse students have;

(2) what experiences they had in building their tool-boxes:

(3) how they use their tools in trying to solve problems;

(4) how they feel about math and their skills in math.

By analyzing this detailed information from a wide range of students, we hope to develop better ways of enlarging the tool-boxes of all students at Beacon Charter High School. Later, we would plan to share the effective methods with mathematics educators in RI and the U.S.A.

\section{How Would My Child Contribute To This Project?}

Students who volunteer--and have their parents'/guardians' consent-to take part in this project will do the following:

(1) work on their own on some math problems, using whatever tools in whatever ways they choose, making some notes about their strategies with each problem;

Figure Bla. Parents' consent form - page 1 
(2) meet individually with a teacher to explain the strategies used in a problem; these brief interviews will be audiovideo taped, in order to retain all of the valuable information that each student contributes;

(3) fill out surveys on their feelings about math, their math skills, and their opinions about solving problems.

Each student will be contributing his/her unique perspectives to the "big picture" of math students' tool-boxes and feelings about math. The accurate, individual details in that overall picture will help guide us toward improvements in the teaching and learning of math.

\section{Who Is Conducting This Research Project?}

This project is directed by Mr. John D. Butler, a mathematics teacher and chairman of the Math Department at the Beacon Charter High School for the Arts. Mr. Butler is also working on a Ph.D. in Education in the URI-RIC Joint Ph.D. Program. He is conducting this research under the supervision of Dr. Louis J. Heifetz at URI-Kingston (401 874-4165). Mr. Butler's research plan has been approved by the Institutional Review Board at URI (401 874-4328).

\section{Students' Rights}

Students' participation--and their parents'/guardians' consent--is completely voluntary. Students' participation--and their work on the math problems--has no bearing on their grades.

There are no known risks or discomforts involved in this research. Students are free to withdraw from the project at any time, without needing to give an explanation.

All information will be kept confidential. Only Mr. Butler will keep the specific responses of students. No students' names will appear on any of the results. No individual information will be disclosed. only the overall patterns of data will be reported and used to guide new approaches to teaching.

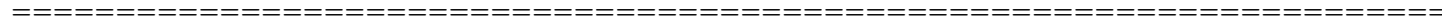
I have read and understood the information about this Research Project to Improve the Teaching and Learning of Mathematics at Beacon Charter High School for the Arts. I understand that I may contact Mr. John D. Butler at Beacon High School (401 671-6261, extension 208) for answers to questions about this research and my child's rights. I freely and voluntarily consent to my child participating in this research project.

Parent's/Guardian's Name please print) Child's Name (please print)

Parent's/Guardian's Signature

Mr. John D. Butler

Researcher's Name
Researcher's Signature

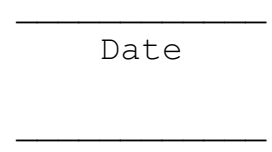

Date

Figure B1b. Parents' consent form - page 2 


\section{Students' Assent Form For JoIning A Research ProJeCt To Improve The teaching And Learning Of Mathematics At The Beacon Charter high School For The ARts}

\section{Volunteers Needed For A Research Project}

My name is Mr. Butler and I am a math teacher and chairman of the Math Department here at Beacon. I am doing a research project to improve the ways that we teach math at Beacon. I am looking for students who are interested in volunteering to help with this project.

\section{Why Is This Research Project Important?}

Today's students need stronger math skills than earlier students did. Many jobs now require workers who are competent and comfortable with math. Strong math skills will help you manage your personal finances.

Helping students develop their math skills is a big challenge for schools in Rhode Island and across the U.S.A. On state and national tests, many students' scores are lower in math than in other subjects.

Even students with good calculating skills often have a hard time using their skills to solve larger problems. While they know how to use the separate tools in their math tool-box, they are not sure how to combine their tools to build a solution.

\section{What Are The Goals of This Research Project?}

Some students enjoy math and do well in their math courses. On the other hand, many other students hate and fear math. They struggle in their math courses and can't wait to be done with math forever.

Here at Beacon, we want to help all students to expand your math tool-boxes, to use your tools more effectively, and to enjoy using them.

The purpose of this project is to learn--with the important help of all levels of math students--how you all use your own math toolboxes:

(1) what math-tools you and other students have;

(2) what experiences you had in building your tool-boxes;

(3) how you use your tools in trying to solve problems;

(4) how you feel about math and your skills in math.

It is very important for us to learn this information from all kinds of math students. We need to hear not only from students who like math, but also from students who dislike or fear math. Only by hearing from you--and many other students at Beacon--can we get the "big picture" of learning and teaching math here. You can help us develop better ways to build the tool-boxes of all students at Beacon Charter High School.

\section{How Could I Contribute To This Project?}

Students who volunteer--and have their parent's/guardian's consent-to take part in this project will do the following:

Figure B2a. Students' assent form - page 1 
(1) work by yourself on some math problems, using whatever tools in whatever ways you choose, making some notes

about your strategies with each problem;

(2) meet individually with a teacher to explain your approaches to each problem; these brief interviews will be audio-video taped, in order to get all of your valuable information;

(3) fill out surveys on your feelings about math, your math skills, and your attitudes about solving problems.

You and other students will each contribute your own important pieces to the "big picture" of students' tool-boxes and feelings about math. That very valuable picture will help guide us toward better ways to teach and learn math--first at Beacon and later at other schools also.

\section{Who Is Conducting This Research Project?}

This project is directed by Mr. John D. Butler, a mathematics teacher and chairman of the Math Department at the Beacon Charter High School for the Arts. Mr. Butler is also working on a Ph.D. in Education in the URI-RIC Joint Ph.D. Program. He is conducting this research under the supervision of Dr. Louis J. Heifetz at URI-Kingston (401 874-4165). Mr. Butler's research plan has been approved by the Institutional Review Board at URI (401 874-4328).

\section{Students' Rights}

Students' participation--and their parents'/guardians' consent--is completely voluntary. Your participation--and your work on the math problems--has no bearing on your grades.

There are no known risks or discomforts involved in this research.

You and all other students are free to withdraw from the project at any time, without needing to give an explanation.

All information will be kept confidential. Only Mr. Butler will keep the specific responses of students. No students' names will appear on any of the results. No individual information will be disclosed. Only the patterns in the "big picture" will be reported and used to help us improve our approaches to teaching and learning math.

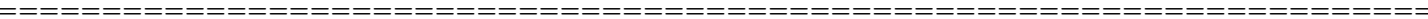

I have read and understood the information about this Research Project to Improve the Teaching and Learning of Mathematics at the Beacon Charter High School for the Arts. I understand that I may contact Mr. John D. Butler (at 401 671-6261, extension 208) for answers to any questions about this research and my rights in joining this project. I freely and voluntarily consent to participate in this research project.

$\overline{\text { Student's Name (please print) }}$
Mr. John D. Butler
Researcher's Name
Student's Signature

Date

\section{Date}

Figure B2b. Students' assent form - page 2 


\section{Appendix C}

\section{Math Skills Assessment}

Table C1

Summary of Math Skills Assessment Resources

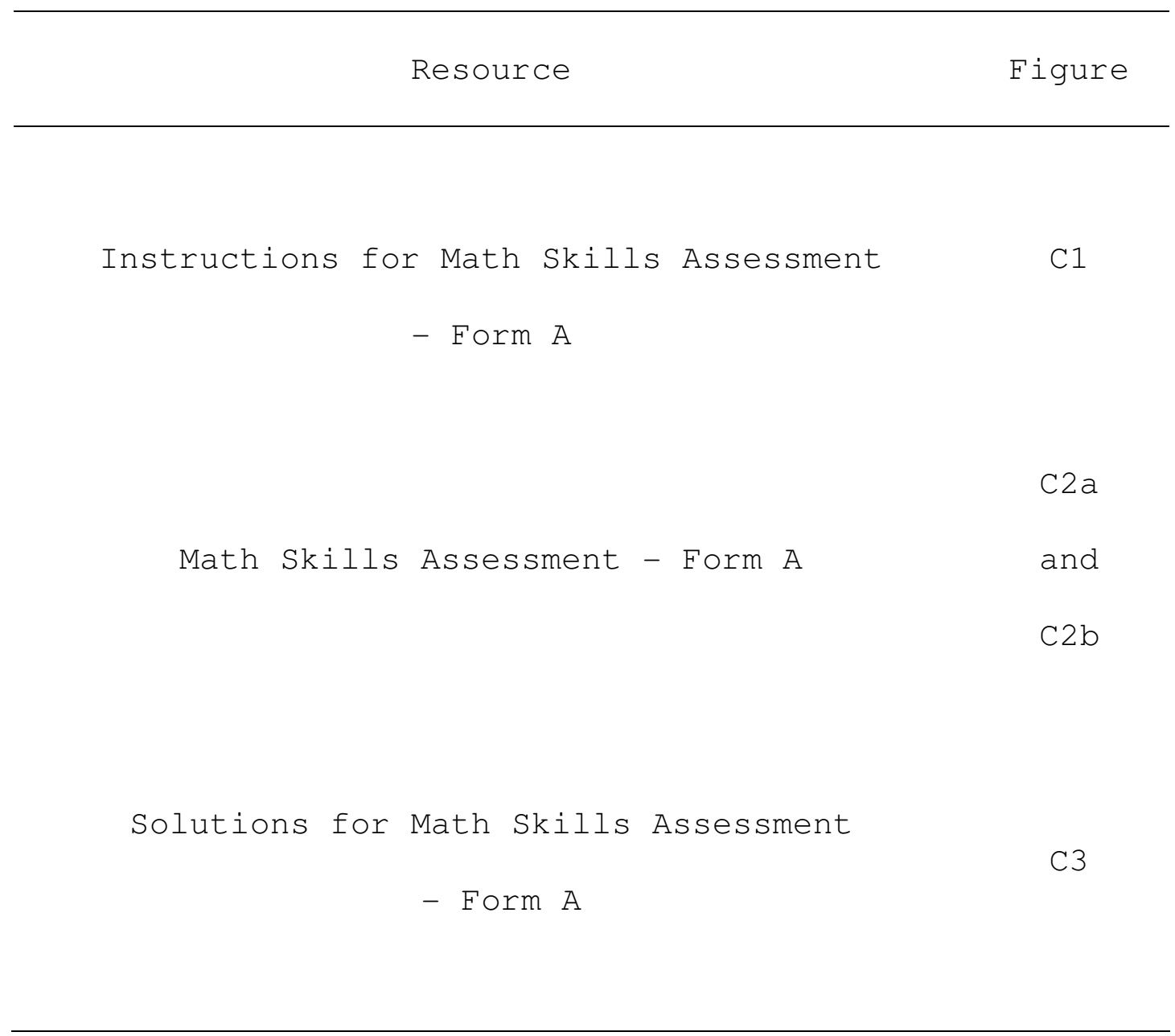


January 28, 2008

\section{Instructions for the Math Skills Assessment - Form A}

All Beacon $9^{\text {th }}$ grade math students are to be given the Math Skills assessment (Form A) within the first week of the start of the semester.

\section{Please make sure that everyone has a pencil. Then read the following to the students prior to distributing the assessment:}

Please clear everything off your desk [Make sure there is no food, drinks, backpacks, books, etc. on the desks].

You are now going to be given a short assessment of your basic math skills. There are only 15 questions. We give this to every $9^{\text {th }}$ grade math student at the beginning of the semester as a means of helping us know what we need to review.

For example, if most of the class has trouble with fractions, we will spend more time on reviewing fractions - if not we'll move on to new areas.

Very important! This does not count towards your grade. It is purely for diagnostic purposes only. There is no pass or failure.

You will not be allowed to use calculators - do the best you can.

Do your own work - this is an assessment of your ability

The first five problems ask you to put some numbers in order from smallest to largest - please write the given numbers on the blank lines provided.

For problems \#6 - \#15, the word "evaluate" means "solve." If you don't know how to solve a problem - write "I don't know."

When you finish, turn the assessment upside down, raise your hand and I will pick it up.

Good Luck!

Figure C1. Instructions for math skills assessment - form A 
Math Skills Assessment

Form A

Name:

Date:

For problems \#1- \#5, please order the terms from Smallest to Largest on the lines provided.

1) $8,11,2,4,13$

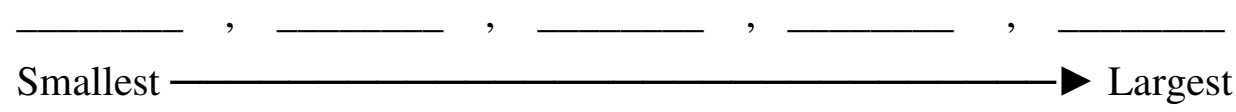

2) $\quad-20,-1,-8,-12$

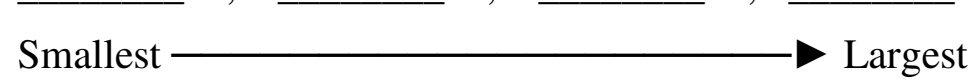

3)

$\frac{1}{2} \quad, \quad \frac{1}{3} \quad, \quad \frac{1}{8} \quad, \quad 1 \frac{1}{4}$

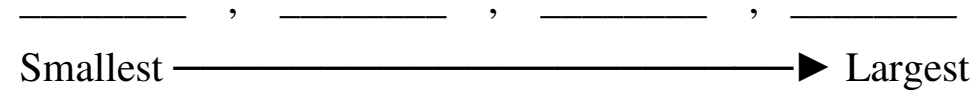

4) $.10, .32, .08, \quad, 19$

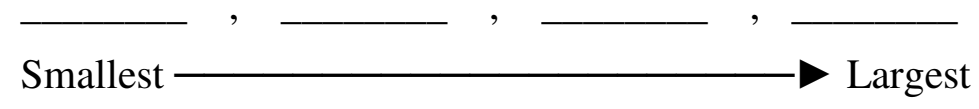

5) $\frac{1}{2}, .6,-3,5,-\frac{2}{3}$

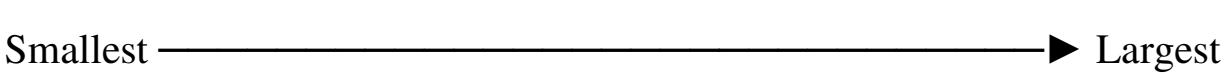

Figure C2a. Math skills assessment - page 1 


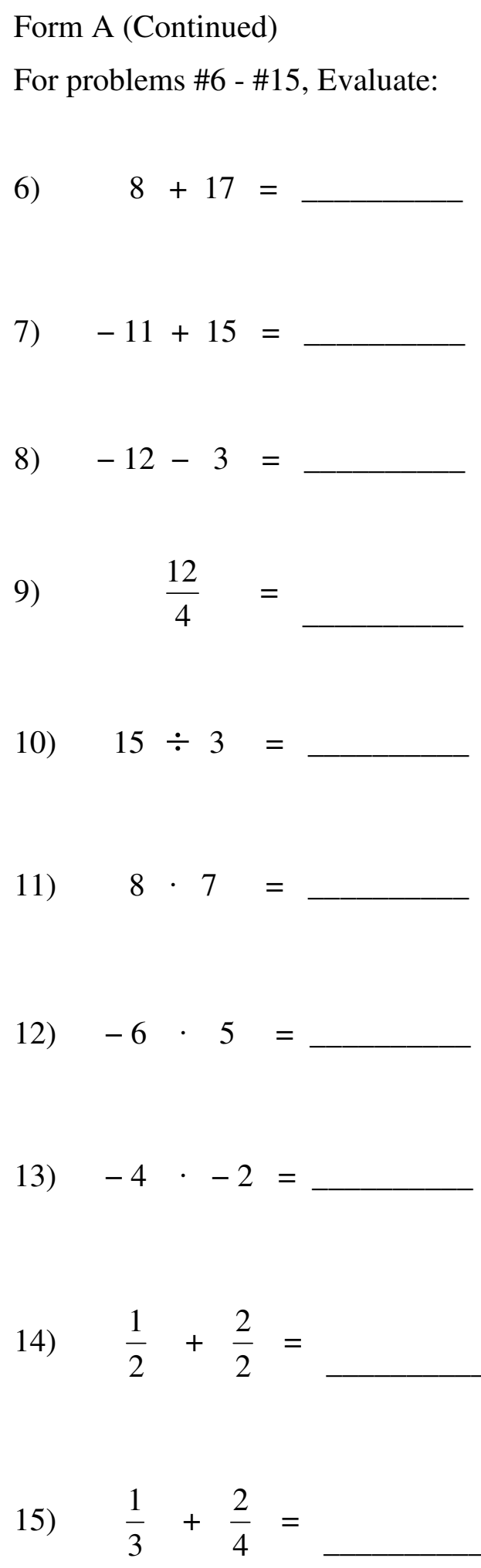

Figure $C 2 b$. Math skills assessment - page 2 


\section{Math Skills Assessment - Form A Answer Key}

\section{Form A (Answers)}

1) $2,4,8,11,13$

2) $-20,-12,-8,-1$

3) $\frac{1}{8}, \frac{1}{3}, \frac{1}{2}, 1 \frac{1}{4}$

4) $.08, .10, \quad .19, \quad .32$

5) $-3,-\frac{2}{3}, \frac{1}{2}, .6,5$

6) 25

7) 4

8) -15

9) 3

10) 5

11) 56

12) -30

13) 8

14) $\frac{3}{2}$ or $1 \frac{1}{2}$ or 1.5

15) $\frac{10}{12}$ or $\frac{5}{6}$ or 0.83 or 0.8

Figure C3. Math skills assessment - form A answer key 


\section{Appendix D}

\section{My Math Experiences Essay}

Table D1

Summary of My Math Experiences Essay Resources

\begin{tabular}{ll}
\hline Resource & Figure \\
\hline
\end{tabular}

Math Regrets Writing Prompt

D2

My Math Experiences Essay Graphic Organizer

D3 


\section{My Math Experiences Writing Assignment \\ $9^{\text {th }}$ Grade \\ Date Due:}

Please submit a typed or neatly handwritten 5 paragraph essay in MLA format:

People have different attitudes towards math. Some people love the challenge; others get a sinking feeling in their stomach when faced with a math class.

1. Read the essay entitled "Math Regrets."

2. Now, consider how you feel about math and your past experiences with math. Before you begin writing, think about the math you learned before school started and your family's experiences with math. You may have watched Sesame Street or read number books. These early years are also influenced by your family members' attitudes towards math. Next, think about your experiences in elementary school. How well did you do? Did you enjoy learning your times tables. Finally, consider your middle school experience. Did you attitude change? How? Why? How was the math class different than ever before?

3. Now plan and write your essay. Include and introduction, body paragraphs, and a conclusion. Be sure to use your graphic organizer. There is no right or wrong answer. The idea of the essay is to describe your feelings about math.

Figure D1. My mathematics experience writing assignment 
[Author's name removed]

[Teachers name removed]

Math Class

February 2, 2007

\section{Math Regrets Writing Prompt}

How come I'm not as smart as her? Why can't I figure out those tough problems? I spent most of my life thinking that I wasn't smart and that I couldn't do math. In elementary school I was able to keep up, in middle school and high school, I fell behind, and in college, I finagled my way through, never really confronting my math aversion.

I grew up in Lincoln, Rhode Island, and went to Saylesville Elementary School. I don't have too many memories of math at that level. I enjoyed school then, and didn't have any real academic problems until middle school.

When I entered Lincoln Middle School, I was put into a lower track. That was hard for me because most of my friends were in the upper level. It took a while for me to fit in and make new friends, but I eventually did. I can remember hating math class and the teacher. I received my first detention from my math teacher for goofing off in class. I managed to get by, but just barely. That set me up for being put in the lower track in high school where things did not get much better for me. I was put into the Business track, and never even took an Algebra class. I had business math, which was mainly being able to balance a checkbook and things like that. I did well in that class, but I still did not like school very much. I was passed along, and when I was a Junior, I thought about quitting. My mom and dad would not hear of that. They found a special program for me at Johnson and Wales College.

For the first time, I felt like I fit in. I was only sixteen, but I was in college! My dad drove me downtown every day to make sure I got to class. He didn't realize that first year that I loved going there, and would have been happy to take the bus to school. I was still in a business program, however, and did not have to take any advanced math classes. I graduated from Johnson and Wales with my Associate's Degree, and went on to have a successful business career that I gave up when I got married and had children. I was a housewife for about six years, and when I thought about going back to work, I realized that I wanted to do something else. I loved working with people, and felt like I had never fully reached my potential. So I went back to college to prepare myself for a new career.

I started at CCRI, and because I had never really done well in math, I had to take remedial classes. This was the basics-starting with addition and subtraction. It was a non-credit class that I had to pay for to get my skills up to par. Then I had to take a remedial Algebra course. That was very difficult for me. I had to study about ten hours a week. My next class was a general introduction class to college math. That came much easier to me, and I managed to pass all my classes at CCRI with As. When I transferred to RIC, I did not have to take any more math classes because I was in the education program. I graduated with top honors, finally proving to myself that I was indeed smart.

So here I am today. I thought that I had escaped math, and that I could get along just fine without knowing Algebra or Geometry or God forbid Trigonometry. However, as a Resource teacher, I have to help kids with their math. It is hard for me, because I still have not learned how to do advanced math. I now realize that it is not because I am not smart, it is only because I have not been taught how to, and I have not put in the effort required to learn advanced math. It takes a lot of practice and hard work to be successful in math class, but it is worth it. Don't spend your life like I did thinking that you are not smart, when everyone is capable of learning math if they just try their best and practice.

Figure D2. Math regrets writing prompt 


\section{My Math Experiences Essay Graphic Organizer}

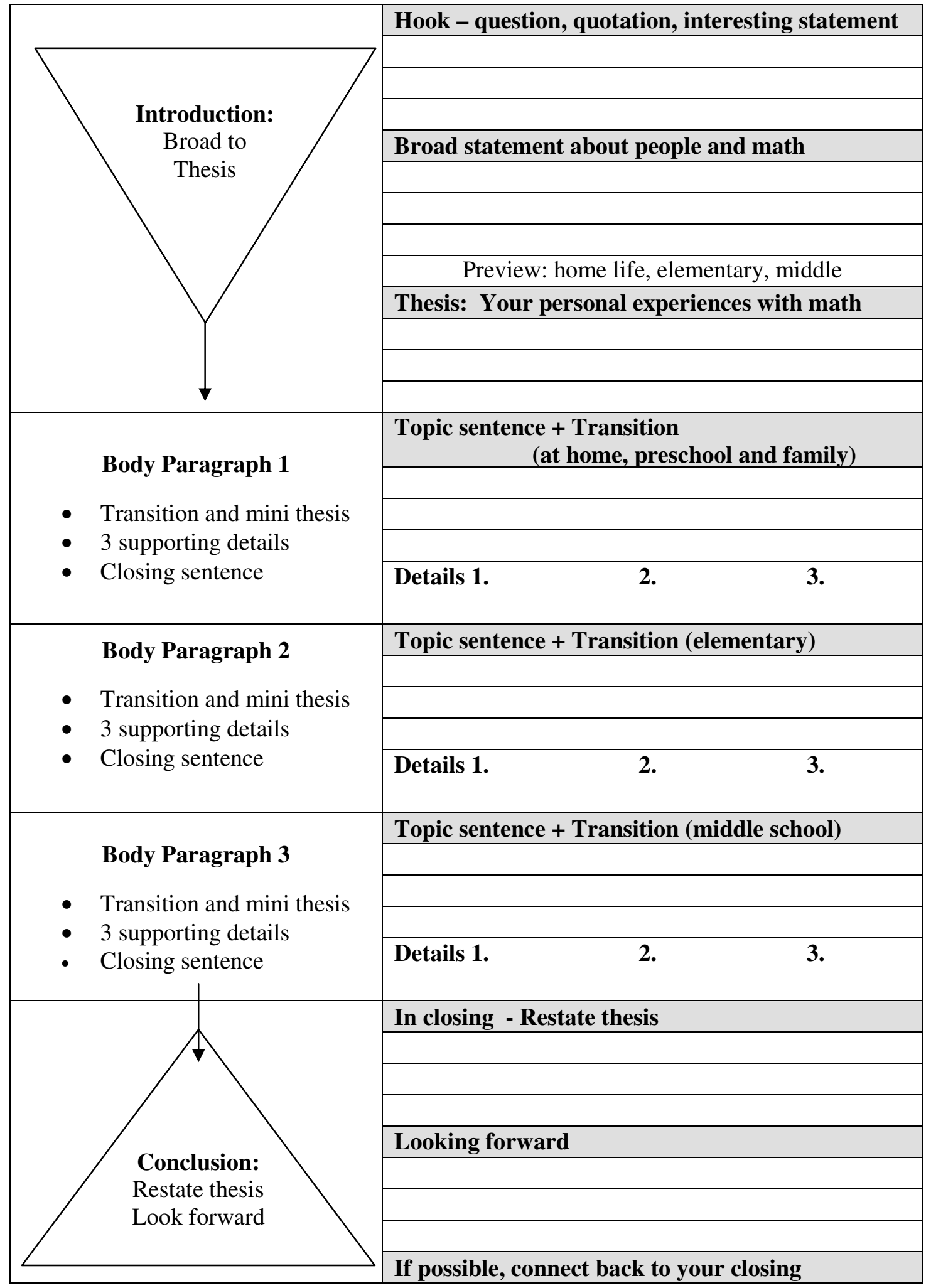

Figure D3. My math experiences writing assignment 


\section{Appendix E}

\section{Six Nonroutine Problems}

Table E1

Summary of the Six Nonroutine Mathematical Problems

\begin{tabular}{|c|c|c|}
\hline Problem & Nonroutine problem title & Figure \\
\hline 1 & Count Your Coins & E1 \\
\hline 2 & Lost in the Auditorium & E2 \\
\hline 3 & Birthday Money & E3 \\
\hline 4 & What's in My Future? & E4 \\
\hline 5 & How Many Children Live Next Door? & E5 \\
\hline 6 & Blind Sided & E6 \\
\hline
\end{tabular}

Note. The above problems are numbered in order of estimated difficulty (easiest to most difficult) and order of administration. 


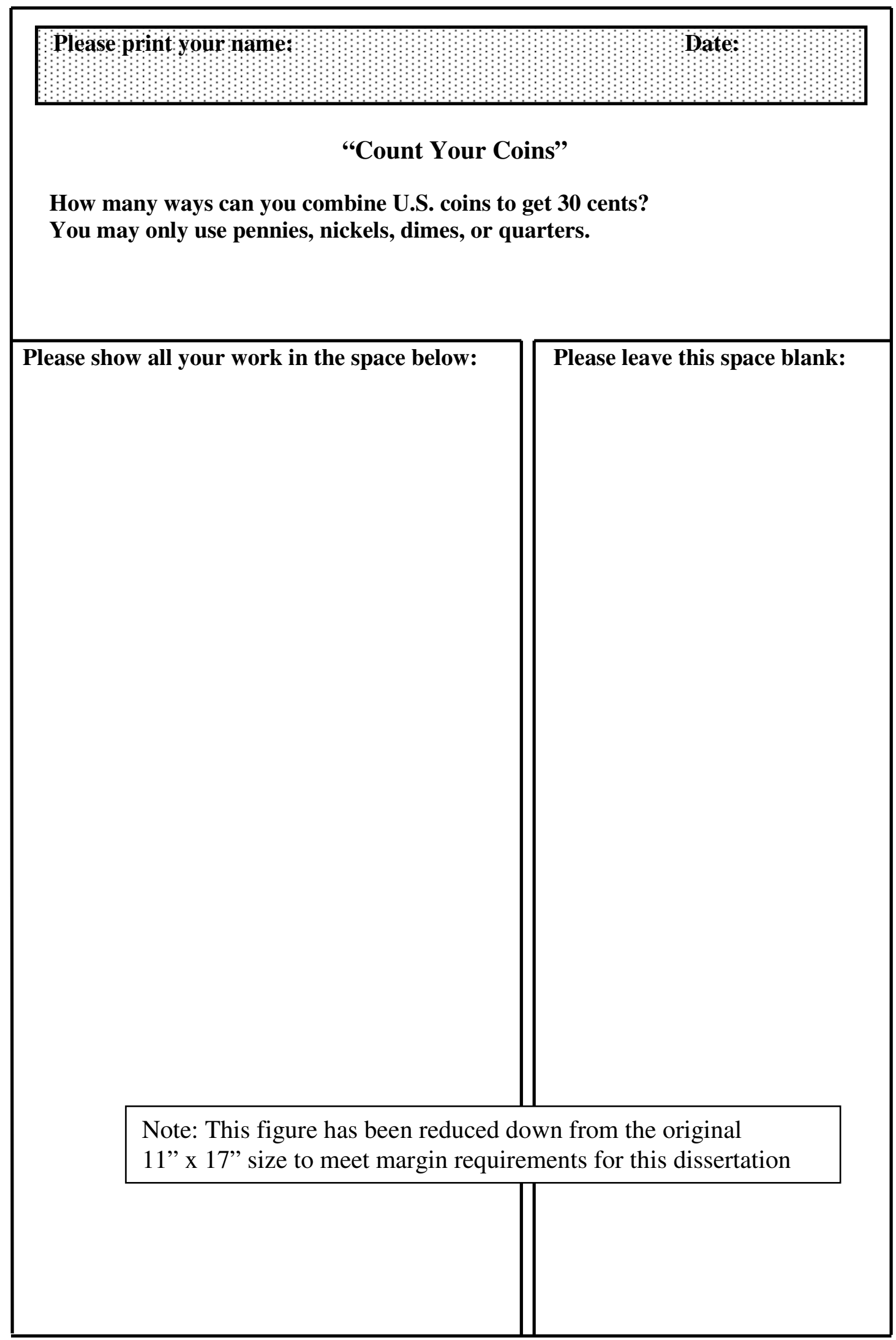

Figure E1. "Count your coins" nonroutine problem 


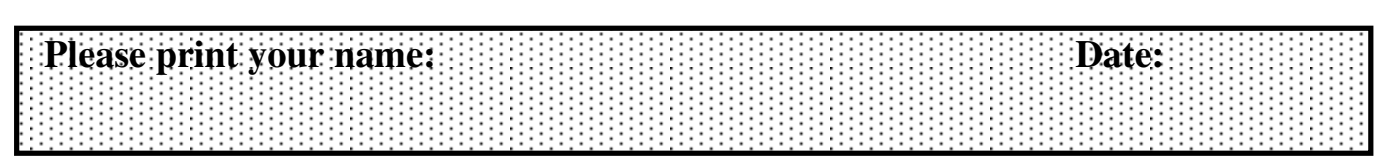

"Lost in the Auditorium"

An auditorium has eight doors. You may enter from every door but you can not leave through the same door you entered. In how many ways is it possible to enter by one door and leave by another?

Please show all your work in the space below:

Please leave this space blank:

Note: This figure has been reduced down from the original 11 " $\mathrm{x} 17$ " size to meet margin requirements for this dissertation

1

Figure E2. "Lost in the auditorium" nonroutine problem 


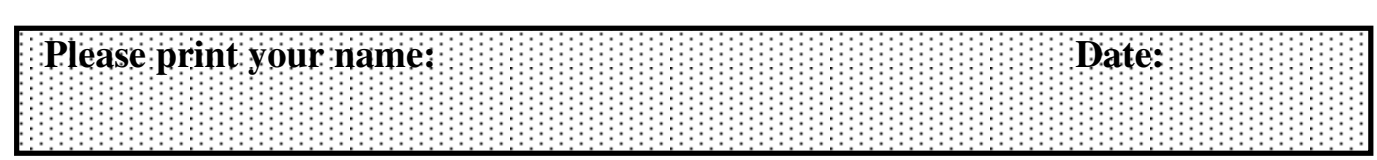

\title{
"Birthday Money"
}

On John's birthday, John's grandfather gave him $\$ 10$.

He gave John $\$ 20$ on his eleventh birthday and \$40 on John's twelfth birthday.

Following this pattern, John's grandfather plans on giving John $\$ 70$ on his thirteenth birthday, but John expects $\$ 80$ from his grandfather on that day. John's sister says that both amounts could be correct.

\author{
Who is right? - \\ John's grandfather, \\ John, \\ or John's sister?
}

Please show all your work in the space below:

Please leave this space blank:

Note: This figure has been reduced down from the original 11 " $\mathrm{x} 17$ " size to meet margin requirements for this dissertation

Figure E3. "Birthday money" nonroutine problem 


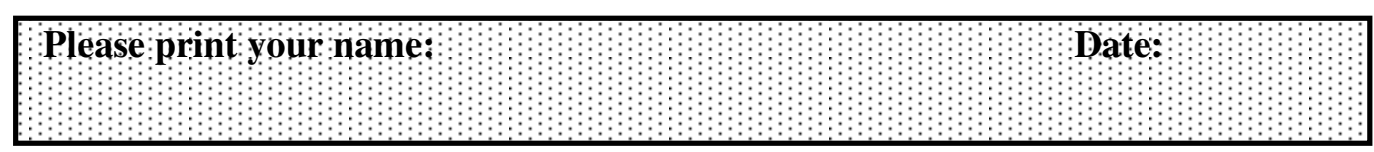

\section{““What's in My Future?"}

A pattern of squares is shown below. At each step, more squares are added to the pattern. The number of squares added at each step is more than the number added in the previous step. The pattern continues infinitely.

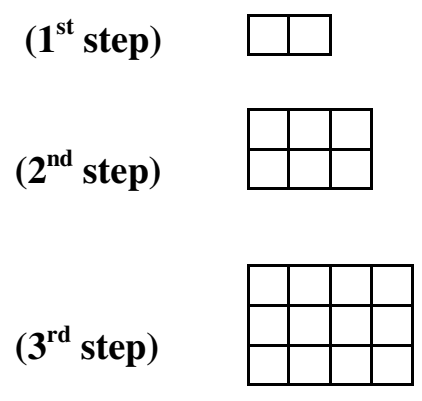

Marcy has to determine the number of squares in the $50^{\text {th }}$ step, but she does not want to draw all 50 pictures and then count the squares. Explain or show how she could do this and give the answer that Marcy should get for the number of squares.

Please show all your work in the space below:

Please leave this space blank:

Note: This figure has been reduced down from the original

$11 " \mathrm{x} 17$ " size to meet margin requirements for this dissertation

Figure E4. "What's in my future?" nonroutine problem 


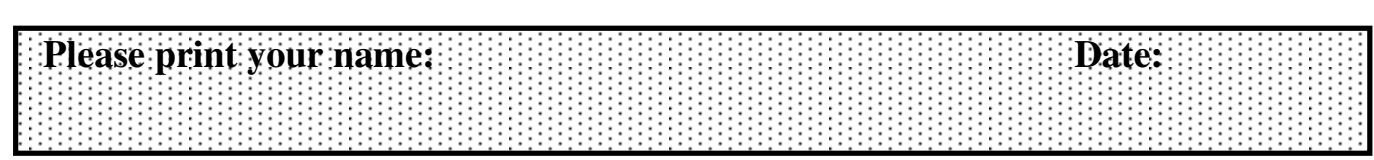

\section{“How many children live next door?"}

The family next door has both girl and boy children. Each of the boys has the same number of brothers as he has sisters and each of the girls has twice as many brothers as she has sisters. How many boys and girls are there?

Please show all your work in the space below:

Please leave this space blank:

Note: This figure has been reduced down from the original

11 " $\mathrm{x} 17$ " size to meet margin requirements for this dissertation

Figure E5. "How many children live next door?" nonroutine problem 


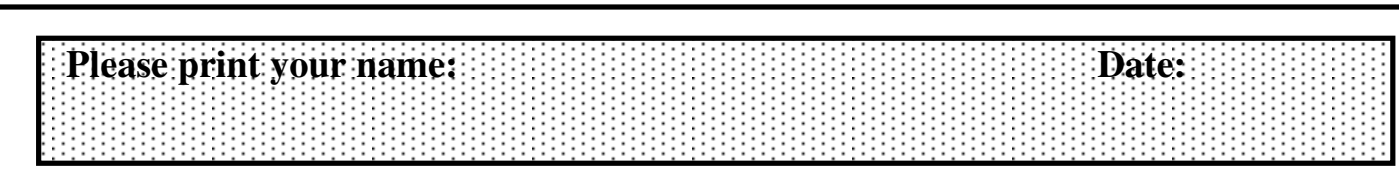

\section{"Blind Sided"}

Here are three views of the same cube. Each side is painted with a color. There are five different colors used. What color is the bottom face in View 1 (the face opposite the one colored white)?

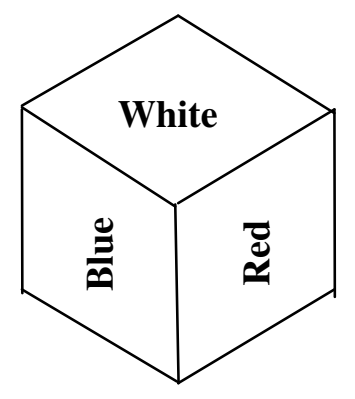

View 1

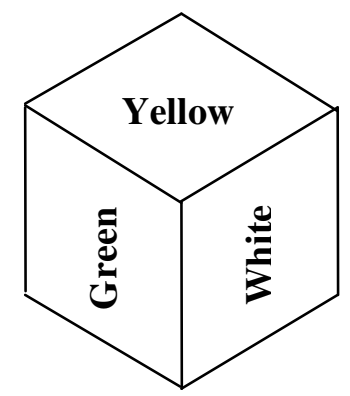

View 2

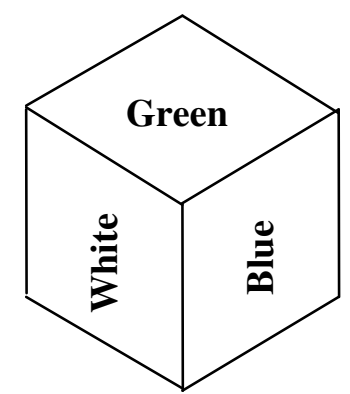

View 3

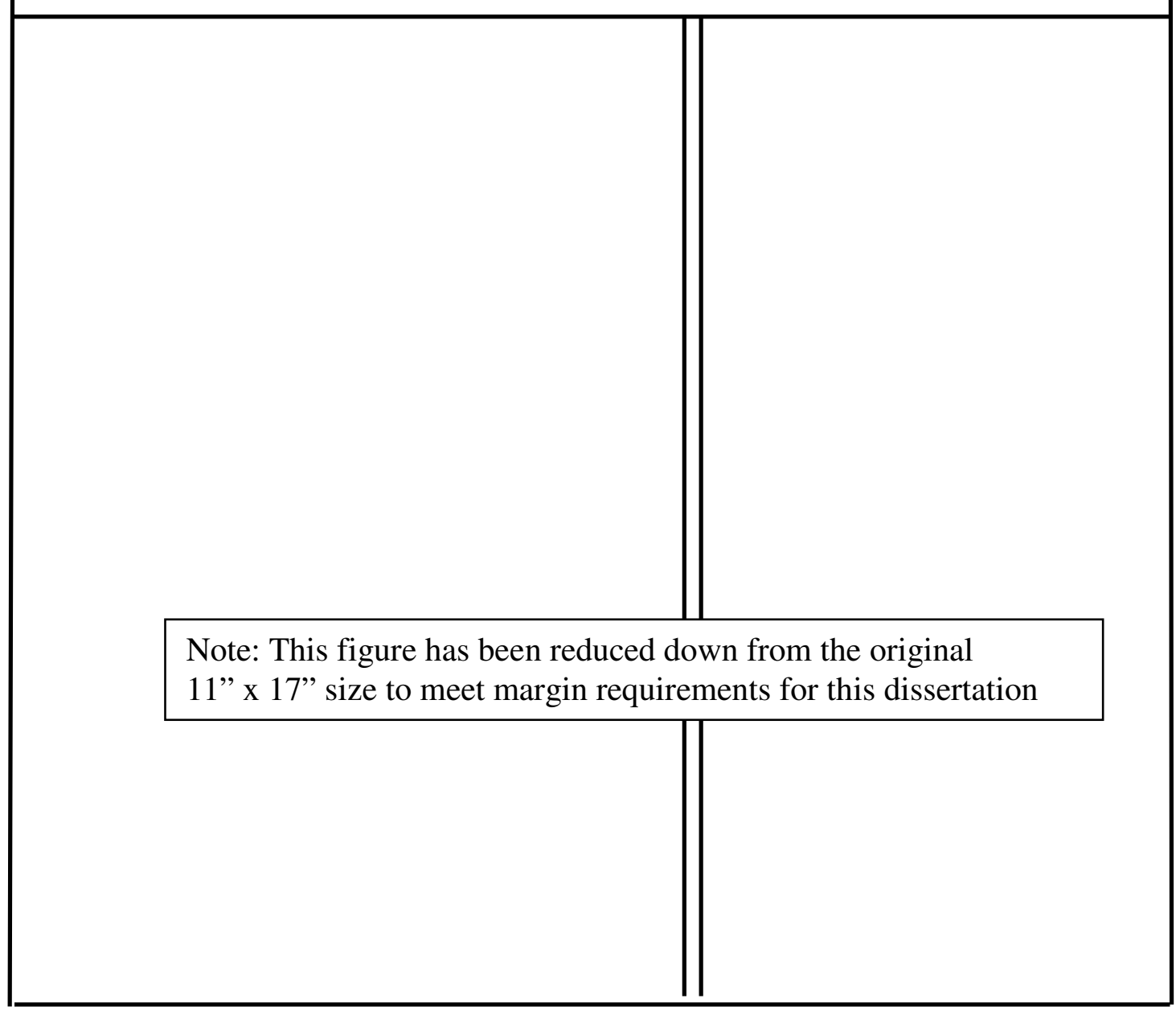

Figure E6. "Blind sided" nonroutine problem 


\section{Appendix F}

Establishing Inter-Rater Agreement for Scoring Nonroutine Math Problems

John D. Butler

URI/RIC Ph.D. in Program in Education

December 21, 2008 


\begin{abstract}
One component of dissertation research by the author involved assessment of the performance of $9^{\text {th }}$ grade urban high school students $(N=38)$ on six non-routine mathematical problems. The research was conducted during the spring of 2008. Major tasks of the assessment included the development and refinement of scoring rubrics for the respective problems, to be used by two raters for independent scoring and the development of a method for establishing inter-rater agreement. Subsequently, a Pearson $r$ correlation value of $r=.96(p<.0001)$ was calculated for the two-rater scoring. The following is a detailed account of the method employed.
\end{abstract}


Establishing Inter-Rater Agreement for Scoring Non-Routine Math Problems

\section{Method}

As part of this study, all $38,9^{\text {th }}$ grade students, completed six non-routine math problems: (1) Count Your Coins; (2) Lost in the Auditorium; (3) Birthday Money; (4) What's in My Future? (5) How Many Children Live Next Door? and (6) Blind Sided. A review of the literature failed to find a scoring rubric suitable for assessing student performance on these particular problems, although foundational material was found in Charles, Lester, and O’Daffer (1987), Polya (1945/2004), Stenmark (1991), and Szetala and Nicole (1992). Although the rubrics were specific to each problem, they were all developed around the same framework, sieved from the limited aforementioned literature, that consisted of four general scales: Understanding the Problem; How Student Solved Problem; Decisions along the Way; and Getting an Answer. The choice of these scales was based on Polya's four stages of problem solving outlined in his epic How to Solve It, first published in 1945: Understanding the Problem; Devising a Plan; Carrying out the Plan; and Looking Back. Although Polya provides tasks for each stage, no formal method of assessing problem solving performance (e.g., a rubric), is offered. In the rubrics developed for this study, each of the four scales allows for five possible scores: $0,1,2,3$, and 4, 4 representing highest achievement. Therefore, a rater's data set consisted of 912 ratings (38 students times 6 problems per student times 4 ratings per problem). Two raters would independently assess all six problems attempted by the 38 students. In cases of rater disagreement, the two rater scores on respective ratings, would be averaged for the student score. 
The statistical methods for calibrating and assessing inter-rater agreement are described below.

A three-stage process was used to assess and refine the rubrics with regards to inter-rater agreement on a statistically appropriate sample size prior to full student assessment. The three-stage process is described in Table F1 with a graphical representation provided in Figure F1. 
Table F1

Framework for Assessing and Approving Inter-Rater Agreement

\begin{tabular}{ll}
\hline $\begin{array}{l}\text { Stage } \\
\text { Number }\end{array}$ & \multicolumn{1}{c}{ Description of task } \\
\hline & Develop specific rubrics for the six non-routine problems. By cursory \\
& review, choose three samples of student work that appear representative \\
& of low, average, and high achievement for each of the six problems. \\
1 & Have two raters independently assess the student work. Compare the \\
& rater scores and determine the causes of inter-rater disagreement and \\
& revise the rubrics if necessary to achieve 100\% agreement between the \\
& raters on all six rubrics.
\end{tabular}

Using the method presented in Yamane (1967), determine an appropriate sample size for the 38 students to test all six rubrics for inter-rater agreement. Use the same two raters and randomly select the

2 sample students for independent rater scoring. Determine whether the two raters agree on at least $95 \%$ of their scores and never disagree by more than one point. If these criteria are not met, revise the rubrics as needed and rescore.

Using the same two raters, with the revised rubrics (if revisions were made), assess all 38 students. Verify that the difference in rater scores for respective scales does not exceed a value of \pm 1 . In the case that the difference in scores exceeds this value, the two raters must revisit the pertinent scores to try to reach consensus equal to or within the \pm 1 constraint. If consensus is not reached, an average will be taken (Note: ultimately, all remaining rater differences will be handled by taking an arithmetic average of the scores). 


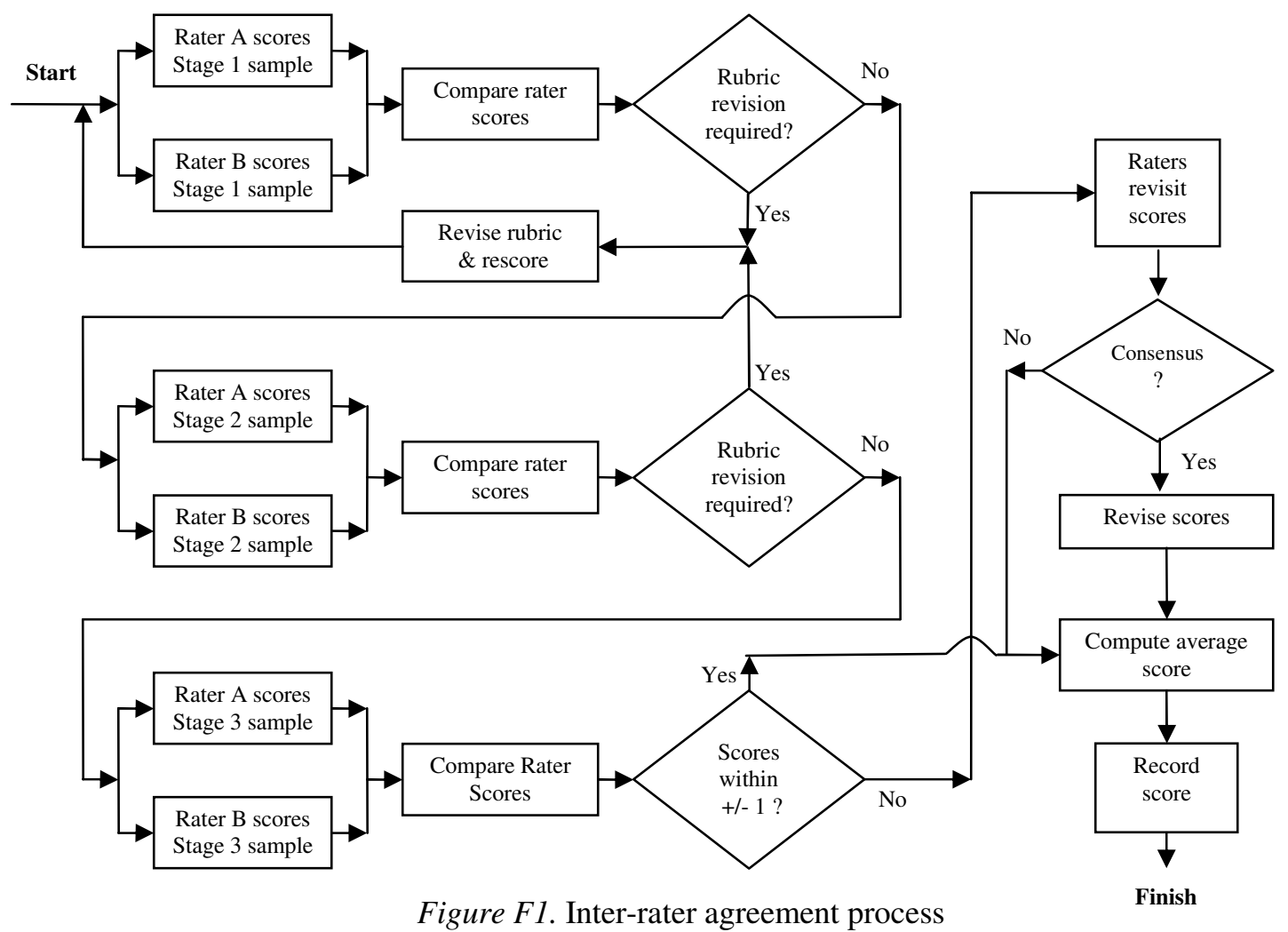


Stage 1

Both raters were certified high school mathematics teachers. Each rater independently assessed three students on each of the six problems. For each problem, the choice of students was based on a cursory holistic agreement of students' work in order to identify "low," "medium," and "high" performance. Table F2 shows the ID numbers of the students selected.

Table F2

Student ID's Selected for Stage 1 Scoring

\begin{tabular}{cccc}
\hline $\begin{array}{c}\text { Problem } \\
\text { No. }\end{array}$ & \multicolumn{3}{c}{ Anticipated scoring performance } \\
\hline 1 & Low & Medium & High \\
\hline 2 & 07 & 07 & 27 \\
3 & 01 & 02 & 08 \\
4 & 03 & 04 & 03 \\
5 & 11 & 06 & 27 \\
6 & 20 & 12 & 27 \\
\hline
\end{tabular}

Each rater generated 72 ratings ( 3 students times 6 problems per student times 4 ratings per problem). Note that the terms ratings and scoring are considered synonymous throughout this discussion. The results, along with subsequent actions taken, are shown in separate tables for each problem (see Table F3 - F8). In summary, the raters agreed on $85 \%$ of the ratings of the independent scoring $(61 / 72)$. Following 
the inter-rater process shown in Figure F1, a discussion between the two raters, relative to the differences in the 11 scores in disagreement, resulted in revisions required for some of the rubrics. Specifically, as noted in the Action column of the tables, 7 of the 11 scores required revisions to the rubrics, while no revisions were deemed necessary for the other four scores (the raters agreed that the different scores were due to minor interpretation issues). All scores were revisited with the new rubric revisions until 100\% agreement was achieved for all 72 ratings prior to continuing on to Stage 2 of the process. 
Table F3

Summary of the Pilot Study of Inter-Rater Agreement on the "Count Your Coin" Problem

\begin{tabular}{|c|c|c|c|c|c|c|}
\hline $\begin{array}{l}\text { ID } \\
\text { No. }\end{array}$ & $\begin{array}{c}\text { Problem } \\
\text { Rubric } \\
\text { No. }\end{array}$ & $\begin{array}{c}\text { Scale } \\
\text { Number }\end{array}$ & $\begin{array}{c}\text { Rater A } \\
\text { response } \\
\text { (revised } \\
\text { score) }\end{array}$ & $\begin{array}{l}\text { Rater B } \\
\text { response } \\
\text { (revised } \\
\text { score ) }\end{array}$ & $\begin{array}{c}\text { Difference } \\
\text { Rater A - } \\
\text { Rater B }\end{array}$ & Action \\
\hline 07 & 1 & I & $2(3)$ & 3 & -1 & $\begin{array}{l}\text { Revised rubric } \\
\text { wording }\end{array}$ \\
\hline 07 & 1 & II & 3 & 3 & 0 & \\
\hline 07 & 1 & III & $3(2)$ & 2 & 1 & $\begin{array}{l}\text { Revised rubric } \\
\text { wording }\end{array}$ \\
\hline 07 & 1 & IV & 3 & 3 & 0 & \\
\hline 27 & 1 & I & 3 & 3 & 0 & \\
\hline 27 & 1 & II & 4 & 4 & 0 & \\
\hline 27 & 1 & III & 4 & 4 & 0 & \\
\hline 27 & 1 & IV & 4 & 4 & 0 & \\
\hline 31 & 1 & I & 0 & $1(0)$ & -1 & $\begin{array}{l}\text { Revised rubric } \\
\text { wording }\end{array}$ \\
\hline 31 & 1 & II & 0 & 0 & 0 & \\
\hline 31 & 1 & III & 0 & 0 & 0 & \\
\hline 31 & 1 & IV & 0 & 0 & 0 & \\
\hline
\end{tabular}


Table F4

Summary of the Pilot Study of Inter-Rater Agreement on the "Lost in the Auditorium" problem

\begin{tabular}{|c|c|c|c|c|c|c|}
\hline $\begin{array}{l}\text { ID } \\
\text { No. }\end{array}$ & $\begin{array}{c}\text { Problem } \\
\text { Rubric } \\
\text { No. }\end{array}$ & $\begin{array}{c}\text { Scale } \\
\text { Number }\end{array}$ & $\begin{array}{c}\text { Rater A } \\
\text { response } \\
\text { (revised } \\
\text { score) }\end{array}$ & $\begin{array}{l}\text { Rater B } \\
\text { response } \\
\text { (revised } \\
\text { score) }\end{array}$ & $\begin{array}{c}\text { Difference } \\
\text { Rater A - } \\
\text { Rater B }\end{array}$ & Action \\
\hline 02 & 2 & I & 2 & 2 & 0 & \\
\hline 02 & 2 & II & 1 & 1 & 0 & \\
\hline 02 & 2 & III & 1 & $2(1)$ & -1 & $\begin{array}{c}\text { No rubric } \\
\text { change required }\end{array}$ \\
\hline 02 & 2 & IV & 2 & 2 & 0 & \\
\hline 07 & 2 & I & 0 & 0 & 0 & \\
\hline 07 & 2 & II & 0 & 0 & 0 & \\
\hline 07 & 2 & III & 0 & 0 & 0 & \\
\hline 07 & 2 & IV & 0 & 0 & 0 & \\
\hline 08 & 2 & I & 4 & 4 & 0 & \\
\hline 08 & 2 & II & 4 & 4 & 0 & \\
\hline 08 & 2 & III & 4 & 4 & 0 & \\
\hline 08 & 2 & IV & 4 & 4 & 0 & \\
\hline
\end{tabular}


Table F5

Summary of the Pilot study of Inter-Rater Agreement on the "Birthday Money" Problem

\begin{tabular}{|c|c|c|c|c|c|c|}
\hline $\begin{array}{l}\text { ID } \\
\text { No. }\end{array}$ & $\begin{array}{c}\text { Problem } \\
\text { Rubric } \\
\text { No. }\end{array}$ & $\begin{array}{c}\text { Scale } \\
\text { Number }\end{array}$ & $\begin{array}{c}\text { Rater A } \\
\text { response } \\
\text { (revised } \\
\text { score) }\end{array}$ & $\begin{array}{c}\text { Rater B } \\
\text { response } \\
\text { (revised } \\
\text { score) }\end{array}$ & $\begin{array}{c}\text { Difference } \\
\text { Rater A - } \\
\text { Rater B }\end{array}$ & Action \\
\hline 01 & 3 & I & 0 & 0 & 0 & \\
\hline 01 & 3 & II & 0 & 0 & 0 & \\
\hline 01 & 3 & III & 0 & 0 & 0 & \\
\hline 01 & 3 & IV & 0 & 0 & 0 & \\
\hline 03 & 3 & I & 4 & 4 & 0 & \\
\hline 03 & 3 & II & 4 & 4 & 0 & \\
\hline 03 & 3 & III & 4 & 4 & 0 & \\
\hline 03 & 3 & IV & 4 & 4 & 0 & \\
\hline 04 & 3 & I & $3(2)$ & 2 & 1 & $\begin{array}{l}\text { Revised rubric } \\
\text { wording }\end{array}$ \\
\hline 04 & 3 & II & 2 & 2 & 0 & \\
\hline 04 & 3 & III & 3 & $2(3)$ & 1 & $\begin{array}{l}\text { Revised rubric } \\
\text { wording }\end{array}$ \\
\hline 04 & 3 & IV & 3 & 3 & 0 & \\
\hline
\end{tabular}


Table F6

Summary of the Pilot Study of Inter-Rater Agreement on the "What's in My Future?" Problem

\begin{tabular}{|c|c|c|c|c|c|c|}
\hline $\begin{array}{l}\text { ID } \\
\text { No. }\end{array}$ & $\begin{array}{c}\text { Problem } \\
\text { Rubric } \\
\text { No. }\end{array}$ & $\begin{array}{c}\text { Scale } \\
\text { Number }\end{array}$ & $\begin{array}{c}\text { Rater A } \\
\text { response } \\
\text { (revised } \\
\text { score) } \\
\end{array}$ & $\begin{array}{c}\text { Rater B } \\
\text { response } \\
\text { (revised } \\
\text { score) } \\
\end{array}$ & $\begin{array}{c}\text { Difference } \\
\text { Rater A - } \\
\text { Rater B }\end{array}$ & Action \\
\hline 03 & 4 & I & 0 & 0 & 0 & \\
\hline 03 & 4 & II & 0 & 0 & 0 & \\
\hline 03 & 4 & III & 0 & 0 & 0 & \\
\hline 03 & 4 & IV & 0 & 0 & 0 & \\
\hline 06 & 4 & I & 2 & 2 & 0 & \\
\hline 06 & 4 & II & 3 & 3 & 0 & \\
\hline 06 & 4 & III & 3 & $4(3)$ & -1 & $\begin{array}{c}\text { No rubric } \\
\text { change required }\end{array}$ \\
\hline 06 & 4 & IV & 2 & 2 & 0 & \\
\hline 27 & 4 & I & 4 & 4 & 0 & \\
\hline 27 & 4 & II & 4 & 4 & 0 & \\
\hline 27 & 4 & III & 4 & 4 & 0 & \\
\hline 27 & 4 & IV & 4 & 4 & 0 & \\
\hline
\end{tabular}


Table F7

Summary of the Pilot Study of Inter-Rater Agreement on the "How Many Children Live Next Door?" Problem

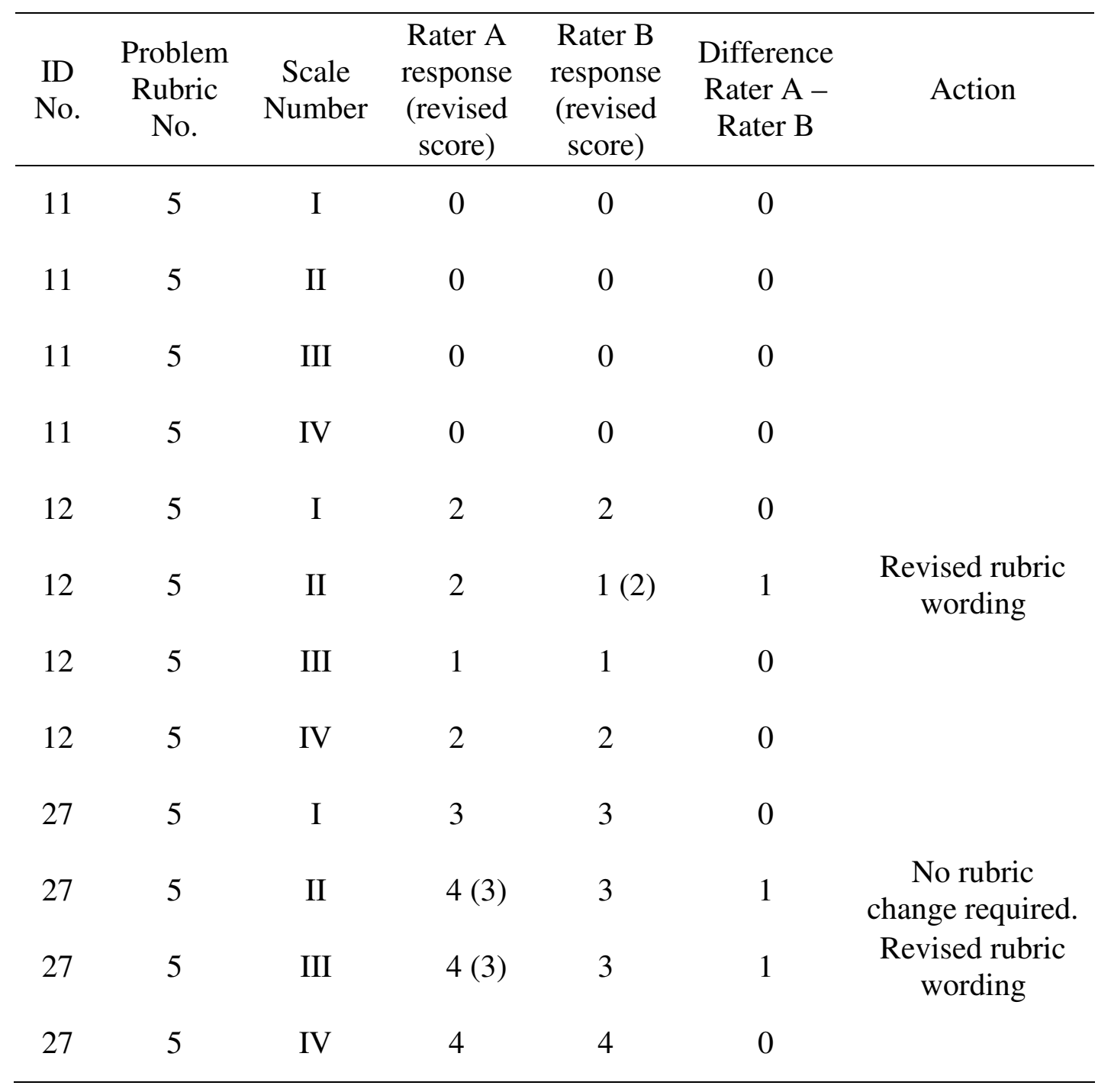


Table F8

Summary of the Pilot Study of Inter-Rater Agreement on the "Blind Sided" Problem

\begin{tabular}{|c|c|c|c|c|c|c|}
\hline $\begin{array}{l}\text { ID } \\
\text { No. }\end{array}$ & $\begin{array}{c}\text { Problem } \\
\text { Rubric } \\
\text { No. }\end{array}$ & $\begin{array}{c}\text { Scale } \\
\text { Number }\end{array}$ & $\begin{array}{c}\text { Rater A } \\
\text { response } \\
\text { (revised } \\
\text { score) }\end{array}$ & $\begin{array}{l}\text { Rater B } \\
\text { response } \\
\text { (revised } \\
\text { score) } \\
\end{array}$ & $\begin{array}{c}\text { Difference } \\
\text { Rater A - } \\
\text { Rater B }\end{array}$ & Action \\
\hline 07 & 6 & I & 2 & 2 & 0 & \\
\hline 07 & 6 & II & $2(1)$ & 1 & 1 & $\begin{array}{c}\text { No rubric } \\
\text { change required }\end{array}$ \\
\hline 07 & 6 & III & 1 & 1 & 0 & \\
\hline 07 & 6 & IV & 2 & 2 & 0 & \\
\hline 11 & 6 & I & 4 & 4 & 0 & \\
\hline 11 & 6 & II & 4 & 4 & 0 & \\
\hline 11 & 6 & III & 4 & 4 & 0 & \\
\hline 11 & 6 & IV & 4 & 4 & 0 & \\
\hline 20 & 6 & I & 0 & 0 & 0 & \\
\hline 20 & 6 & II & 0 & 0 & 0 & \\
\hline 20 & 6 & III & 0 & 0 & 0 & \\
\hline 20 & 6 & IV & 0 & 0 & 0 & \\
\hline
\end{tabular}


Stage 2

After Stage 1 was completed, the process was extended to assess a statistically appropriate sample of the population of students $(N=38)$ for all six problems with their respective rubrics. The same two raters were used.

The statistically appropriate sample was determined by using the following simplified equation, assuming a 95\% confidence level and a maximum degree of variability $\mathrm{P}=0.5$ found in Yamane (1967):

$$
n=\frac{N}{1+N(e)^{2}}
$$

Where $n=$ sample size, $N$ is the population size, and $e$ is the level of precision (i.e., sampling error).

Now applying the equation for the 912 ratings (38 students times 6 problems per student times 4 ratings per problem) and a level of precision of $+/-5 \%$ :

$$
\begin{aligned}
& n=\frac{912}{1+912(.05)^{2}} \\
& n=278 \text { ratings required. }
\end{aligned}
$$

Since there are 24 ratings per student ( 6 problems per student times 4 ratings per problem), 278 ratings divided by 24 ratings per student results in 11.58 students. Therefore, rounding up, a sample size of 12 students of the student population $(N=$ 38) should suffice in providing a statistically sound prediction of rater agreement for the 912 ratings prior to full assessment of the population. 
Using SAS® statistical analysis software, a routine was developed to randomly select 12 of the 38 students. The resulting 12 ID numbers in order of selection were: 9 , $10,14,1,20,4,17,24,16,36,30$, and 37 (sorted: 1, 4, 9, 10, 14, 16, 17, 20, 24, 30, 36, and 37).

Following the inter-rater process mapped in Figure F1, the six problems of each of the 12 randomly selected students were independently scored. There were 288 ratings per rater (12 students x 6 problems per student x 4 ratings per problem). An overall summary of rater consensus performance of the Stage 2 independent scoring for each of the 6 problems is depicted in Table F9. Exact agreement on paired scores was found to be $82 \%(237 / 288)$.

Following the inter-rater process shown in Figure F1, a discussion between the two raters, relative to the differences in the 51 scores in disagreement $(288-237=$ 51), resulted in revisions required for some of the rubrics and revisions to 50 of the 51 scores (the raters agreed to disagree on ID 030, Problem No. 3, Scale I, and agreed to take an average of the two different scores). The details of rater scoring, scoring revisions, and action taken for all 51 disagreements, are detailed in Table F10. All scores (Stage 1 and Stage 2) were revisited with the new rubric revisions. At the conclusion of the Stage 2 process, 99.7\% (347/348) of the rater scores were in exact agreement thereby exceeding the goal of a minimum of $95 \%$ as stated in Stage 2 of Table F1. 
Table F9

Percent Consensus between Raters after Independent Scoring

\begin{tabular}{cccc}
\hline $\begin{array}{c}\text { Problem } \\
\text { No. }\end{array}$ & $\begin{array}{c}\text { No. of total } \\
\text { scores }\end{array}$ & $\begin{array}{c}\text { No. of } \\
\text { exact } \\
\text { agreements }\end{array}$ & $\begin{array}{c}\text { \% Consensus } \\
\text { between Raters }\end{array}$ \\
\hline 1 & 48 & 47 & 98 \\
2 & 48 & 42 & 88 \\
3 & 48 & 37 & 77 \\
4 & 48 & 33 & 69 \\
5 & 48 & 41 & 85 \\
6 & 48 & 37 & 77 \\
\hline
\end{tabular}


Table F10

Summary of Stage 2 Disagreement Action $(n=51)$

\begin{tabular}{|c|c|c|c|c|c|c|}
\hline $\begin{array}{l}\text { ID } \\
\text { No. }\end{array}$ & $\begin{array}{c}\text { Problem } \\
\text { Rubric } \\
\text { No. }\end{array}$ & $\begin{array}{c}\text { Scale } \\
\text { Number }\end{array}$ & $\begin{array}{c}\text { Rater A } \\
\text { response } \\
\text { (revised } \\
\text { score) }\end{array}$ & $\begin{array}{c}\text { Rater B } \\
\text { response } \\
\text { (revised } \\
\text { score ) }\end{array}$ & $\begin{array}{c}\text { Difference } \\
\text { Rater A - } \\
\text { Rater B }\end{array}$ & Action $^{a}$ \\
\hline 36 & 1 & III & $3(2)$ & 2 & 1 & $\begin{array}{l}\text { Revised rubric } \\
\text { wording }\end{array}$ \\
\hline 16 & 2 & II & $4(3)$ & 3 & 1 & $\begin{array}{l}\text { Revised rubric } \\
\text { wording }\end{array}$ \\
\hline 20 & 2 & I & 2 & $1(2)$ & 1 & $\begin{array}{c}\text { Revised rubric } \\
\text { wording }\end{array}$ \\
\hline 24 & 2 & III & $1(2)$ & $3(2)$ & -2 & $\begin{array}{l}\text { Revised rubric } \\
\text { wording }\end{array}$ \\
\hline 30 & 2 & II & 4 & $3(4)$ & 1 & $\begin{array}{l}\text { Revised rubric } \\
\text { wording }\end{array}$ \\
\hline 36 & 2 & II & $4(1)$ & 1 & 3 & $\begin{array}{l}\text { Revised rubric } \\
\text { wording }\end{array}$ \\
\hline 37 & 2 & I & $4(3)$ & 3 & 1 & $\begin{array}{l}\text { Revised rubric } \\
\text { wording }\end{array}$ \\
\hline 09 & 3 & I & $3(4)$ & 4 & -1 & $\begin{array}{l}\text { Revised rubric } \\
\text { wording }\end{array}$ \\
\hline 09 & 3 & III & 2 & $3(2)$ & -1 & $\begin{array}{l}\text { Revised rubric } \\
\text { wording }\end{array}$ \\
\hline 10 & 3 & III & $2(3)$ & $3(2)$ & -1 & $\begin{array}{l}\text { Revised rubric } \\
\text { wording }\end{array}$ \\
\hline 16 & 3 & IV & $0(1)$ & 1 & -1 & $\begin{array}{l}\text { Revised rubric } \\
\text { wording }\end{array}$ \\
\hline 17 & 3 & I & $2(1)$ & 1 & 1 & $\begin{array}{l}\text { Revised rubric } \\
\text { wording }\end{array}$ \\
\hline 20 & 3 & II & 1 & $0(1)$ & 1 & $\begin{array}{l}\text { Revised rubric } \\
\text { wording }\end{array}$ \\
\hline 20 & 3 & III & 1 & $0(1)$ & 1 & $\begin{array}{l}\text { Revised rubric } \\
\text { wording }\end{array}$ \\
\hline 30 & 3 & I & 3 & 2 & 1 & $\begin{array}{c}\text { Take average } \\
\text { score }\end{array}$ \\
\hline 36 & 3 & II & $1(2)$ & 2 & -1 & $\begin{array}{l}\text { Revised rubric } \\
\text { wording }\end{array}$ \\
\hline 36 & 3 & III & $1(2)$ & 2 & -1 & $\begin{array}{l}\text { Revised rubric } \\
\text { wording }\end{array}$ \\
\hline
\end{tabular}




\begin{tabular}{|c|c|c|c|c|c|c|}
\hline $\begin{array}{l}\text { ID } \\
\text { No. }\end{array}$ & $\begin{array}{c}\text { Problem } \\
\text { Rubric } \\
\text { No. }\end{array}$ & $\begin{array}{c}\text { Scale } \\
\text { Number }\end{array}$ & $\begin{array}{c}\text { Rater A } \\
\text { response } \\
\text { (revised } \\
\text { score) } \\
\end{array}$ & $\begin{array}{l}\text { Rater B } \\
\text { response } \\
\text { (revised } \\
\text { score ) }\end{array}$ & $\begin{array}{l}\text { Difference } \\
\text { Rater A - } \\
\text { Rater B }\end{array}$ & Action $^{\mathrm{a}}$ \\
\hline 37 & 3 & III & 3 & $4(3)$ & -1 & $\begin{array}{l}\text { Revised rubric } \\
\text { wording }\end{array}$ \\
\hline 10 & 4 & I & $1(2)$ & 2 & -1 & $\begin{array}{c}\text { No rubric } \\
\text { change required }\end{array}$ \\
\hline 10 & 4 & II & $0(1)$ & 1 & -1 & $\begin{array}{c}\text { No rubric } \\
\text { change required }\end{array}$ \\
\hline 10 & 4 & III & $0(1)$ & 1 & -1 & $\begin{array}{c}\text { No rubric } \\
\text { change required }\end{array}$ \\
\hline 10 & 4 & IV & $0(2)$ & 2 & -2 & $\begin{array}{c}\text { No rubric } \\
\text { change required }\end{array}$ \\
\hline 14 & 4 & III & 2 & $0(2)$ & 2 & $\begin{array}{c}\text { No rubric } \\
\text { change required }\end{array}$ \\
\hline 16 & 4 & I & $0(2)$ & 2 & -2 & $\begin{array}{c}\text { No rubric } \\
\text { change required }\end{array}$ \\
\hline 16 & 4 & II & 1 & $3(1)$ & -2 & $\begin{array}{c}\text { No rubric } \\
\text { change required }\end{array}$ \\
\hline 16 & 4 & III & 1 & $3(1)$ & -2 & $\begin{array}{c}\text { No rubric } \\
\text { change required }\end{array}$ \\
\hline 17 & 4 & II & 1 & $2(1)$ & -1 & $\begin{array}{c}\text { No rubric } \\
\text { change required }\end{array}$ \\
\hline 17 & 4 & III & 1 & $3(1)$ & -2 & $\begin{array}{c}\text { No rubric } \\
\text { change required }\end{array}$ \\
\hline 20 & 4 & I & $0(1)$ & 1 & -1 & $\begin{array}{c}\text { No rubric } \\
\text { change required }\end{array}$ \\
\hline 20 & 4 & III & $0(1)$ & 1 & -1 & $\begin{array}{c}\text { No rubric } \\
\text { change required }\end{array}$ \\
\hline 24 & 4 & I & $4(3)$ & 3 & 1 & $\begin{array}{c}\text { No rubric } \\
\text { change required }\end{array}$ \\
\hline 24 & 4 & III & $4(3)$ & 3 & 1 & $\begin{array}{c}\text { No rubric } \\
\text { change required }\end{array}$ \\
\hline 30 & 4 & I & $4(3)$ & 3 & 1 & $\begin{array}{c}\text { No rubric } \\
\text { change required }\end{array}$ \\
\hline 09 & 5 & I & $3(2)$ & 2 & 1 & $\begin{array}{l}\text { No rubric } \\
\text { change required } \\
\text { table continued }\end{array}$ \\
\hline
\end{tabular}




\begin{tabular}{|c|c|c|c|c|c|c|}
\hline $\begin{array}{l}\text { ID } \\
\text { No. }\end{array}$ & $\begin{array}{c}\text { Problem } \\
\text { Rubric } \\
\text { No. }\end{array}$ & $\begin{array}{c}\text { Scale } \\
\text { Number }\end{array}$ & $\begin{array}{c}\text { Rater A } \\
\text { response } \\
\text { (revised } \\
\text { score) } \\
\end{array}$ & $\begin{array}{c}\text { Rater B } \\
\text { response } \\
\text { (revised } \\
\text { score ) } \\
\end{array}$ & $\begin{array}{c}\text { Difference } \\
\text { Rater A - } \\
\text { Rater B }\end{array}$ & Action $^{a}$ \\
\hline 14 & 5 & I & $0(1)$ & 1 & -1 & $\begin{array}{c}\text { No rubric } \\
\text { change required }\end{array}$ \\
\hline 20 & 5 & I & 0 & $1(0)$ & -1 & $\begin{array}{c}\text { No rubric } \\
\text { change required }\end{array}$ \\
\hline 20 & 5 & II & 0 & $1(0)$ & -1 & $\begin{array}{c}\text { No rubric } \\
\text { change required }\end{array}$ \\
\hline 20 & 5 & III & 0 & $1(0)$ & -1 & $\begin{array}{c}\text { No rubric } \\
\text { change required }\end{array}$ \\
\hline 20 & 5 & IV & 0 & $2(0)$ & -2 & $\begin{array}{c}\text { No rubric } \\
\text { change required }\end{array}$ \\
\hline 24 & 5 & I & 3 & $4(3)$ & -1 & $\begin{array}{c}\text { No rubric } \\
\text { change required }\end{array}$ \\
\hline 01 & 6 & III & $2(3)$ & $4(3)$ & -2 & $\begin{array}{l}\text { Revised rubric } \\
\text { wording }\end{array}$ \\
\hline 01 & 6 & IV & 1 & $4(1)$ & -3 & $\begin{array}{l}\text { Revised rubric } \\
\text { wording }\end{array}$ \\
\hline 09 & 6 & I & $0(1)$ & 1 & -1 & $\begin{array}{l}\text { Revised rubric } \\
\text { wording }\end{array}$ \\
\hline 14 & 6 & I & $0(2)$ & 2 & -2 & $\begin{array}{l}\text { Revised rubric } \\
\text { wording }\end{array}$ \\
\hline 24 & 6 & II & $3(2)$ & 2 & 1 & $\begin{array}{l}\text { Revised rubric } \\
\text { wording }\end{array}$ \\
\hline 24 & 6 & III & $1(2)$ & 2 & -1 & $\begin{array}{l}\text { Revised rubric } \\
\text { wording }\end{array}$ \\
\hline 36 & 6 & I & $0(2)$ & 2 & -2 & $\begin{array}{l}\text { Revised rubric } \\
\text { wording }\end{array}$ \\
\hline 36 & 6 & II & $1(2)$ & 2 & -1 & $\begin{array}{l}\text { Revised rubric } \\
\text { wording }\end{array}$ \\
\hline 36 & 6 & III & $1(2)$ & 2 & -1 & $\begin{array}{l}\text { Revised rubric } \\
\text { wording }\end{array}$ \\
\hline 37 & 6 & II & $4(1)$ & 1 & 3 & $\begin{array}{l}\text { Revised rubric } \\
\text { wording }\end{array}$ \\
\hline 37 & 6 & III & $2(1)$ & 1 & 1 & $\begin{array}{l}\text { Revised rubric } \\
\text { wording }\end{array}$ \\
\hline
\end{tabular}

${ }^{a}$ Specific rubric changes: The Revised rubric wording action is stated even if the specific scale number was not revised since any change on the rubric may have affected a rater's choice. The actual wording revision locations are as follows: 
Problem No. 1: Scale IV: 2 pt. category Problem No. 2: Scale II: 4 pt. category Problem No. 3: Scale I: 1 pt. category Problem No. 3: Scale III: 2 pt. category Problem No. 6: Scale II: 1 pt. category Problem No. 6: Scale II: 4 pt. category

Stage 3

Using the revised 4-scale rubrics, the final stage entailed an independent scoring all 38 students' six problems by the same two raters as Stage 1 and Stage 2. Consequently, 912 ratings by each of the two raters for a total of 1824 ratings were recorded. A comparison of the scores revealed that $86 \%(784 / 912)$ were in exact agreement. Of the remaining 128 scores, 99\% (127/128) were at $+/-1$ point. The remaining pair of scores had a difference equal to 2 (ID 25, Problem \#6, Scale IV). The raters revisited their scores (Rater A scored a 2, Rater B scored a 0) on this scale and could not reach consensus and agreed to take the average score.

At this point, the high percentage of inter-rater agreement on ratings seems highly supportive of calculating and reporting a correlation coefficient such as the Pearson $r$.

Pearson $r$ correlations were calculated for the paired scores of Rater A and Rater B for each problem/scale and reported in Table F11. As expected, very high Pearson $r$ correlations were achieved ranging from .88 to .99 with a mean of .96 (p < .0001) indicating a very strong positive correlation between rater scoring. 
However, it is possible to have a high Pearson $r$ correlation between raters without high inter-rater agreement. This scenario would result if the mean scores were significantly different. In this analysis, the mean of Rater A was found to be $M_{A}=$ 1.817 and $M_{B}=1.846$ for a less than $2 \%$ difference. A Chi Square test was performed

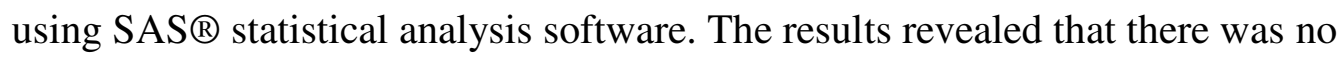
significant difference between the scores of Rater A and Rater B,

$$
\chi^{2}(4, N=1824)=1.1053, p=0.8934 .
$$

In conclusion, with a very strong positive correlation having been achieved and confirmed by both the Pearson $r$ correlation and Chi Square test, the final step in the Figure F1 inter-rater agreement process was to average all remaining Stage 3 scores that differed from exactness and construct a data file of the averaged paired scores to be used in further analyses. As a consequence, the data file contains scores representative of $100 \%$ inter-rater agreement.

The revised rubrics (used for Stage 3) are included in the following and are summarized in Table F12. 
Table F11

Stage 3 Pearson r Correlations between Rater A and Rater B

by Problem/Scale $(N=912)$

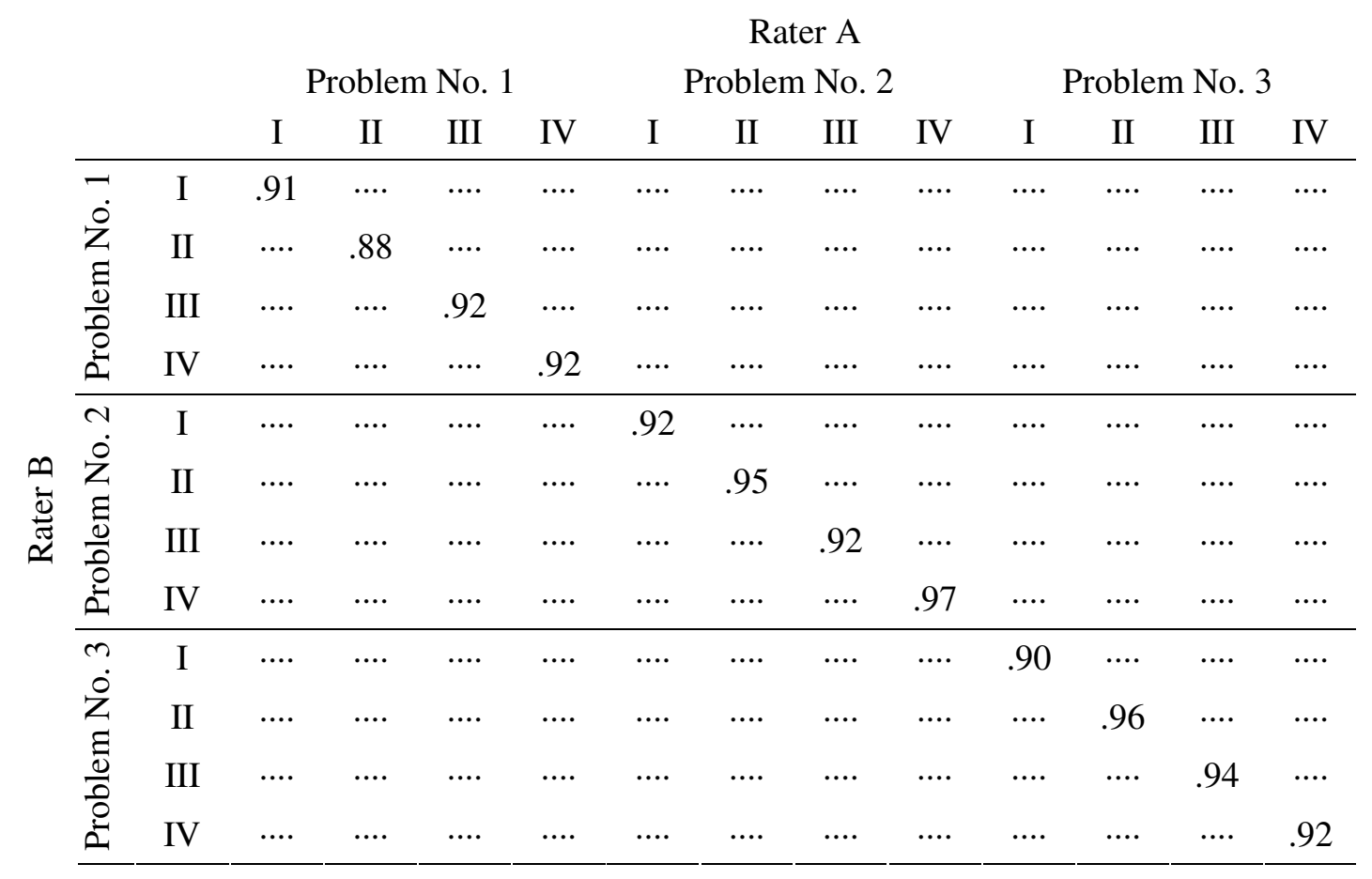

\begin{tabular}{|c|c|c|c|c|c|c|c|c|c|c|c|c|c|}
\hline & & \multicolumn{12}{|c|}{ Rater A } \\
\hline & & \multicolumn{4}{|c|}{ Problem No. 4} & \multicolumn{4}{|c|}{ Problem No. 5} & \multicolumn{4}{|c|}{ Problem No. 6} \\
\hline & & I & II & III & IV & I & II & III & IV & I & II & III & IV \\
\hline \multirow{4}{*}{$\begin{array}{l}+ \\
0 \\
Z \\
\Xi \\
0 \\
0 \\
0 \\
0\end{array}$} & I & .97 & $\ldots$. & $\ldots$. & $\ldots$. & $\ldots$. & $\ldots$. & $\ldots$ & $\ldots$. & $\cdots$. & $\cdots$ & $\cdots$ & $\ldots$. \\
\hline & II & $\ldots$ & .99 & $\ldots$ & $\ldots$ & $\ldots$. & $\ldots$. & $\ldots$. & $\ldots$ & $\ldots$ & $\ldots$ & $\ldots$. & $\ldots$. \\
\hline & III & $\cdots$ & $\cdots$ & .96 & $\ldots$ & $\cdots$ & $\ldots$ & $\cdots$ & $\cdots$ & $\cdots$ & $\ldots$ & $\cdots$ & $\cdots$ \\
\hline & IV & $\ldots$ & $\ldots$ & $\cdots$ & .99 & $\ldots$ & $\ldots$ & $\ldots$ & $\ldots$ & $\ldots$ & $\ldots$ & $\ldots$ & $\ldots$. \\
\hline \multirow{4}{*}{$\begin{array}{l}n \\
\dot{z} \\
0 \\
0 \\
0 \\
0 \\
0\end{array}$} & I & $\ldots$ & $\ldots$ & $\ldots$ & $\ldots$ & .95 & $\ldots$ & $\ldots$. & $\ldots$. & $\ldots$. & $\ldots$ & $\ldots$. & $\ldots$. \\
\hline & II & $\cdots$ & $\cdots$ & $\cdots$ & $\cdots$ & $\cdots$ & .94 & $\cdots$. & $\cdots$ & $\cdots$ & $\cdots$ & $\cdots$ & $\ldots$ \\
\hline & III & $\cdots$ & $\cdots$ & $\ldots$ & $\ldots$ & $\cdots$ & $\cdots$ & .94 & $\cdots$ & $\cdots$ & $\cdots$ & $\cdots$ & $\cdots$ \\
\hline & IV & $\ldots$ & $\ldots$ & $\ldots$ & $\ldots$ & $\ldots$ & $\ldots$. & $\cdots$ & .99 & $\ldots$ & $\ldots$ & $\ldots$ & $\ldots$ \\
\hline \multirow{4}{*}{$\begin{array}{l}0 \\
\dot{0} \\
z \\
0 \\
\frac{0}{0} \\
0 \\
0 \\
0\end{array}$} & I & $\ldots$ & $\ldots$ & $\ldots$ & $\ldots$ & $\ldots$. & $\ldots$ & $\ldots$ & $\ldots$ & .96 & $\ldots$ & $\ldots$. & $\ldots$. \\
\hline & II & $\ldots$ & $\ldots$ & $\ldots$ & $\ldots$ & $\ldots$ & $\ldots$ & $\ldots$ & $\ldots$. & $\ldots$ & .95 & $\ldots$ & $\ldots$. \\
\hline & III & $\ldots$ & $\cdots$ & $\ldots$ & $\ldots$ & $\cdots$ & $\ldots$ & $\cdots$ & $\cdots$ & $\cdots$ & $\ldots$ & .92 & $\cdots$ \\
\hline & IV & $\ldots$. & $\ldots$. & $\ldots$ & $\ldots$ & $\ldots$. & $\ldots$ & $\ldots$. & $\ldots$. & $\ldots$. & $\ldots$ & $\ldots$ & .97 \\
\hline
\end{tabular}




\section{Table F12}

Summary of Scoring Rubrics for the Six Nonroutine Mathematical Problems

\begin{tabular}{|c|c|c|}
\hline Problem & Nonroutine problem scoring rubric & Figure \\
\hline \multirow[b]{2}{*}{1} & Count Your Coins - Page 1 & $\mathrm{~F} 2 \mathrm{a}$ \\
\hline & Count Your Coins - Page 2 & $\mathrm{~F} 2 \mathrm{~b}$ \\
\hline \multirow{2}{*}{2} & Lost in the Auditorium - Page 1 & $\mathrm{~F} 3 \mathrm{a}$ \\
\hline & Lost in the Auditorium - Page 2 & F3b \\
\hline \multirow[b]{2}{*}{3} & Birthday Money - Page 1 & F $4 \mathrm{a}$ \\
\hline & Birthday Money - Page 2 & $\mathrm{~F} 4 \mathrm{~b}$ \\
\hline \multirow{2}{*}{4} & What's in My Future? - Page 1 & F5a \\
\hline & What's in My Future? - Page 2 & F 5 b \\
\hline \multirow{2}{*}{5} & $\begin{array}{l}\text { How Many Children Live Next Door? } \\
\text { - Page } 1\end{array}$ & F6a \\
\hline & $\begin{array}{l}\text { How Many Children Live Next Door? } \\
\text { - Page } 2\end{array}$ & $\mathrm{~F} 6 \mathrm{~b}$ \\
\hline \multirow[b]{2}{*}{6} & Blind Sided - Page 1 & F $7 a$ \\
\hline & Blind Sided - Page 2 & F 7b \\
\hline
\end{tabular}


Math Problem Scoring Rubric (Rev. 08/30/08)

Problem \#1 Title: "Count Your Coins"

Rater's Initials:

Participant ID Number (3 digits):

(Circle the appropriate "best fit" score for each of the four scales)

\begin{tabular}{|c|c|c|}
\hline \multicolumn{3}{|c|}{ Scale I: Understanding the Problem } \\
\hline Score & General & Specific to this problem \\
\hline 4 & $\begin{array}{l}\text { Identified special factors that influenced the } \\
\text { approach before starting the problem. }\end{array}$ & $\begin{array}{l}\text { Identified the } 4 \text { coins involved, stated a sum of } \\
30 \text { cents was required, stated the numerical } \\
\text { value of the coins involved, stated the number } \\
\text { of each type of coin used, and stated a final } \\
\text { count (right or wrong) for the total number of } \\
\text { ways somewhere (including narrative section). }\end{array}$ \\
\hline 3 & Understood the problem. & $\begin{array}{l}\text { Must have stated a final count (right or wrong) } \\
\text { for the total number of ways somewhere } \\
\text { (including narrative section). Must have } \\
\text { provided a detailed description of each } \\
\text { combination attempted including some } \\
\text { mention/indication to the } 30 \text { cent sum (Note: all } \\
\text { combinations adding to } 30 \text { cents implies } 30 \\
\text { cents sum without actually stating } 30 \text { cents). }\end{array}$ \\
\hline 2 & $\begin{array}{l}\text { Understood enough to solve part of the problem or } \\
\text { to get part of the solution; or at least showed some } \\
\text { steps toward a solution (beyond just simply } \\
\text { restating what was given). }\end{array}$ & $\begin{array}{l}\text { May have listed all or some of the possible ways } \\
\text { but did not state a final count (right or wrong) } \\
\text { for the total number of ways somewhere } \\
\text { (including narrative section) and/or did not } \\
\text { mention the sum of } 30 \text { cents. }\end{array}$ \\
\hline 1 & $\begin{array}{l}\text { Could only restate all or some of the information } \\
\text { given in the problem statement. }\end{array}$ & Use the "General" column. \\
\hline $\mathbf{0}$ & Did not understand enough to get started. & $\begin{array}{l}\text { May have written "I don't know" or similar; } \\
\text { provided an answer with no work (e.g., a guess); } \\
\text { or, workspace is blank. Crossed-out work } \\
\text { counts as blank work. }\end{array}$ \\
\hline
\end{tabular}

\begin{tabular}{|c|c|c|}
\hline \multicolumn{3}{|c|}{ Scale II: How Student Solved Problem } \\
\hline Score & General & Specific to this problem \\
\hline 4 & Approach was efficient or sophisticated. & $\begin{array}{l}\text { Indication of a systematic approach for at least } \\
75 \% \text { of the ways listed such as listing } \\
\text { combinations with quarters first, then dimes, } \\
\text { then nickels, then pennies or the reverse. }\end{array}$ \\
\hline 3 & Approach would work for the problem. & $\begin{array}{l}\text { No apparent systematic approach or a weak } \\
\text { systematic approach, however, all combinations } \\
\text { attempted add up to } 30 \text { cents and all four coins } \\
\text { are used somewhere in the combinations }\end{array}$ \\
\hline 2 & $\begin{array}{l}\text { Approach would only lead to solving part of the } \\
\text { problem. }\end{array}$ & $\begin{array}{l}\text { Combinations attempted did not consider one } \\
\text { or more of the coins. }\end{array}$ \\
\hline 1 & $\begin{array}{l}\text { Approach didn't work; approach was wrong; } \\
\text { approach was unclear. }\end{array}$ & Sum of coins do not add to 30cents. \\
\hline $\mathbf{0}$ & Approach was nonexistent. & $\begin{array}{l}\text { May have written "I don't know" or similar; } \\
\text { provided an answer with no work (e.g., a } \\
\text { guess); or, workspace is blank. Crossed-out } \\
\text { work counts as blank work. }\end{array}$ \\
\hline
\end{tabular}

“Count Your Coins” Scoring Rubric Continued on back $\downarrow$

Figure F2a. Math scoring rubric: count your coins - front side 


\begin{tabular}{|c|c|c|}
\hline \multicolumn{3}{|c|}{ Scale III: Decisions Along the Way } \\
\hline Score & General & Specific to this problem \\
\hline 4 & $\begin{array}{l}\text { Clearly explained the reasons for the correct } \\
\text { decisions made throughout the problem. }\end{array}$ & $\begin{array}{l}\text { Specified "quantity of" and "type of" coin used } \\
\text { in each combination along with an indication } \\
\text { that the sum must equal } 30 \text { cents; and each } \\
\text { combination is numbered (or a total count of the } \\
\text { ways is provided after the last listing). }\end{array}$ \\
\hline 3 & $\begin{array}{l}\text { Didn't clearly explain the reasons for decisions, but } \\
\text { work suggests correct reasoning. }\end{array}$ & $\begin{array}{l}\text { Either by the use of words, symbols, or } \\
\text { combination of both, somewhere (including the } \\
\text { narrative section) there is an indication that the } \\
\text { sum of each combination must equal } 30 \text { cents } \\
\text { (must have stated "= } 30, \text {, "30 cents," etc.). }\end{array}$ \\
\hline 2 & $\begin{array}{l}\text { Only partly correct reasoning, or correct reasoning } \\
\text { used for only part of the problem. }\end{array}$ & $\begin{array}{l}\text { Correct combinations are provided but no } \\
\text { mention of the sum being } 30 \text { cents; or, not all } \\
\text { combinations provided are correct. }\end{array}$ \\
\hline 1 & $\begin{array}{l}\text { No reasoning is evident from the work or } \\
\text { reasoning is incorrect. }\end{array}$ & $\begin{array}{l}\text { Combinations are provided but no indication } \\
\text { that they were chosen because they add to } 30 \\
\text { cents. }\end{array}$ \\
\hline $\mathbf{0}$ & No work is provided. & $\begin{array}{l}\text { May have written "I don't know" or similar; } \\
\text { provided an answer with no work (e.g., a } \\
\text { guess); or, workspace is blank. Crossed-out } \\
\text { work counts as blank work. }\end{array}$ \\
\hline
\end{tabular}

\begin{tabular}{|c|l|l|}
\hline \multicolumn{3}{|c|}{ Scale IV: Getting an Answer } \\
\hline $\mathbf{4}$ & $\begin{array}{l}\text { General } \\
\text { Specific to this problem }\end{array}$ \\
\hline $\mathbf{3}$ & $\begin{array}{l}\text { correct answer and correct label for the answer; } \\
\text { student's work; work was shown and supported } \\
\text { correct answer. }\end{array}$ & $\begin{array}{l}\text { The correct answer of 18 ways is clearly } \\
\text { discernable and is supported by the } \\
\text { combinations provided. }\end{array}$ \\
\hline $\mathbf{2}$ & $\begin{array}{l}\text { copying error, computational error. } \\
\text { Incorrect answer based on an inappropriate plan or } \\
\text { work. }\end{array}$ & $\begin{array}{l}\text { The answer provided (including narrative } \\
\text { section) is not 18 ways but all combinations } \\
\text { stated are correct; or, no specific number of } \\
\text { ways is stated but combinations are numbered. }\end{array}$ \\
\hline $\mathbf{1}$ & $\begin{array}{l}\text { Construction; or, combinations may be correct } \\
\text { but no total quantity for the number of ways is } \\
\text { provided and/or the combinations provided are } \\
\text { not numbered. }\end{array}$ \\
\hline $\mathbf{0}$ & $\begin{array}{l}\text { correct answer (e.g., a random guess as opposed to } \\
\text { an educated guess). }\end{array}$ & $\begin{array}{l}\text { The correct answer of 18 ways is stated } \\
\text { without work or the work provided does not } \\
\text { support the correct answer (e.g., incorrectly } \\
\text { constructed combinations). }\end{array}$ \\
\hline
\end{tabular}

Adapted from:

Charles, R., Lester Jr., F. K., and O’Daffer, P. (1987). How to evaluate problem solving. Reston, VA.:

National Council of Teachers of Mathematics.

Polya, G. (2004). How to solve it. Princeton, N.J.: Princeton University Press.

(Original work published 1945)

Stenmark, J. K. (1991). Mathematics assessment: Myths, models, good questions and practical suggestions. Reston, VA.: National Council of Teachers of Mathematics.

Szetala, W., and Nicole, C. (1992). Evaluating problem solving in mathematics. Educational Leadership, May $1992,42-45$

Figure F2b. Math scoring rubric: count your coins - back side 
Math Problem Scoring Rubric (Rev. 08/30/08)

Problem \#2 Title: "Lost in the Auditorium"

Rater's Initials:

Participant ID Number (3 digits):

(Circle the appropriate "best fit" score for each of the four scales)

\begin{tabular}{|c|c|c|}
\hline \multicolumn{3}{|c|}{ Scale I: Understanding the Problem } \\
\hline Score & General & Specific to this problem \\
\hline 4 & $\begin{array}{l}\text { Identified special factors that influenced the } \\
\text { approach before starting the problem. }\end{array}$ & $\begin{array}{l}\text { Drew a correctly constructed diagram or stated } \\
\text { verbally that } 8 \text { doors are involved and that you } \\
\text { can not exit the same door entered; and } \\
\text { somewhere (including narrative section).stated } \\
\text { a final count (right or wrong) for the total } \\
\text { number of ways one can enter and exit. }\end{array}$ \\
\hline 3 & Understood the problem. & $\begin{array}{l}\text { May or may not have drawn diagrams, but work } \\
\text { indicates that } 8 \text { doors are involved, and that you } \\
\text { can not exit the same door entered, and } \\
\text { somewhere (including narrative section) stated } \\
\text { a final count (right or wrong) for the total } \\
\text { number of ways one can enter and exit. }\end{array}$ \\
\hline 2 & $\begin{array}{l}\text { Understood enough to solve part of the problem or } \\
\text { to get part of the solution; or at least showed some } \\
\text { steps toward a solution (beyond just simply } \\
\text { restating what was given). }\end{array}$ & $\begin{array}{l}\text { May have listed/indicated all or some of the } \\
\text { possible ways but did not state a final count } \\
\text { (right or wrong) for the total number of ways } \\
\text { somewhere (including narrative section) and/or } \\
\text { did not understand that you cannot exit the } \\
\text { same door entered. }\end{array}$ \\
\hline 1 & $\begin{array}{l}\text { Could only restate all or some of the information } \\
\text { given in the problem statement. }\end{array}$ & Use the "General" column. \\
\hline $\mathbf{0}$ & Did not understand enough to get started. & $\begin{array}{l}\text { May have written "I don't know" or similar; } \\
\text { provided an answer with no work (e.g., a } \\
\text { guess); or, workspace is blank. Crossed-out } \\
\text { work counts as blank work. }\end{array}$ \\
\hline
\end{tabular}

\begin{tabular}{|c|c|c|}
\hline \multicolumn{3}{|c|}{ Scale II: How Student Solved Problem } \\
\hline Score & General & Specific to this problem \\
\hline 4 & Approach was efficient or sophisticated. & $\begin{array}{l}\text { Indication of a systematic approach such as } \\
\text { constructing a table, listing pairs of doors, } \\
\text { drawing a diagram with } 8 \text { doors and connecting } \\
\text { permissible paths. }\end{array}$ \\
\hline 3 & Approach would work for the problem. & $\begin{array}{l}\text { No apparent systematic approach or a weak } \\
\text { systematic approach, however, method should } \\
\text { lead to a correct solution. }\end{array}$ \\
\hline 2 & $\begin{array}{l}\text { Approach would only lead to solving part of the } \\
\text { problem. }\end{array}$ & $\begin{array}{l}\text { Method led to a correct partial answer of } 7 \\
\text { ways per door but method failed to consider } 8 \\
\text { doors. }\end{array}$ \\
\hline 1 & $\begin{array}{l}\text { Approach didn't work; approach was wrong; } \\
\text { approach was unclear. }\end{array}$ & $\begin{array}{l}\text { Method did not result in a correct calculation of } \\
\text { seven ways per door (e.g., exiting the same } \\
\text { door entered). }\end{array}$ \\
\hline $\mathbf{0}$ & Approach was nonexistent. & $\begin{array}{l}\text { May have written "I don't know" or similar; } \\
\text { provided an answer with no work (e.g., a } \\
\text { guess); or, workspace is blank. Crossed-out } \\
\text { work counts as blank work. }\end{array}$ \\
\hline
\end{tabular}

“Lost in the Auditorium” Scoring Rubric Continued on back $\downarrow$

Figure F3a. Math scoring rubric: lost in the auditorium - front side 


\begin{tabular}{|c|c|c|}
\hline \multicolumn{3}{|c|}{ Scale III: Decisions Along the Way } \\
\hline Score & General & Specific to this problem \\
\hline 4 & $\begin{array}{l}\text { Clearly explained the reasons for the correct } \\
\text { decisions made throughout the problem. }\end{array}$ & $\begin{array}{l}\text { Explained verbally/algebraically that there were } \\
7 \text { ways per } 8 \text { doors so } 7 \text { x } 8=56 \text { ways total (i.e., } \\
\text { just did not write simply } 7 \text { × } 8=56 \text { ). }\end{array}$ \\
\hline 3 & $\begin{array}{l}\text { Didn't clearly explain the reasons for decisions, } \\
\text { but work suggests correct reasoning. }\end{array}$ & $\begin{array}{l}\text { Either by the use of words, symbols, diagrams, } \\
\text { or combination, somewhere (including the } \\
\text { narrative section) there is an indication that the } \\
\text { answer involved multiplying } 7 \times 8 \text {. }\end{array}$ \\
\hline 2 & $\begin{array}{l}\text { Only partly correct reasoning, or correct reasoning } \\
\text { used for only part of the problem. }\end{array}$ & $\begin{array}{l}\text { Considered only one door and gave an answer of } \\
7 \text { ways. }\end{array}$ \\
\hline 1 & $\begin{array}{l}\text { No reasoning is evident from the work or } \\
\text { reasoning is incorrect. }\end{array}$ & $\begin{array}{l}\text { Work makes no sense or reasoning is incorrect } \\
\text { (e.g., entering and exiting the same door). }\end{array}$ \\
\hline $\mathbf{0}$ & No work is provided. & $\begin{array}{l}\text { May have written "I don't know" or similar; } \\
\text { provided an answer with no work (e.g., a guess); } \\
\text { or, workspace is blank. Crossed-out work counts } \\
\text { as blank work. }\end{array}$ \\
\hline
\end{tabular}

\begin{tabular}{|c|l|l|}
\hline \multicolumn{3}{|c|}{ Scale IV: Getting an Answer } \\
\hline $\mathbf{4}$ & $\begin{array}{l}\text { General } \\
\text { correct answer and correct label for the answer; } \\
\text { student's work; work was shown and supported } \\
\text { correct answer. }\end{array}$ & $\begin{array}{l}\text { The correct answer of 56 ways is clearly } \\
\text { discernable and is supported by the work } \\
\text { provided (e.g., 8 x 7, diagrams). }\end{array}$ \\
\hline $\mathbf{3}$ & $\begin{array}{l}\text { Partially correct answer due to unfinished work, } \\
\text { copying error, computational error. }\end{array}$ & $\begin{array}{l}\text { The answer provided (including narrative } \\
\text { section) is not 56 ways but all supporting work } \\
\text { provided is correct; or, no specific number of } \\
\text { ways is stated but the number of ways could } \\
\text { be determined from the work. }\end{array}$ \\
\hline $\mathbf{2}$ & $\begin{array}{l}\text { Incorrect answer based on an inappropriate plan or } \\
\text { reasoning error; or, no answer based on incomplete } \\
\text { work. }\end{array}$ & $\begin{array}{l}\text { Diagrams/work provided are wrong by } \\
\text { construction causing an incorrect answer; or, } \\
\text { work may be correct but no total quantity for } \\
\text { the number of ways is provided and/or number } \\
\text { of ways cannot be determined from provided } \\
\text { work without significant assumptions by rater. }\end{array}$ \\
\hline $\mathbf{1}$ & $\begin{array}{l}\text { Correct answer with no work shown; or, } \\
\text { work/reasoning/explanation did not support the } \\
\text { correct answer (e.g., a random guess as opposed to } \\
\text { an educated guess). }\end{array}$ & $\begin{array}{l}\text { The correct answer of 56 ways is stated } \\
\text { without work; or, the work provided does not } \\
\text { support the correct answer (e.g., incorrectly } \\
\text { constructed diagram). }\end{array}$ \\
\hline \multirow{2}{*}{$\begin{array}{l}\text { Incorrect or no answer with no work shown. } \\
\text { May have written "I don't know" or similar; } \\
\text { provided an incorrect answer with no work } \\
\text { (e.g., a guess); or, workspace is blank. } \\
\text { Crossed-out work counts as blank work. }\end{array}$} \\
\hline
\end{tabular}

Adapted from:

Charles, R., Lester Jr., F. K., and O’Daffer, P. (1987). How to evaluate problem solving. Reston, VA.: National Council of Teachers of Mathematics.

Polya, G. (2004). How to solve it. Princeton, N.J.: Princeton University Press.

(Original work published 1945)

Stenmark, J. K. (1991). Mathematics assessment: Myths, models, good questions and practical suggestions. Reston, VA.: National Council of Teachers of Mathematics.

Szetala, W., and Nicole, C. (1992). Evaluating problem solving in mathematics. Educational Leadership, May 1992, 42-45

Figure F3b. Math scoring rubric: lost in the auditorium - back side 
Math Problem Scoring Rubric (Rev. 08/30/08)

Problem \#3 Title: "Birthday Money"

Rater's Initials:

Participant ID Number (3 digits):

(Circle the appropriate "best fit" score for each of the four scales)

\begin{tabular}{|c|c|c|}
\hline \multicolumn{3}{|c|}{ Scale I: Understanding the Problem } \\
\hline Score & General & Specific to this problem \\
\hline 4 & $\begin{array}{l}\text { Identified special factors that influenced the } \\
\text { approach before starting the problem. }\end{array}$ & $\begin{array}{l}\text { Recognized that the sister may be correct and } \\
\text { sought how both patterns could be formed; and } \\
\text { provided an answer (right or wrong) as to who } \\
\text { was correct. }\end{array}$ \\
\hline 3 & Understood the problem. & $\begin{array}{l}\text { Did not begin by testing the sister's thought but } \\
\text { identified one or more patterns (and how it was } \\
\text { formed - doubled or increased by } \$ 10 \text { ) for } \\
\text { money amount given on the consecutive } \\
\text { birthdays; and provided an answer (right or } \\
\text { wrong) as to who was correct. }\end{array}$ \\
\hline 2 & $\begin{array}{l}\text { Understood enough to solve part of the problem or } \\
\text { to get part of the solution; or at least showed some } \\
\text { steps toward a solution (beyond just simply } \\
\text { restating what was given). }\end{array}$ & $\begin{array}{l}\text { Identified only one pattern: }\{10,20,40,80\} \text { or } \\
\{10,20,40,70\} \text { for the given money amounts } \\
\text { for the consecutive birthdays; and may or may } \\
\text { not provided an answer (right or wrong) as to } \\
\text { who was correct. }\end{array}$ \\
\hline 1 & $\begin{array}{l}\text { Could only restate all or some of the information } \\
\text { given in the problem statement. }\end{array}$ & Use the "General" column. \\
\hline $\mathbf{0}$ & Did not understand enough to get started. & $\begin{array}{l}\text { May have written "I don't know" or similar; } \\
\text { provided an answer with no work (e.g., a } \\
\text { guess); or, workspace is blank. Crossed-out } \\
\text { work counts as blank work. }\end{array}$ \\
\hline
\end{tabular}

\begin{tabular}{|c|l|l|}
\hline \multicolumn{2}{|c|}{ Scale II: How Student Solved Problem } \\
\hline Score & General & Specific to this problem \\
\hline $\mathbf{4}$ & Approach was efficient or sophisticated. & $\begin{array}{l}\text { Both patterns: }\{10,20,40,80\} \text { and }\{10,20,40, \\
70\} \text { were recognized by a systematic approach } \\
\text { such as showing birth year, money amount, for } \\
\text { Grandfather and John organized into columns, } \\
\text { rows, or tables; and/or calculating the first } \\
\text { difference between consecutive amounts. }\end{array}$ \\
\hline $\mathbf{3}$ & Approach would work for the problem. & $\begin{array}{l}\text { No apparent systematic approach or a weak } \\
\text { systematic approach (i.e., little explanation); } \\
\text { However, work led to both correct patterns: } \\
\{10,20,40,80\} \text { and }\{10,20,40,70\}\end{array}$ \\
\hline $\mathbf{2}$ & $\begin{array}{l}\text { Approach would only lead to solving part of the } \\
\text { problem. }\end{array}$ & $\begin{array}{l}\text { No apparent systematic approach or a weak } \\
\text { systematic approach; However, work led to one } \\
\text { correct pattern: }\{10,20,40,80\} \text { or }\{10,20,40, \\
70\} . \text { The sister's thought was not tested. }\end{array}$ \\
\hline $\mathbf{0}$ & $\begin{array}{l}\text { Approach didn't work; approach was wrong; } \\
\text { approach was unclear. }\end{array}$ & $\begin{array}{l}\text { Work is provided but makes no sense or hard to } \\
\text { follow. }\end{array}$ \\
\hline & $\begin{array}{l}\text { Approach was nonexistent. } \\
\text { May have written "I don't know" or similar; } \\
\text { provided an answer with no work (e.g., a } \\
\text { guess); or, workspace is blank. Crossed-out } \\
\text { work counts as blank work. }\end{array}$ \\
\hline
\end{tabular}

"Birthday Money" Scoring Rubric Continued on back $\downarrow$

Figure F4a. Math scoring rubric: birthday money - front side 


\begin{tabular}{|c|c|c|}
\hline \multicolumn{3}{|c|}{ Scale III: Decisions Along the Way } \\
\hline Score & General & Specific to this problem \\
\hline 4 & $\begin{array}{l}\text { Clearly explained the reasons for the correct } \\
\text { decisions made throughout the problem. }\end{array}$ & $\begin{array}{l}\text { (e.g., mentioned "doubling" the previous } \\
\text { amount, or increasing each year by } \$ 10 \text { ) and } \\
\text { then stated an answer based on the work. }\end{array}$ \\
\hline 3 & $\begin{array}{l}\text { Didn't clearly explain the reasons for decisions, } \\
\text { but work suggests correct reasoning. }\end{array}$ & $\begin{array}{l}\text { Cleary explained/indicated how one or both } \\
\text { patterns }\{10,20,40,80\} \text { and/or }\{10,20,40,70\} \\
\text { were formed but gave an answer based on which } \\
\text { one or both pattern(s) recognized. }\end{array}$ \\
\hline 2 & $\begin{array}{l}\text { Only partly correct reasoning, or correct reasoning } \\
\text { used for only part of the problem. }\end{array}$ & $\begin{array}{l}\text { An incorrect answer of John's grandfather or } \\
\text { John is provided based on not recognizing two } \\
\text { patterns; on reasoning errors (i.e., answer is not } \\
\text { supported by the work) or work makes no sense; } \\
\text { or, no specific name is stated because work was } \\
\text { not completed. }\end{array}$ \\
\hline 1 & $\begin{array}{l}\text { No reasoning is evident from the work or } \\
\text { reasoning is incorrect. }\end{array}$ & Use the "General" column. \\
\hline $\mathbf{0}$ & No work is provided. & $\begin{array}{l}\text { May have written "I don't know" or similar; } \\
\text { provided an answer with no work (e.g., a guess); } \\
\text { or, workspace is blank. Crossed-out work counts } \\
\text { as blank work. }\end{array}$ \\
\hline \multicolumn{3}{|c|}{ Scale IV: Getting an Answer } \\
\hline Score & General & Specific to this problem \\
\hline 4 & $\begin{array}{l}\text { Correct answer and correct label for the answer; } \\
\text { correct answer was clearly discernable from } \\
\text { student's work; work was shown and supported } \\
\text { correct answer. }\end{array}$ & $\begin{array}{l}\text { The correct answer of John's sister is clearly } \\
\text { discernable and is supported by the } \\
\text { work/explanation provided whereby both } \\
\text { patterns }\{10,20,40,80\} \text { and }\{10,20,40,70\} \\
\text { are justified (e.g., doubling the previous } \\
\text { amount, or increasing each year by } \$ 10) \text {. }\end{array}$ \\
\hline 3 & $\begin{array}{l}\text { Partially correct answer due to unfinished work, } \\
\text { copying error, computational error. }\end{array}$ & $\begin{array}{l}\text { An incorrect answer of John's grandfather or } \\
\text { John is provided because only one of the two } \\
\text { patterns is recognized but that one pattern is } \\
\text { clearly supported by the work; or, no specific } \\
\text { name is stated but the creation of the pattern }(\mathrm{s}) \\
\text { is clearly defined by explanation (e.g., } \\
\text { doubling the previous amount, or increasing } \\
\text { each year by } \$ 10) \text {. }\end{array}$ \\
\hline 2 & $\begin{array}{l}\text { Incorrect answer based on an inappropriate plan or } \\
\text { reasoning error; or, no answer based on incomplete } \\
\text { work. }\end{array}$ & $\begin{array}{l}\text { An incorrect answer of John's grandfather or } \\
\text { John is provided based on reasoning errors } \\
\text { (i.e., answer is not supported by the work) or } \\
\text { work makes no sense; or, no specific name is } \\
\text { stated because work was not completed. }\end{array}$ \\
\hline 1 & $\begin{array}{l}\text { Correct answer with no work shown; or, } \\
\text { work/reasoning/explanation did not support the } \\
\text { correct answer (e.g., a random guess as opposed to } \\
\text { an educated guess). }\end{array}$ & $\begin{array}{l}\text { The correct answer of John's sister is stated } \\
\text { without work (e.g., a guess) or the work } \\
\text { provided does not support the correct answer. }\end{array}$ \\
\hline $\mathbf{0}$ & Incorrect or no answer with no work shown. & $\begin{array}{l}\text { May have written "I don't know" or similar; } \\
\text { provided an incorrect answer with no work } \\
\text { (e.g., a guess); or, workspace is blank. } \\
\text { Crossed-out work counts as blank work. }\end{array}$ \\
\hline
\end{tabular}

Adapted from:

Charles, R., Lester Jr., F. K., and O’Daffer, P. (1987). How to evaluate problem solving. Reston, VA.:

National Council of Teachers of Mathematics.

Polya, G. (2004). How to solve it. Princeton, N.J.: Princeton University Press. (Original work published 1945)

Stenmark, J. K. (1991). Mathematics assessment: Myths, models, good questions and practical suggestions. Reston, VA.: National Council of Teachers of Mathematics.

Szetala, W., and Nicole, C. (1992). Evaluating problem solving in mathematics. Educational Leadership, May 1992, 42-45

Figure F4b. Math scoring rubric: birthday money - back side 
Math Problem Scoring Rubric (Rev. 08/30/08)

Problem Title \#4: “What's in My Future?"

Rater's Initials:

Participant ID Number (3 digits):

(Circle the appropriate "best fit" score for each of the four scales)

\begin{tabular}{|c|c|c|}
\hline \multicolumn{3}{|c|}{ Scale I: Understanding the Problem } \\
\hline Score & General & Specific to this problem \\
\hline 4 & $\begin{array}{l}\text { Identified special factors that influenced the } \\
\text { approach before starting the problem. }\end{array}$ & $\begin{array}{l}\text { Clearly identified a correct pattern between the } \\
\text { steps, explained the pattern, and provided a } \\
\text { value (correct or incorrect) for the number of } \\
\text { squares in the } 50^{\text {th }} \text { step. }\end{array}$ \\
\hline 3 & Understood the problem. & $\begin{array}{l}\text { Although not clearly explained, it is apparent } \\
\text { from the work that a correct pattern was } \\
\text { identified that would help predict the number of } \\
\text { squares in the } 50^{\text {th }} \text { step; and provided a value } \\
\text { (correct or incorrect) for the number of squares } \\
\text { in the } 50^{\text {th }} \text { step. }\end{array}$ \\
\hline 2 & $\begin{array}{l}\text { Understood enough to solve part of the problem or } \\
\text { to get part of the solution; or at least showed some } \\
\text { steps toward a solution (beyond just simply } \\
\text { restating what was given). }\end{array}$ & $\begin{array}{l}\text { Work shows an attempt (correct or incorrect) } \\
\text { toward a method of predicting the number of } \\
\text { squares in the } 50^{\text {th }} \text { step; but, no value for the } \\
\text { number of squares in the } 50^{\text {th }} \text { step was } \\
\text { provided. }\end{array}$ \\
\hline 1 & $\begin{array}{l}\text { Could only restate all or some of the information } \\
\text { given in the problem statement. }\end{array}$ & Use the "General" column. \\
\hline $\mathbf{0}$ & Did not understand enough to get started. & $\begin{array}{l}\text { May have written "I don't know" or similar; } \\
\text { provided an answer with no work (e.g., a } \\
\text { guess); or, workspace is blank. Crossed-out } \\
\text { work counts as blank work. }\end{array}$ \\
\hline
\end{tabular}

\begin{tabular}{|c|c|c|}
\hline \multicolumn{3}{|c|}{ Scale II: How Student Solved Problem } \\
\hline Score & General & Specific to this problem \\
\hline 4 & Approach was efficient or sophisticated. & $\begin{array}{l}\text { A relation was established between the number } \\
\text { of rows, columns, and/or the step number } \\
\text { resulting in the simple arithmetic calculation of } \\
50 \times 51 \text { or } x^{2}+x \text { (where } x=\text { step number). }\end{array}$ \\
\hline 3 & Approach would work for the problem. & $\begin{array}{l}\text { A pattern based on the "first difference" } \\
\text { between successive steps }\{4,6,8,10, \ldots\} \text { was } \\
\text { recognized and a tedious method (correct or } \\
\text { incorrect) of listing the } 50 \text { elements of the } \\
\text { sequence was attempted/ performed. }\end{array}$ \\
\hline 2 & $\begin{array}{l}\text { Approach would only lead to solving part of the } \\
\text { problem. }\end{array}$ & $\begin{array}{l}\text { A graphical method was proposed but no } \\
\text { formula for predicting the number of squares in } \\
\text { the } 50^{\text {th }} \text { step, without having to draw } 50\end{array}$ \\
\hline 1 & $\begin{array}{l}\text { Approach didn't work; approach was wrong; } \\
\text { approach was unclear. }\end{array}$ & Use the "General" column. \\
\hline 0 & Approach was nonexistent. & $\begin{array}{l}\text { May have written "I don't know" or similar; } \\
\text { provided an answer with no work (e.g., a } \\
\text { guess); or, workspace is blank. Crossed-out } \\
\text { work counts as blank work. }\end{array}$ \\
\hline
\end{tabular}

“What's in My Future?" Scoring Rubric Continued on back $\downarrow$

Figure F5a. Math scoring rubric: what's in my future? - front side 


\begin{tabular}{|c|c|c|}
\hline \multicolumn{3}{|c|}{ Scale III: Decisions Along the Way } \\
\hline Score & General & Specific to this problem \\
\hline 4 & $\begin{array}{l}\text { Clearly explained the reasons for the correct } \\
\text { decisions made throughout the problem. }\end{array}$ & $\begin{array}{l}\text { Clearly noted an algorithm such as: } \\
\text { (1) The number of rows was equal to the step } \\
\text { number; and the number of columns was one } \\
\text { more than the step number; or, } \\
\text { (2) The number of columns is one more than } \\
\text { the number of rows; or, } \\
\text { (3) The "first difference" produced a pattern of } \\
\{4,6,8,10, \ldots\} \text {. }\end{array}$ \\
\hline 3 & $\begin{array}{l}\text { Didn't clearly explain the reasons for decisions, but } \\
\text { work suggests correct reasoning. }\end{array}$ & $\begin{array}{l}\text { Either by the use of words, symbols, or } \\
\text { combination of both, somewhere (including the } \\
\text { narrative section) there is an indication that the } \\
\text { reasoning behind the work shown is correct. } \\
\text { (e.g., a correct pattern is shown). }\end{array}$ \\
\hline 2 & $\begin{array}{l}\text { Only partly correct reasoning, or correct reasoning } \\
\text { used for only part of the problem. }\end{array}$ & $\begin{array}{l}\text { Either the method for calculating the number of } \\
\text { rows or the number of columns is incorrect. }\end{array}$ \\
\hline 1 & $\begin{array}{l}\text { No reasoning is evident from the work or } \\
\text { reasoning is incorrect. }\end{array}$ & $\begin{array}{l}\text { Some work is provided but makes no sense or } \\
\text { is totally wrong. }\end{array}$ \\
\hline $\mathbf{0}$ & No work is provided. & $\begin{array}{l}\text { May have written "I don't know" or similar; } \\
\text { provided an answer with no work (e.g., a } \\
\text { guess); or, workspace is blank. Crossed-out } \\
\text { work counts as blank work. }\end{array}$ \\
\hline
\end{tabular}

\begin{tabular}{|c|c|c|}
\hline \multicolumn{3}{|c|}{ Scale IV: Getting an Answer } \\
\hline Score & General & Specific to this problem \\
\hline 4 & $\begin{array}{l}\text { Correct answer and correct label for the answer; } \\
\text { correct answer was clearly discernable from } \\
\text { student's work; work was shown and supported } \\
\text { correct answer. }\end{array}$ & $\begin{array}{l}\text { The correct answer of } \mathbf{2 5 5 0} \text { squares (also } \\
\text { accept } 2550 \text { without "squares") is stated; and } \\
\text { the work/explanation supports the answer. }\end{array}$ \\
\hline 3 & $\begin{array}{l}\text { Partially correct answer due to unfinished work, } \\
\text { copying error, computational error. }\end{array}$ & $\begin{array}{l}\text { An answer is provided (including narrative } \\
\text { section) but is not } 2550 \text { squares. However, the } \\
\text { work presented should have resulted in a } \\
\text { correct answer (e.g., careless mistake or }\end{array}$ \\
\hline 2 & $\begin{array}{l}\text { Incorrect answer based on an inappropriate plan or } \\
\text { reasoning error; or, no answer based on incomplete } \\
\text { work. }\end{array}$ & $\begin{array}{l}\text { Sequence/Pattern/method is wrong by } \\
\text { construction; and/or, no answer for the total } \\
\text { number of squares is provided for the } 50^{\text {th }} \text { step. }\end{array}$ \\
\hline 1 & $\begin{array}{l}\text { Correct answer with no work shown; or, } \\
\text { work/reasoning/explanation did not support the } \\
\text { correct answer (e.g., a random guess as opposed to } \\
\text { an educated guess). }\end{array}$ & $\begin{array}{l}\text { The correct answer of } \mathbf{2 5 5 0} \text { squares is stated } \\
\text { without work or the work provided does not } \\
\text { support the correct answer (e.g., sequence of } \\
\text { numbers/pattern stated does not lead to } 2550 \text {. }\end{array}$ \\
\hline $\mathbf{0}$ & Incorrect or no answer with no work shown. & $\begin{array}{l}\text { May have written "I don't know" or similar; } \\
\text { provided an incorrect answer with no work } \\
\text { (e.g., a guess); or, workspace is blank. Crossed- } \\
\text { out work counts as blank work. }\end{array}$ \\
\hline
\end{tabular}

Adapted from:

Charles, R., Lester Jr., F. K., and O’Daffer, P. (1987). How to evaluate problem solving. Reston, VA.: National Council of Teachers of Mathematics.

Polya, G. (2004). How to solve it. Princeton, N.J.: Princeton University Press.

(Original work published 1945)

Stenmark, J. K. (1991). Mathematics assessment: Myths, models, good questions and practical suggestions. Reston, VA.: National Council of Teachers of Mathematics.

Szetala, W., and Nicole, C. (1992). Evaluating problem solving in mathematics. Educational Leadership, May $1992,42-45$

Figure F5b. Math scoring rubric: what's in my future? - back side 
Math Problem Scoring Rubric (Rev. 08/30/08)

Problem \#5 Title: “How Many Children Live Next Door?” Rater's Initials:

Participant ID Number (3 digits):

(Circle the appropriate "best fit" score for each of the four scales)

\begin{tabular}{|c|c|c|}
\hline \multicolumn{3}{|c|}{ Scale I: Understanding the Problem } \\
\hline Score & General & Specific to this problem \\
\hline 4 & $\begin{array}{l}\text { Identified special factors that influenced the } \\
\text { approach before starting the problem. }\end{array}$ & $\begin{array}{l}\text { Clearly noted somewhere (including narrative } \\
\text { section) that two conditions had to be satisfied } \\
\text { (i.e., every boy has the same number of brothers } \\
\text { as sisters, and every girl has twice as many } \\
\text { brothers as she has sisters). }\end{array}$ \\
\hline 3 & Understood the problem. & $\begin{array}{l}\text { Although not clearly explained or noted, it is } \\
\text { apparent from the work that there were two } \\
\text { conditions that had to be satisfied: every boy } \\
\text { has the same number of brothers as sisters, and } \\
\text { every girl has twice as many brothers as she has } \\
\text { sisters. }\end{array}$ \\
\hline 2 & $\begin{array}{l}\text { Understood enough to solve part of the problem or } \\
\text { to get part of the solution; or at least showed some } \\
\text { steps toward a solution (beyond just simply } \\
\text { restating what was given). }\end{array}$ & $\begin{array}{l}\text { Some correct work is shown such as trying } \\
\text { different combinations of boys and girls that } \\
\text { might lead to the correct answer. }\end{array}$ \\
\hline 1 & $\begin{array}{l}\text { Could only restate all or some of the information } \\
\text { given in the problem statement. }\end{array}$ & $\begin{array}{l}\text { Could only restate all or some of the } \\
\text { information given in the problem statement; or, } \\
\text { work makes no sense. }\end{array}$ \\
\hline $\mathbf{0}$ & Did not understand enough to get started. & $\begin{array}{l}\text { May have written "I don't know" or similar; } \\
\text { provided an answer with no work (e.g., a } \\
\text { guess); or, workspace is blank. Crossed-out } \\
\text { work counts as blank work. }\end{array}$ \\
\hline
\end{tabular}

\begin{tabular}{|c|l|l|}
\hline \multicolumn{2}{|c|}{ Scale II: How Student Solved Problem } \\
\hline $\mathbf{4}$ & General & Specific to this problem \\
\hline $\mathbf{3}$ & Approach was efficient or sophisticated. & $\begin{array}{l}\text { A systematic approach was used such as an } \\
\text { algebraic solution (e.g., simultaneous } \\
\text { equations), diagrams, or a table to arrive at an } \\
\text { answer. More than just "guess and check." }\end{array}$ \\
\hline $\mathbf{2}$ & $\begin{array}{l}\text { Approach would only lead to solving part of the } \\
\text { problem. }\end{array}$ & $\begin{array}{l}\text { No systematic approach (e.g., guess and check) } \\
\text { was apparent but is evident that several } \\
\text { reasonable tries were made and tested against } \\
\text { the two conditions. }\end{array}$ \\
\hline $\mathbf{1}$ & $\begin{array}{l}\text { Approach didn't work; approach was wrong; } \\
\text { approach was unclear. }\end{array}$ & $\begin{array}{l}\text { "every boy has the same number of brothers as } \\
\text { sisters" or "every girl has twice as many } \\
\text { brothers as she has sisters." }\end{array}$ \\
\hline $\mathbf{0}$ & $\begin{array}{l}\text { Approach was nonexistent. } \\
\text { Use the "General" column. }\end{array}$ \\
\hline
\end{tabular}

“How Many Children Live Next Door?” Scoring Rubric Continued on back $\downarrow$

Figure F6a. Math scoring rubric: how many children live next door? - front side 


\begin{tabular}{|c|c|c|}
\hline \multicolumn{3}{|c|}{ Scale III: Decisions Along the Way } \\
\hline Score & General & Specific to this problem \\
\hline 4 & $\begin{array}{l}\text { Clearly explained the reasons for the correct } \\
\text { decisions made throughout the problem. }\end{array}$ & $\begin{array}{l}\text { Clearly described or noted attempts at solution } \\
\text { and why they were abandoned or why they } \\
\text { were pursued (e.g., checked work against the } \\
\text { two conditions: "every boy has the same } \\
\text { number of brothers as sisters" and "every girl } \\
\text { has twice as many brothers as she has sisters"). }\end{array}$ \\
\hline 3 & $\begin{array}{l}\text { Didn't clearly explain the reasons for decisions, but } \\
\text { work suggests correct reasoning. }\end{array}$ & $\begin{array}{l}\text { Didn't clearly describe or note attempts at } \\
\text { solution and why they were abandoned or why } \\
\text { they were pursued but work implies correct } \\
\text { reasoning. }\end{array}$ \\
\hline 2 & $\begin{array}{l}\text { Only partly correct reasoning, or correct reasoning } \\
\text { used for only part of the problem. }\end{array}$ & $\begin{array}{l}\text { The work shows that only one condition was } \\
\text { tested: "every boy has the same number of } \\
\text { brothers as sisters" or "every girl has twice as } \\
\text { many brothers as she has sisters." }\end{array}$ \\
\hline 1 & $\begin{array}{l}\text { No reasoning is evident from the work or } \\
\text { reasoning is incorrect. }\end{array}$ & $\begin{array}{l}\text { Some work is provided but makes no sense or } \\
\text { is totally wrong. }\end{array}$ \\
\hline $\mathbf{0}$ & No work is provided. & $\begin{array}{l}\text { May have written "I don't know" or similar; } \\
\text { provided an answer with no work (e.g., a } \\
\text { guess); or, workspace is blank. Crossed-out } \\
\text { work counts as blank work. }\end{array}$ \\
\hline
\end{tabular}

\begin{tabular}{|c|c|c|}
\hline \multicolumn{3}{|c|}{ Scale IV: Getting an Answer } \\
\hline Score & General & Specific to this problem \\
\hline 4 & $\begin{array}{l}\text { Correct answer and correct label for the answer; } \\
\text { correct answer was clearly discernable from } \\
\text { student's work; work was shown and supported } \\
\text { correct answer. }\end{array}$ & $\begin{array}{l}\text { The correct answer of } 4 \text { boys and } 3 \text { girls is } \\
\text { stated; and the work/explanation supports the } \\
\text { answer. }\end{array}$ \\
\hline 3 & $\begin{array}{l}\text { Partially correct answer due to unfinished work, } \\
\text { copying error, computational error. }\end{array}$ & $\begin{array}{l}\text { Either } 4 \text { boys or } 3 \text { girls is stated and the work } \\
\text { appears to be unfinished but heading for the } \\
\text { complete right answer. }\end{array}$ \\
\hline 2 & $\begin{array}{l}\text { Incorrect answer based on an inappropriate plan or } \\
\text { reasoning error; or, no answer based on incomplete } \\
\text { work. }\end{array}$ & $\begin{array}{l}\text { Sequence/Pattern/method is wrong by } \\
\text { construction; and/or, no answer for the total } \\
\text { number of boys and girls is provided. }\end{array}$ \\
\hline 1 & $\begin{array}{l}\text { Correct answer with no work shown; or, } \\
\text { work/reasoning/explanation did not support the } \\
\text { correct answer (e.g., a random guess as opposed to } \\
\text { an educated guess). }\end{array}$ & $\begin{array}{l}\text { The correct answer of } \mathbf{4} \text { boys and } \mathbf{3} \text { girls is } \\
\text { stated without work or the work provided does } \\
\text { not support the correct answer (e.g., a guess). }\end{array}$ \\
\hline $\mathbf{0}$ & Incorrect or no answer with no work shown. & $\begin{array}{l}\text { May have written "I don't know" or similar; } \\
\text { provided an incorrect answer with no work } \\
\text { (e.g., a guess); or, workspace is blank. Crossed- } \\
\text { out work counts as blank work. }\end{array}$ \\
\hline
\end{tabular}

Adapted from:

Charles, R., Lester Jr., F. K., and O’Daffer, P. (1987). How to evaluate problem solving. Reston, VA.:

National Council of Teachers of Mathematics.

Polya, G. (2004). How to solve it. Princeton, N.J.: Princeton University Press.

(Original work published 1945)

Stenmark, J. K. (1991). Mathematics assessment: Myths, models, good questions and practical suggestions. Reston, VA.: National Council of Teachers of Mathematics.

Szetala, W., and Nicole, C. (1992). Evaluating problem solving in mathematics. Educational Leadership, May 1992, 42-45

Figure F6b. Math scoring rubric: how many children live next door? - back side 
Math Problem Scoring Rubric (Rev. 08/30/08)

Problem \#6 Title: "Blind Sided"

Rater's Initials:

Participant ID Number (3 digits):

(Circle the appropriate "best fit" score for each of the four scales)

\begin{tabular}{|c|c|c|}
\hline \multicolumn{3}{|c|}{ Scale I: Understanding the Problem } \\
\hline Score & General & Specific to this problem \\
\hline 4 & $\begin{array}{l}\text { Identified special factors that influenced the } \\
\text { approach before starting the problem. }\end{array}$ & $\begin{array}{l}\text { First listed all the colors involved; recognized } \\
\text { from the problem statement that the final } \\
\text { answer must be one of the colors given and } \\
\text { stated a color (right or wrong). A "no color" or } \\
\text { "blank" answer is not acceptable. }\end{array}$ \\
\hline 3 & Understood the problem. & $\begin{array}{l}\text { Recognized from the problem statement that } \\
\text { the final answer must be one of the colors given } \\
\text { and stated a color (right or wrong). A "no } \\
\text { color" or "blank" answer is not acceptable. }\end{array}$ \\
\hline 2 & $\begin{array}{l}\text { Understood enough to solve part of the problem or } \\
\text { to get part of the solution; or at least showed some } \\
\text { steps toward a solution (beyond just simply } \\
\text { restating what was given). }\end{array}$ & $\begin{array}{l}\text { Work shows some attempt toward associating } \\
\text { hidden sides with colors. }\end{array}$ \\
\hline 1 & $\begin{array}{l}\text { Could only restate all or some of the information } \\
\text { given in the problem statement. }\end{array}$ & Use the "General" column. \\
\hline $\mathbf{0}$ & Did not understand enough to get started. & $\begin{array}{l}\text { May have written "I don't know" or similar; } \\
\text { provided an answer with no work (e.g., a } \\
\text { guess); or, workspace is blank. Crossed-out } \\
\text { work counts as blank work. }\end{array}$ \\
\hline
\end{tabular}

\begin{tabular}{|c|c|c|}
\hline \multicolumn{3}{|c|}{ Scale II: How Student Solved Problem } \\
\hline Score & General & Specific to this problem \\
\hline 4 & Approach was efficient or sophisticated. & $\begin{array}{l}\text { A systematic approach was used such as } \\
\text { creating a 3-D model, drawing a flat pattern, } \\
\text { drawing multiple views; colored views, and } \\
\text { stated a color (right or wrong) based on the } \\
\text { work. A response of "no color" or "blank" is } \\
\text { unacceptable. }\end{array}$ \\
\hline 3 & Approach would work for the problem. & $\begin{array}{l}\text { No apparent systematic approach or a weak } \\
\text { systematic approach, however, } \\
\text { work/explanation indicates correct assumptions } \\
\text { and/or some attempt at checking the answer. }\end{array}$ \\
\hline 2 & $\begin{array}{l}\text { Approach would only lead to solving part of the } \\
\text { problem. }\end{array}$ & $\begin{array}{l}\text { One or more of the given colors were not } \\
\text { considered. }\end{array}$ \\
\hline 1 & $\begin{array}{l}\text { Approach didn't work; approach was wrong; } \\
\text { approach was unclear. }\end{array}$ & Answer is not white and work makes no sense. \\
\hline $\mathbf{0}$ & Approach was nonexistent. & $\begin{array}{l}\text { May have written "I don't know" or similar; } \\
\text { provided an answer with no work (e.g., a } \\
\text { guess); or, workspace is blank. Crossed-out } \\
\text { work counts as blank work. }\end{array}$ \\
\hline
\end{tabular}

"Blind Sided" Scoring Rubric Continued on back $\downarrow$

Figure F7a. Math scoring rubric: blind sided - front side 


\begin{tabular}{|c|c|c|}
\hline \multicolumn{3}{|c|}{ Scale III: Decisions Along the Way } \\
\hline Score & General & Specific to this problem \\
\hline 4 & $\begin{array}{l}\text { Clearly explained the reasons for the correct } \\
\text { decisions made throughout the problem. }\end{array}$ & $\begin{array}{l}\text { All or nearly all correct decisions (e.g., } \\
\text { assigning a color to a hidden side) made } \\
\text { anywhere (including the narrative section) are } \\
\text { clearly explained either by the use of words, } \\
\text { symbols, or combination of both. }\end{array}$ \\
\hline 3 & $\begin{array}{l}\text { Didn't clearly explain the reasons for decisions, but } \\
\text { work suggests correct reasoning. }\end{array}$ & $\begin{array}{l}\text { All or nearly all correct decisions (e.g., } \\
\text { assigning a color to a hidden side) made } \\
\text { anywhere (including the narrative section) are } \\
\text { not clearly explained but work suggests correct } \\
\text { reasoning. }\end{array}$ \\
\hline 2 & $\begin{array}{l}\text { Only partly correct reasoning, or correct reasoning } \\
\text { used for only part of the problem. }\end{array}$ & $\begin{array}{l}\text { Only some of the decisions made anywhere } \\
\text { (including the narrative section) are correct and } \\
\text { are supported by some form of explanation.. }\end{array}$ \\
\hline 1 & $\begin{array}{l}\text { No reasoning is evident from the work or } \\
\text { reasoning is incorrect. }\end{array}$ & $\begin{array}{l}\text { An incorrect answer of "no color" or "blank" } \\
\text { is stated and/or work makes no sense.. }\end{array}$ \\
\hline $\mathbf{0}$ & No work is provided. & $\begin{array}{l}\text { May have written "I don't know" or similar; } \\
\text { provided an answer with no work (e.g., a } \\
\text { guess); or, workspace is blank. Crossed-out } \\
\text { work counts as blank work. }\end{array}$ \\
\hline
\end{tabular}

\begin{tabular}{|c|c|c|}
\hline \multicolumn{3}{|c|}{ Scale IV: Getting an Answer } \\
\hline Score & General & Specific to this problem \\
\hline 4 & $\begin{array}{l}\text { Correct answer and correct label for the answer; } \\
\text { correct answer was clearly discernable from } \\
\text { student's work; work was shown and supported }\end{array}$ & $\begin{array}{l}\text { The correct answer of white is clearly } \\
\text { discernable and is supported by the work } \\
\text { provided. }\end{array}$ \\
\hline 3 & $\begin{array}{l}\text { Partially correct answer due to unfinished work, } \\
\text { copying error, computational error. }\end{array}$ & $\begin{array}{l}\text { The answer provided (including narrative } \\
\text { section) is not white but is one of the colors } \\
\text { shown in the problem statement and the } \\
\text { answer given is supported by some work. }\end{array}$ \\
\hline 2 & $\begin{array}{l}\text { Incorrect answer based on an inappropriate plan or } \\
\text { reasoning error; or, no answer based on incomplete } \\
\text { work. }\end{array}$ & $\begin{array}{l}\text { An incorrect answer of "no color" or "blank" } \\
\text { is given; or, no color is stated based on } \\
\text { incomplete work - but at least some work is }\end{array}$ \\
\hline 1 & $\begin{array}{l}\text { Correct answer with no work shown; or, } \\
\text { work/reasoning/explanation did not support the } \\
\text { correct answer (e.g., a random guess as opposed to } \\
\text { an educated guess). }\end{array}$ & $\begin{array}{l}\text { The correct answer of white is stated without } \\
\text { work or the work provided does not support } \\
\text { the correct answer (e.g., incorrectly } \\
\text { constructions or simply a guess). }\end{array}$ \\
\hline $\mathbf{0}$ & Incorrect or no answer with no work shown. & $\begin{array}{l}\text { May have written "I don't know" or similar; } \\
\text { provided an incorrect answer with no work } \\
\text { (e.g., a guess); or, workspace is blank. } \\
\text { Crossed-out work counts as blank work. }\end{array}$ \\
\hline
\end{tabular}

Adapted from:

Charles, R., Lester Jr., F. K., and O’Daffer, P. (1987). How to evaluate problem solving. Reston, VA.:

National Council of Teachers of Mathematics.

Polya, G. (2004). How to solve it. Princeton, N.J.: Princeton University Press.

(Original work published 1945)

Stenmark, J. K. (1991). Mathematics assessment: Myths, models, good questions and practical suggestions. Reston, VA.: National Council of Teachers of Mathematics.

Szetala, W., and Nicole, C. (1992). Evaluating problem solving in mathematics. Educational Leadership, May $1992,42-45$

Figure F7b. Math scoring rubric: blind sided - back side 


\section{References}

Charles, R., Lester Jr., F. K., and O’Daffer, P. (1987). How to evaluate problem solving. Reston, VA.: National Council of Teachers of Mathematics.

Polya, G. (2004). How to solve it. Princeton, N.J.: Princeton University Press. (Original work published 1945)

Stenmark, J. K. (1991). Mathematics assessment: Myths, models, good questions and practical suggestions. Reston, VA.: National Council of Teachers of Mathematics.

Szetala, W., and Nicole, C. (1992). Evaluating problem solving in mathematics. Educational Leadership, May 1992, 42-45

Yamane, T. (1967). Statistics, An introductory analysis, $2^{\text {nd }}$ ed, New York: Harper and Row. 


\section{Appendix G}

\section{A Shortened Form of the Fennema - Sherman Mathematics Attitudes Scales (FSMAS-SF)}

Note. The following instructions and inventory have been adapted from Mulhern and Rae (1998): The scale statements are verbatim. The scoring method is the same. However, the format of presentation of the scales has been modified from the original to achieve a more universal look across the various scales used in this multi-dimensional instrument.

The FSMAS-SF scale is a 51-item (six scales) 5-point Likert-type response format developed by Mulhern and Rae (1998) based on an analysis of the original 108-item (nine scales) 5-point Likert-type response format (FSMAS) presented in Fennema and Sherman (1976).The original Fennema and Sherman instrument took about 45 minutes to complete and participants often lost interest as time went on (Mulhern \& Rae, 1998). The following is a shortened 51-item six scale instrument developed from the original as presented in Mulhern and Rae, with a comparison of the two instruments provided in Table G1: 


\section{Table G1}

Comparison of the FSMAS and FSMAS-SF Instruments (adapted from Mulhern \& Rae, 1998)

\begin{tabular}{|c|c|c|c|}
\hline \multicolumn{2}{|c|}{ FSMAS } & \multicolumn{2}{|c|}{ FSMAS-SF } \\
\hline $\begin{array}{l}\text { Scale Number / } \\
\text { Name }\end{array}$ & $\begin{array}{l}\text { Item Numbers } \\
(N=108)\end{array}$ & $\begin{array}{l}\text { Scale Number / } \\
\text { Name }\end{array}$ & $\begin{array}{l}\text { Item Numbers } \\
\text { Retained }(n=51)\end{array}$ \\
\hline $\begin{array}{l}\text { 1. The Attitude toward } \\
\text { Success in } \\
\text { Mathematics Scale } \\
\text { (AS) }\end{array}$ & $\begin{array}{l}\text { AS1, AS2, AS3, AS4, } \\
\text { AS5, AS6, AS7, AS8, } \\
\text { AS9, AS10, AS11, } \\
\text { AS12 }\end{array}$ & 5. Success Scale & $\begin{array}{l}\text { AS1, AS2, AS3, } \\
\text { AS4, AS5, AS6, } \\
\text { AS10, AS11, AS12 }\end{array}$ \\
\hline $\begin{array}{l}\text { 2. The Mathematics as } \\
\text { a Male Domain } \\
\text { Scale (MD) }\end{array}$ & $\begin{array}{l}\text { MD1, MD2, MD3, } \\
\text { MD4, MD5, MD6, } \\
\text { MD7, MD8, MD9, } \\
\text { MD10, MD11, MD12 }\end{array}$ & $\begin{array}{l}\text { 4. Male Domain } \\
\text { Scale }\end{array}$ & $\begin{array}{l}\text { MD1, MD2, MD3, } \\
\text { MD4, MD7, MD9, } \\
\text { MD10, MD11, } \\
\text { MD12 }\end{array}$ \\
\hline $\begin{array}{l}\text { 3. The Mother Scale } \\
\text { (M) }\end{array}$ & $\begin{array}{l}\text { M1, M2, M3, M4, M5, } \\
\text { M6, M7, M8, M9, }\end{array}$ & & \\
\hline 4. The Father Scale (F) & $\begin{array}{l}\text { M10, M11, M12 } \\
\text { F1, F2, F3, F4, F5, F6, } \\
\text { F7, F8, F9, F10, F11, } \\
\text { F12 }\end{array}$ & $\begin{array}{l}\text { 2. Parent's Attitudes } \\
\text { Scale }\end{array}$ & $\begin{array}{l}\text { M3, M5, M10 } \\
\text { F1, F2, F3, F5, F9, } \\
\text { F11 }\end{array}$ \\
\hline $\begin{array}{l}\text { 5. The Teacher Scale } \\
\text { (T) }\end{array}$ & $\begin{array}{l}\text { T1, T2, T3, T4, T5, } \\
\text { T6, T7, T8, T9, T10, } \\
\text { T11, T12 }\end{array}$ & 6. Teacher Scale & $\begin{array}{l}\mathrm{T} 2, \mathrm{~T} 3, \mathrm{~T} 5, \mathrm{~T} 8, \mathrm{~T} 10, \\
\mathrm{~T} 12\end{array}$ \\
\hline $\begin{array}{l}\text { 6. The Confidence in } \\
\text { Learning } \\
\text { Mathematics Scale } \\
\text { (C) }\end{array}$ & $\begin{array}{l}\mathrm{C} 1, \mathrm{C} 2, \mathrm{C} 3, \mathrm{C} 4, \mathrm{C} 5, \\
\mathrm{C} 6, \mathrm{C} 7, \mathrm{C} 8, \mathrm{C} 9, \mathrm{C} 10, \\
\mathrm{C} 11, \mathrm{C} 12\end{array}$ & $\begin{array}{l}\text { 1. Mathematics - } \\
\text { Related Affect }\end{array}$ & $\mathrm{C} 1, \mathrm{C} 7, \mathrm{C} 10, \mathrm{C} 11$ \\
\hline $\begin{array}{l}\text { 7. The Mathematics } \\
\text { Anxiety Scale } \\
\text { (A) }\end{array}$ & $\begin{array}{l}\mathrm{A} 1, \mathrm{~A} 2, \mathrm{~A} 3, \mathrm{~A} 4, \mathrm{~A} 5, \\
\mathrm{~A} 6, \mathrm{~A} 7, \mathrm{~A} 8, \mathrm{~A} 9, \mathrm{~A} 10, \\
\mathrm{~A} 11, \mathrm{~A} 12\end{array}$ & Scale & A6, A7, A8, A9, A12 \\
\hline $\begin{array}{l}\text { 8. The Effectance } \\
\text { Motivation Scale } \\
\text { in Mathematics (E) }\end{array}$ & $\begin{array}{l}\text { E1, E2, E3, E4, E5, } \\
\text { E6, E7, E8, E9, E10, } \\
\text { E11, E12 }\end{array}$ & & EM3, \\
\hline $\begin{array}{l}\text { 9. The Mathematics } \\
\text { Usefulness Scale } \\
\text { (U) }\end{array}$ & $\begin{array}{l}\mathrm{U} 1, \mathrm{U} 2, \mathrm{U} 3, \mathrm{U} 4, \mathrm{U} 5 \\
\mathrm{U6}, \mathrm{U} 7, \mathrm{U} 8, \mathrm{U} 9, \mathrm{U} 10 \\
\mathrm{Ul,}, \mathrm{U} 12\end{array}$ & 3. Usefulness Scale & $\begin{array}{l}\text { U2, U3, U4, U5, U6, } \\
\text { U7, U8, U9 }\end{array}$ \\
\hline
\end{tabular}




\section{A Shortened Form of the Fennema - Sherman \\ Mathematics Attitudes Scales (FSMAS-SF)}

\section{Instructions to be read to participants:}

The following questionnaire consists of several statements that you may or may not agree with. You are asked to determine how strongly you feel about the statement from strongly disagree to strongly agree. Please select the one of the five choices and place a checkmark $\sqrt{ }$ in the appropriate box. This is a measure of personal belief; obviously there are no right or wrong answers. directions.

Print your name and date at the top of each page and then finish reading these

Please answer these items carefully. Take as much time as you need to answer each of the questions. Be sure to find an answer for every statement but mark one box only.

In some instances you may discover that you can't decide or you are neutral on the statement. In this case, place a checkmark $\sqrt{ }$ in the box under the undecided heading. Also try to respond to each statement independently when making your choice; do not be influenced by your previous choices.

\section{An example of the FSMAS-SF format:}

Instructions: Please place a checkmark $\sqrt{ }$ indicating how much you agree or disagree with each statement.

\begin{tabular}{|l|l|c|l|c|c|c|}
\hline & Statement & $\begin{array}{c}\text { Strongly } \\
\text { Disagree }\end{array}$ & Disagree & $\begin{array}{c}\text { Un- } \\
\text { decided }\end{array}$ & Agree & $\begin{array}{c}\text { Strongly } \\
\text { Agree }\end{array}$ \\
\hline Ex.1. & $\begin{array}{l}\text { I don't like doing } \\
\text { word problems in } \\
\text { math. }\end{array}$ & & & & $\sqrt{ }$ & \\
\hline
\end{tabular}

\section{Do not begin until you are told to do so.}

Figure G1. Instructions for the a shortened form of the Fennema - Sherman mathematics attitudes scales (FSMAS-SF) 
Name:

Date:

Form FSMAS-SF - Page 1 of 9 (adapted from Mulhearn and Rae, 1998)

Instructions: Please place a checkmark $\sqrt{ }$ indicating how much you agree or disagree with each statement.

\begin{tabular}{|c|c|c|c|c|c|c|}
\hline $\begin{array}{l}\text { Item } \\
\text { No. }\end{array}$ & Statement & $\begin{array}{l}\text { Strongly } \\
\text { Disagree }\end{array}$ & Disagree & $\begin{array}{c}\text { Un- } \\
\text { decided }\end{array}$ & Agree & $\begin{array}{c}\text { Strongly } \\
\text { Agree }\end{array}$ \\
\hline 1.-S1 & $\begin{array}{l}\text { It would make me } \\
\text { happy to be } \\
\text { recognized as an } \\
\text { excellent student } \\
\text { in mathematics. }\end{array}$ & & & & & \\
\hline 2.-MD1 & $\begin{array}{l}\text { Females are as } \\
\text { good as males in } \\
\text { geometry. }\end{array}$ & & & & & \\
\hline 3.-M3 & $\begin{array}{l}\text { My mother has } \\
\text { always been } \\
\text { interested in my } \\
\text { progress in } \\
\text { mathematics. }\end{array}$ & & & & & \\
\hline 4.-T2 & $\begin{array}{l}\text { My teachers think } \\
\text { I'm the kind of } \\
\text { person who could } \\
\text { do well in } \\
\text { mathematics. }\end{array}$ & & & & & \\
\hline 5.-C1 & $\begin{array}{l}\text { Generally I have } \\
\text { felt secure about } \\
\text { attempting } \\
\text { mathematics. }\end{array}$ & & & & & \\
\hline 6.-EM3 & $\begin{array}{l}\text { When a math } \\
\text { problem arises that } \\
\text { I can't } \\
\text { immediately solve, } \\
\text { I stick with it until } \\
\text { I have the solution. }\end{array}$ & & & & & \\
\hline
\end{tabular}

\section{Continued next page}

Figure G2a. FSMAS-SF - page 1 


\section{Form FSMAS-SF - Page 2 of 9}

Instructions: Please place a checkmark $\sqrt{ }$ indicating how much you agree or disagree with each statement.

\begin{tabular}{|c|c|c|c|c|c|c|}
\hline $\begin{array}{l}\text { Item } \\
\text { No. }\end{array}$ & Statement & $\begin{array}{l}\text { Strongly } \\
\text { Disagree }\end{array}$ & Disagree & $\begin{array}{c}\text { Un- } \\
\text { decide }\end{array}$ & Agree & $\begin{array}{c}\text { Strongly } \\
\text { Agree }\end{array}$ \\
\hline 7.-S2. & $\begin{array}{l}\text { I'd be proud to be } \\
\text { the outstanding } \\
\text { student in math. }\end{array}$ & & & & & \\
\hline 8.-MD2 & $\begin{array}{l}\text { Studying } \\
\text { mathematics is just } \\
\text { as appropriate for } \\
\text { women as men. }\end{array}$ & & & & & \\
\hline 9.-M5 & $\begin{array}{l}\text { My mother thinks } \\
\text { that mathematics is } \\
\text { one of the most } \\
\text { important subjects } \\
\text { I have studied. }\end{array}$ & & & & & \\
\hline 10.-T3 & $\begin{array}{l}\text { My math teachers } \\
\text { have made me feel } \\
\text { I have the ability } \\
\text { to go on in } \\
\text { mathematics. }\end{array}$ & & & & & \\
\hline 11.-C7 & $\begin{array}{l}\text { I'm no good at } \\
\text { math. }\end{array}$ & & & & & \\
\hline 12.-U2 & $\begin{array}{l}\text { I'll need } \\
\text { mathematics for } \\
\text { my future work. }\end{array}$ & & & & & \\
\hline
\end{tabular}

\section{Continued next page}

Figure $G 2 b$. FSMAS-SF - page 2 
Form FSMAS-SF - Page 3 of 9

Instructions: Please place a checkmark $\sqrt{ }$ indicating how much you agree or disagree with each statement.

\begin{tabular}{|c|c|c|c|c|c|c|}
\hline Item No. & Statement & $\begin{array}{l}\text { Strongly } \\
\text { Disagree }\end{array}$ & Disagree & $\begin{array}{c}\text { Un- } \\
\text { decided }\end{array}$ & Agree & $\begin{array}{c}\text { Strongly } \\
\text { Agree }\end{array}$ \\
\hline 13.-S3 & $\begin{array}{l}\text { I am happy to } \\
\text { get top grades } \\
\text { in mathematics. }\end{array}$ & & & & & \\
\hline 14.-MD3 & $\begin{array}{l}\text { I would trust a } \\
\text { woman just as } \\
\text { much as I } \\
\text { would trust a } \\
\text { man to figure } \\
\text { out important } \\
\text { calculations. }\end{array}$ & & & & & \\
\hline 15.-M10 & $\begin{array}{l}\text { My mother has } \\
\text { shown no } \\
\text { interest in } \\
\text { whether I take } \\
\text { more math } \\
\text { courses. }\end{array}$ & & & & & \\
\hline 16.-T5 & $\begin{array}{l}\text { My math } \\
\text { teachers have } \\
\text { been interested } \\
\text { in my progress } \\
\text { in mathematics. }\end{array}$ & & & & & \\
\hline 17.-C10 & $\begin{array}{l}\text { For some } \\
\text { reason even } \\
\text { though I study, } \\
\text { math seems } \\
\text { unusually hard } \\
\text { for me. }\end{array}$ & & & & & \\
\hline 18.-U3 & $\begin{array}{l}\text { Knowing } \\
\text { mathematics } \\
\text { will help me } \\
\text { earn a living. }\end{array}$ & & & & & \\
\hline
\end{tabular}

Continued next page

Figure G2c. FSMAS-SF - page 3 
Form FSMAS-SF - Page 4 of 9

Instructions: Please place a checkmark $\sqrt{ }$ indicating how much you agree or disagree with each statement.

\begin{tabular}{|c|c|c|c|c|c|c|}
\hline Item No. & Statement & $\begin{array}{l}\text { Strongly } \\
\text { Disagree }\end{array}$ & Disagree & $\begin{array}{c}\text { Un- } \\
\text { decided }\end{array}$ & Agree & $\begin{array}{c}\text { Strongly } \\
\text { Agree }\end{array}$ \\
\hline 19.-S4 & $\begin{array}{l}\text { It would be really } \\
\text { great to win a prize } \\
\text { in mathematics. }\end{array}$ & & & & & \\
\hline 20.-MD4 & $\begin{array}{l}\text { Girls can do just as } \\
\text { well as boys in } \\
\text { mathematics. }\end{array}$ & & & & & \\
\hline 21.-F1 & $\begin{array}{l}\text { My father thinks } \\
\text { that mathematics is } \\
\text { one of the most } \\
\text { important subjects } \\
\text { I have studied. }\end{array}$ & & & & & \\
\hline 22.-T8 & $\begin{array}{l}\text { I have found it hard } \\
\text { to win the respect } \\
\text { of math teachers. }\end{array}$ & & & & & \\
\hline 23.-C11 & $\begin{array}{l}\text { Most subjects I can } \\
\text { handle OK, but I } \\
\text { have a knack of } \\
\text { messing up in } \\
\text { math. }\end{array}$ & & & & & \\
\hline 24.-U4 & $\begin{array}{l}\text { Mathematics is a } \\
\text { worthwhile and } \\
\text { necessary subject. }\end{array}$ & & & & & \\
\hline
\end{tabular}

Continued next page

Figure G2d. FSMAS-SF - page 4 
Form FSMAS-SF - Page 5 of 9

Instructions: Please place a checkmark $\sqrt{ }$ indicating how much you agree or disagree with each statement.

\begin{tabular}{|c|c|c|c|c|c|c|}
\hline Item No. & Statement & $\begin{array}{l}\text { Strongly } \\
\text { Disagree }\end{array}$ & Disagree & $\begin{array}{c}\text { Un- } \\
\text { decided }\end{array}$ & Agree & $\begin{array}{c}\text { Strongly } \\
\text { Agree }\end{array}$ \\
\hline 25.-S5 & $\begin{array}{l}\text { Being first in a } \\
\text { mathematics } \\
\text { competition would } \\
\text { make me pleased. }\end{array}$ & & & & & \\
\hline 26.-MD7 & $\begin{array}{l}\text { It's hard to believe } \\
\text { a female could be a } \\
\text { genius in } \\
\text { mathematics. }\end{array}$ & & & & & \\
\hline 27.-F2 & $\begin{array}{l}\text { My father has } \\
\text { strongly } \\
\text { encouraged me to } \\
\text { do well in } \\
\text { mathematics. }\end{array}$ & & & & & \\
\hline 28.-T10 & $\begin{array}{l}\text { Getting a } \\
\text { mathematics } \\
\text { teacher to take me } \\
\text { seriously usually } \\
\text { has been a } \\
\text { problem. }\end{array}$ & & & & & \\
\hline 29.-A6 & $\begin{array}{l}\text { I usually have been } \\
\text { at ease in math } \\
\text { classes. }\end{array}$ & & & & & \\
\hline 30.-U5 & $\begin{array}{l}\text { I'll need a firm } \\
\text { mastery of } \\
\text { mathematics for } \\
\text { my future work. }\end{array}$ & & & & & \\
\hline
\end{tabular}

Continued next page

Figure G2e. FSMAS-SF - page 5 


\section{Form FSMAS-SF - Page 6 of 9}

Instructions: Please place a checkmark $\sqrt{ }$ indicating how much you agree or disagree with each statement.

\begin{tabular}{|c|c|c|c|c|c|c|}
\hline Item No. & Statement & $\begin{array}{l}\text { Strongly } \\
\text { Disagree }\end{array}$ & Disagree & $\begin{array}{c}\text { Un- } \\
\text { decided }\end{array}$ & Agree & $\begin{array}{c}\text { Strongly } \\
\text { Agree }\end{array}$ \\
\hline 31.-S6 & $\begin{array}{l}\text { Being regarded as } \\
\text { smart in } \\
\text { mathematics would } \\
\text { be a great thing. }\end{array}$ & & & & & \\
\hline 32.-MD9 & $\begin{array}{l}\text { I would have more } \\
\text { faith in an answer } \\
\text { for a math problem } \\
\text { solved by a man } \\
\text { than a woman. }\end{array}$ & & & & & \\
\hline 33.-F3 & $\begin{array}{l}\text { My father has } \\
\text { always been } \\
\text { interested in my } \\
\text { progress in } \\
\text { mathematics. }\end{array}$ & & & & & \\
\hline 34.-T12 & $\begin{array}{l}\text { I have a hard time } \\
\text { getting teachers to } \\
\text { talk seriously with } \\
\text { me about } \\
\text { mathematics. }\end{array}$ & & & & & \\
\hline 35.-A7 & $\begin{array}{l}\text { Mathematics } \\
\text { usually makes me } \\
\text { feel uncomfortable } \\
\text { and nervous. }\end{array}$ & & & & & \\
\hline 36.-U6 & $\begin{array}{l}\text { I will use } \\
\text { mathematics in } \\
\text { many ways as an } \\
\text { adult. }\end{array}$ & & & & & \\
\hline
\end{tabular}

\section{Continued next page}

Figure G2f. FSMAS-SF - page 6 


\section{Form FSMAS-SF - Page 7 of 9}

Instructions: Please place a checkmark $\sqrt{ }$ indicating how much you agree or disagree with each statement.

\begin{tabular}{|l|l|l|l|l|l|l|}
\hline Item No. & Statement & $\begin{array}{l}\text { Strongly } \\
\text { Disagree }\end{array}$ & Disagree & $\begin{array}{c}\text { Un- } \\
\text { decided }\end{array}$ & Agree & $\begin{array}{c}\text { Strongly } \\
\text { Agree }\end{array}$ \\
\hline 37.-S10 & $\begin{array}{l}\text { If I got the } \\
\text { highest grade in } \\
\text { math, I'd prefer } \\
\text { no one knew. }\end{array}$ & & & & & \\
\hline 39.-MD10.-F5 & $\begin{array}{l}\text { Girls who enjoy } \\
\text { studying math } \\
\text { are a bit } \\
\text { peculiar. }\end{array}$ & $\begin{array}{l}\text { I'm the kind of } \\
\text { person who } \\
\text { could do well in } \\
\text { mathematics. }\end{array}$ & & & & \\
\hline 40.-A8 & $\begin{array}{l}\text { Mathematics } \\
\text { makes me feel } \\
\text { uncomfortable, } \\
\text { restless, } \\
\text { irritable, and }\end{array}$ & & & & & \\
\hline 41.-U7 & $\begin{array}{l}\text { Mathematics is } \\
\text { of no relevance } \\
\text { to my life. }\end{array}$ & & & & & \\
\hline
\end{tabular}

\section{Continued next page}

Figure G2g. FSMAS-SF - page 7 


\section{Form FSMAS-SF - Page 8 of 9}

Instructions: Please place a checkmark $\sqrt{ }$ indicating how much you agree or disagree with each statement.

\begin{tabular}{|c|c|c|c|c|c|c|}
\hline Item No. & Statement & $\begin{array}{l}\text { Strongly } \\
\text { Disagree }\end{array}$ & Disagree & $\begin{array}{c}\text { Un- } \\
\text { decided }\end{array}$ & Agree & $\begin{array}{c}\text { Strongly } \\
\text { Agree }\end{array}$ \\
\hline 42.-S11 & $\begin{array}{l}\text { It would make } \\
\text { people like me } \\
\text { less if I were a } \\
\text { really good } \\
\text { student in math. }\end{array}$ & & & & & \\
\hline 43.-MD11 & $\begin{array}{l}\text { Mathematics is } \\
\text { for men, } \\
\text { arithmetic is for } \\
\text { women. }\end{array}$ & & & & & \\
\hline 44.-F9 & $\begin{array}{l}\text { As long as I } \\
\text { have passed, my } \\
\text { father hasn't } \\
\text { cared how I do } \\
\text { in math. }\end{array}$ & & & & & \\
\hline 45.-A9 & $\begin{array}{l}\text { I get a sinking } \\
\text { feeling when I } \\
\text { think of trying } \\
\text { math problems. }\end{array}$ & & & & & \\
\hline 46.-U8 & $\begin{array}{l}\text { Mathematics } \\
\text { will not be } \\
\text { important to me } \\
\text { in my life's } \\
\text { work. }\end{array}$ & & & & & \\
\hline
\end{tabular}

\section{Continued next page}

Figure G2h. FSMAS-SF - page 8 
Form FSMAS-SF - Page 9 of 9

Instructions: Please place a checkmark $\sqrt{ }$ indicating how much you agree or disagree with each statement.

\begin{tabular}{|c|c|c|c|c|c|c|}
\hline Item No. & Statement & $\begin{array}{l}\text { Strongly } \\
\text { Disagree }\end{array}$ & Disagree & $\begin{array}{c}\text { Un- } \\
\text { decided }\end{array}$ & Agree & $\begin{array}{c}\text { Stron } \\
\text { gly }\end{array}$ \\
\hline 47.-S12 & $\begin{array}{l}\text { I don't like } \\
\text { people to think } \\
\text { I'm smart in } \\
\text { math. }\end{array}$ & & & & & \\
\hline 48.-MD12 & $\begin{array}{l}\text { I would expect a } \\
\text { woman } \\
\text { mathematician } \\
\text { to be a } \\
\text { masculine type } \\
\text { of person. }\end{array}$ & & & & & \\
\hline 49.-F11 & $\begin{array}{l}\text { My father } \\
\text { thinks I need to } \\
\text { know just a } \\
\text { minimum of } \\
\text { math. }\end{array}$ & & & & & \\
\hline 50.-A12 & $\begin{array}{l}\text { Mathematics } \\
\text { makes me feel } \\
\text { uneasy and } \\
\text { confused. }\end{array}$ & & & & & \\
\hline 51.-U9 & $\begin{array}{l}\text { I see } \\
\text { mathematics as } \\
\text { a subject I will } \\
\text { rarely use in } \\
\text { daily life as an } \\
\text { adult. }\end{array}$ & & & & & \\
\hline
\end{tabular}

Stop here - do not proceed.

Figure G2i. FSMAS-SF - page 9 


\section{Appendix $\mathrm{H}$ \\ The Rotter Internal-External Locus of Control (I-E)}

(Rotter, 1966)

Note. The following instructions and inventory have been adapted from Lefcourt (1976, Appendix VII, pp.177-181): The instructions and scale statements are verbatim. The scoring method is the same. However, the format of presentation of the scales has been modified from the original to achieve a more universal look across the various scales used in this multi-dimensional instrument.

The Rotter internal-external locus of control scale is a 23 -item forced choice questionnaire with six filler items adapted from the 60-item James scale (Lefcourt, 1976, Appendix IV, pp. 166-169). The Rotter I-E is scored in the external direction, that is, the higher the score the more external the individual:

Scoring Method: score one point for only the specified item numbers. The total possible score is 23 (high external locus of control).

2.A; 3.B; 4.B; 5.B; 6.A; 7.A; 9.A; 10.B; 11.B; 12.B; 13.B; 15.B; 16.A; 17.A; 18.A; 20.A; 21.A; 22.B; 23.A; 25.A; 26.B; 28.B; 29.A 
Table H1

Some Selected Reported Norms for the Rotter I-E Scale provided in Lefcourt (1976, Appendix VII, pp. 181-182):

\begin{tabular}{lccc}
\multicolumn{1}{c}{ Study } & $N$ & Mean & SD \\
\hline Undergrads (Levy, 1967) & $\begin{array}{r}24 \text { males \& } \\
24 \text { females }\end{array}$ & 9.77 & 4.11 \\
& & & \\
College males (Zytowski, 1967) & 62 males & 6.82 & 2.49 \\
& & & \\
$\begin{array}{l}\text { Undergrads in introductory psychology } \\
\text { (Feather, 1968) }\end{array}$ & 46 males & 9.8 & 1.42 \\
& 88 females & 11.44 & 1.69
\end{tabular}

High School students

(Hsieh, Shybut \& Lotsof, 1969)

1. Anglo-American

2. American-born Chinese

3. Hong Kong students
131 males \& 108 females

38 males \& 42 females

241 males \& 102 females
8.58

3.89

9.79

3.07

12.07

3.96

99 females

7.97

3.8

Female undergrads (Crego, 1970)

Male undergrads (Lefcourt \& Telegdi, 1971)
90 males

8.16

4.38 


\section{Rotter Internal-External Locus of Control (I-E) Questionnaire}

\section{Instructions to be read to participants: "Why do things happen?"}

This is a questionnaire to find out the way in which important events in our society affect different people. Each item consists of a pair of alternative statements lettered A or B. Please select the one statement of each pair (and only one) which you more strongly believe to be the case as far as you're concerned. Be sure to select the one you actually believe to be more true rather than the one you think you should choose or the one you would like to be true. This is a measure of personal belief; obviously there are no right or wrong answers.

Your answer, either A or B to each question on this inventory, is to be reported in the box provided at the right of each statement pair. Print your name and date at the top of each page and then finish reading these directions.

Please answer these items carefully but do not spend too much time on any one item. Be sure to find an answer for every choice. For each numbered pair of alternative statements, mark A or B, whichever you choose as the statement most true, in the box provided at the right of the statement pair.

In some instances you may discover that you believe both statements or neither one. In such cases, be sure to select the one you more strongly believe to be the case as far as you're concerned. Also try to respond to each item independently when making your choice; do not be influenced by your previous choices.

\section{An example of the I-E format:}

\begin{tabular}{|l|l|c|}
\hline & $\begin{array}{c}\text { Ex1. Statements A and B: Write A or B for the statement you feel } \\
\text { is more true in the box at the right. }\end{array}$ & $\begin{array}{c}\text { A or B? } \\
\text { is more }\end{array}$ \\
\cline { 1 - 2 } A. & Children don't like traveling to visit relatives because it's boring. & \multirow{2}{*}{ B } \\
\cline { 1 - 2 } B. & Most children feel relatives should come visit them. & \\
\hline
\end{tabular}

In this case the responder believes that alternative statement $B$ is more true and marked $B$ in the box at the right.

\section{Do not begin until you are told to do so.}

Figure H1. Instructions for the Rotter Internal-External Locus of Control (I-E) questionnaire 
Name:

Date:

Form I-E - Page 1 of 6; (adapted from Lefcourt, 1976)

\begin{tabular}{|c|c|c|}
\hline & $\begin{array}{l}\text { 1. Statements A and B: Write A or B for the statement you feel } \\
\text { is more true in the box at the right. }\end{array}$ & $\begin{array}{l}\text { A or } B ? \\
\text { is more } \\
\text { true }\end{array}$ \\
\hline A. & $\begin{array}{l}\text { Children get into trouble because their parents punish them too } \\
\text { much. }\end{array}$ & \\
\hline \multirow[t]{2}{*}{ B. } & $\begin{array}{l}\text { The trouble with most children nowadays is that their parents are } \\
\text { too easy with them. }\end{array}$ & \\
\hline & $\begin{array}{l}\text { 2. Statements A and B: Write A or B for the statement you feel } \\
\text { is more true in the box at the right. }\end{array}$ & $\begin{array}{c}\text { A or B? } \\
\text { is more } \\
\text { true }\end{array}$ \\
\hline A. & $\begin{array}{l}\text { Many of the unhappy things in people's lives are partly due to bad } \\
\text { luck. }\end{array}$ & \\
\hline \multirow[t]{2}{*}{ B. } & People's misfortunes result from the mistakes they make. & \\
\hline & $\begin{array}{l}\text { 3. Statements A and B: Write A or B for the statement you feel } \\
\text { is more true in the box at the right. }\end{array}$ & $\begin{array}{c}\text { A or B? } \\
\text { is more } \\
\text { true }\end{array}$ \\
\hline A. & $\begin{array}{l}\text { One of the major reasons why we have wars is because people don't } \\
\text { take enough interest in politics. }\end{array}$ & \\
\hline \multirow[t]{2}{*}{ B. } & $\begin{array}{l}\text { There will always be wars, no matter how hard people try to prevent } \\
\text { them. }\end{array}$ & \\
\hline & $\begin{array}{l}\text { 4. Statements A and B: Write A or B for the statement you feel } \\
\text { is more true in the box at the right. }\end{array}$ & $\begin{array}{c}\text { A or B? } \\
\text { is more } \\
\text { true }\end{array}$ \\
\hline A. & In the long run people get the respect they deserve in this world. & \\
\hline \multirow[t]{2}{*}{ B. } & $\begin{array}{l}\text { Unfortunately, an individual's worth often passes unrecognized no } \\
\text { matter how hard he tries. }\end{array}$ & \\
\hline & $\begin{array}{l}\text { 5. Statements A and B: Write A or B for the statement you feel } \\
\text { is more true in the box at the right. }\end{array}$ & $\begin{array}{c}\text { A or B? } \\
\text { is more } \\
\text { true }\end{array}$ \\
\hline A. & The idea that teachers are unfair to students is nonsense. & \\
\hline B. & $\begin{array}{l}\text { Most students don't realize the extent to which their grades are } \\
\text { influenced by accidental happenings. }\end{array}$ & \\
\hline
\end{tabular}

\section{Continued next page}

Figure H2a. Form I-E - page 1 
Form I-E - Page 2 of 6

\begin{tabular}{|c|c|c|}
\hline & $\begin{array}{l}\text { 6. Statements A and B: Write A or B for the statement you feel } \\
\text { is more true in the box at the right. }\end{array}$ & $\begin{array}{c}\text { A or B? } \\
\text { is more } \\
\text { true }\end{array}$ \\
\hline A. & Without the right breaks one cannot be an effective leader. & \\
\hline \multirow[t]{2}{*}{ B. } & $\begin{array}{l}\text { Capable people who fail to become leaders hive not taken } \\
\text { advantage of their opportunities. }\end{array}$ & \\
\hline & $\begin{array}{l}\text { 7. Statements A and B: Write A or B for the statement you feel } \\
\text { is more true in the box at the right. }\end{array}$ & $\begin{array}{c}\text { A or B? } \\
\text { is more } \\
\text { true }\end{array}$ \\
\hline A. & No matter how hard you try, some people just don't like you. & \\
\hline \multirow[t]{2}{*}{ B. } & $\begin{array}{l}\text { People who can't get others to like them don't understand how to get } \\
\text { along with others. }\end{array}$ & \\
\hline & $\begin{array}{l}\text { 8. Statements A and B: Write A or B for the statement you feel } \\
\text { is more true in the box at the right. }\end{array}$ & $\begin{array}{c}\text { A or B? } \\
\text { is more } \\
\text { true }\end{array}$ \\
\hline A. & Heredity plays the major role in determining one's personality. & \\
\hline \multirow[t]{2}{*}{ B. } & It is one's experiences in life which determine what they're like. & \\
\hline & $\begin{array}{l}\text { 9. Statements A and B: Write A or B for the statement you feel } \\
\text { is more true in the box at the right. }\end{array}$ & $\begin{array}{c}\text { A or B? } \\
\text { is more } \\
\text { true }\end{array}$ \\
\hline A. & I have often found that what is going to happen will happen. & \\
\hline \multirow[t]{2}{*}{ B. } & $\begin{array}{l}\text { Trusting to fate has never turned out as well for me as making a } \\
\text { decision to take a definite course of action. }\end{array}$ & \\
\hline & $\begin{array}{l}\text { 10. Statements A and B: Write A or B for the statement you feel } \\
\text { is more true in the box at the right. }\end{array}$ & $\begin{array}{c}\text { A or B? } \\
\text { is more } \\
\text { true }\end{array}$ \\
\hline A. & $\begin{array}{l}\text { In the case of the well prepared student there is rarely, if ever, such } \\
\text { a thing as an unfair test. }\end{array}$ & \\
\hline B. & $\begin{array}{l}\text { Many times exam questions tend to be so unrelated to course work } \\
\text { that studying in really useless. }\end{array}$ & \\
\hline
\end{tabular}

\section{Continued next page}

Figure H2b. Form I-E - page 2 
Form I-E - Page 3 of 6

\begin{tabular}{|c|c|c|}
\hline & $\begin{array}{l}\text { 11. Statements A and B: Write A or B for the statement you feel } \\
\text { is more true in the box at the right. }\end{array}$ & $\begin{array}{c}\text { A or B? } \\
\text { is more } \\
\text { true }\end{array}$ \\
\hline A. & $\begin{array}{l}\text { Becoming a success is a matter of hard work; luck has little or } \\
\text { nothing to do with it. }\end{array}$ & \\
\hline \multirow[t]{2}{*}{ B. } & $\begin{array}{l}\text { Getting a good job depends mainly on being in the right place at the } \\
\text { right time. }\end{array}$ & \\
\hline & $\begin{array}{l}\text { 12. Statements A and B: Write A or B for the statement you feel } \\
\text { is more true in the box at the right. }\end{array}$ & $\begin{array}{c}\text { A or B? } \\
\text { is more } \\
\text { true }\end{array}$ \\
\hline A. & The average citizen can have an influence in government decisions. & \\
\hline \multirow[t]{2}{*}{ B. } & $\begin{array}{l}\text { This world is run by the few people in power, and there is not much } \\
\text { the little guy can do about it. }\end{array}$ & \\
\hline & $\begin{array}{l}\text { 13. Statements A and B: Write A or B for the statement you feel } \\
\text { is more true in the box at the right. }\end{array}$ & $\begin{array}{c}\text { A or B? } \\
\text { is more } \\
\text { true }\end{array}$ \\
\hline A. & When I make plans, I am almost certain that I can make them work. & \\
\hline \multirow[t]{2}{*}{ B. } & $\begin{array}{l}\text { It is not always wise to plan too far ahead because many things turn } \\
\text { out to be a matter of good or bad fortune anyhow. }\end{array}$ & \\
\hline & $\begin{array}{l}\text { 14. Statements A and B: Write A or B for the statement you feel } \\
\text { is more true in the box at the right. }\end{array}$ & $\begin{array}{c}\text { A or B? } \\
\text { is more } \\
\text { true }\end{array}$ \\
\hline A. & There are certain people who are just no good. & \\
\hline \multirow[t]{2}{*}{ B. } & There is some good in everybody. & \\
\hline & $\begin{array}{l}\text { 15. Statements } A \text { and } B \text { : Write } A \text { or } B \text { for the statement you feel } \\
\text { is more true in the box at the right. }\end{array}$ & $\begin{array}{c}\text { A or B? } \\
\text { is more } \\
\text { true }\end{array}$ \\
\hline A. & In my case getting what I want has little or nothing to do with luck. & \\
\hline B. & $\begin{array}{l}\text { Many times we might just as well decide what to do by flipping a } \\
\text { coin. }\end{array}$ & \\
\hline
\end{tabular}

\section{Continued next page}

Figure H2c. Form I-E - page 3 
Form I-E - Page 4 of

\begin{tabular}{|c|c|c|}
\hline & $\begin{array}{l}\text { 16. Statements A and B: Write A or B for the statement you feel } \\
\text { is more true in the box at the right. }\end{array}$ & $\begin{array}{c}\text { A or } B ? \\
\text { is more } \\
\text { true }\end{array}$ \\
\hline A. & $\begin{array}{l}\text { Who gets to be the boss often depends on who was lucky enough to } \\
\text { be in the right place first. }\end{array}$ & \\
\hline \multirow[t]{2}{*}{ B. } & $\begin{array}{l}\text { Getting people to do the right thing depends upon ability, luck has } \\
\text { little or nothing to do with it. }\end{array}$ & \\
\hline & $\begin{array}{l}\text { 17. Statements A and B: Write A or B for the statement you feel } \\
\text { is more true in the box at the right. }\end{array}$ & $\begin{array}{c}\text { A or } B ? \\
\text { is more } \\
\text { true }\end{array}$ \\
\hline A. & $\begin{array}{l}\text { As far as world affairs are concerned, most of us are the victims of } \\
\text { forces we can neither understand, nor control. }\end{array}$ & \\
\hline \multirow[t]{2}{*}{ B. } & $\begin{array}{l}\text { By taking an active part in political and social affairs the people } \\
\text { can control world events. }\end{array}$ & \\
\hline & $\begin{array}{l}\text { 18. Statements A and B: Write A or B for the statement you feel } \\
\text { is more true in the box at the right. }\end{array}$ & $\begin{array}{l}\text { A or } B ? \\
\text { is more } \\
\text { true }\end{array}$ \\
\hline A. & $\begin{array}{l}\text { Most people don't realize the extent to which their lives are } \\
\text { controlled by accidental happenings. }\end{array}$ & \\
\hline \multirow[t]{2}{*}{ B. } & There really is no such thing as "luck." & \\
\hline & $\begin{array}{l}\text { 19. Statements A and B: Write A or B for the statement you feel } \\
\text { is more true in the box at the right. }\end{array}$ & $\begin{array}{c}\text { A or } B ? \\
\text { is more } \\
\text { true }\end{array}$ \\
\hline A. & One should always be willing to admit mistakes. & \\
\hline \multirow[t]{2}{*}{ B. } & It is usually best to cover up one's mistakes. & \\
\hline & $\begin{array}{l}\text { 20. Statements A and B: Write A or B for the statement you feel } \\
\text { is more true in the box at the right. }\end{array}$ & $\begin{array}{c}\text { A or } B ? \\
\text { is more } \\
\text { true } \\
\end{array}$ \\
\hline A. & It is hard to know whether or not a person really likes you. & \\
\hline B. & $\begin{array}{l}\text { How many friends you have depends upon how nice a person you } \\
\text { are. }\end{array}$ & \\
\hline
\end{tabular}

\section{Continued next page}

Figure H2d. Form I-E - page 4 


\section{Form I-E - Page 5 of 6}

\begin{tabular}{|c|c|c|}
\hline & $\begin{array}{l}\text { 21. Statements A and B: Write A or B for the statement you feel } \\
\text { is more true in the box at the right. }\end{array}$ & $\begin{array}{c}\text { A or B? } \\
\text { is more } \\
\text { true }\end{array}$ \\
\hline A. & $\begin{array}{l}\text { In the long run the bad things that happen to us are balanced by the } \\
\text { good ones. }\end{array}$ & \\
\hline \multirow[t]{2}{*}{ B. } & $\begin{array}{l}\text { Most misfortunes are the result of lack of ability, ignorance, } \\
\text { laziness, or all three. }\end{array}$ & \\
\hline & $\begin{array}{l}\text { 22. Statements A and B: Write A or B for the statement you feel } \\
\text { is more true in the box at the right. }\end{array}$ & $\begin{array}{c}\text { A or B? } \\
\text { is more } \\
\text { true }\end{array}$ \\
\hline A. & With enough effort we can wipe out political corruption. & \\
\hline \multirow[t]{2}{*}{ B. } & $\begin{array}{l}\text { It is difficult for people to have much control over the things } \\
\text { politicians do in office. }\end{array}$ & \\
\hline & $\begin{array}{l}\text { 23. Statements A and B: Write A or B for the statement you feel } \\
\text { is more true in the box at the right. }\end{array}$ & $\begin{array}{c}\text { A or B? } \\
\text { is more } \\
\text { true }\end{array}$ \\
\hline A. & $\begin{array}{l}\text { Sometimes I can't understand how teachers arrive at the grades they } \\
\text { give. }\end{array}$ & \\
\hline \multirow[t]{2}{*}{ B. } & $\begin{array}{l}\text { There is a direct connection between how hard } 1 \text { study and the } \\
\text { grades I get. }\end{array}$ & \\
\hline & $\begin{array}{l}\text { 24. Statements A and B: Write A or B for the statement you feel } \\
\text { is more true in the box at the right. }\end{array}$ & $\begin{array}{c}\text { A or B? } \\
\text { is more } \\
\text { true }\end{array}$ \\
\hline A. & $\begin{array}{l}\text { A good leader expects people to decide for themselves what they } \\
\text { should do. }\end{array}$ & \\
\hline \multirow[t]{2}{*}{ B. } & A good leader makes it clear to everybody what their jobs are. & \\
\hline & $\begin{array}{l}\text { 25. Statements } A \text { and } B: \text { Write } A \text { or } B \text { for the statement you feel } \\
\text { is more true in the box at the right. }\end{array}$ & $\begin{array}{c}\text { A or } B ? \\
\text { is more } \\
\text { true }\end{array}$ \\
\hline A. & $\begin{array}{l}\text { Many times I feel that I have little influence over the things that } \\
\text { happen to me. }\end{array}$ & \\
\hline B. & $\begin{array}{l}\text { It is impossible for me to believe that chance or luck plays an } \\
\text { important role in my life. }\end{array}$ & \\
\hline
\end{tabular}

\section{Continued next page}

Figure H2e. Form I-E - page 5 


\section{Form I-E - Page 6 of 6}

\begin{tabular}{|c|c|c|}
\hline & $\begin{array}{l}\text { 26. Statements A and B: Write A or B for the statement you feel } \\
\text { is more true in the box at the right. }\end{array}$ & $\begin{array}{c}\text { A or B? } \\
\text { is more } \\
\text { true }\end{array}$ \\
\hline A. & People are lonely because they don't try to be friendly. & \\
\hline \multirow[t]{2}{*}{ B. } & $\begin{array}{l}\text { There's not much use in trying too hard to please people, if they } \\
\text { like you, they like you }\end{array}$ & \\
\hline & $\begin{array}{l}\text { 27. Statements A and B: Write A or B for the statement you feel } \\
\text { is more true in the box at the right. }\end{array}$ & $\begin{array}{c}\text { A or B? } \\
\text { is more } \\
\text { true }\end{array}$ \\
\hline A. & There is too much emphasis on athletics in high school. & \\
\hline \multirow[t]{2}{*}{ B. } & Team sports are an excellent way to build character. & \\
\hline & $\begin{array}{l}\text { 28. Statements A and B: Write A or B for the statement you feel } \\
\text { is more true in the box at the right. }\end{array}$ & $\begin{array}{c}\text { A or } B ? \\
\text { is more } \\
\text { true }\end{array}$ \\
\hline A. & What happens to me is my own doing. & \\
\hline \multirow[t]{2}{*}{ B. } & $\begin{array}{l}\text { Sometimes I feel that I don't have enough control over the direction } \\
\text { my life is taking. }\end{array}$ & \\
\hline & $\begin{array}{l}\text { 29. Statements A and B: Write A or B for the statement you feel } \\
\text { is more true in the box at the right. }\end{array}$ & $\begin{array}{c}\text { A or B? } \\
\text { is more } \\
\text { true }\end{array}$ \\
\hline A. & $\begin{array}{l}\text { Most of the time I can't understand why politicians behave the way } \\
\text { they do. }\end{array}$ & \\
\hline B. & $\begin{array}{l}\text { In the long run the people are responsible for bad government on a } \\
\text { national as well as on a local level. }\end{array}$ & \\
\hline
\end{tabular}

\section{$\underline{\text { Stop here - do not proceed. }}$}

Figure H2f. Form I-E - page 6 
For the 6 problems you completed, please rank the problem in order: Like the most $=1$ to Like the least $=6$

\begin{tabular}{|c|c|c|c|}
\hline Task Title & Reminder of Problem Statement & $\begin{array}{l}\text { Place a } 1,2,3 \text {, } \\
4,5 \text { or } 6 \text { in the } \\
\text { boxes below }\end{array}$ & $\begin{array}{c}\text { Why did you assign this number? } \\
\text { Please provide comments about } \\
\text { your feelings of the problem }\end{array}$ \\
\hline $\begin{array}{l}\text { Count Your } \\
\text { Coins }\end{array}$ & $\begin{array}{l}\text { How many ways can you combine U.S. coins to get } 30 \text { cents? You } \\
\text { may only use pennies, nickels, dimes, or quarters. }\end{array}$ & & \\
\hline $\begin{array}{l}\text { Lost in the } \\
\text { Auditorium }\end{array}$ & $\begin{array}{l}\text { An auditorium has eight doors. You may enter from every door but } \\
\text { you can not leave through the same door you entered. In how many } \\
\text { ways is it possible to enter by one door and leave by another? }\end{array}$ & & \\
\hline $\begin{array}{l}\text { Birthday } \\
\text { Money }\end{array}$ & $\begin{array}{l}\text { On John's birthday, John's grandfather gave him } \$ 10 \text {. He gave John } \\
\$ 20 \text { on his eleventh birthday and } \$ 40 \text { on John's twelfth birthday. } \\
\text { Following this pattern, John's grandfather plans on giving John } \\
\$ 70 \text { on his thirteenth birthday, but John expects } \$ 80 \text { from his } \\
\text { grandfather on that day. John's sister says that both amounts } \\
\text { could be correct. }\end{array}$ & & \\
\hline $\begin{array}{l}\text { What's in My } \\
\text { Future? }\end{array}$ & $\begin{array}{l}\text { A pattern of squares is shown below. At each step, more squares } \\
\text { are added to the pattern. The number of squares added at each } \\
\text { step is more than the number added in the previous step. The } \\
\text { pattern continues infinitely. } \\
\text { Marcy has to determine the number of squares in the } 50^{\text {th }} \text { step, but } \\
\text { she does not want to draw all } 50 \text { pictures and then count the squares. } \\
\text { Explain or show how she could do this and give the answer that } \\
\text { Marcy should get for the number of squares }\end{array}$ & & \\
\hline $\begin{array}{l}\text { How Many } \\
\text { Children Live } \\
\text { Next Door? }\end{array}$ & $\begin{array}{l}\text { The family next door has both girl and boy children. Each of the } \\
\text { boys has the same number of brothers as he has sisters and each of } \\
\text { the girls has twice as many brothers as she has sisters. How many }\end{array}$ & & \\
\hline Blind Sided & $\begin{array}{l}\text { Here are three views of the same cube. Each side is painted with a } \\
\text { color. There are five different colors used. What color is the bottom } \\
\text { face in View } 1 \text { (the face opposite the one colored white)? }\end{array}$ & & \\
\hline
\end{tabular}

Appendix I: Preferred Problem Choice (PPC) Questionnaire 


\section{Individual \\ Graduation Plan}

\section{Student Questions for reading and mathematics}

These questions are to help you think about ways you can improve your reading and math skills. A new sheet is needed each year.

\section{Reading}

1. Why do I read, what do I read and how often do I read?

2. What do my grades and test scores show about my reading ability?

3. How will reading help me with my educational and career goals?

\section{Mathematics}

1. When and how is mathematics important in my life?

2. What do my grades and test scores show about my Mathematics ability?

3. How will reading help me with my educational and career goals?

What type of help do I need to succeed in reading and mathematics?

Appendix J. Individual Graduation Plan - Page 47 
Bibliography

Aiken, L. R. (1970a). Affective factors in mathematics learning: Comments on a paper by Neale and a plan for research. Journal for Research in Mathematics Education, 1(4), 251-255.

Aiken, L. R. (1970b). Nonintellective variables and mathematics achievement: Directions for research. Journal of School Psychology, 8(1), 28-36.

Aiken, L. R. (1970c). Attitudes toward mathematics. Review of Educational Research, 40(4), 551-596.

Aiken, L. R. (1972). Biodata correlates of attitudes toward mathematics in three age and two sex groups. School Science and Mathematics, 72, 386-395.

Aiken, L. R. (1976). Update on attitudes and other affective variables in learning mathematics. Review of Educational Research, 46(2), 293-311.

Anttonen, R. G. (1967). An examination into the stability of mathematics attitude and its relationship to mathematics achievement from elementary to secondary school level, (Doctoral Dissertation, University of Michigan, 1967), University Microfilms No. 68-1, 521.

Bandura, A. (1994). Self-efficacy. In V. S. Ramachaudran (Ed.), Encyclopedia of human behavior (Vol. 4, pp. 71-81). New York: Academic Press.

Behr, A. N. (1973). Achievement, aptitude and attitude in mathematics. Two-Year College Mathematics Journal, 4, 72-74.

Berliner, D., \& Biddle, B. (1995). The manufactured crisis: Myths, fraud, and the attack on America's public schools. Cambridge, MA: Perseus Books.

Birkhoff, G. D. (1956). Mathematics of aesthetics. In John R. Newman (Ed.), The world of mathematics (Vol. 4, pp. 2185-2195). New York: Simon and Schuster.

Branca, N. A. (1985). Mathematical problem-solving: lessons from the British experience. In E. A. Silver (Ed.), Teaching and learning mathematical problem solving: Multiple research perspectives (pp. 71-80). Hillsdale, NJ: Lawrence Erlbaum Associates, Publishers.

Brief summary of the reliabilty and validity of the COPSystem assessment. (2007). Retrieved August 27, 2009, from http://www.edits.net/N-assess.html 
Brown, A. L., Bransford, J. D., Ferrara, R. A., \& Campione, J. C. (1983). Learning, remembering, and understanding. In J. Flavell \& E. Markman (Eds.), Mussen's handbook of child psychology (Vol. 3, pp. 77-166). Somerset, NJ: Wiley.

Brownell, W. A. (1942). Problem Solving. In The psychology of learning: Forty-first yearbook of the national society for the study of education, chapter xii, Part 2 Chicago: University of Chicago Press.

Burbank, K. I.. (1970). Relationships between parental attitude toward mathematics and student attitude toward mathematics and between student attitude toward mathematics and student achievement in mathematics (Doctoral Dissertation, Utah State University, 1968), Dissertation Abstracts International, 1970, 30, 3359A-3360A. (University Microfilms No. 70-2427).

Burton, L. (1999). Why is intuition so important to mathematicians but missing from mathematics education. For the Learning of Mathematics, 19(3), 27-32.

Callahan, W. J. (1971). Adolescent attitudes toward mathematics. Mathematics Teacher, 64, 751-755.

Campione, J. C., Brown, A. L., \& Connell, A. L. (1989). Metacognition: On the importance of understanding what you are doing. In The teaching and assessing of mathematical problem solving (pp. 93-114). Reston, VA: National Council of Teachers of Mathematics, and Hillsdale, NJ: Lawrence Earlbaum.

Cattell, R. B., \& Butcher, H. J. (1968). The prediction of achievement and creativity. New York: The Bobbs-Merrill Company, Inc.

Cawley, J. F., Fitzmaurice, A. M., Shaw, R. A., Kahn, H., \& Bates III, H. (1979). Math word problems: Suggestions for LD students. Learning Disibility Quarterly, 2(7), 25-41.

Charles, R., Lester Jr., F. K., and O’Daffer, P. (1987). How to evaluate problem solving. Reston, VA.: National Council of Teachers of Mathematics.

COPSystem: Comprehensive career guide. (2004). San Diego, CA: EdITS.

Countryman, J. (1992). Writing to learn mathematics: Strategies that work. Portsmouth, NH: Heinemann.

Davis, P. J., \& Hersh, R. (1981). The mathematical experience. Boston: Birkhäuser.

Dreyfus, T., \& Eisenberg, T. (1986). On the aesthetics of mathematical thought. For the Learning of Mathematics, 6, 2-10. 
Erlwanger, S. H. (1973). Benny's conception of rules and answers in IPI mathematics. Journal of Children's Mathematical Behavior, 1(2), 7-26.

Ethington, C. A. (1992). Gender differences in a psychological model of mathematics achievement. Journal for Research in Mathematics Education, 23(2), 161-181.

Feierabend, R. L. (1960). Review of research on psychological problems in mathematical education. In Research problems in mathematics education. U.S. Office of Education, Cooperative Research Monograph No. 3 (pp. 3-46).

Fennema, E. (1974). Mathematics learning and the sexes: A review. Journal for Research in Mathematics Education, 5(3), 126-139.

Fennema, E. (1978). Sex-related differences in mathematical achievement: Where and why? In J. E. Jacobs (Ed.), Perspectives on women in mathematics (pp. 1-20). Columbus, OH: ERIC Clearinghouse for Science, Mathematics, and Environmental Education.

Fennema, E., \& Sherman, J. A. (1976). Fennema-Sherman mathematics attitude scales: Instruments designed to measure attitudes toward the learning of mathematics by females and males. JSAS Catalog of Selected Documents in Psychology, 6(31) (Ms No. 1225).

Fennema, E., \& Sherman, J. A. (1977). Sex-related differences in mathematics achievement, spatial visualization, and affective factors. American Educational Research Journal, 14, 51-71.

Fennema, E., \& Sherman, J. A. (1978). Sex-related differences in mathematics achievement and related factors: A further study. Journal for Research in Mathematics Education, 9, 189-203.

Free and reduced price school meals application and verification forms: Instructions for school districts. (2009). Retrieved August 24, 2009, from United States Department of Agriculture (USDA): Food and Nutrition Services Web site: http://www.fns.usda.gov/cnd/FRP/frp.process.htm

Friedman, L. (1989). Mathematics and the gender gap: A meta-analysis of recent studies on sex differences in mathematical tasks. Review of Educational Research, 59(2), 185-213.

Fuchs, L. S., Fuchs, D., Stueberg, K., Fletcher, J. M., Hamlett, C. L., \& Lambert, W. (2008). Problem solving and computational skill: Are they shared or distinct aspects of mathematical cognition? Journal of Educational Psychology, 100(1), 30-47. 
Garner, R., \& Alexander, P. A. (1989). Metacognition, answered and unanswered questions. Educational Psychologist, 24, 143-158.

Garofalo, J., \& Lester, F. K. (1985). Metacognition, cognitive monitoring, and mathematical performance. Journal for Research in Mathematics Education, 16(3), 163-176.

Geary, D. (2004). Mathematics and learning disabilities. Journal of Learning Disabilities, 37(1), 4-15.

Glennon, V. J. (1957). Arithmetic for the gifted child. The Elementary School Journal, $58(2), 91-96$.

Goldin, G., \& Shteingold, N. (2001). System of representations and the development of mathematical concepts. In Albert A. Cuoco \& Frances R. Curcio (Eds.), The roles of representation in school mathematics: 2001 yearbbook (pp. 1-23). Reston, VA: National Council of Teachers of Mathematics.

Hardy, G. H. (1967). A mathematician's apology. Cambridge, United Kingdom: Cambridge University Press.

Holliday, B., Cuevas, G. J., Luchin, B., Carter, J. A., Marks, D., Day, R., Casey, R. M., \& Hayek, L. M. (2008). Algebra 1. Columbus, Ohio: Glencoe/McGrawHill.

Husén, T. (Ed.). (1967). International study of achievement in mathematics (Vol. 1\&2). New York: John Wiley \& Sons.

Individual graduation plan - p. 47. (2007). Retrieved September 5, 2009, from Beacon Charter High School for the Arts Web site: http://beaconart.org/ documents/beacon2.pdf

Information Works!, \& Center for School Improvement \& Eductional Policy (CSEIP). (2009). Characteristics of students attending Rhode Island public schools (School year 2007-2008). Providence, RI: Rhode Island Department of Education. Retrieved September 26, 2009, from http//: www.infoworks.ride.uri.edu/2009/state/profile-char-class.pdf

Jackson, P. W. (1990). Life in class rooms. New York: Teachers College Press. (Original work published 1928).

Kaput, J. J. (1985). Representation and problem solving: Methodological issues related to modeling. In E. A. Silver (Ed.), Teaching and learning mathematical problem solving: Multiple research perspectives (pp. 381-397). Hillsdale, NJ: Lawrence Erlbaum Associates, Publishers. 
Kifer, E., \& Robitaille, D. F. (1989). Attitudes, preferences, and opinions. In D. F. Robitaille \& R. A. Garden (Eds.), The IEA study of mathematics II: Contexts and outcomes of school mathematics (pp. 178-208). New York: Pergamon Press.

Kilpatrick, J. (1985). A retrospective account of the past 25 years of research on teaching mathematical problem solving. In Edward A. Silver (Ed.), Teaching and learning mathematical problem solving: Multiple research perspectives (pp. 1-15). Hillsdale, NJ: Lawrence Erlbaum Associates, Publishers.

King, J. P. (1992). The art of mathematics. Mineola, NY: Dover Publications, Inc.

Knapp-Lee, L. J. (1995). Use of the COPSystem in career assessment. Journal of Career Assessment, 3(4), 411-428.

Koichu, B., Katz, E., \& Berman, A. (2007). What is a beautiful problem? An undergraduate student's perspective. In H. C. Lew. J. H. Woo, K. S. Park, \& D. Y. Seo (Eds.), Proceedings of the 31st conference of the international group for the psychology of mathematics education 3(1), (pp. 113-120). Seol, Korea: Psychology of Mathematics education (PME).

Langford, E., Schwertman, N., \& Owens, M. (2001). Is the property of being positively correlated transitive? The American Statistician, 55(4), 322-325.

Lawson, M. J. (1984). Being executive about metacognition. In J. A. Kirby (Ed.), Cognitive strategies and educational performance (pp. 89-109). Orlando, FL: Academic Press.

Leake, C. R.. (1970). Interest changes in mathematics of selected college students in New York State (Doctoral Dissertation, New York State University, 1969), Dissertation Abstracts International, 1970, 30, 2853A. (University Microfilms No. 70-734).

Leatham, K. R., Lawrence, K., \& Mewborn, D. S. (2005). Getting started with openended assessment. Teaching Children Mathematics, 11(8), 413-419.

Leder, G. (1980). Bright girls, mathematics and fear. Educational Studies in Mathematics, 11(4), 411-422.

Lefcourt, H. M. (1976). Locus of Control. Hillsdale, NJ: Lawrence Erlbaum Associates, Publishers.

Lester, F. K. (1994). Musings about mathematical problem-solving research: 19701994. Journal for Research in Mathematics Education, 25(6), 660-675. 
Lester, J. S. (2005). The relationship of school location and school size on eighth grade mathematics achievement on SOL tests in Virginia: A comparison of rural, urban, and suburban schools. Unpublished doctoral dissertation, East Tennessee State University, Johnson City.

Lester, F. K., \& Garafalo, J. (Eds.). (1982). Mathematical problem solving: Issues in research. Philadelphia: Franklin Institute Press.

Levine, G. I. (1973). Actual and perceived attitudes toward mathematics of pupils and their mothers. (Doctoral Dissertation, Columbia University, 1972), Dissertation Abstracts International, 1973, 33, 3960A. (University Microfilms No. 73-2609).

Lewis, C., Hitch, G., \& Walker, P. (1994). The prevalence of specific arithmetic difficulties and specific reading difficulties in 9- and 10-year-old boys and girls. Journal of Child Psychology and Psychiatry, 35, 283-292.

London, R. (1989). Nonroutine problems: Doing mathematics. Providence, RI: Janson Publications, Inc.

London, R. (1993, April). A curriculum of nonroutine problems. 44p.; presented at the annual meeting of the American Research Association, Atlanta, GA.

London, R. (2007, February). What is essential in mathematics education: A holistic viewpoint. MSOR Connections, 7(1), 30-34.

Lubienski, S. T., \& Bowen, A. (2000). Who's counting? A survey of mathematics education research 1982-1998. Journal for Research in Mathematics Education, 31(5), 626-633.

Ma, X., \& Kishor, N. (1997). Assessing the relationship between attitude toward mathematics and achievement in mathematics: A meta-analysis. Journal for Research in Mathematics Education, 28(1), 26-47.

Mandler, G. (1989). Affect and learning: Causes and consequences of emotional interactions. In D. B. McLeod \& V. M. Adams (Eds.), Affect and mathematical problem solving (pp. 3-19). New York: Springer-Verlag.

Mathews, W., Carpenter, T. P., Lindquist, M. M., \& Silver, E. A. (1984). The third national assessment: Minorities and mathematics. Journal for Research in Mathematics Education, 15(2), 165-171.

May, D. C. (1971). An investigation of the relationship between selected personality characteristics of eighth-grade students and their achievement in mathematics, (Doctoral Dissertation, University of Florida, 1971), Dissertation Abstracts International, 1972, 33, 555A. (University Microfilms No. 72-21, 080). 
McCall, G. J., \& Simmons, J. L. (Eds.). (1969). Issues in participant observation: A text and reader. Reading, MA: Addison-Wesley Publishing Company.

McLeod, D. B. (1985). Affective issues in research on teaching mathematical problem solving. In E. A. Silver (Ed.), Teaching and learning mathematical problem solving: Multiple research perspectives (pp. 267-279). Hillsdale, NJ: Lawrence Erlbaum Associates, Publishers.

McLeod, D. B. (1992). Research on affect in mathematics education: A reconceptualization. In D. A. Grouws (Ed.), Handbook of research on mathematics teaching and learning (pp. 575-596). New York: Macmillan.

Meyer, M. R., \& Fennema E. (1988). Girls, boys, and mathematics. In T. R. Post (Ed.), Teaching mathematics in grades K-8: Research-based methods (pp. 406425). Boston: Allyn \& Bacon.

Mueller, C. W., \& Parcel, T. L. (1981). Measures of socioeconomic status: Alternatives and recommendations. Child Development, 52, 13-30.

Mulhern, F., \& Rae, G. (1998). Development of a shortened form of the FennemaSherman Mathematics Attitude Scales. Educational and Psychological Measurement, 58(2), 295-306.

National Center for Educational Statistics, Institute of Educational Sciences. (2009a). What are the differences between long-term trend NAEP and main NAEP? Washington, DC: U.S. Department of Education. Retrieved August 24, 2009, from http://nces.ed/nationsreportcard/about/ltt_main_diff_asp

National Center for Educational Statistics, common core of data (CCD). (2009b). Identification of rural locales. Washington, DC: U.S. Department of Education. Retrieved September 29, 2009, from http://nces.ed.gov/ccd/ rural_locales.asp

National Center on Public Education, \& Social Policy/University of Rhode Island. (2008a). Using Information: Value added/ Rhode Island high schools. In Information Works! 2008. Providence, RI: Rhode Island Department of Education. Retrieved August 24, 2009, from http:// www.infoworks.ride.uri.edu/2008/state/va-high.pdf

National Center on Public Education, \& Social Policy/University of Rhode Island. (2008b). User's guide: Value added indicators/ The rationale. In Information Works! 2008. Providence, RI: Rhode Island Department of Education. Retrieved August 24, 2009, from http://www.infoworks.ride.uri.edu/2008/ userguide/09va.asp 
National Center on Public Education, \& Social Policy/University of Rhode Island. (2008c). Learning and achievement: assessments/ Beacon charter high school. In Information Works! 2008. Providence, RI: Rhode Island Department of Education. Retrieved August 24, 2009, from http:// www.infoworks.ride.uri.edu/2008/pdf/achievement/39601H-achi.pdf

National Council of Teachers of Mathematics. (2000). Principles and standards for school mathematics. Reston, VA: author.

Neale, D. C. (1969). The role of attitudes in learning mathematics. The Arithmetic Teacher, 16, 631-640.

Noddings, N. (1985). Small groups as a setting for research on mathematical problem solving. In E. A. Silver (Ed.), Teaching and learning mathematical problem solving: Multiple research perspectives (pp. 345-359). Hillsdale, NJ: Lawrence Erlbaum Associates, Publishers.

Normative data. (2008). Retrieved September 5, 2009, from http://www.nwea.org/ support/article/980

NWEA. (2004). Reliability and validity estimates: NWEA achievement level tests and measures of academic progress. Lake Oswego, OR: Northwest Evaluation Association.

Office of the Commisioner. (2006). Charter schools: Purpose of charter schools. Providence, RI: Rhode Island Department of Education. Retrieved September 5, 2009, from http://www.ride.gov./commissioner/charterschools/purpose.aspx

Olson, L. (2003, December 3). "Proficient" mark shifts by state, grade, subject. Education Week, 23(14), 10.

Overmier, J. B., \& Seligman, M. E. P. (1967). Effects of inescapable shock on subsequent escape and avoidance learning. Journal of Comparative and Physiological Psychology, 63, 28-33.

Pajares, F., \& Schunk, D. H. (2001). Self-beliefs and school success: Self-efficacy, self-concept, and school achievement. In R. Riding \& S. Rayner (Eds.), Perception (pp. 239-266). London: Ablex Publishing.

Papert, S. A. (1978). The mathematical unconscious. In Judith Wechsler (Ed.), On aesthetics in science (pp. 105-119). Cambridge, MA: Massachusetts Institute of Technology. 
Pedro, J. D., Wolleat, P., Fennema, E., \& Becker, A. D. (1981). Election of high school mathematics by females and males: attributions and attitudes. American Educational Research Journal, 18(2), 207-218.

Peterson, C. (1991a). The meaning and measurement of explanatory style. Psychological Inquiry, 2(1), 1-10.

Peterson, C. (1991b). Further thoughts on explanatory style. Psychological Inquiry, 2(1), 50-57.

Peterson, C., Maier, S., \& Seligman, M. E. P. (1993). Learned helplessness: A theory for the age of personal control. New York: Oxford University Press.

Peterson, C., Semmel, A., von Baeyer, C., Abramson, L. Y., Metalsky, G. I., \& Seligman, M. E. P. (1982). The attributional style questionnaire. Cognitive Therapy and Research, 6, 287-300.

Philipp, R. A. (2007). Mathematics teachers' beliefs and affect. In F. K. Lester (Ed.), Second handbook of research on mathematics teaching and learning (pp. 257315). Charlotte, NC: Information Age Pub.

Poincare, H. (1956). Mathematical creation. In J. Newman (Ed.), The world of mathematics (Vol. 4, pp. 2041-2050). New York: Simon and Schuster. (Original work published 1908)

Polya, G. (1962). Mathematical discovery (Vol. 1). New York: John Wiley \& Sons, Inc.

Polya, G. (2004). How to solve it. Princeton, NJ: Princeton University Press. (Original work published 1945)

Prawat, R. S. (1989). Promoting access to knowledge, strategy, and disposition in students: A research synthesis. Review of Educational Research, 59, 1-41.

Publication manual of the american pyschological association (5th ed.). (2002). Washington, DC: American Psychological Association.

Pugalee, D. K. (2004). A comparison of verbal and written descriptions of students' problem solving processes. Educational Studies in Mathematics, 55, 27-47.

Reflections on educational studies in mathematics. (2002). Educational Studies in Mathematics, 50(3), 251-257.

Reyes, L. H. (1984). Affective variables and mathematics education. The Elementary School Journal, 84(5), 558-581. 
Robitaille, D. F. (1989). Students' achievements: Population A. In D. F. Robitaille \& R. A. Garden (Eds.), The IEA study of mathematics II: Contexts and outcomes of school mathematics (pp. 102-125). New York: Pergamon Press.

Robitaille, D. F., \& Garden, R. A. (Eds.). (1989). The IEA study of mathematics II: Contexts and outcomes of school mathematics. New York: Pergamon Press.

Rosenberg, M. (1989). Self-concept research: A historical overview. Social Forces, 68(1), 34-44.

Rotter, J. B. (1966). Generalized expectancies for internal versus external control of reinforcement. Psychological Monographs, 80(1, Whole No. 609).

Ryan, J. J. (1968). Effects of modern and conventional mathematics curricula on pupil attitudes, interests, and perception of proficiency (Final Report OF-5-10-051). Washington, D.C: USOE Bureau of Research, 1968. Mimeographed.

Sander, W. (1997). Catholic high schools and rural academic achievement. American Journal of Agricultural Economics, 79(1), 1-12.

Schoenfeld, A. H. (1985). Mathematical problem solving. Orlando, FL: Academic Press.

Schoenfeld, A. H. (1987). What's all the fuss about metacognition? In A. H. Schoenfeld (Ed.), Cognitive science and mathematics education (pp. 189-215). Hillsdale, NJ: Lawrence Erlbaum.

Seely, K. W. (1985). The readability of six measures of locus of control. Unpublished manuscript, Syracuse University, Syracuse, NY.

Seligman, M. E. P. (1975). Helplessness: On depression, development, and death. San Francisco: Freeman.

Seligman, M. E. P. (1990). Learned optimism. New York: Alfred A. Knopf.

Seligman, M. E. P., \& Maier, S. F. (1967). Failure to escape traumatic shock. Journal of Experimental Psychology, 74(1), 1-9.

Sherman, J., \& Fennema, E. (1977). The study of mathematics by high school girls and boys: Related variables. American Educational Research Journal, 14(2), 159-168.

Shield, M., \& Galbraith, P. (1998). The analysis of student expository writing in mathematics. Educational Studies in Mathematics, 36, 29-52. 
Silver, E. A. (1985). Research on teaching mathematical problem solving: Some underrepresented themes and needed directions. In E. A. Silver (Ed.), Teaching and learning mathematical problem solving: Multiple research perspectives (pp. 247-266). Hillsdale, NJ: Lawrence Erlbaum Associates, Publishers.

Silver, E. A., \& Metzger, W. (1989). Aesthetic influences on expert mathematical problem solving. In D. B. McLeod \& V. M. Adams (Eds.), Affect and mathematical problem solving: A new perspective (pp. 59-74). New York: Springer-Verlag.

Sinclair, N. (2001). The Aesthetic is relevant. For the Learning of Mathematics, 21(1), 25-32.

Sinclair, N. (2004). The roles of the aesthetic in mathematical inquiry. Mathematical Thinking and Learning, 6(3), 261-284.

Sinclair, N., \& Crespo, S. (2006). What makes a good problem? An aesthetic lens. In H. Moraova. J. Novotna, M. Kratka, \& N. Stehlikova (Eds.), Proceedings of the 30th conference of the international group for the psychology of mathematics education (Vol. 5, pp. 129-136). Prague.

Sirin, S. R. (2005). Socioeconomic status and academic achievement: A meta-analytic review of research. Review of Educational Research, 75(3), 417-453.

Stenmark, J. K. (1991). Mathematics assessment: Myths, models, good questions and practical suggestions. Reston, VA.: National Council of Teachers of Mathematics.

Swafford, J. O. (1980). Differences in first-year algebra. Journal for Research in Mathematics Education, 11(5), 335-346.

Swanson, H. L. (1993). An information processing analysis of learning disabled children's problem solving. American Educational Research Journal, 30(4), 861-893.

Swanson, H. L., \& Jerman, O. (2006). Math disabilities: A selective meta-analysis of the literature. Review of Educational Research, 70(2), 249-274.

Szetala, W., and Nicole, C. (1992). Evaluating problem solving in mathematics. Educational Leadership, May 1992, 42-45.

Tartre, L. A., \& Fennema, E. (1995). Mathematics achievement and gender: A longitudinal study of selected cognitive and affective variables (grades 6-12). Educational Studies in Mathematics, 28, 199-217. 
Taylor, W. T. (1970). A cross-sectional study of the modification of attitudes of selected prospective elementary school teachers toward mathematics (Doctoral Dissertation, Oklahoma State University, 1969), Dissertation Abstracts International, 1970, 31, 4024A. (University Microfilms No. 7021,497).

Taylor, H., \& Taylor, L. (1993). George Polya: Master of discovery. Palo Alto, CA: Dale Seymour Publications.

Tyler, R. W. (1973). Assessing educational achievement in the affective domain. NCME: Measurement in Education, 4(3), 1-8.

United Nations Educational, Scientific., \& Cultural Organization. (2004). The plurality of literacy and its implications for policies and programmes: Position paper. ED-2004/WS/31 cld.16763, Paris. Retrieved October 11, 2009, from http://unescodoc.unesco.org/images/0013/001362/136246e.pdf

Vanneman, A., Hamilton, L., Baldwin Anderson, J., \& Rahman, T. (2009). Achievement gaps: How black and white students in public schools perform in mathematics and reading on the national assessment of educational progress (NCES 2009-455). Washington, DC: National Center for Educational Statistics, Institute of Educational Sciences, U.S. Department of Education.

Wagner, R. V. (1969). The study of attitude change. In R. V. Wagner \& J. J. Sherwood (Eds.), The study of attitude change (pp. 1-18). Belmont, CA: Brooke Cole.

Walker, S. P., \& Butler, J. D. (2005). Evaluating the need for a math placement exam (Rev. 031505). Coventry, RI: Coventry High School Math Department.

Weiner, B. (1986). An attributional theory of motivation and emotion. New York: Springer-Verlag.

Wells, D. (2008, January). Pupils, surprise and beauty. Mathematics in school, 37(1), $8-9$.

Weston, L. D. (1969). An exploration of the interrelationship between children's arithmetic achievement, their styles of learning, their responsibility for intellectual academic achievement, and their parents' attitudes (Doctoral Dissertation, Wayne State University, 1968). Dissertation Abstracts International, 1970, 30, 1087A-1088A. (University Microfilms No. 69-14, 690).

Yamane, T. (1967). Statistics, An introductory analysis, $2^{\text {nd }}$ ed, New York: Harper and Row. 
Yong, H. T., \& Kiong, L. N. (2005, August). Metacognitive aspect of mathematics problem solving. presented at the ICM regional conference: The Third East Asia Regional Conference on Mathematical Education, Shanghai, Nanjing, and Hangzhou, China. Retrieved September 5, 2009, from http://www.math.ecnu.edu.cn/earcome3/TSG4/EARCOME3_HWA_TEE\%20 YONG_TSG407().doc 
